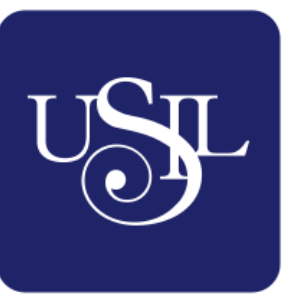

UNIVERSIDAD

SAN IGNACIO

DE LOYOLA

ESCUELA DE POST GRADO

\title{
PLAN ESTRATÉGICO PARA LA EMPRESA RANSA COMERCIAL S.A., CALLAO, PARA LOS PERIODOS 2019 - 2022
}

Trabajo de Investigación para optar el grado de:

EDDIE SERGIO PASTOR DEL ALCÁZAR

Maestro en Ciencias Empresariales con Mención en Gestión de Proyectos

\section{XIMENA ALEJANDRA ANTEZANA CORRALES}

Maestro en Ciencias Empresariales con Mención en Gestión de Proyectos

\author{
Asesor: \\ Carlos Ossio Sal y Rosas \\ Lima - Perú \\ 2020
}




\section{Resumen}

Ransa Comercial S.A. es una empresa dedicada a diseñar y gestionar soluciones logísticas especializadas, sus 80 años en el mercado le ha permitido alcanzar un alto nivel de experiencia en el servicio logístico integrado, habiendo logrado un crecimiento geográfico sostenido de sus operaciones hasta el año 2014 para luego entrar en un escenario de bajo crecimiento en los siguientes años.

La presente Tesis desarrolla el Plan Estratégico para la empresa Ransa Comercial S.A. para el periodo 2019 - 2022, teniendo como objetivo principal incrementar la rentabilidad de los principales servicios ofrecidos por la empresa, posicionándola en una tendencia positiva en el periodo mencionado.

Ransa, a la fecha, ha perdido clientes que representaban grandes volúmenes de servicios contratados como son los casos de las empresas Hunt Oil, Pacific Stratus, General Cable, Sally Pery, Brailard, Aceros Arequipa, Rio Mantaro, Minera Chinalco, Pesquera Diamante, Lindley, Cal del Centro, Pesquera Hayduk, Lindley, Delkor, CPC, Siemens y Constructor Ductos, cuyos contratos significaban para Ransa un ingreso de millones; sin embargo, la salida de clientes no redujo lo suficiente los costos operativos como para mantener la utilidad operativa dentro de una tendencia positiva. Asimismo, cabe mencionar también que Ransa en la última década ha expandido su alcance geográfico en la búsqueda de llegar a nuevos clientes y fortalecer sus relaciones contractuales existentes, expansión que ha incrementado los costos operativos; y, sin un incremento en las ventas, la utilidad operativa no dejaría la tendencia negativa en la que se encuentra. Es así como, la situación actual de los principales servicios de Ransa, respecto a sus ventas en los últimos años, han caído significativamente o alcanzado un lento crecimiento. 
El mercado peruano, en los últimos años, ha mostrado una tendencia positiva y un aumento de empresas pertenecientes a diferentes industrias, escenarios que tienen un impacto directa e indirectamente sobre la industria logística, lo que proporciona distintas alternativas para su explotación a favor de la empresa. Debido a ello, se formula diversas estrategias que son evaluadas cualitativa y cuantitativamente para luego seleccionar las de mayor calificación y someterlas a un análisis final en la matriz cuantitativa (MCPE), obteniendo como resultado la estrategia de eficiencia operativa (principal) y la estrategia de desarrollo de producto (contingente).

En este sentido, se proponen acciones alineadas a las estrategias seleccionadas, acciones que se encuentran enfocadas en el mejoramiento de procesos y uso de tecnología avanzada que permitan a la empresa agilizar el flujo de sus operaciones y reducir sus costos operativos, a la par de la creación de nuevas competencias en los colaboradores para un mayor rendimiento en las operaciones; generando así una nueva propuesta de valor orientada a la recuperación, retención y captación de nuevos clientes, con el fin que aquellos clientes que se encuentren contratando servicios atomizados (solo uno o dos de los tres principales servicios) completen la cadena de operaciones logísticas integrada, logrando a través de la venta cruzada reducir los costos y gastos por cliente.

La proyección de la Utilidad Neta para los años 2019, 2020, 2021 y 2022, considerando el mejor de los escenarios sin la implementación de nuevas estrategias, alcanzaría las sumas de S/19,179, S/19,932, S/20,665, y S/21,383 (expresadas en miles de soles), resultado obtenido principalmente por el reajuste estricto de sus costos frente a la caída de sus ventas; mientras que la proyección de la Utilidad Neta para el mismo periodo, luego de la implementación de nuevas 
estrategias, alcanzaría las sumas de S/18,682, S/22,177, S/25,982, y S/30,375 (expresadas en miles de soles).

La implementación de las estrategias seleccionadas se proyectaron para el periodo establecido 2019 - 2022, y financieramente se evaluaron bajo el concepto de flujo de caja neto, obteniendo un VAN de S/18,278 MM y una TIR de 61.97\%; resultados que determinan la aceptación del Plan Estratégico e indican la viabilidad de la implementación de las estrategias, los mismos que brindan resultados económicos positivos. 


\section{Tabla de contenidos}

Pág.

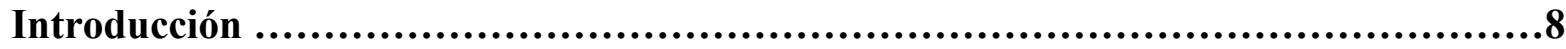

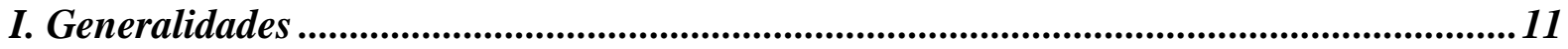

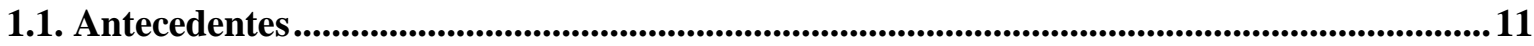

1.2. Determinación del problema u oportunidad ............................................................. 16

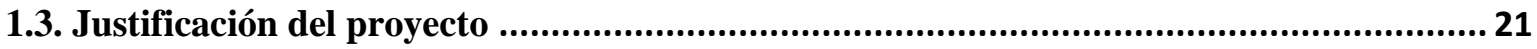

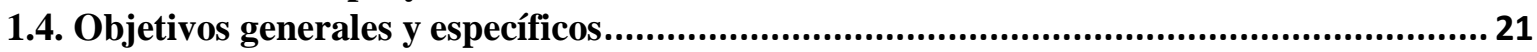

1.5. Alcances y limitaciones de la investigación................................................................. 22

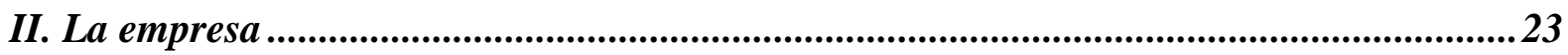

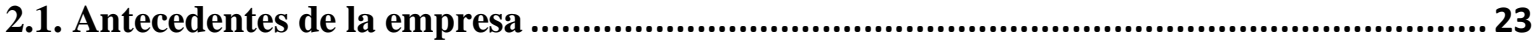

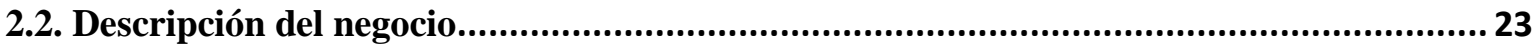

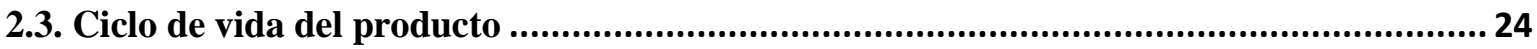

2.4. Estructura organizacional actual de la empresa .................................................... 26

2.5. Situación de mercado y financiera actual de la industria ............................................. 29

III. Formulación de visión, misión y valores de la empresa ....................................... 31

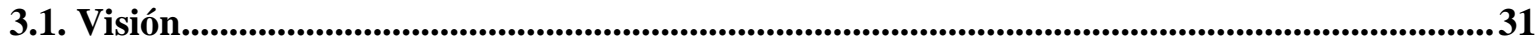

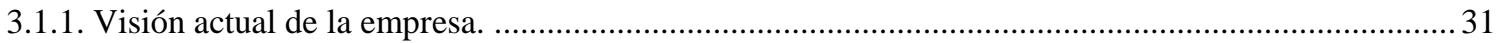

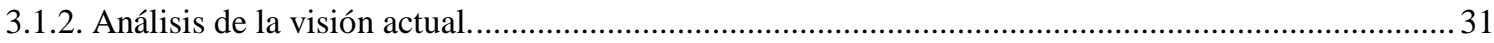

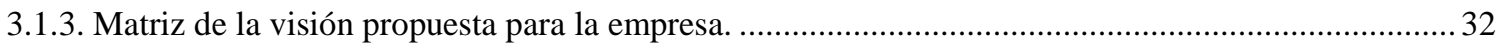

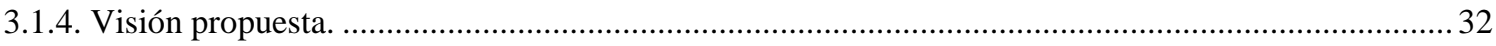

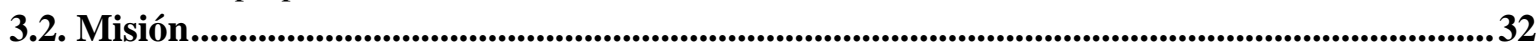

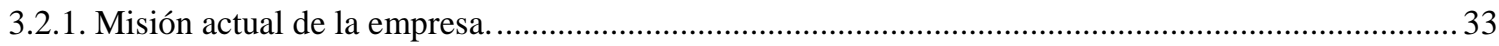

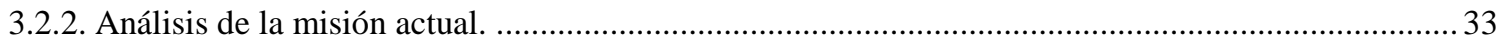

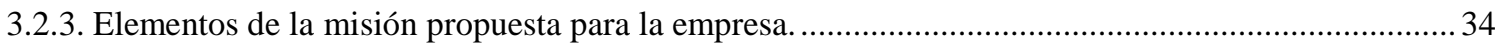

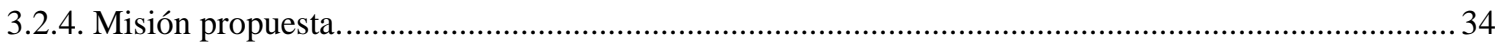

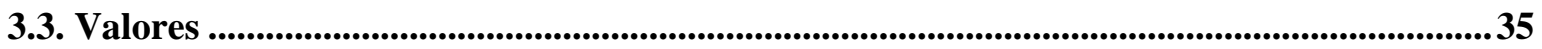

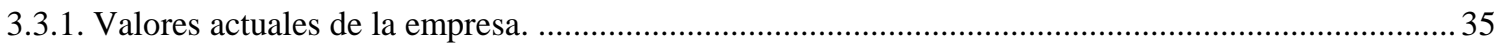

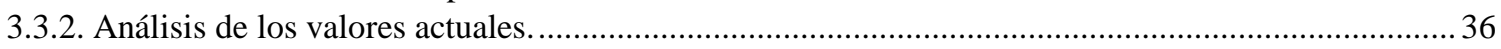

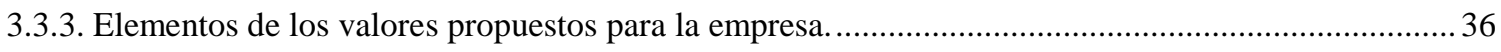

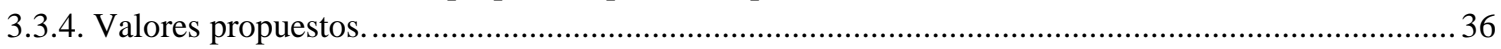

3.4. Alineamiento estratégico de la visión, misión y valores de la empresa............................. 36

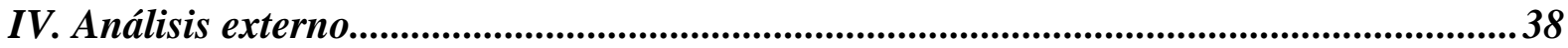

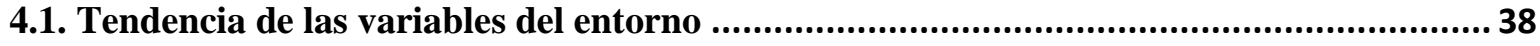

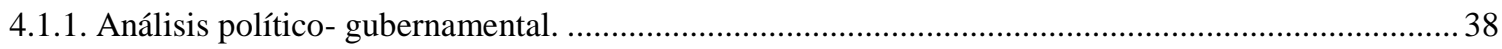

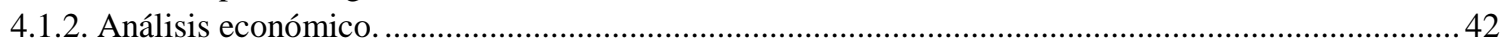

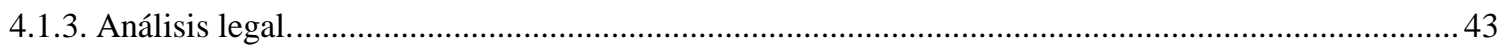

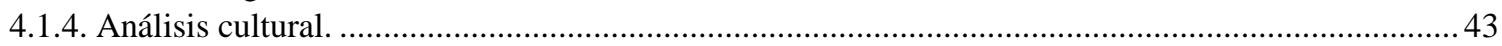

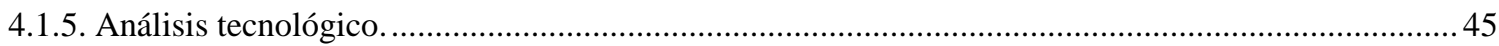

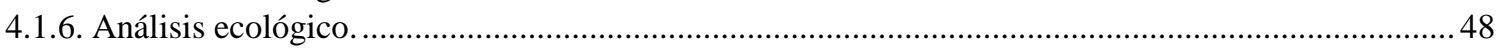

4.2. Impacto en clientes/ proveedores de cada una de las variables del entorno ..................... 49

4.3. Efecto en la empresa de cada una de las variables del entorno...................................... 53

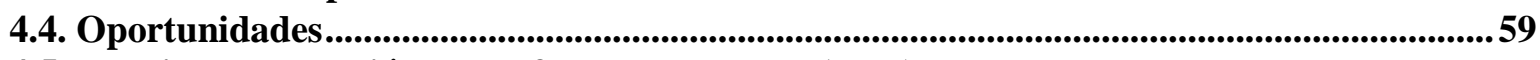

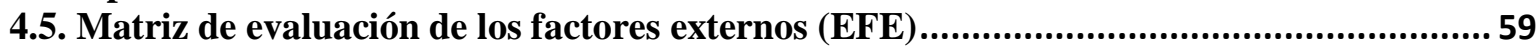


V. Análisis de la industria .......................................................................................61

5.1. Descripción del mercado (demanda) e industria (oferta) ..........................................61 61

5.2. Descripción de las cinco fuerzas competitivas de la industria...................................66 66

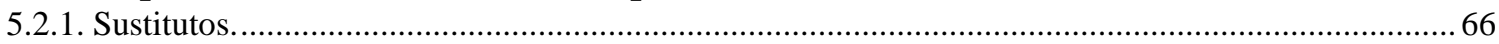

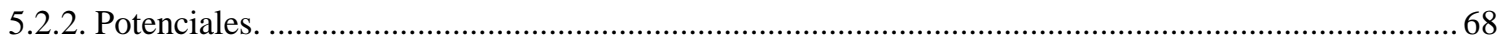

5.2.3. Clientes. .

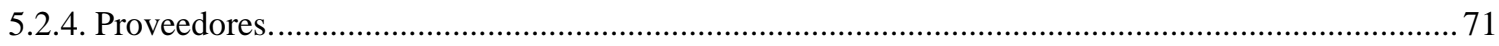

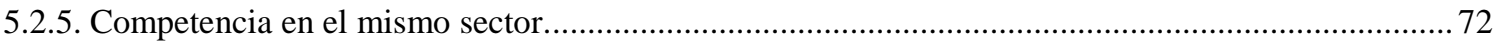

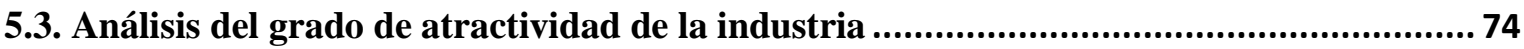

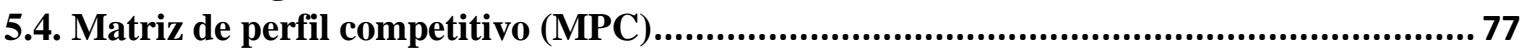

5.5 Benchmarking y comparación con los líderes de la industria en cada uno de los factores

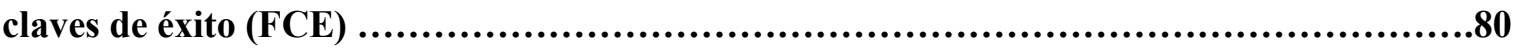

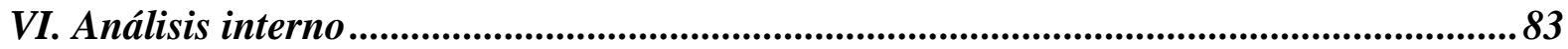

6.1. Descripción de las actividades de la cadena de valor de la empresa $\ldots . . \ldots \ldots . . . \ldots . . . . . . .83$

6.2. Indicadores de cada una de las actividades de la cadena de valor ................................ 91

6.3. Benchmarking y comparación con los líderes de la industria de cada una de las actividades

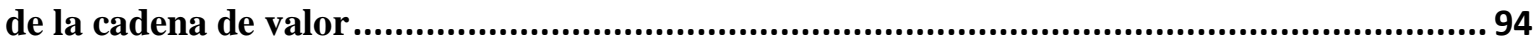

6.4. Determinar las competencias de la empresa................................................................. 96

6.5. Identificación y determinación de las ventajas competitivas de la empresa..................... 97

6.6. Matriz de evaluación de los factores internos (EFI) ................................................ 99

VII. Formulación de los objetivos y diseño de las estrategias................................. 101

7.1. Alcance y planeamiento de los objetivos estratégicos ................................................. 101

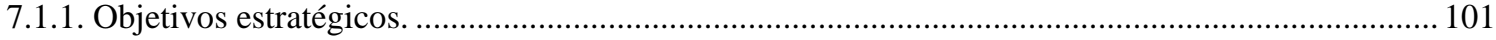

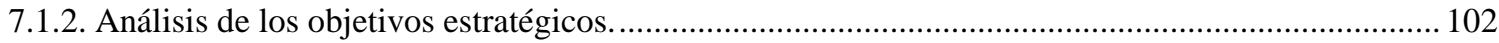

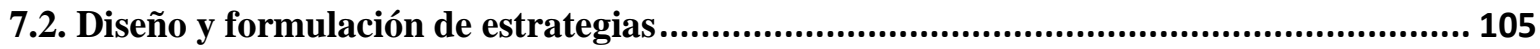

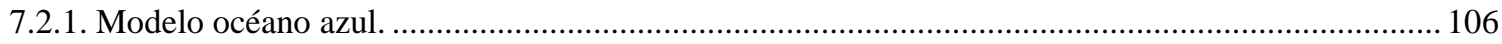

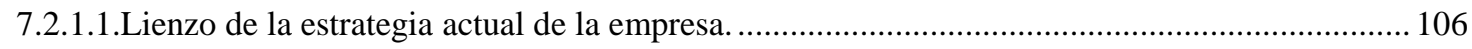

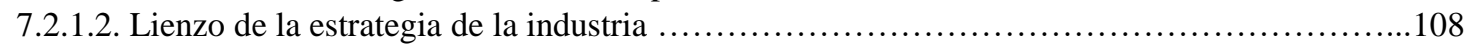

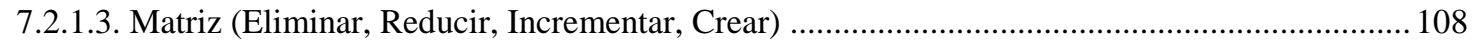

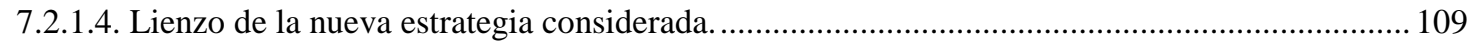

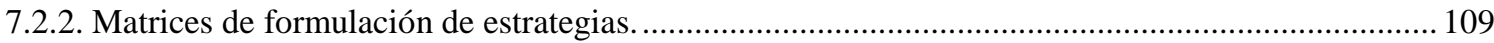

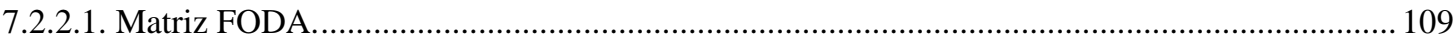

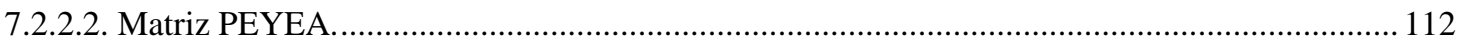

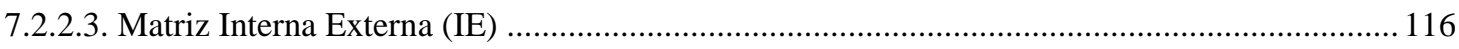

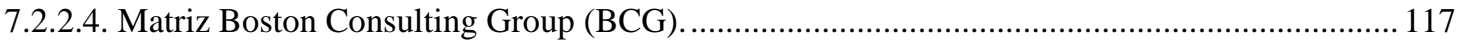

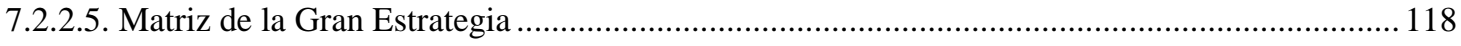

7.3. Resumen de las estrategias formuladas.................................................................. 119

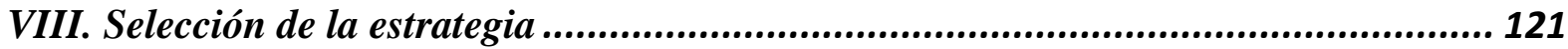

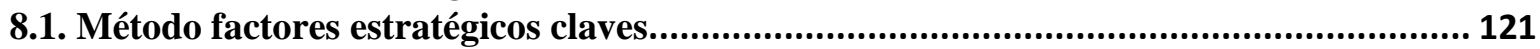

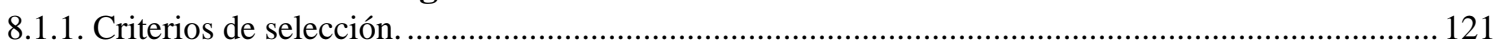

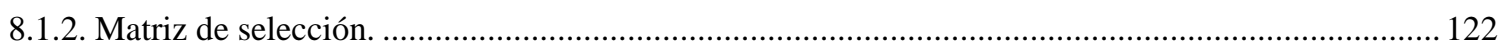

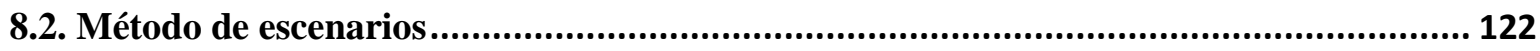

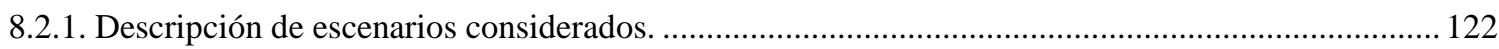

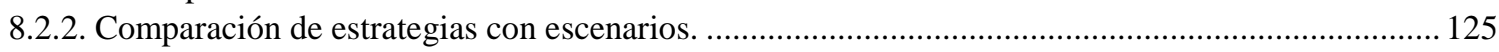

8.3. Matriz de planeación estratégica cuantitativa (MPEC)........................................ 126

8.4. Descripción de estrategia seleccionada..................................................................... 128

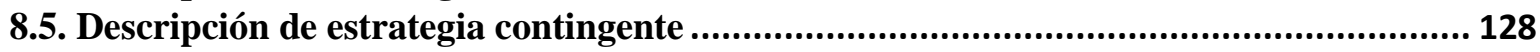




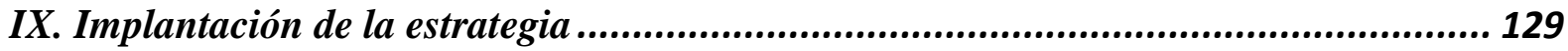

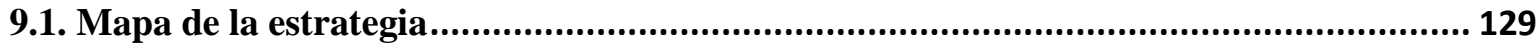

9.2. Objetivos específicos según el mapa de la estrategia ............................................ 131

9.3. Indicadores para cada uno de los objetivos específicos ............................................ 132

9.4. Metas para cada uno de los objetivos específicos ................................................... 133

9.5. Iniciativas (acciones a llevar a cabo para cada uno de los objetivos específicos) estrategias, programas, políticas, reglas, procedimientos.................................................................... 134

9.6. Responsable de cada una de las iniciativas................................................................ 137

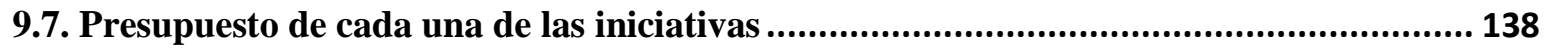

9.8. Cronograma de cada una de las iniciativas ........................................................... 148

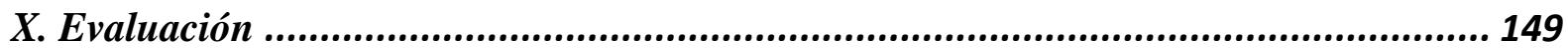

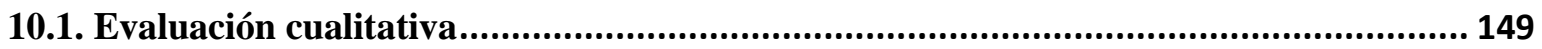

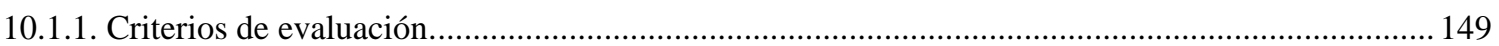

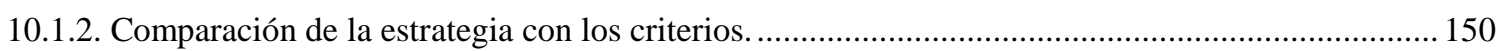

10.2. Evaluación financiera de la estrategia............................................................ 152

10.2.1. Proyección de estados financieros (situación actual y con la nueva estrategia).............................. 152

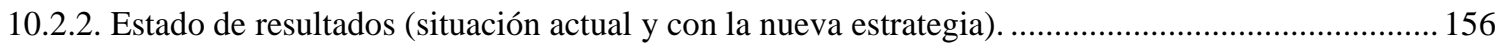

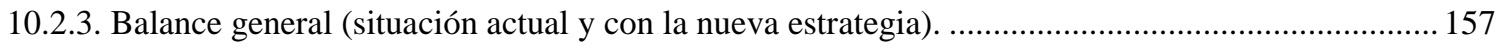

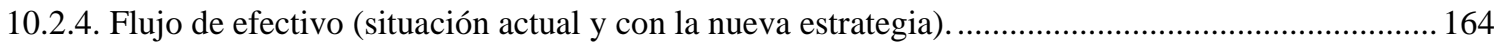

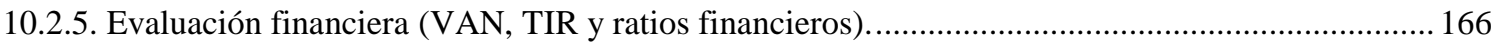

Conclusiones y Recomendaciones.......................................................... 172

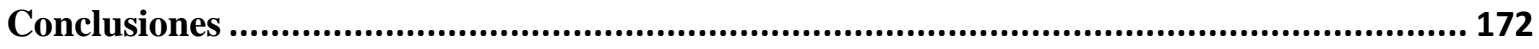

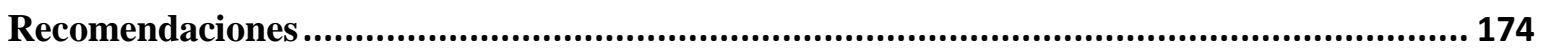

Índice de Figuras ......................................................................................... 176

Índice de Tablas .................................................................................... 176

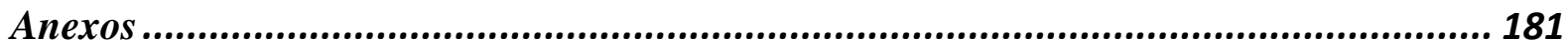

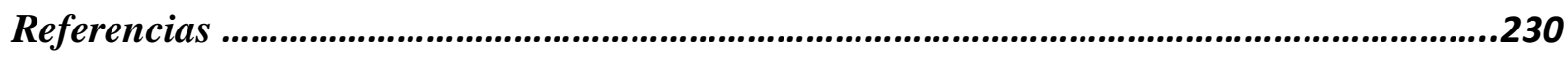

Referencias electrónicas..............................................................232 


\section{Introducción}

La presente tesis desarrolla un plan estratégico para la empresa Ransa Comercial S.A. para el periodo 2019 - 2022, con el fin de evitar que sus ventas sigan una tendencia negativa; en consecuencia, a una incompleta aplicación de estrategias que no aprovechan al máximo las fortalezas y oportunidades de la empresa. Por ello, el presente trabajo plantea objetivos y estrategias alcanzables en el periodo evaluado.

La estructura del plan estratégico se presenta de la siguiente forma:

En el capítulo I se describe los antecedentes de la industria logística y la evolución que tuvo en el Perú, los problemas que presenta la empresa y la justificación para el desarrollo de la investigación. Además, se plantea el objetivo general y los específicos, y expone el alcance y limitaciones de la investigación.

En el capítulo II se describe los antecedentes de la empresa y su evolución, y la estructura organizacional que gestiona, ejecuta y controla las acciones de le empresa. Además, presenta la línea de servicios en cartera y el ciclo de vida de los principales servicios (transporte, almacenaje y distribución). Finalmente, se desarrolla la situación de la industria.

En el capítulo III se describe la visión y la misión de la empresa y se plantean modificaciones, siendo explicadas y alineadas a los valores practicados por la empresa.

En el capítulo IV desarrolla el análisis del entorno externo, evaluando las tendencias de las siguientes variables: político-gubernamental, económico, legal, cultural, tecnológico y ecológico. Luego se evalúa el impacto de cada una de las variables sobre los clientes y proveedores, así como en la empresa; de este modo, se determinan las oportunidades y 
amenazas. Finalmente, se presenta la matriz EFE para conocer la respuesta de las estrategias de Ransa Comercial frente a las oportunidades y amenazas identificadas.

En el capítulo V se desarrolla el análisis de la industria, describiendo la demanda del mercado y la oferta de la industria. Además, se aplica al análisis las cinco fuerzas competitivas de la industria para luego elaborar la matriz de atractividad de la industria. Finalmente, se presenta la matriz del perfil competitivo, en el cual se compara a Ransa Comercial con sus principales competidores.

En el capítulo VI se desarrolla el análisis interno de Ransa, se muestra la cadena de valor, se presenta los indicadores de las actividades y se compara con sus principales competidores, y se expone la ventaja competitiva de la empresa. Finalmente, se elabora la matriz EFI para conocer cómo aprovecha la empresa sus fortalezas y soluciona sus debilidades.

En el capítulo VII se formulan los objetivos estratégicos y se proponen las estrategias, como el resultado de aplicar el modelo del océano azul y las siguientes matrices: FODA, PEYEA, IE, BCG y GE.

En el capítulo VIII se seleccionan las potenciales estrategias a aplicar, planteadas en el capítulo anterior. Además, se desarrolla el método de escenario que permite visualizar supuestas situaciones venideras. Finalmente, se presenta la matriz MCPE que permite determinar la estrategia principal y la contingente.

En el capítulo IX se presenta la implementación de la estrategia, para lo cual se desarrolla el BSC. Además, se formulan los objetivos específicos, los indicadores, las iniciativas y los responsables. Finalmente, se detalla el presupuesto y el cronograma para cada una de las iniciativas. 
En el capítulo X se evalúa cualitativa y financieramente la estrategia principal y contingente, demostrando la viabilidad y congruencia de éstas, así como beneficios que se pueden alcanzar.

Por último, se enuncian conclusiones y recomendaciones finales que derivan de toda la investigación realizada para una apropiada implementación de las iniciativas. 


\section{Capítulo I. Generalidades}

\subsection{Antecedentes}

Se entiende por logística el proceso de gestionar, planificar, ejecutar y controlar de manera eficiente y segura la circulación y almacenamiento de materias primas, inventarios en proceso, productos terminados y aquellos servicios e información relacionada, desde su origen hasta el punto de consumo, satisfaciendo así las necesidades del cliente (Christopher, 2000).

En los últimos años la oferta y demanda de los mercados mundiales se han incrementado, del mismo modo como los avances tecnológicos y los constantes cambios en la económica mundial que se viven actualmente, muestran constantes retos que deben superar las organizaciones. En el campo de la logística, el servicio tiene una definición amplificada y distinta en relación como se gestionaba la logística 20 años atrás. Actualmente, el proceso logístico empieza en el proceso operativo de las organizaciones, seguido de la gestión de actividades de ingreso y salida de la mano con todos los involucrados en la cadena de abastecimiento. Este concepto ampliado de logística se le conoce también como multiplicidad de servicios, cuya base está en atender a los clientes interesados de distintas industrias durante toda la cadena de abastecimiento, mejorando el control de los movimientos, costos y tiempos de los mismos (Dellazzoppa, 2011).

La logística se origina a inicios del siglo VII antes de Cristo, en el mundo militar de Grecia, donde existía el "Logístiko", quien se encargaba de determinar las cantidades de armas, municiones, armas, etc. que se necesitarían los griegos para sus conquistas. Es decir, nace como un "calculista" de necesidades de sus clientes. En el siglo II D.C., durante la época romana surge el "Logista", con la misión de abastecer los suministros para las legiones romanas. Además, como parte de sus labores debía buscar las mejores fuentes de aprovisionamiento (proveedores) y 
entregar a las unidades pertinentes. Con el tiempo y dado los buenos resultados obtenidos la logística se fue posicionando a en la gestión empresarial en los niveles operativos, tácticos y estratégicos (Meserón, 2007).

Durante los años 50`s, la logística incrementa su importancia debido a la transición, de los países más desarrollados, de una economía caracterizada por el exceso de demanda a una economía con exceso de oferta. Finalizando los sesenta, los gestores de negocio logran comprender que reducir los inventarios y cuentas por cobrar generar un mayor flujo de caja, afectando directamente la rentabilidad mejorando la gestión de las operaciones de distribución (Meserón, 2007).

A partir de ese momento, se conceptualizan y estandarizan algunas características de la logística, como: el análisis de los costos de logística, el incremento de los canales de distribución, los sistemas de medición en la cadena de abastecimiento e ingreso de la tecnología en la logística (Meserón, 2007).

En los últimos años, la gestión logística se ha facilitado con la incorporación de aplicaciones tecnológicas genéricas y específicas existentes en el mercado que permiten una mayor integración entre las diversas áreas de la empresa. Este concepto se conoce como logística integrada, el cual consiste en la automatización de la cadena de suministro, buscando alcanzar soluciones transversales a través de la infraestructura y los recursos apropiados, lo que frecuentemente resulta costoso costosos para los clientes (Meserón, 2007).

El Perú es unos de los países exportadores más importantes del mundo durante el año 2017 se exportaron bienes valorados en US\$ 44,058 millones, que representa un incremento de 22.7\% sobre el año 2016. Sin embargo, este crecimiento contrasta con los resultados de la 
logística peruana la que se encuentra entre los últimos puestos en relación con otros países de América Latina ("Perú aumentó sus exportaciones en 22.7\%," 31 de enero de 2018)

Según la Sociedad Nacional de Industria (SIN) en el año 2017, los costos logísticos agregados del Perú fueron del 13\% respecto del PBI, lo que nos vuelve menos competitivos frente a los resultados de nuestros socios comerciales como EE. UU. (8\%), Chile (12\%), Brasil (12\%) y México (12\%) (Ministerio de Comercio Exterior y Turismo [MINCETUR], 2016). Ver Figura 01.

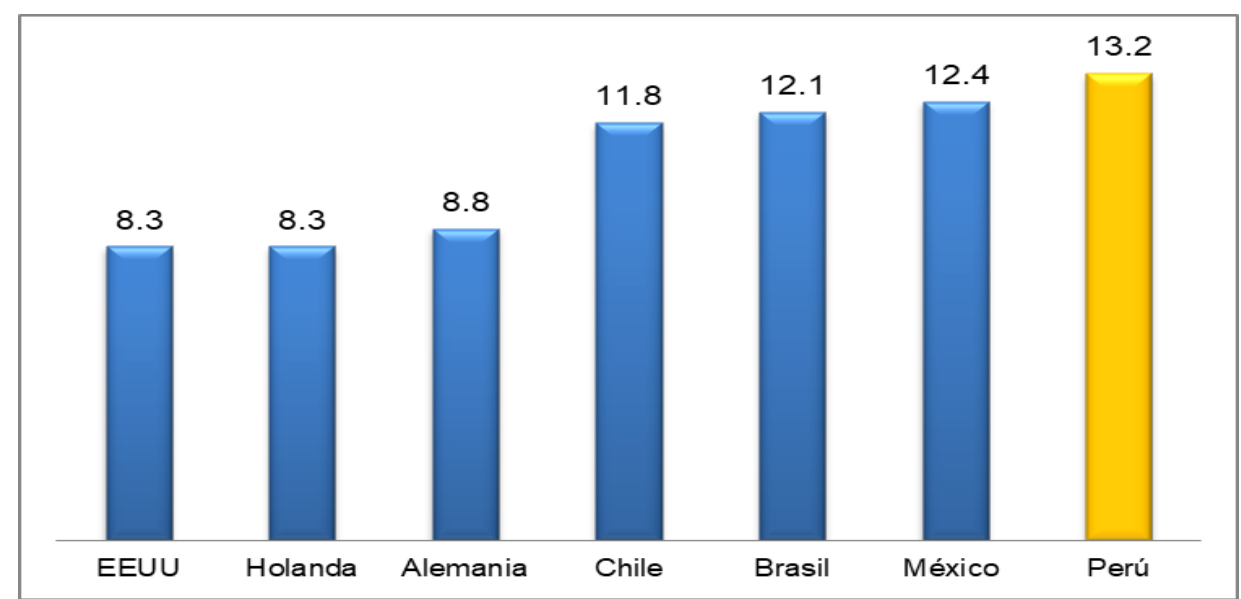

Figura 01. Costos Logísticos como porcentaje del PBI. Tomado de “Análisis Integral de Logística en Perú," por el Ministerio de Comercio Exterior y Turismo, 2017. Recuperado de https://bit.ly/2KqFnxe

Además, el Índice de Desempeño Logístico (IDL), el cual evalúa la eficiencia logística de 160 países, posiciona al Perú en el puesto 83 a nivel global y en el puesto 10 de 21 países de América Latina. Los conceptos utilizados para la evaluación son los siguientes: (a) eficiencia aduanera, (b) infraestructura, (c) embarques internacionales, (d) competencias logísticas, (e) seguimiento y rastreo, y (f) puntualidad. Ver Tabla 01. 
Tabla 01

Niveles de estructura para operaciones logísticas por países

\begin{tabular}{|c|c|c|c|c|c|c|c|c|}
\hline País & $\begin{array}{l}\text { Clasificación } \\
\text { Total IDL }\end{array}$ & $\begin{array}{l}\text { Índice } \\
\text { Total } \\
\text { IDL }\end{array}$ & $\begin{array}{c}\text { Índice } \\
\text { Eficiencia } \\
\text { Aduanera }\end{array}$ & $\begin{array}{c}\text { Índice } \\
\text { Infraestructura }\end{array}$ & $\begin{array}{c}\text { Índice } \\
\text { Embarques } \\
\text { Internacionales }\end{array}$ & $\begin{array}{c}\text { Índice } \\
\text { Competencias } \\
\text { logísticas }\end{array}$ & $\begin{array}{c}\text { Índice } \\
\text { Seguimiento y } \\
\text { Rastreo }\end{array}$ & $\begin{array}{c}\text { Índice } \\
\text { Puntualidad }\end{array}$ \\
\hline Chile & 34 & 3.32 & 3.27 & 3.21 & 3.27 & 3.13 & 3.20 & 3.80 \\
\hline Panamá & 38 & 3.28 & 2.87 & 3.13 & 3.31 & 3.33 & 3.40 & 3.60 \\
\hline México & 51 & 3.05 & 2.77 & 2.85 & 3.10 & 3.02 & 3.00 & 3.53 \\
\hline Brasil & 56 & 2.99 & 2.41 & 2.93 & 2.88 & 3.09 & 3.11 & 3.51 \\
\hline Colombia & 58 & 2.94 & 2.61 & 2.67 & 3.19 & 2.87 & 3.08 & 3.17 \\
\hline Argentina & 61 & 2.89 & 2.42 & 2.77 & 2.92 & 2.78 & 3.05 & 3.37 \\
\hline Ecuador & 62 & 2.88 & 2.8 & 2.72 & 2.75 & 2.75 & 3.07 & 3.19 \\
\hline Costa Rica & 73 & 2.79 & 2.63 & 2.49 & 2.78 & 2.7 & 2.96 & 3.16 \\
\hline Paraguay & 74 & 2.78 & 2.64 & 2.55 & 2.69 & 2.72 & 2.61 & 3.45 \\
\hline Perú & 83 & 2.69 & 2.53 & 2.28 & 2.84 & 2.42 & 2.55 & 3.45 \\
\hline Uruguay & 85 & 2.69 & 2.51 & 2.43 & 2.73 & 2.71 & 2.78 & 2.91 \\
\hline R. Dominicana & 87 & 2.66 & 2.41 & 2.36 & 2.77 & 2.44 & 2.97 & 2.98 \\
\hline Honduras & 93 & 2.6 & 2.24 & 2.47 & 2.66 & 2.72 & 2.68 & 2.83 \\
\hline El Salvador & 101 & 2.58 & 2.3 & 2.25 & 2.71 & 2.56 & 2.47 & 3.10 \\
\hline Jamaica & 113 & 2.52 & 2.42 & 2.32 & 2.53 & 2.54 & 2.48 & 2.79 \\
\hline Trinid. \& Tob. & 124 & 2.42 & 2.42 & 2.38 & 2.59 & 2.27 & 2.27 & 2.53 \\
\hline Guatemala & 125 & 2.41 & 2.16 & 2.2 & 2.33 & 2.25 & 2.42 & 3.11 \\
\hline Bolivia & 131 & 2.36 & 2.32 & 2.15 & 2.54 & 2.21 & 2.13 & 2.74 \\
\hline Venezuela & 142 & 2.23 & 1.79 & 2.1 & 2.38 & 2.21 & 2.29 & 2.58 \\
\hline Cuba & 146 & 2.2 & 2.03 & 2.04 & 2.27 & 2.2 & 2.15 & 2.46 \\
\hline Haití & 153 & 2.11 & 2.03 & 1.94 & 2.01 & 2.19 & 2.05 & 2.44 \\
\hline
\end{tabular}

Nota. La calificación de los índices va de 0 (siendo el más bajo) a 5 (siendo el más alto). Adaptado de "International LPI," por The World Bank, 2018, Global Rankings 2018. Recuperado de http://cort.as/-EAw7 
Es así como, de acuerdo con los resultados arrojados por el IDL a través de sus conceptos evaluados (ver Tabla 01), se evidencia que el Perú se encuentra en vías de desarrollo en lo que refiere al sector logístico, información que es determinada por las siguientes variables de acuerdo con The World Bank: (a) no se tiene eficientes procedimientos aduaneros que permitan velocidad, simplicidad y previsibilidad de los trámites; (b) no se cuenta con infraestructura apropiada relacionada a puertos, ferrocarriles, carreteras y tecnología de la información; (c) no existe facilidad de organizar envíos internacionales a precios competitivos; (d) los operadores logísticos no han desarrollado competencias claras que les permita ofrecer un servicio de alta calidad; del mismo modo, (e) los operadores logísticos no implementan herramientas adecuadas para la trazabilidad y el seguimiento de los producto; y, por último, (f) la puntualidad del servicio de distribución tiene aún cierto grado de incidencias en llegar a destino fuera del tiempo programado o esperado.

Por otro lado, los clientes cada vez exigen más a las empresas de logística a mejorar su eficiencia y desempeño, exigencias que definen barreras de ingreso bien establecidas, las mismas que presionan a los operadores que deseen continuar en la industria logística, siendo estas exigencias la característica propia de todo servicio de alta especialización.

Por ello, el mercado es sumamente competitivo por lo que los operadores logísticos 3PL deben enfocarse en el Perú como bloque, ya que las operaciones logísticas se vuelven más complejas con los años. El reto actual para las organizaciones logísticas es asegurar un servicio moderno, basados en equipos con tecnología moderna, personal con sólidos conocimientos y capacitados, precios acordes al mercado, amplio conocimiento del sector que permitan brindar servicios innovadores, y amplios espacios para el almacenamiento de los productos. 
Es importante mencionar que, a la fecha, en el Perú se encuentran operadores logísticos que proveen sus servicios en diferentes niveles de integración; siendo éstos, por su clasificación PL (Proveedores Logísticos), los siguientes: (a) 1PL, son quienes proveen el servicio de transporte, encargados únicamente del recojo y distribución de bienes; (b) 2PL, son quienes proveen el servicio de transporte y almacenamiento; (c) 3PL, son quienes proveen el servicio de transporte y almacenamiento, además de la organización de las operaciones de transporte y la gestión del almacén ; (d) 4PL, son quienes supervisan el funcionamiento de la logística a través de su experiencia especializada y capacidad tecnológica, no cuentan con recursos físicos para brindar los servicios de transporte y almacenamiento. (PerúRetail, 2019).

\subsection{Determinación del problema u oportunidad}

En la Figura 02 se puede observar el volumen de ventas de los servicios de Ransa Comercial, expresado en miles de soles, y la cantidad de clientes de los últimos 03 años. Cabe mencionar que los servicios de Almacenaje, Transporte y Distribución se evalúan independientemente a los demás servicios, debido que la suma de éstos representa el 70\% de la venta total de la organización. Asimismo, los demás servicios se evalúan bajo el concepto "Otros" que agrupa los resultados correspondientes de los servicios de Depósito Temporal, Proceso de Valor agregado, On Site, Alquiler de Contenedores y SILE (Servicio de Logística Integral). 


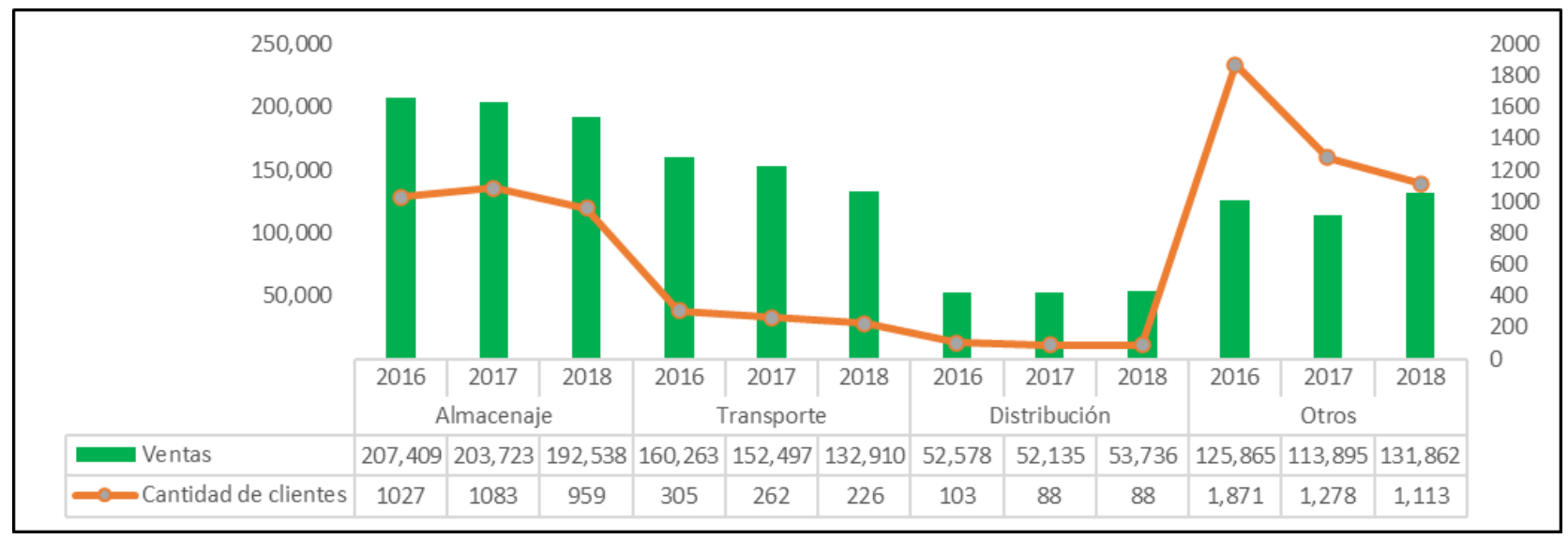

Figura 02. Ventas Netas (2016 - 2018, expresado en miles de soles). Adaptado de "Reporte de Control Presupuestal Ventas - Perú Logístico," por Control de Gestión, 2018. Recuperado de la Vicepresidencia de Finanzas.

Los servicios principales desde el 2016 en adelante presentan una disminución en las ventas debido a salida de clientes y a la disminución de operaciones de los clientes vigentes. De este modo, si hacemos el comparativo del 2016 vs 2017, se observa una contracción en las ventas del servicio de almacenaje equivalente a S/4 MM, debido principalmente a la salida de Hunt Oil, Pacific Stratus, General Cable, Sally Pery y Brailard, quienes representan S/2 MM. Asimismo, el servicio de transporte presenta una caída de S/8 MM, debido a la salida de Aceros Arequipa y Rio Mantaro, quienes representan S/4 MM.

Igualmente, al comparar los resultados del 2017 vs 2018, se observa una disminución en el servicio de almacenaje de S/12 MM, debido principalmente a la salida de la Minera Chinalco, Pesquera Diamante, Lindley, Cal del Centro y Pesquera Hayduk, quienes representan S/9 MM. Por su parte, el servicio de transporte presenta una contracción de S/20 MM, debido a salida de clientes como Lindley, Delkor, CPC, Siemens y Constructor Ductos, quienes representan S/5 MM. Finalmente, el servicio de distribución mantiene menor venta en S/5 K. 
Es importante mencionar que los clientes no necesariamente tienen contrato por todos los servicios de la cadena logística, es decir, pueden tener uno o más servicios con Ransa Comercial y trabajar los demás con otro operador.

Por otro lado, en la siguiente tabla se visualiza el detalle de los costos más representativos (Costos Variables, Costos Fijos Directos e Indirectos). Ver Tabla 02.

En este sentido, en el servicio de almacenamiento se observa que los Costos Fijos Directos e Indirectos ascienden por encima de los Costos Variables, en el que resaltan los conceptos de alquiler de inmuebles (espacio designado para el servicio de almacenamiento), alquiler maquinaria y equipos (ejemplo: elevadores, montacargas y transpaletas eléctricas), sueldos y salarios del personal asignado a las operaciones (sueldos, sobretiempo, CTS, Gratificación, movilidad, entre otros) siendo el costos por horas extras (sobretiempo) uno de los más altos, y común planta que hace referencia a los gastos comunes de la sede. Por otro lado, en los Costos Variables resaltan los costos de manipuleo (subcontratación de personal para actividades como estiba y desestiba), y los costos por suministros de materiales (ejemplo: la compra de stretch film, cajas, cintas, entre otros).

Por su parte, en los servicios de transporte y distribución se observa que los Costos Variables ascienden por encima de los Costos Fijos Directos e Indirectos, en el que resaltan los costos de transporte y flete; mientras que, en los Costos Fijos Directos e Indirectos, se observa principalmente la partida de sueldos y salarios del personal.

De este modo, al observar la Figura 02 y la Tabla 02, se evidencian las deficiencias que existen dentro del área Comercial de Ransa, deficiencias que han provocado la pérdida de clientes y la reducción de servicios subcontratados, debido a la falta de propuestas atractivas para atraer, retener y recuperar clientes; asimismo, las deficiencias alcanzan también al área de Operaciones, 
responsable de ofrecer un servicio de calidad, utilizando los recursos necesarios para cumplir con el servicio esperado por parte del cliente, situación que parece no alcanzar completamente con el 6.84\% de clientes que piensan que la empresa ha desmejorado (ver Anexo 06).

Por otro lado, se evidencia una alta estructura de Costos Variables, siendo las partidas de manipuleo y de materiales las de mayor volumen, las cuales deben tener un control y uso responsable; además, se tiene la partida de sueldos y salarios, los cuales deben ser ajustados en la medida de lo posible, ya que se tiene altos costos de sobretiempo.

Por último, es importante mencionar que la asignación de recursos por operación se realiza en base al dimensionamiento, es decir, en base a los volúmenes y la productividad del personal. 
Tabla 02

Costos Variables, Costos Fijos Directos e Indirectos por servicio

\begin{tabular}{|c|c|c|c|}
\hline & $2016 \mathrm{R}$ & $2017 \mathrm{R}$ & $2018 \mathrm{R}$ \\
\hline \multicolumn{4}{|c|}{ Almacenaje } \\
\hline COSTOS VARIABLES & $-20,998$ & $-19,391$ & $-20,209$ \\
\hline ALQUILER DE MAQUINARIAS Y EQUIPOS & $-3,499$ & $-2,356$ & $-1,112$ \\
\hline SERVICIOS DE MANIPULEO & $-9,726$ & $-9,028$ & $-8,481$ \\
\hline SUMINISTROS - MATERIALES & $-2,156$ & $-2,139$ & $-2,289$ \\
\hline SUMINISTROS - PETRÓLEO Y OTROS & -894 & -969 & -985 \\
\hline TRANSPORTE Y FLETES & $-1,927$ & -905 & -846 \\
\hline OTROS & $-2,797$ & $-3,994$ & $-6,496$ \\
\hline COSTOS FIJOS DIRECTOS E INDIRECTOS & $-179,480$ & $-169,043$ & $-151,009$ \\
\hline ALQUILER DE INMUEBLES & $-62,079$ & $-57,302$ & $-47,052$ \\
\hline ALQUILER DE MAQUINARIAS Y EQUIPOS & $-8,467$ & $-8,918$ & $-7,080$ \\
\hline REPARACIÓN Y MANTENIMIENTO & $-3,992$ & $-3,653$ & $-3,884$ \\
\hline SEGUROS & $-5,020$ & $-3,856$ & $-3,500$ \\
\hline SUELDOS Y SALARIOS & $-30,477$ & $-31,116$ & $-33,335$ \\
\hline COMÚN PLANTA & $-11,249$ & $-9,839$ & $-9,807$ \\
\hline OTROS & $-58,196$ & $-54,359$ & $-46,352$ \\
\hline \multicolumn{4}{|c|}{ Transporte } \\
\hline COSTOS VARIABLES & $-121,109$ & $-116,199$ & $-103,210$ \\
\hline ALIMENTACIÓN & $-1,891$ & $-2,615$ & $-1,609$ \\
\hline ALQUILER DE UNIDADES DE TRANSPORTE & $-3,734$ & $-5,498$ & $-5,277$ \\
\hline OTROS GASTOS DE VIAJE & $-2,028$ & $-2,055$ & $-1,520$ \\
\hline SUMINISTROS - PETRÓLEO Y OTROS & $-7,857$ & $-8,886$ & $-9,037$ \\
\hline TRANSPORTE Y FLETES & $-99,895$ & $-91,096$ & $-80,888$ \\
\hline OTROS & $-5,704$ & $-6,049$ & $-4,879$ \\
\hline COSTOS FIJOS DIRECTOS E INDIRECTOS & $-46,235$ & $-49,837$ & $-41,342$ \\
\hline ALQUILER DE UNIDADES DE TRANSPORTE & $-6,274$ & $-4,855$ & $-3,982$ \\
\hline SUELDOS Y SALARIOS & $-13,750$ & $-15,312$ & $-13,132$ \\
\hline COMÚN TRANSPORTE & $-7,611$ & $-10,090$ & $-7,676$ \\
\hline OTROS & $-18,600$ & $-19,580$ & $-16,552$ \\
\hline \multicolumn{4}{|c|}{ Distribución } \\
\hline COSTOS VARIABLES & $-29,917$ & $-32,954$ & $-34,820$ \\
\hline SERVICIOS DE MANIPULEO & $-7,269$ & $-7,188$ & $-10,411$ \\
\hline SERVICIOS DE VIGILANCIA & $-1,918$ & $-2,794$ & $-1,141$ \\
\hline SUMINISTROS - PETRÓLEO Y OTROS & $-1,620$ & $-1,863$ & $-2,406$ \\
\hline TRANSPORTE Y FLETES & $-15,992$ & $-17,811$ & $-18,026$ \\
\hline OTROS & $-3,118$ & $-3,299$ & $-2,835$ \\
\hline COSTOS FIJOS DIRECTOS E INDIRECTOS & $-16,586$ & $-15,464$ & $-13,685$ \\
\hline SUELDOS Y SALARIOS & $-8,734$ & $-8,089$ & $-6,749$ \\
\hline OTROS & $-7,851$ & $-7,376$ & $-6,936$ \\
\hline \multicolumn{4}{|c|}{ Otros } \\
\hline COSTOS VARIABLES & $-61,166$ & $-63,312$ & $-74,090$ \\
\hline SERVICIOS DE CARGA Y DESCARGA & $-21,129$ & $-24,824$ & $-27,347$ \\
\hline SERVICIOS DE MANIPULEO & $-10,927$ & $-10,149$ & $-12,738$ \\
\hline SERVICIOS LOGÍSTICOS & $-6,171$ & $-6,769$ & $-7,903$ \\
\hline TRANSPORTE Y FLETES & $-9,253$ & $-11,789$ & $-13,289$ \\
\hline OTROS & $-13,686$ & $-9,782$ & $-12,811$ \\
\hline COSTOS FIJOS DIRECTOS E INDIRECTOS & $-42,431$ & $-33,839$ & $-33,988$ \\
\hline SUELDOS Y SALARIOS & $-4,253$ & $-2,250$ & $-2,097$ \\
\hline ALQUILER DE INMUEBLES & $-4,786$ & $-4,454$ & $-3,092$ \\
\hline ALQUILER DE MAQUINARIAS Y EQUIPOS & $-1,654$ & -925 & $-1,054$ \\
\hline REPARACIÓN Y MANTENIMIENTO & $-2,716$ & $-2,164$ & $-2,210$ \\
\hline SUELDOS Y SALARIOS & $-11,220$ & $-9,901$ & $-13,512$ \\
\hline OTROS & $-17,803$ & $-14,145$ & $-12,023$ \\
\hline
\end{tabular}

Nota: Costos Variables, Costos Fijos Directos e Indirectos, y Gastos de Administración y Ventas (2016 - 2018, en miles de soles). Adaptado de "Reporte de Control Presupuestal Ventas - Perú Logístico," por Control de Gestión, 2018. Recuperado de la Vicepresidencia de Finanzas. 


\subsection{Justificación del proyecto}

La elaboración del Plan Estratégico para la empresa Ransa Comercial S.A. podrá ser utilizada para replantear las estrategias de los servicios que se ofrecen e implementar soluciones propuestas. Además, se tiene como finalidad aplicar los conocimientos adquiridos durante los años de estudio de la Maestría de Ciencias Empresariales y demostrar el resultado.

\subsection{Objetivos generales y específicos}

\section{- Objetivo General}

OG: Elaborar el Plan Estratégico para la empresa Ransa Comercial S.A. ubicada en la provincia Constitucional del Callao para los períodos 2019-2022, que permita el incrementar la rentabilidad de las operaciones.

\section{- Objetivos Específicos}

OE1: Realizar un análisis de la situación interna y externa de la empresa para obtener un diagnóstico que permitan tomar decisiones estratégicas.

OE2: Analizar y mejorar el planteamiento de la misión, visión y valores de la empresa para precisar los objetivos y la forma de aproximarse a sus clientes.

OE3: Replantear los objetivos de la empresa y diseñar las estrategias para el cumplimiento del plan estratégico planteado.

OE4: Elaborar las matrices para formular las estrategias de la organización en base al diagnóstico obtenido.

OE5: Desarrollar el Balance Scorecard para definir y hacer seguimiento a las estrategias de la organización.

OE6: Evaluar los resultados de la organización a través de indicadores operativos, contables y financieros para evaluar el impacto de las estrategias planteadas. 


\subsection{Alcances y limitaciones de la investigación}

\section{- Alcances}

- Geográfico: República del Perú

- Tiempo: Periodo 2019-2022.

- Proyecto: Plan Estratégico para la empresa Ransa Comercial S.A.

- Servicios de estudio: Transporte, almacenaje y distribución.

\section{- Limitaciones}

La dificultad para recabar información de expertos de la competencia para el desarrollo del planeamiento estratégico, es decir, no poder obtener encuestas o entrevistas por parte de los líderes de otros operadores logísticos, debido a la confidencialidad con la que se maneja el sector en la actualidad. Asimismo, es limitada la comunicación con los clientes de la organización para poder obtener de primera mano una retroalimentación en relación a los servicios ofrecidos por Ransa Comercial. 


\section{Capítulo II. La empresa}

\subsection{Antecedentes de la empresa}

Ransa comienza sus operaciones en 1939 con el nombre de Reprensa Algodonera y Almacén Nacional S.A. con instalaciones en 5 puntos de la costa peruana (puertos del Callao, Cerro Azul, Huacho, Pisco y Paita), ofreciendo los servicios de acopio y reprensaje de algodón destinado al comercio exterior. Luego, en 1950 Ransa expande sus actividades, brindando servicios de operaciones de carga, tanto nacional como internacional, ingresando así al negocio de transporte, almacenamiento, terminal y naviero, consolidándose como Transportes Ransa S.A. Más tarde, en 1974 la organización cambia su denominación a Ransa Comercial S.A. y extiende sus actividades a almacenaje simple, depósitos en aduana y cámaras frigoríficas, convirtiéndose en pioneros de la industria en el Perú. Después de unos años, para el 2013, Ransa ya había ingresado al mercado de San Agustín, Bolivia, Ecuador, Guatemala, El Salvador, Torre Blanca y Honduras. Para éste mismo año, Ransa ingresaba al mercado de Colombia, ofreciendo los servicios de Almacén General de Depósito a los sectores de retail y consumo masivo de alimentos para secos. Un tiempo después, en el año 2015, Ransa refuerza su posicionamiento en Guatemala y Ecuador agregando en su cartera de servicios la logística refrigerada. Hace poco, en el año 2016 Ransa vuelve afirmar su liderazgo en el Perú construyendo el más moderno centro automotriz, ubicado en Lurín (Ransa, 2018).

\subsection{Descripción del negocio}

El negocio de Ransa Comercial consiste en diseñar y gestionar soluciones logísticas especializadas para los clientes, ofreciendo a la fecha seis distintos servicios (Ransa, 2018). Éstos se describen a continuación: 
- Almacenamiento: Ofrece desde almacenes en tránsito hasta almacenes de carga en stock para carga especializada, materiales peligrosos y congelados.

- Distribución: Ofrece el traslado de mercadería de un centro de distribución propio o tercero hacia un destino final.

- Transporte: Ofrece traslado de mercadería en las modalidades de temperatura controlada, carga regular y sobre dimensionada, y carga peligrosa hacia un terminal portuario o a cualquier punto del país.

- Depósito Temporal: Ofrece la descarga y embarque de carga suelta y carga rodante de contenedores exclusivos, consolidados por DP World y APM Terminals en Callao y TPE en Paita.

- On Site: Ofrece la gestión de operaciones en los almacenes del cliente.

- Servicio de Valor Agregado: Ofrece el servicio de cross docking, preparación de pedidos, maquila especializada y otros.

\subsection{Ciclo de vida del producto}

En la Figura 03 se observa las tendencias de las ventas netas de Ransa Comercial y el Producto Bruto Interno (PBI) de la industria desarrollada, actualizado al 2017.

La tendencia del Producto Bruto Interno (PBI) de la industria de Transporte, Almacenamiento y Mensajería es creciente desde el año 2007 hasta el 2017, alcanzando un crecimiento promedio de $+6.09 \%$ en los últimos diez años y poniendo en evidencia que la industria se encuentra en la etapa de crecimiento. Este escenario puede estar relacionado a un aumento en el consumo final público y privado, a la recuperación de la inversión bruta y a un buen desempeño de las exportaciones. 


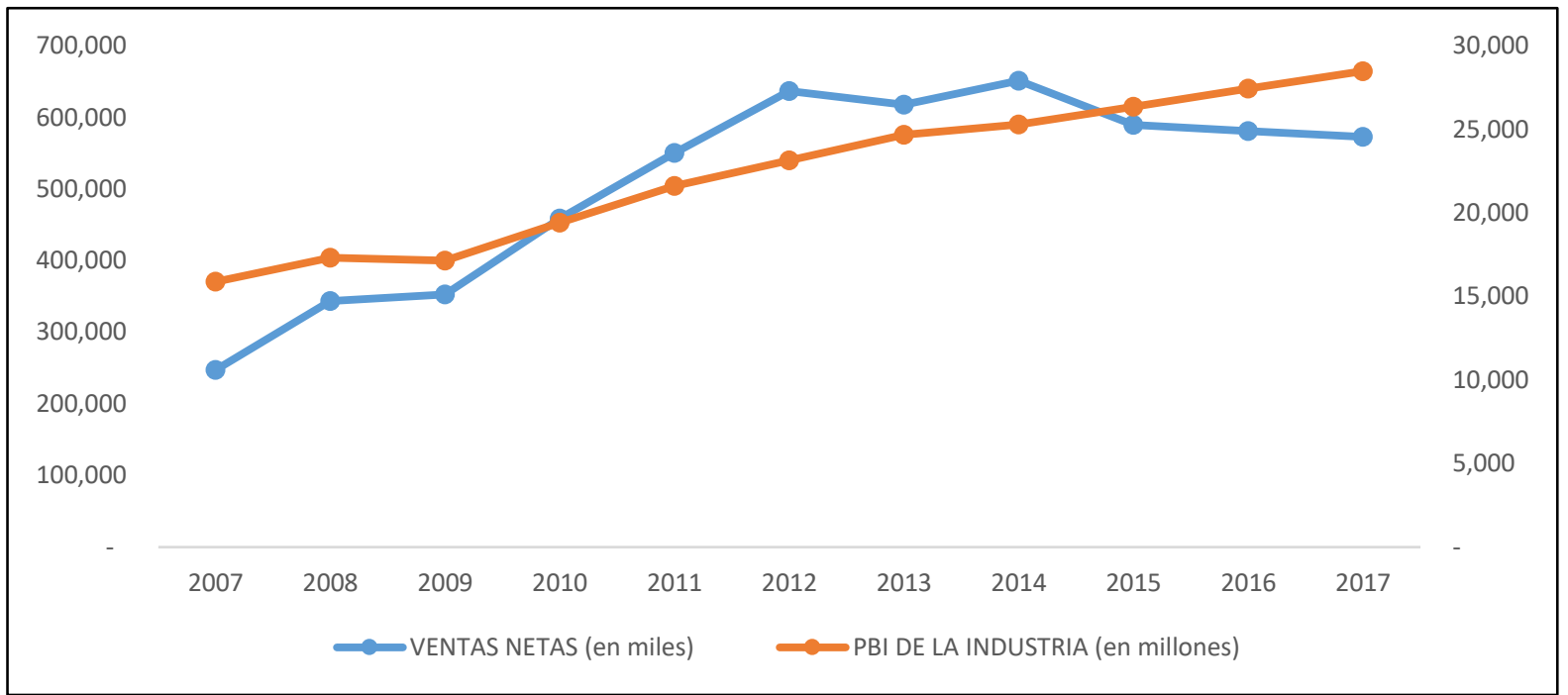

Figura 03. Comparativo de Ventas Ransa Comercial SA y Producto Bruto Interno de la industria (1994 - 2017). Adaptado de "Producto Bruto Interno según Actividad Económica (Nivel 54) 2007 - 2017 (Valores a precios constantes de 2007)" por el Instituto Nacional de Estadística e Informática, 2018. Recuperado de goo.gl/GhkeR8

De igual modo, la tendencia de las ventas muestra un crecimiento desde el año 2007 hasta el 2015; sin embargo, a partir de esa fecha se muestra una caída en las ventas como consecuencia de lo salida clientes y disminución de operaciones, como se explicó anteriormente.

En conclusión, el comportamiento de las cifras de ventas anuales de Ransa y el PBI de la industria mantienen la misma tendencia de crecimiento hasta el año 2014; sin embargo, a partir del año 2015 en adelante la tendencia de Ransa pasa a ser decreciente, mientras que el PBI de la industria mantiene su crecimiento; escenario que coincide cuando una empresa alcanza la etapa de madurez.

Por otro lado, como se mencionó anteriormente, los principales servicios de Ransa que aportan más del 70\% de los ingresos totales son: transporte, almacenaje y distribución. Logrando en el año 2016 alcanzar el monto de 420MM de un total de 546MM, en el año 2017 un monto de 408MM de un total de 522MM y en el año 2018 el monto de 379MM de un total de 511MM. Por ello, el presente plan estratégico involucra únicamente estos servicios. Ver Figura 04. 
Además, en la misma figura, se observa que los principales servicios ofrecidos por la empresa muestran la misma tendencia decreciente en los resultados de los tres últimos años, donde las ventas tienen un crecimiento lento, y los clientes y las operaciones se reducen. Por esta razón, se afirma que los principales servicios de la empresa se encuentran en una etapa de crecimiento/madurez.

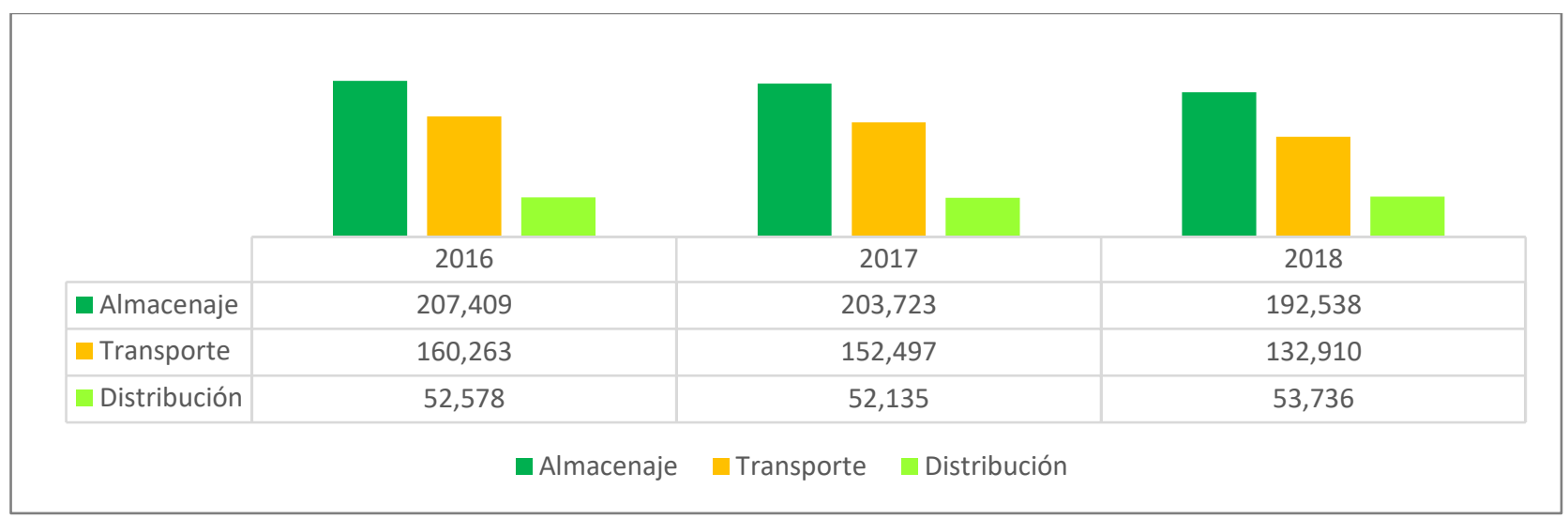

Figura 04. Ventas de servicios principales de Ransa Comercial SA (2016 - 2018, expresado en miles de soles). Adaptado de "Reporte de Control Presupuestal Ventas - Perú Logístico," por Control de Gestión, 2018. Recuperado de la Vicepresidencia de Finanzas.

Por último, la razón del por qué Ransa disminuye sus ingresos dentro de una industria que se encuentra en la etapa de crecimiento, se relaciona con el ingreso de nuevos operadores logísticos (ver Tabla 12), quienes provocan y mantienen las siguientes eventualidades: (a) ralentización en la captación de nuevos clientes y (b) salida de los clientes actuales; sin embargo, esta última puede tener un origen distinto, que es cuando el cliente decide implementar y gestionar su propia cadena logística.

\subsection{Estructura organizacional actual de la empresa}

El organigrama presentado en la Figura 05 es de tipo funcional, dado que contiene información representativa de la empresa en base a las principales funciones e interrelaciones de las Gerencias asignadas. 
La Gerencia Central de Operaciones es la encargada de gestionar los servicios logísticos ofrecidos por Ransa; de esta manera, la gerencia tiene a su cargo al Gerente de División Almacenes, Depósito Temporal y On Site, al Gerente de Operaciones Transporte que gestiona el sector de Minería y Energía, al Gerente de Distribución y finalmente al Gerente de División Zona Norte.

Respecto a las Gerencias de Negocios Industriales, Minería y Energía, Gas y Petróleo, y Construcción e Infraestructura corresponden a la Gestión Comercial de los servicios de la empresa.

Por otro lado, se tiene a las Vicepresidencias de Finanzas, RR.HH. y Sistemas, y a las Sub gerencias de Innovación y Consultoría, y Seguridad y Calidad como áreas de soporte para la Gerencia de Operaciones.

Sin embargo, el área de Innovación y Consultoría, en los últimos años, ha demostrado deficiencias en la gestión de sus proyectos, entregándolos fuera del plazo establecido con altos sobrecostos; ejemplo de ello son el proyecto de optimización en línea de producción maquila y el proyecto de implementación WMS Sodexo (ver Anexo 01). La razón principal de esta deficiencia gira entorno a: (a) baja respuesta por parte de TI, (b) responsabilidades no bien definidas en los actores del proyecto, (c) procesos y documentación innecesaria para la aprobación de nuevas solicitudes (ver Anexo 02). Esto se debe a que Ransa aplica metodologías tradicionales (ver Anexo 03) en proyectos de optimización de procesos y desarrollo de softwares, siendo la metodología inconveniente por la naturaleza de estos proyectos. 


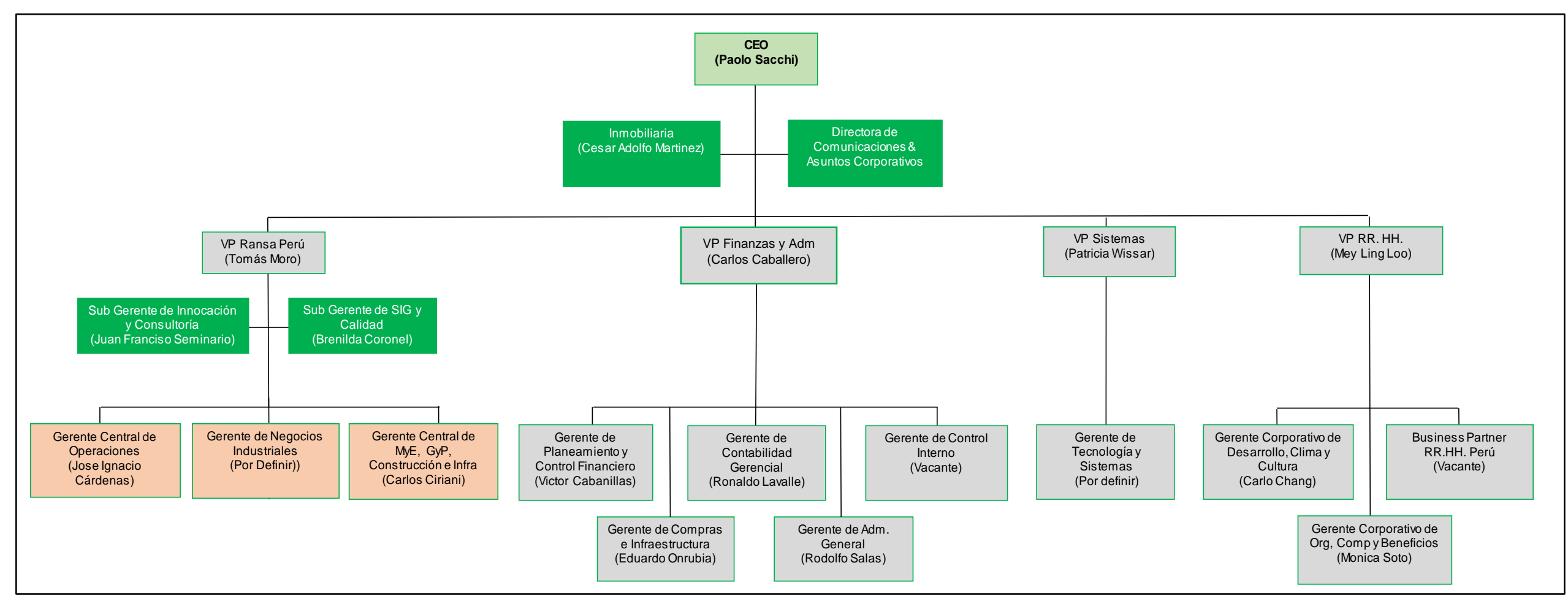

Figura 05. Organigrama Corporativo Ransa 2018. Adaptado de "Impulsa," por Recursos Humanos, 2018. Recuperado de goo.gl/qznja4 


\subsection{Situación de mercado y financiera actual de la industria}

En el año 2017 la actividad transporte, almacenamiento, correo y mensajería, mantuvo un porcentaje de crecimiento de 2,9\%, representando el séptimo lugar del total de actividades económicas, tal como se observa en la Figura 06.

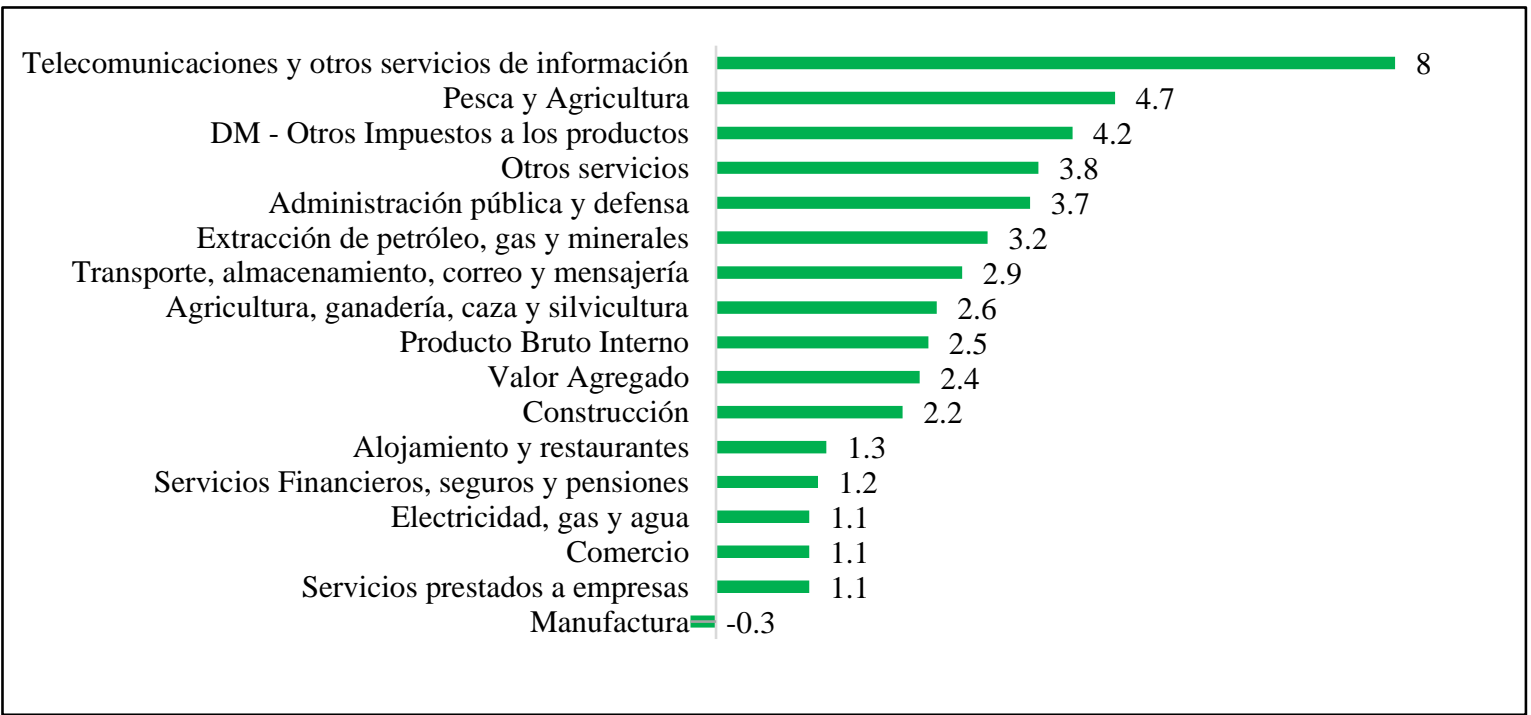

Figura 06. Producto Bruto Interno según Actividad Económica. Los porcentajes representan la variación respecto al año anterior. Tomado de "Panorama de la Economía Peruana", por INEI, 2017, p.21

El sector de transporte, almacenamiento, correo y mensajería presenta un crecimiento debido al incremento de 4,2\% del subsector de almacenamiento, correo y mensajería en consecuencia a un aumento en los servicios de almacenamiento y las actividades de apoyo de transporte; asimismo, el subsector de transporte incrementó en un $2.8 \%$ debido al aumento del transporte de carga marítima y transporte aéreo. Ver Figura 07. 


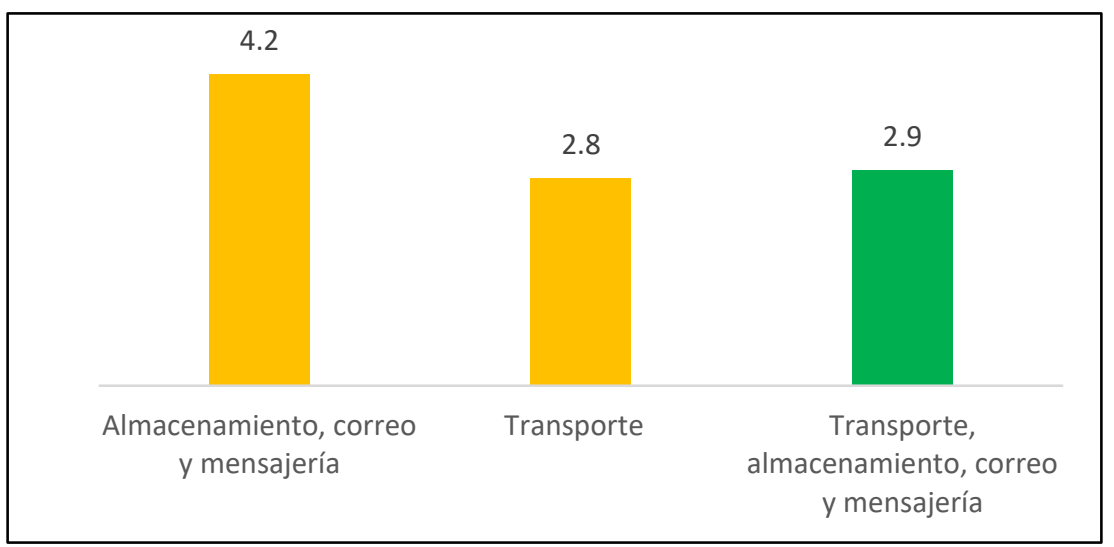

Figura 07. Transporte, Almacenamiento, Correo y Mensajería, Valor Agregado Bruto. Adaptado de "Panorama de la Economía Peruana", por INEI, 2017, p.29.

Para enero del 2018, la producción nacional se incrementó en 2,81\% y sumó 102 meses de crecimiento sostenido. Asimismo, en el periodo anualizado febrero 2017 a enero 2018 lo hizo en $2,33 \%$ (INEI, 2018).

Respecto al Sector Transporte, Almacenamiento y Mensajería, mantuvo un incremento del 4,62\% registrando la tasa más alta de los últimos 22 meses. Este resultado tuvo lugar por la mayor actividad del subsector Transporte presentando una variación del 5,25\%, así como del subsector Almacenamiento y Mensajería con 3,30\%. En el subsector transporte aumentó el transporte aéreo por el mayor tráfico de pasajeros y carga; el transporte por vía terrestre y tuberías debido al mayor tráfico de carga y pasajeros por vía férrea y por carretera (INEI, 2018).

Por último, el crecimiento del sector está ampliamente relacionado al incremento de otros sectores (ver Figura 08), tales como los sectores de pesca y agricultura, gas y minería, comercio, construcción, servicios financieros, entre otros; pudiendo afirmarse que el sector logístico depende del desenvolvimiento de éstos. Además, con un crecimiento de $2.9 \%$, porcentaje superior al crecimiento del BPI (2.5\%), el sector logístico ha llegado a ser uno de los sectores que mueve la economía nacional. 


\section{Capítulo III. Formulación de visión, misión y valores de la empresa}

\subsection{Visión}

La visión de una organización plantea una imagen a largo plazo, una expectativa ideal de lo que se espera que ocurra. Por lo tanto, debe ser realista pero ambiciosa, y su función debe ser el guiar y motivar a los colaboradores a continuar con el trabajo (D'Alessio, 2008).

A continuación, se mostrará la visión actual de la empresa, el análisis de ésta y una propuesta de mejora.

\subsubsection{Visión actual de la empresa}

"Ser una organización de clase mundial posicionada entre los primeros operadores de Latinoamérica con ventas superiores a S/600 millones al 2020”. (Ransa, s.f).

\subsubsection{Análisis de la visión actual}

A continuación, en la Tabla 03, se observa la descomposición de la visión actual de Ransa de acuerdo con las siete (7) características establecidas por D’Alessio, las cuales deben cubrir la visión de toda organización, mostrando finalmente el cumplimiento de seis (6) de ellas.

Tabla 03

Visión actual de la empresa

\begin{tabular}{|c|c|c|}
\hline Caracteristica & Situación de la Visión Actual & Cumple / No cumple \\
\hline Simple & & Cumple \\
\hline Ambiciosa & $\begin{array}{l}\text { "Ser una organización de clase mundial..." } \\
\text { "...con ventas superiores a USS } 600 \text { millones al } \\
2020 "\end{array}$ & Cumple \\
\hline Temporal & “...al $2020 "$ & Cumple \\
\hline Alcance Geográfico & "... operadores de Latinoamérica..." & Cumple \\
\hline Conocida por todos & - & No cumple \\
\hline Sentido de Urgencia & $\begin{array}{l}\text { "...posicionada entre los primeros operadores de } \\
\text { Latinoamérica..." }\end{array}$ & Cumple \\
\hline Panorama de Futuro & $\begin{array}{l}\text { "...organización de clase mundial ....entre los } \\
\text { primeros operadores de Latinoamérica ....al 2020" }\end{array}$ & Cumple \\
\hline
\end{tabular}

Nota. Adaptado de El proceso estratégico: Un enfoque de gerencia (p. 61), por F. D’Alessio, 2008, México D.F.: Pearson Educación. 
Cabe mencionar que el siguiente fragmento "Ser una organización de clase mundial..." asume un escenario en el que Ransa debe estar al nivel de los operadores logísticos de clase mundial y preparada para competir con éstas mismas si entraran al mercado nacional. De igual modo, el siguiente fragmento “... con ventas superiores a S/600 millones al 2020” apunta a recuperar las ventas registradas por Ransa hasta el año 2014 en un plazo de seis años. Concluyendo, que la visión propuesta por la empresa es realista y alcanzable.

\subsubsection{Matriz de la visión propuesta para la empresa}

Considerando que la visión de Ransa cumple con seis (06) de las siete (07) características establecidas por D'Alessio y que además es realista y alcanzable, se considera que la propuesta debe mantenerse.

\subsubsection{Visión propuesta}

"Ser una organización de clase mundial posicionada entre los primeros operadores de Latinoamérica con ventas superiores a S/600 millones al 2020”. (Ransa, s.f).

\subsection{Misión}

La misión de una organización refleja la razón de ser de una empresa, se enfoca en el presente y justifica lo que el grupo o un individuo realiza en determinado momento. (D'Alessio, 2008).

A continuación, se mostrará la misión actual de la empresa, el análisis de ésta y una propuesta. 


\subsubsection{Misión actual de la empresa}

“Mejorar el nivel de la logística en los países en los que trabajamos, ayudando a nuestros clientes a incrementar su valor a través de nuestros servicios y asesoría”. (Ransa Comercial, s.f.).

\subsubsection{Análisis de la misión actual}

La Tabla 04 muestra la descomposición de la misión actual, contrastándola con las nueve (9) características establecidas por D'Alessio, cumpliendo con tres (3) de éstas, siendo necesario ajustar la misión actual y así lograr un mejor entendimiento de nuestra razón de ser.

Tabla 04

Misión actual de la empresa

\begin{tabular}{|c|c|c|}
\hline Característica & Situación de la misión actual & Cumple/No cumple \\
\hline Cliente de la empresa & - & No cumple \\
\hline Principales servicios & $\begin{array}{l}\text { "Mejorar el nivel de la logística...", "...nuestros } \\
\text { servicios y asesorías..." }\end{array}$ & Cumple \\
\hline Mercado & "...en los países en los que trabajamos..." & Cumple \\
\hline $\begin{array}{l}\text { Interés en la supervivencia } \\
\text { y crecimiento }\end{array}$ & - & No cumple \\
\hline $\begin{array}{l}\text { Principal ventaja } \\
\text { competitiva }\end{array}$ & - & No cumple \\
\hline Filosofía implícita & - & No cumple \\
\hline Imagen pública & - & No cumple \\
\hline Imagen en el sector & $\begin{array}{l}\text { "....ayudando a nuestros clientes a } \\
\text { incrementar su valor" }\end{array}$ & Cumple \\
\hline $\begin{array}{l}\text { Interés en los } \\
\text { colaboradores }\end{array}$ & - & No cumple \\
\hline
\end{tabular}

Nota. Adaptado de El proceso estratégico: Un enfoque de gerencia (p. 65), por F. D’Alessio, 2008, México D.F.: Pearson Educación. 


\subsubsection{Elementos de la misión propuesta para la empresa}

La Tabla 05 muestra la descomposición de la misión propuesta, la cual cumple con seis (6) de nueve (9) características que una misión debe cubrir, respondiendo así con mayor certeza la pregunta ¿quiénes somos?

Acerca de las características aceptadas en el enunciado de la misión, D’Alessio (2008) afirma. "Los enunciados de cada misión pueden variar en extensión, contenido, formato, y especificación" (p.64).

Tabla 05

Misión propuesta para la empresa

\begin{tabular}{|c|c|c|}
\hline Característica & Situación de la Misión actual & $\begin{array}{l}\text { Cumple / } \\
\text { No cumple }\end{array}$ \\
\hline Clientes de la empresa & - & No cumple \\
\hline Principales servicios & "Mejorar el nivel de la logística..." & Cumple \\
\hline Mercado & "...en los países en los que trabajamos..." & Cumple \\
\hline $\begin{array}{l}\text { Interés en la supervivencia y } \\
\text { crecimiento }\end{array}$ & 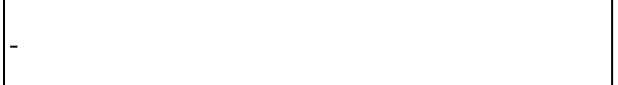 & No cumple \\
\hline Principal ventaja competitiva & $\begin{array}{l}\text { "...mediante el uso de nuestra tecnología } \\
\text { avanzada..." }\end{array}$ & Cumple \\
\hline Filosofía implícita & $\begin{array}{l}\text { "...colaboradores como principal clave de } \\
\text { éxito" }\end{array}$ & Cumple \\
\hline Imagen pública & - & No cumple \\
\hline Imagen en el sector & $\begin{array}{l}\text { "...ayudando a nuestros clientes a incrementar } \\
\text { su valor..." }\end{array}$ & Cumple \\
\hline Interés en los colaboradores & $\begin{array}{l}\text { "...manteniendo motivados a nuestros } \\
\text { colaboradores..." }\end{array}$ & Cumple \\
\hline
\end{tabular}

Nota. Adaptado de El proceso estratégico: Un enfoque de gerencia (p. 65), por F.

D’Alessio, 2008, México D.F.: Pearson Educación.

\subsubsection{Misión propuesta}

“Mejorar el nivel de la logística en los países en los que trabajamos, incrementando el valor de nuestros clientes con ayuda de nuestros servicios y asesoría, mediante el uso de nuestra tecnología de avanzada y manteniendo motivados a nuestros colaboradores como principal clave de nuestro éxito". 
Cabe mencionar que el siguiente fragmento “... tecnología de avanzada ...” hace referencia a lo siguiente: primero, almacenes especializados por tipo de producto; segundo, instalaciones amplias y modernas para la fácil circulación, gestión y control de los productos entrantes y salientes; tercero, softwares actualizados de acuerdo con las necesidades de la industria que agreguen valor al servicio principal y a las actividades de apoyo.

De este modo, el siguiente fragmento “... tecnología avanzada ...” puede aplicarse desde equipos básicos como por ejemplo las videocámaras, las cuales son utilizadas para la gestión y el control del personal y la seguridad de la empresa; sin embargo, las videocámaras convencionales que la empresa utiliza solo graban determinados cuadros y ángulos, dejando puntos ciegos, por lo que es necesario utilizar varias de éstas y acomodarlas en lugares estratégicos, lo que implica mayor inversión de tiempo y dinero, sumando a éstos el estrés causado en el personal que controla monitorea éstas cámaras; todo ello puede mitigarse con solo una videocámara fisheye $4 \mathrm{k}$, la cual puede controlar la seguridad en $360^{\circ}$, permitiendo tener una navegación sencilla en alta calidad sobre todo su alcance.

\subsection{Valores}

Establecer los valores empresariales le permite a una organización orientar las decisiones, acciones y conductas de los trabajadores en función de éstos (D'Alessio, 2008).

A continuación, se mostrarán los valores actuales de la empresa, el análisis y las propuestas.

\subsubsection{Valores actuales de la empresa}

- Honestidad: Sentido de justicia que se tiene con relación a los hechos, a las personas y a sí mismo. En Ransa, se entiende como la expresión de la verdad, la equidad y la objetividad. 
- Respeto: Consideración del entorno y de las personas con las que interactuamos. Saber valorar los intereses y necesidades ajenas a las nuestras. En Ransa, se entiende como la consideración con que se debe tratar a las personas, sin importar su jerarquía o condición.

- Compromiso: Voluntad de sentirse parte de la organización, aportando a las metas y creyendo en los valores. En Ransa se entiende como la contribución para el beneficio de la empresa, buscando su constante crecimiento.

\subsubsection{Análisis de los valores actuales}

Los valores actuales de la empresa representan la conducta de esta misma y están directamente relacionados con el propósito de ésta, respondiendo claramente en lo que cree la empresa.

\subsubsection{Elementos de los valores propuestos para la empresa}

De acuerdo con el análisis del punto anterior los valores actuales de la empresa se mantendrán.

\subsubsection{Valores propuestos}

Ver el punto 3.3.1

\subsection{Alineamiento estratégico de la visión, misión y valores de la empresa}

Los valores actuales cumplen un rol importante para el planteamiento estratégico de la empresa. Cada cualidad o pauta de comportamiento del personal busca lograr el cumplimiento de objetivos a mediano y corto plazo. Es decir, se interrelacionan, ya que la honestidad, respeto y compromiso se necesitan para formar una empresa con los atributos mencionados en la visión y con las metas redactadas en la misión. Ver Tabla 06. 
Tabla 06

Alineamiento estratégico de la misión, visión y valores de Ransa

\begin{tabular}{|c|c|c|c|c|c|}
\hline \multirow[b]{2}{*}{ Valores } & \multicolumn{3}{|c|}{ Visión } & \multicolumn{2}{|c|}{ Misión } \\
\hline & $\begin{array}{l}\text { Organización de } \\
\text { clase mundial }\end{array}$ & $\begin{array}{c}\text { Primeros } \\
\text { Operadores de } \\
\text { Latinoamérica }\end{array}$ & $\begin{array}{c}\text { Ventas } \\
\text { superiores } \\
\text { a US\$ } 600 \\
\text { millones al } \\
2025 "\end{array}$ & $\begin{array}{c}\text { Mejorar el } \\
\text { nivel de } \\
\text { logística }\end{array}$ & $\begin{array}{c}\text { Incrementar } \\
\text { valor de los } \\
\text { clientes }\end{array}$ \\
\hline Honestidad & $\mathrm{x}$ & & & & $\mathrm{x}$ \\
\hline Respeto & $\mathrm{x}$ & & & & $\mathrm{x}$ \\
\hline Compromiso & $\mathrm{x}$ & $\mathrm{X}$ & $\mathrm{x}$ & $\mathrm{x}$ & $\mathrm{x}$ \\
\hline
\end{tabular}

Nota. Adaptado de El proceso estratégico: Un enfoque de gerencia (p. 69), por F. D’Alessio, 2008, México D.F.: Pearson Educación. 


\section{Capítulo IV. Análisis externo}

\subsection{Tendencia de las variables del entorno}

A continuación, se analizarán los factores del macroentorno de la empresa para determinar las tendencias y el contexto en el que opera. Además, evaluar el impacto de las variables en el desempeño de la organización.

\subsubsection{Análisis político- gubernamental}

El transporte es la columna vertebral de las operaciones logísticas y, existiendo proyectos de gran envergadura, es importante que la red vial cuente con troncales claves que permitan a las empresas reducir sus costos logísticos. Por tanto, es prioritario mejorar la carretera central, ampliándola para soportar la capacidad de camiones que circulan en ella, logrando elevar los niveles de eficiencia y ahorrando tiempo (“Operadores logísticos esperan mejora de la red vial," 27 de julio de 2016).

Cabe señalar, que la Asociación de Exportadores del Perú (ADEX) manifestó que son 7.000 vehículos diarios los que transitan por algunos de los tramos de los 377 kilómetros de la congestionada carretera central. Asimismo, estimó que por cada día que el tramo 2 de la Carretera Central se mantiene bloqueado, el país deja de exportar US\$6 millones. (“Los desafíos que enfrenta la Carretera Central," 26 de febrero de 2018)

Problemática que fue abordada en el año 2017 por el Ministerio de Transportes y Comunicaciones (MTC), año que anunció la creación del Plan Nacional de Infraestructura, que priorizará el impacto en la reducción de los costos logísticos y el incremento de la competitividad del país, resaltando que los sobrecostos logísticos del sector privado alcanzan los 3,800 millones de dólares anuales, lo cual resta competitividad ("Habrá mayor competitividad para el sector logístico," 02 de diciembre de 2017). 
Por ello, la modernización y desarrollo de los terminales portuarios, ampliación y modernización de aeropuertos, desarrollo del transporte fluvial, mejora de vías terrestres y un decidido impulso al transporte marino logrará reducir los costos y potenciar a las empresas de la industria ("Habrá mayor competitividad para el sector logístico,” 02 de diciembre de 2017).

Por otro lado, los países que han logrado desarrollarse los últimos años son aquellos que se han incorporado en el comercio internacional, ampliando el tamaño del mercado para sus empresas. De este modo, con la finalidad de consolidar mercados para los productos peruanos y de desarrollar una oferta exportable competitiva, tal como se observa en la Tabla 07, el Perú ha concretado distintos acuerdos internacionales, logrando promover la integración comercial (Ministerio de Economía y Finanzas [MEF], 2018).

Tabla 07.

\section{Acuerdos comerciales}

\section{Acuerdos}

1. Acuerdo de Promoción Comercial con Estados Unidos

2. Tratado de Libre Comercio con Canadá 2009

3. Acuerdo de Libre Comercio con Singapur 2009

4. Tratado de Libre Comercio con China 2010

5. Acuerdo de Libre Comercio entre el Perú y Corea del Sur

6. Acuerdo de Libre Comercio entre Perú y los Estados de la Asociación Europea de Libre Comercio (AELC)

7. Protocolo entre la República del Perú y el Reino de Tailandia

8. Acuerdo de Integración Comercial con México 2012

9. Acuerdo de Asociación Económica entre el Perú y Japón 2012

10. Tratado de Libre Comercio Perú - Panamá

11. Acuerdo Comercial entre Perú y Colombia, y La Unión Europea y sus Estados Miembros

12. Tratado de Libre Comercio entre la República del Perú y la República de Costa Rica 
Asimismo, los acuerdos comerciales traen consigo beneficios para la economía en su conjunto, ya que permiten reducir y eliminar las barreras arancelarias y no arancelarias al comercio, mejorar la competitividad de las empresas, facilitan el incremento del flujo de inversión extranjera, y, finalmente, fomentan la creación de empleos derivados de una mayor actividad exportadora (MEF, 2018).

Sobre la informalidad laboral en el Perú, ésta está acelerando su ritmo de crecimiento, logrando a junio del 2018 un crecimiento de 5,1\%, es decir, en el país se tiene 12,2 millones de personas que trabajan en dichas condiciones representando el $73 \%$ de la fuerza laboral ("La informalidad sigue dominando la creación de empleo en el Perú,” 16 de agosto del 2018).

Así, entre junio del 2017 y junio del 2018 se han destruido 21,100 empleos formales y en contraste se han creado 413.000 puestos de trabajo informales, lo que significa que la informalidad domina el mercado laboral ("La informalidad sigue dominando la creación de empleo en el Perú," 16 de agosto del 2018).

Ante esta problemática, la industria logística alcanza un 35\% de trabajadores informales dentro de sus procesos de almacenaje o distribución; es decir, que más de 1/3 de trabajadores de la industria logística no cuenta con un contrato de servicio, no gozan de beneficios de ley, trabaja en condiciones de seguridad inadecuadas, entre otras (“Sector logístico en el Perú,” 22 de octubre de 2019).

Sin embargo, la cifra aumenta cuando se habla del servicio de transporte, servicio que alcanza un $83 \%$ de informalidad; y, si a ello le agregamos la descontrolada inmigración, es posible que el porcentaje de informalidad sea aún mayor (“Sector logístico en el Perú," 22 de octubre de 2019). 
Por otro lado, uno de los más grandes temas de coyuntura es la corrupción que existe dentro de las entidades públicas del país, sobre todo al momento de ejecutar proyectos de gran envergadura, por ejemplo, el caso Lava Jato.

El caso Lava Jato habría provocado la paralización de obras en varios países de la región por un monto de 27 billones de dólares. En el caso del Perú, la paralización de obras podría alcanzar una pérdida aproximada de 1.5\% del PBI (Cruz \& Barón, 2018).

Además, Jorge Medina, el presidente de Proética, indicó que la corrupción le cuesta al Perú entre 3\% y 4\% del PBI; añadiendo que solo el caso Lava Jato le costaría al país un punto menos en el crecimiento del PBI, es decir que alrededor de 150 mil peruanos no podrían salir de la pobreza ("La corrupción no solo afecta el PBI," 09 de diciembre de 2017).

Entre las obras paralizadas por el caso Lava Jato se tiene los siguientes proyectos: Majes siguas II, Carretera costanera, Variante tramo III, obras afectadas en Cusco y Tacna (“Obras perjudicadas en el sur a consecuencia de la corrupción,” 30 de diciembre de 2018). Lo que representa un atraso de años en el crecimiento potencial de distintas industrias del país.

Por ello, Michel Canta, el viceministro de Economía, informó que el Plan Nacional de Infraestructura, presentado a finales de julio del 2019, contempla la promoción de 52 proyectos valorizados en S/100,000 MM para los siguientes cinco años; además, existe una brecha de S/360,000 MM para los próximos 20 años, brecha enfocada en infraestructura básica mas no de calidad ("MEF: Plan de infraestructura contempla 52 proyectos," 25 de julio de 2019). De este modo, se espera reactivar el crecimiento de la economía a mediano y largo plazo. 


\subsubsection{Análisis económico}

El Banco Central de Reserva (BCR) presentó las siguientes proyecciones para el 2018: crecimiento del PBI en 4.2\%, reducción de la exportación de bienes y servicios a 3.8\% y crecimiento de la importación de bienes y servicios de 4.1\%, inflación de 2\% para el presente año, crecimiento de las inversiones de $22.2 \%$, crecimiento de la entrada de capitales externos de largo plazo de 4\%, déficit fiscal de 3.5\% para el presente año ("Proyecciones económicas del BCR para 2017 - 2018,” 19 de septiembre de 2017).

Por su lado, el Instituto Nacional de Estadística e Informática (INEI) al final del III trimestre de 2017, presentó el número de empresas activas en el Directorio de Empresas y Establecimientos, el cual asciende a $2 ` 258,741$ unidades, mayor en $7.1 \%$ respecto al periodo similar del año 2016; asimismo, se crearon 78,754 empresas y se dieron de baja 47,506. El 2017 cerró con una tasa de crecimiento de $3.5 \%$ y una tasa de mortalidad empresarial de $2.1 \%$ (INEI, 2017). Ver Tabla 08.

Tabla 08

Cantidad de empresas entrantes y salientes (2015 - 2017)

\begin{tabular}{|c|c|c|c|c|c|c|c|c|c|c|c|c|}
\hline \multirow{2}{*}{ Concepto } & \multicolumn{4}{|c|}{2015} & \multicolumn{4}{|c|}{2016} & \multicolumn{3}{|c|}{2017} & \multirow{2}{*}{\begin{tabular}{|c} 
Var \\
$\%$ \\
Trim \\
2017 \\
\end{tabular}} \\
\hline & $\begin{array}{c}\text { I } \\
\text { Trim }\end{array}$ & $\begin{array}{l}\text { II } \\
\text { Trim }\end{array}$ & $\begin{array}{c}\text { III } \\
\text { Trim }\end{array}$ & $\begin{array}{l}\text { IV } \\
\text { Trim }\end{array}$ & $\begin{array}{c}\text { I } \\
\text { Trim }\end{array}$ & $\begin{array}{c}\text { II } \\
\text { Trim }\end{array}$ & $\begin{array}{l}\text { III } \\
\text { Trim }\end{array}$ & $\begin{array}{c}\text { IV } \\
\text { Trim }\end{array}$ & $\begin{array}{c}\text { I } \\
\text { Trim }\end{array}$ & $\begin{array}{c}\text { II } \\
\text { Trim }\end{array}$ & $\begin{array}{l}\text { III } \\
\text { Trim }\end{array}$ & \\
\hline $\begin{array}{l}\text { Stock al inicio del } \\
\text { periodo }\end{array}$ & 1883531 & 1942600 & 1972725 & 2011755 & 2042992 & 2084725 & 2085499 & 2108295 & 2124280 & 2177500 & 2216081 & 6.3 \\
\hline Altas & 55081 & 68116 & 65473 & 62581 & 63658 & 63940 & 70390 & 68746 & 68746 & 67976 & 78754 & 11.9 \\
\hline Bajas & -32722 & -39845 & -44571 & -45393 & -47097 & -47391 & -46740 & -49588 & -26590 & -39322 & -47506 & 1.6 \\
\hline $\begin{array}{l}\text { Otros ingresos y } \\
\text { salidas } \\
\text { Stock al final del }\end{array}$ & 36710 & 1854 & 18128 & 14049 & 25172 & -15775 & -854 & 724 & 11064 & 9927 & 11412 & \\
\hline periodo & 1942600 & 1972725 & 2011755 & 2042992 & 2084725 & 2085499 & 2108295 & 2124280 & 2177500 & 2216081 & 2258741 & 7.1 \\
\hline Tasa de altas (\%) & 2.8 & 3.5 & 3.3 & 3.1 & 3.1 & 3.1 & 3.3 & 3.1 & 3.2 & 3.1 & 3.5 & \\
\hline Tasa de bajas (\%) & 1.7 & 2 & 2.2 & 2.2 & 2.3 & 2.3 & 2.2 & 2.3 & 1.2 & 1.8 & 2.1 & \\
\hline
\end{tabular}

Nota. Tomado de "Demografía empresarial en el Perú, III trimestre 2017”, por INEI, 2017. Recuperado de https://bit.ly/2SIZzOE 
Cabe mencionar que el consumo privado o consumo de los hogares, generalmente representa el 67.38\% del PBI (Pontificia Universidad Católica del Perú [PUCP], 2012).

\subsubsection{Análisis legal}

Las "Reglas de la Haya-Visby" ayudan a desarrollar transparencia del proceso logístico, logrando claridad en ambas partes de los conocimientos de embarque (reglas de la Haya-Visby, 1984). Asimismo, la "reglas de Hamburgo" ayudan a definir quiénes son los participantes involucrados en el proceso logístico, sus derechos y responsabilidades, dónde inicia y dónde termina (Convenio de las Naciones Unidas [CNU], 1978).

Además, el entorno legal busca desarrollar y modernizar la industria logística a través de la innovación e implementación de nuevas tecnologías para aumentar la eficiencia y el valor agregado de los servicios, lo que lograría reducir costos energéticos, residuos y emisiones de carbono (Ministerio de Transporte y Comunicaciones [MTC], 2014).

De esta manera, la existencia de distintos marcos legales, nacionales e internacionales logran crear como mínimo un servicio estandarizado por parte de los operadores logísticos, asegurando una calidad mínima aceptable del servicio; además; genera confianza entre los clientes y proveedores porque identifica a los participantes, define los procesos y el embarque a transportar.

\subsubsection{Análisis cultural}

De acuerdo con el Censo del año 2017, la población nacional incrementó en 10.7\% respecto del año 2017, último censo realizado, representando un crecimiento promedio de $1 \%$ anual durante el periodo 2007-2017, confirmando la tendencia decrecimiento en la tasa de crecimiento poblacional de los últimos 50 años. (INEI, 2018). 
El nivel socioeconómico en Lima en el 2017 se incrementó en los sectores C, B Y D en $41 \%, 24.4 \%$ y $23.3 \%$ respectivamente. (INEI, 2017).

En tanto la Población Económicamente Activa (PEA) en Lima supera los 5 millones, donde la PEA ocupada alcanza el $93.2 \%$ y la desocupada el 6.8\% ("INEI: más de 9 millones de personas habitan en Lima," 18 de enero de 2017).

La tasa de desempleo en Lima a febrero del 2017 se puntuó en 7.7\%, la tasa más alta registrada desde el 2012, la cual fluctuó entre $8.7 \%$ y $8.1 \%$. Los más afectados por el desempleo son los jóvenes y la población femenina, llegando a sumar aproximadamente 403 mil personas (INEI, 2017).

Los jóvenes y la población joven que integran la Población Económicamente Activa (PEA) suman 5 millones, de ellos aproximadamente 4 millones se encuentran en el área urbana y 1 millón en el área rural. Del total de jóvenes de la PEA, el 91.6\% tiene empleo y el 8.4\% busca empleo activamente (INEI, 2017).

Por otro lado, se tienen tendencias globales de consumo que se actualizan cada año y para el 2019, se tiene que los clientes buscan una experiencia en los servicios libres de problemas y demandan inmediatez, lo que les permita dedicar más tiempo a sus actividades sociales, académicos o profesionales. Además, el internet está creciendo a gran velocidad y como consecuencia, las expectativas de los clientes respecto a las interacciones en línea han crecido hasta esperar que sean lo más similares a la vida cotidiana. De esta manera, a medida que las capacidades tecnológicas crecen, el rango de cosas que se puede hacer digitalmente aumenta en la misma medida. 
Asimismo, los consumidores buscan tener un impacto en el mundo a través de los esfuerzos por lograr una sociedad libre de plásticos. De esta manera, los clientes incluso usarán sus fondos para protestar contra el uso irresponsable, creando un círculo virtuoso donde la industria, desde alimentos y bebidas hasta fabricantes de productos de belleza, logren beneficios para mejorar la sostenibilidad (EuroMonitor, 2019).

\subsubsection{Análisis tecnológico}

En los últimos años el avance tecnológico ha sido exponencial, llegando a impactar en muchas industrias a distintos niveles, una de ellas es la industria logística. Es así como, al hablar de las tendencias actuales en el mundo, el concepto de tecnología avanzada alcanza al concepto de tecnología de vanguardia, concepto que abarca lo siguiente: (a) robótica y almacenes automatizados, los cuales optimizan los flujos en los almacenes, mejoran la productividad, brindan exactitud en la gestión del stock e inventarios de forma permanente, disminuyen los costos de explotación, y registran y etiquetan la mercadería que permiten identificarlas y localizarlas las 24/7; (b) Internet de las cosas (IoT), el cual controla la mercadería en tiempo real y brinda el estado físico de la misma, y propone rutas alternas que optimicen el transporte; (c) Big Data, el cual establece un mapa objetivo y detallado que permite alcanzar procesos más eficientes, mejora el control de los activos fijos, segmenta la demanda según intereses y necesidades, detecta mejores rutas, controla la situación de máquinas y el estado de la mercadería, y propone precios de acuerdo al registro anticipado de los costos; (c) impresión 3D, el cual mejora la manufactura de productos, reduce los costos de producción, y ofrece la personalización de productos; (d) ERP, el cual optimiza la operación de los almacenes, reduce los costos directos relacionados al inventario y a lo tecnológico, facilita la adaptación de las necesidades actuales y futuras, y controla el tiempo de los pedidos mejorando la puntualidad. 
En ese sentido, de acuerdo con la revista Logistiguía, existe tecnologías no tan nuevas para algunos países, pero que aun así forman parte de la tendencia tecnológica en el mundo, tales como: (a) los sistemas de identificación por radiofrecuencia (RFID), (b) el sistema de información geográfica (SIG), y (c) vehículos híbridos y eléctricos (MD Group, 2019).

Por otro lado, en la misma revista, se menciona una herramienta que acaba de sumarse a la tendencia tecnológica, herramienta que junta la internet de las cosas (IoT) con la inteligencia artificial (IA), con el fin de generar mecanismos de retroalimentación automatizados en tiempo real, con sentido y respuesta; permitiendo, por ejemplo, evaluar segundo a segundo la seguridad y calidad de los alimentos y productos farmacéuticos dentro de una cadena ininterrumpida de ambiente refrigerado, pronosticando además vulnerabilidades de alto riesgo como robos y accidentes, e incluyendo finalmente la ubicación, el clima y eventualidades de la zona que interrumpan la fluidez del transporte (MD Group, 2019).

Sin embargo, en una entrevista a Jorge Pérez Vásquez, el gerente comercial de Dinet, la cual fue presentada en la revista Logistiguía, menciona que los atributos que en el Perú marcan la diferencia dentro de la industria son la visibilidad y la trazabilidad de la carga de un cliente en tiempo real a través de toda la cadena logística, ya sea por aplicaciones o páginas web; razón por la que Dinet solo desarrolla, integra e implementa plataformas con estos atributos a través de todo su servicio integrado (MD Group, 2019).

Bajo el mismo enfoque, Fernando Duthurburu, gerente de negocios industriales de Ransa, afirma que la realidad del mercado extranjero y nacional son distintas, ya que un mercado completamente automatizado necesita mayor madurez que la nuestra, cosa que no impide que se vayan robotizando gradualmente los almacenes; sin embargo, se debe identificar y alcanzar lo 
que realmente piden los clientes, cierto grado de logística ("Estamos haciendo repartos," 15 de octubre del 2018).

Además, en una entrevista a Mary Wong, gerente general adjunta de GS1 Perú, la cual fue presentada también en la revista Logistiguía, menciona que efectivamente existe en el mundo una Revolución 4.0 dentro de todos los procesos logísticos (gestión de almacenes, transporte, distribución e inventario); por ejemplo: los drones como herramienta que facilita el traslado de la mercadería. Sin embargo, en el Perú, las empresas no explotan el uso de esta herramienta y solo la limitan al control de inventarios en los centros de distribución, agilizando así la captura de información (MD Group, 2019).

Por último, de acuerdo con Johana Chuquino, jefe de gestión de la demanda en Neptunia, actualmente en el mercado peruano existe una variedad de TIC's (Tecnologías de la Información y Comunicación) que soportan la gestión y organización de la cadena de suministros (Chuquino, 2014). Las principales TIC's son las siguientes:

- Sistema de Planificación de Recursos Empresariales (ERP): Software que permite acceder a una amplia lista de aplicaciones como RRHH, compras, producción, marketing, ventas, finanzas, etc., demandando un alto conocimiento especializado en costos y compras para la apropiada gestión de la cadena de suministros.

- Software de Planificación de Demanda (DIP): Software que planifica la necesidad de materiales para satisfacer la demanda a través de sus principales funciones que son la estimación de ventas futuras, creación de necesidades de aprovisionamiento según ventas, plazo de entrega y stock, y la proyección del stock óptimo de cada producto, sin embargo hay DIP que están integrados a los ERP's. 
- Sistema de Gestión de Transporte (TMS): Sistema que reduce los costos al optimizar la ruta del transporte, facilitando información exacta y oportuna sobre la flota y los pedidos, además algunos TMS tienen entre sus opciones la Gestión de Distribución (DMS), permitiendo ubicar con mayor facilidad la mercadería y elegir el vehículo apropiado.

- Sistema de Gestión de Almacenes (WMS): Sistema que administra el movimiento interno de los materiales a través de técnicas como FIFO, FEFO, LIFO, etc., además el software utiliza distintas herramientas como lector de código de barras, radiofrecuencia y SGA, con el objetivo de optimizar el espacio de los almacenes con la apropiada administración de ubicaciones y optimizar el flujo o movimiento de los materiales.

- El entorno Web: Herramienta fundamental que da soporte a la gestión logística a través de su integración con los ERP's y con los Portales Colaborativos B2B de los clientes.

\subsubsection{Análisis ecológico}

Los operadores logísticos son empresas que dejan una gran huella de carbono al poner en funcionamientos sus grandes almacenes, sus refrigerados, sus camiones, entre otras. Desde el punto legal y empresarial no tiene un impacto negativo siempre que cumpla con los pagos de luz, agua e impuestos; sin embargo, utilizar estrategias que aplique responsabilidad ambiental, ante los ojos de la población (individuos y empresas) están teniendo mayor éxito, ya que aplicar responsabilidad ambiental empresarial es considerado un atributo positivo y valorado (Del Moral, 2013).

Por otro lado, en los últimos años la industria logística ha crecido gracias al fomento de iniciativas verdes, reconociendo que solo el servicio de transporte emite el $10 \%$ de CO2 a nivel 
mundial. Las iniciativas más desarrolladas son: (a) repartos y recogidas en bicicleta, vehículos ecológicos o autónomos; (b) taquillas para centralizar las entregas; (c) MiniHubs urbanos; y (d) Backhaul (MD Group, 2019).

\subsection{Impacto en clientes/ proveedores de cada una de las variables del entorno}

En el presente apartado se analizará el efecto que tiene cada una de las variables en los proveedores y clientes de Ransa, revelando escenarios de oportunidades o amenazas.

\section{a. Entorno Político - Gubernamental}

Empresas de diversos sectores, siendo algunas de éstas parte de la cartera de clientes de Ransa, esperan de sus proveedores el cumplimiento de los acuerdos de servicio en cuanto a tiempo y sin incidencias. Por ello, los operadores logísticos, incluido Ransa, dependen en gran medida del alcance y la calidad de la infraestructura interna y externa, recayendo la responsabilidad de la primera en la empresa y la segunda en el Estado Peruano. El Estado sabe que existe una brecha de infraestructura entre los países mejores calificados y el Perú, es por ello por lo que se deciden crear un Plan Nacional de Infraestructura, el cual será oficializado a fines de junio del presente año, siendo éste una oportunidad relativa muy prometedora para el crecimiento de la industria logística, dado que buscará mejorar las condiciones viales y brindar a las empresas logísticas las condiciones adecuadas para operar.

Sin embargo; la corrupción que existe dentro de las entidades públicas y el historial de incumplimiento de obras en los últimos años aumentan la incertidumbre del completo desarrollo del Plan Nacional de Infraestructura, provocando que los operadores logísticos no incluyan esta iniciativa al proyectar sus estrategias en los próximos años. 
Por otro lado, las empresas logísticas que promueven la informalidad son consideradas una amenaza para la competencia formal y para los mismos clientes, ya que sus servicios de bajo costo no cuentan con la seguridad mínima requerida ni con las condiciones estándares de almacenamiento o transporte; sin embargo, las pequeñas y medianas empresas siguen utilizando estos servicios por sus bajos precios.

\section{b. Entorno Legal}

Los entes reguladores internacionales y nacionales permiten a los operadores logísticos entender dónde inicia y termina su responsabilidad con la mercancía, así como identificar minuciosamente sus derechos. Además, delimita el nivel mínimo de calidad que deben ofrecer, y en algunos casos los reguladores determinan, de manera opcional, el orden de cómo se debe ejecutar las actividades en el proceso logístico.

Como se mencionó anteriormente, el MTC busca desarrollar y modernizar la industria logística impulsando la innovación y el desarrollo de nuevas tecnologías con la finalidad de reducir los costos y aumentar el valor agregado de los servicios, lo que permitirá a los operadores logísticos ser más competitivos al reducir sus costos y poder reducir sus precios, o esperar aumentar su utilidad al tener mayor margen e invertir en la optimización de sus procesos, ambas estrategias son válidas, la elección de una ellas depende de los objetivos que la empresa decida alcanzar primero, a corto o largo plazo.

Para terminar, la existencia de diferentes marcos legales para el funcionamiento de un operador logísticos, sumando a ello las responsabilidades legales, se considera un escenario oportuno para Ransa, debido que éstos aumentan las barreras de ingreso a la industria. 


\section{c. Entorno Económico}

De acuerdo con la Tabla 08, se aprecia una marcada tendencia creciente en las empresas registradas en el periodo 2015 - 2017; información que se complementa con la Figura 06, la cual muestra un claro crecimiento de la industria logística; tendencias que convergen con el crecimiento de otras industrias, debido a la mayor producción y comercialización de bienes y servicios; beneficiando, por ejemplo, a empresas dentro del rubro retail y consumo masivo (Listo y Alicorp), quienes responderán a las mencionadas curvas con una mayor producción, que repercutirá en su proceso logístico como almacenaje, transporte y distribución.

Sin embargo, la economía no alcanzó su potencial crecimiento debido a temas de corrupción en los últimos años, siendo el más sonado el caso Lavajato, problemática que afectó y afecta a más de una industria debido a la mala infraestructura que existe en el Perú, siendo ésta una variable que afecta altamente los costos del proceso logístico y, por ende, el costo final de los productos.

\section{d. Entorno Social, Cultural y Demográfico}

El incremento de la población (crecimiento demográfico) es una oportunidad de negocio para Ransa; debido a que el incremento de la población genera un incremento en el número de clientes potenciales o se incrementa la demanda de productos en distintas industrias que por defecto genera un aumento en la demanda de servicios logísticos.

Asimismo, mayor población con empleo asegura un aumento en el consumo, generando un aumento en la producción de distintas marcas; en consecuencia, ello aumenta la contratación de servicios logísticos ofrecidos por Ransa, como almacenaje, transporte y distribución. 
Las tendencias globales de consumo apuntan a un tipo de comportamiento donde los clientes esperan inmediatez en sus transacciones y generar un impacto positivo en la sociedad. De esta manera, si las empresas conocen el proceso de decisión de compra de sus clientes y las variables que modulan su comportamiento, estarán preparados y atenderán con inteligencia las necesidades de los mismos, cubriendo sus expectativas, diferenciándose en el mercado y generando ventajas competitivas, lo cual representa una oportunidad.

\section{e. Entorno Tecnológico}

El impacto de la tendencia tecnológica en los proveedores puede favorecer el nivel de especialización de sus servicios, mejorando la calidad éstos y reduciendo sus costos, incrementando así la diferenciación entre estos operadores (1PL y 2PL); diferenciación que puede capturar nuevos clientes o retener los actuales.

Por otro lado, la tendencia tecnológica en los clientes impactaría directamente en la toma de decisiones, puesto que éste tendría conocimiento en tiempo real sobre el estado de su mercadería las 24/7 y la cantidad exacta de la que dispone; información útil al momento de cerrar ventas, designar la distribución de productos, y establecer cantidades a producir; circunstancias que protegen los intereses de la empresa, así como la imagen de ésta frente a sus clientes.

\section{f. Entorno Ecológico}

Existe una tendencia creciente a nivel mundial de los consumidores que consideran de mucha importancia la responsabilidad ambiental que aplica la empresa, sobre su infraestructura, operaciones o productos, convirtiéndose en un factor de decisión a la hora de comprar un producto o contratar un servicio. 
Ante ello, muchas empresas, proveedores y clientes, valoran las actividades responsables con el ambiente que éstas aplican, ya que muestran un compromiso más profundo con la parte ética empresarial, lo que genera mayor confianza entre ellas.

\subsection{Efecto en la empresa de cada una de las variables del entorno}

En el presente apartado se analizará el efecto que tiene cada una de las variables PESTEL en Ransa, revelando escenarios de oportunidades o amenazas.

\section{a. Entorno Político - Gubernamental}

En primer lugar, se debe enfatizar que el Plan Nacional de Infraestructura ha sido elaborado con el objetivo de beneficiar las cadenas logísticas del país, con una vista enfocada en las exportaciones y el comercio interno. Este plan de trabajo busca crear infraestructura, orientada a potenciar el crecimiento del país, beneficiando rotundamente a Ransa como operador logístico de llegar a realizarse, dado que contará con mejores condiciones para su operación a mediano y largo plazo (modernización de terminales portuarios, aeropuertos, desarrollo del transporte fluvial, mejora de vías terrestres y un decidido impulso al transporte marino) logrando reducir costos e incrementando su competitividad en la industria; asimismo, con mejores condiciones de infraestructura, Ransa podría mejorar sus niveles de servicio agilizando sus operaciones y estableciendo nuevos tiempos en los servicios de entrega y distribución, convirtiéndose en una empresa aún más competitiva; además, el desarrollo de infraestructura reducirá los escenarios que generen contratiempos durante la ejecución de los servicios contratados.

Sin embargo, cabe mencionar que Ransa al pertenecer a la industria logística, se ve directamente afectada por temas de corrupción como el caso Lavajato, problemática que retrasó o canceló proyectos de infraestructuras a nivel nacional en los últimos años, perjudicando sus 
representativos costos de operación en los años venideros; sin embargo, se espera que, con la nueva propuesta del Plan Nacional de Infraestructura, los costos de operación de la empresa disminuyan a mediano y largo plazo.

Por otro lado, Ransa también hace uso de flota tercera (proveedores de movilidad) para el transporte y la distribución de la mercadería de sus distintos clientes; por ello, de realizarse el Plan Nacional de Infraestructura los proveedores de transporte tendrán mayor control en la seguridad de los productos trasladados, evitando contratiempos y cumpliendo con lo acordado por Ransa con sus clientes, cuidando la imagen de la empresa.

Por último, es importante mencionar que la informalidad de trabajadores dentro de la industria logística afecta directamente en los costos de estas empresas que la practican, lo que perjudica la competencia justa; por lo que es importante brindar un servicio excelente, donde las condiciones brindadas sean las apropiadas.

\section{b. Entorno Legal}

Los reguladores permiten a la empresa operadora logística saber dónde inicia y termina su responsabilidad con la mercancía e identificar minuciosamente sus derechos; además, delimita el nivel mínimo de calidad del servicio que ofrece, y en algunos casos los reguladores determinan, de manera opcional, el orden de cómo se debe ejecutar las actividades en el proceso logístico.

La existencia de diferentes marcos legales para el funcionamiento de un operador logísticos, sumando a ello las responsabilidades legales, se considera un escenario oportuno para Ransa, debido que éstos aumentan las barreras de ingreso a la industria. 


\section{c. Entorno Económico}

Considerando que el consumo privado o consumo de los hogares generalmente representa el 67.38\% del PBI (PUCP, 2012), información que va de la mano de la tendencia creciente del PBI; ya que una leve variación positiva generaría un incremento en el consumo de distintos productos como los de consumo masivo, lo que generaría una mayor producción en ciertas marcas, producto de una mayor demanda.

Por otro lado, al hablar puntualmente de la tendencia positiva de la economía nacional y de Ransa como el único operador logístico de Alicorp, quien es el líder de productos masivos en el mercado peruano, se deduce que al incrementarse el consumo de productos, éste conlleva a empresas como Alicorp a aumentar la producción de sus bienes, y, por ende, ello aumenta la producción de sus proveedores de materia prima y servicios; dicho escenario beneficia a Ransa, quien presta servicios a Alicorp, lo que en principio debe incrementar el volumen que éste despacha y distribuye a nivel local e interregional. Bajo esta lógica, son muchas las empresas que se benefician, incrementando su producción gracias al aumento del consumo, es así como más de una industria son afectadas positivamente por el entorno económico.

\section{d. Entorno Social, Cultural y Demográfico}

La población demográfica y la tasa de empleabilidad muestran una tendencia positiva; por ello, se genera un círculo virtuoso temporal donde al haber más personas necesariamente aumenta la demanda de diversos productos, por lo que las empresas necesitan producir más, para lo cual necesitan contratar en ciertas ocasiones nuevo personal. Entonces, estos escenarios producen un aumento en la venta de los clientes y proveedores de los operadores logísticos relacionados con las marcas afectadas por el aumento del consumo. 
Por otro lado, Ransa es una empresa que busca brindar soluciones tecnológicas a sus clientes a través de sistemas gestión de sus servicios, así como ser responsables con el medio ambiente a través de actividades que se realizan anualmente y que se detallan en sus reportes de sostenibilidad. De esta manera, las tendencias globales de consumo van acorde al enfoque de la empresa, lo que representa una clara oportunidad para la organización.

\section{g. Entorno Tecnológico}

Ransa es consciente de la tendencia tecnológica que revoluciona la industria logística en el mundo; sin embargo, como se mencionó anteriormente, tanto Ransa como otros operadores logísticos 3PL están realizando mejoras tecnológicas de forma gradual dentro de sus procesos logísticos y la gestión de éste; por lo que la empresa debería mostrar el siguiente comportamiento: reducción paulatina de sus costos de producción, optimización de recursos, y mayor eficiencia en la gestión de procesos.

Cabe mencionar que la implementación de tecnología más avanzada, que mejora tanto el proceso logístico como la gestión de éste, incrementa la calidad percibida por el cliente, aumentando los servicios contratados por los clientes actuales o por el ingreso de nuevos clientes, permitiendo como mínimo retener los servicios contratados por los existentes.

\section{h. Entorno Ambiental}

Ransa se ve en la obligación de implementar estrategias verdes que se alineen con las nuevas demandas del mercado (proveedores, clientes y consumidores), generando una salida de dinero adicional que, aunque proyecten una mejor imagen de la marca frente a los grupos de intereses externos, afecta directamente en el precio final de sus servicios, precios que se encuentran por encima del mercado, pudiendo disminuir la captación de nuevos clientes o reducir los servicios contratados por los clientes actuales. 
Por ello, para contrarrestar los altos costos que generan estas estrategias verdes y sus consecuencias, Ransa presenta anualmente un reporte de sostenibilidad donde detalla todas sus actividades con principios sostenibles, a la cuales pueden acceder todos los grupos de interés; buscando de esta manera alcanzar una mayor aceptación del mercado y así incrementar sus ventas.

En conclusión, en la Tabla 09, se muestra el análisis de las tendencias actuales de cada una de las variables, señalando el impacto que éstas tienen en los clientes, proveedores y la empresa.

Es importante mencionar que la tendencia creciente de empresas registradas y el crecimiento poblacional no fueron incluidas dentro de las fortalezas y oportunidades, puesto que este segundo se relaciona directamente con el primero; es decir, que al incrementarse la población, la demanda de distintos productos aumenta, en consecuencia, a distintos niveles, lo que resulta en la aparición de nuevos negocios que buscan satisfacer ese incremento de la demanda, trayendo como resultado una mayor producción de bienes y servicios, que finalmente se relacionan y se incluyen dentro del crecimiento económico del Perú. 
Tabla 09

Impacto del entorno externo en los clientes, los proveedores y la empresa

\begin{tabular}{|c|c|c|c|c|}
\hline \multirow{2}{*}{ Tipo } & \multirow{2}{*}{ Tendencia } & \multicolumn{2}{|c|}{ Impacto } & \multirow{2}{*}{ Impacto en la empresa } \\
\hline & & Cliente & Proveedor & \\
\hline \multirow{4}{*}{$\begin{array}{l}\text { Análisis político } \\
\text { gubernamental }\end{array}$} & $\begin{array}{l}\text { Falta de infraestructura nacional } \\
\text { vial }\end{array}$ & $\begin{array}{l}\text { Riesgo de incumplimiento de } \\
\text { los servicios en cuanto a } \\
\text { tiempo e incidencias por parte } \\
\text { del proveedor }\end{array}$ & $\begin{array}{l}\text { Riesgo de incumplir con el } \\
\text { servicio en cuanto a tiempo e } \\
\text { incidencias }\end{array}$ & $\begin{array}{l}\text { Riesgo de incumplir con el } \\
\text { servicio en cuanto a tiempo e } \\
\text { incidencias }\end{array}$ \\
\hline & Plan Nacional de Infraestructura & $\begin{array}{l}\text { Mercadería recibida a tiempo } \\
\text { con menor incidencias }\end{array}$ & $\begin{array}{l}\text { Reducción de costos en el } \\
\text { servicio de transporte y } \\
\text { distribución, y mejora de la } \\
\text { imagen empresarial }\end{array}$ & $\begin{array}{l}\text { Cumplimiento de acuerdos en } \\
\text { cuanto a tiempo con menor } \\
\text { incidencias; reducción de } \\
\text { costos en el servicio de } \\
\text { transporte y distribución; y } \\
\text { mejora de la imagen } \\
\text { corporativa }\end{array}$ \\
\hline & $\begin{array}{l}\text { Corrupción en las licitaciones de } \\
\text { proyectos de infraestructura }\end{array}$ & $\begin{array}{l}\text { Mercadería recibida fuera de } \\
\text { tiempo con incidencias }\end{array}$ & $\begin{array}{l}\text { Entregas fuera de tiempo con } \\
\text { incidencias, y empobrecimiento } \\
\text { de la imagen empresarial }\end{array}$ & $\begin{array}{l}\text { Entregas fuera de tiempo con } \\
\text { incidencias, y empobrecimiento } \\
\text { de la imagen corporativa }\end{array}$ \\
\hline & $\begin{array}{l}\text { La informalidad laboral en el } \\
\text { Perú }\end{array}$ & $\begin{array}{l}\text { Mayor rango de precios en } \\
\text { operadores logísticos 1PL y } \\
\text { 2PL }\end{array}$ & $\begin{array}{l}\text { Implementación de estrategias } \\
\text { de diferenciación }\end{array}$ & $\begin{array}{l}\text { Implementación de estrategias } \\
\text { de diferenciación }\end{array}$ \\
\hline \multirow{2}{*}{$\begin{array}{l}\text { Análisis } \\
\text { económico }\end{array}$} & $\begin{array}{l}\text { Crecimiento económico en el } \\
\text { Perú y América Latina }\end{array}$ & $\begin{array}{l}\text { Mayor comercialización y } \\
\text { producción de sus productos }\end{array}$ & $\begin{array}{l}\text { Mayor comercialización y } \\
\text { producción de servicios de } \\
\text { transporte y distribución }\end{array}$ & $\begin{array}{l}\text { Mayor comercialización y } \\
\text { producción de servicios de } \\
\text { transporte, almacenaje, } \\
\text { distribución y otros }\end{array}$ \\
\hline & $\begin{array}{l}\text { Tedencia creciente de empresas } \\
\text { registradas }\end{array}$ & $\begin{array}{l}\text { Mayor comercialización y } \\
\text { producción de sus productos }\end{array}$ & $\begin{array}{l}\text { Mayor comercialización y } \\
\text { producción de servicios de } \\
\text { transporte y distribución }\end{array}$ & $\begin{array}{l}\text { Mayor comercialización y } \\
\text { producción de servicios de } \\
\text { transporte, almacenaje, } \\
\text { distribución y otros }\end{array}$ \\
\hline \multirow[b]{2}{*}{ Análisis legal } & $\begin{array}{l}\text { Reglas de la Haya-Visby y } \\
\text { Hamburgo }\end{array}$ & $\begin{array}{l}\text { Seguridad al tercerizar sus } \\
\text { operaciones logísticas }\end{array}$ & Oportunidad de diferenciación & Oportunidad de diferenciación \\
\hline & Tratados de Libre Comercio & $\begin{array}{l}\text { Acceso a operadores logísticos } \\
\text { de alta calidad }\end{array}$ & $\begin{array}{l}\text { Reducción de costos e } \\
\text { incremento de calidad en sus } \\
\text { operaciones }\end{array}$ & $\begin{array}{l}\text { Reducción de costos e } \\
\text { incremento de calidad en sus } \\
\text { operaciones }\end{array}$ \\
\hline \multirow{3}{*}{ Análisis cultural } & Crecimiento poblacional & $\begin{array}{l}\text { Mayor comercialización y } \\
\text { producción de sus productos }\end{array}$ & $\begin{array}{l}\text { Mayor comercialización y } \\
\text { producción de servicios de } \\
\text { transporte y distribución }\end{array}$ & $\begin{array}{l}\text { Mayor comercialización y } \\
\text { producción de servicios de } \\
\text { transporte, almacenaje, } \\
\text { distribución y otros }\end{array}$ \\
\hline & $\begin{array}{l}\text { Inestabilidad social y política } \\
\text { del país }\end{array}$ & $\begin{array}{l}\text { Menor comercialización de sus } \\
\text { productos }\end{array}$ & $\begin{array}{l}\text { Menor comercialización de } \\
\text { servicios de transporte y } \\
\text { distribución }\end{array}$ & $\begin{array}{l}\text { Menor comercialización de } \\
\text { servicios de transporte, } \\
\text { almacenaje, distribución y } \\
\text { otros }\end{array}$ \\
\hline & Tendencia globales de consumo & $\begin{array}{l}\text { Oportunidad de línea de } \\
\text { negocio }\end{array}$ & $\begin{array}{l}\text { Oportunidad de línea de } \\
\text { negocio }\end{array}$ & $\begin{array}{l}\text { Oportunidad de línea de } \\
\text { negocio }\end{array}$ \\
\hline $\begin{array}{l}\text { Análisis } \\
\text { tecnológico }\end{array}$ & $\begin{array}{l}\text { Tecnología, soporte de la } \\
\text { actividad logística }\end{array}$ & $\begin{array}{l}\text { Acceso a operadores logísticos } \\
\text { de alta calidad que permiten } \\
\text { tomar decisiones apropiadas }\end{array}$ & $\begin{array}{l}\text { Reducción de costos e } \\
\text { incremento de calidad en sus } \\
\text { operaciones, y aumento en la } \\
\text { contratación de sus servicios }\end{array}$ & $\begin{array}{l}\text { Reducción de costos e } \\
\text { incremento de calidad en sus } \\
\text { operaciones, y aumento en la } \\
\text { contratación de sus servicios }\end{array}$ \\
\hline $\begin{array}{l}\text { Análisis } \\
\text { ecológico }\end{array}$ & $\begin{array}{l}\text { Aumento de exigencias } \\
\text { medioambientales }\end{array}$ & $\begin{array}{l}\text { Mayor salidad de dinero con un } \\
\text { precio final incrementado, y } \\
\text { posible aumento de clientes por } \\
\text { una mayor aceptación de la } \\
\text { marca }\end{array}$ & $\begin{array}{l}\text { Mayor salidad de dinero con un } \\
\text { precio final incrementado, y } \\
\text { posible aumento de clientes por } \\
\text { una mayor aceptación de la } \\
\text { marca }\end{array}$ & $\begin{array}{l}\text { Mayor salidad de dinero con un } \\
\text { precio final incrementado, y } \\
\text { posible aumento de clientes por } \\
\text { una mayor aceptación de la } \\
\text { marca }\end{array}$ \\
\hline
\end{tabular}

Nota. Adaptado de El proceso estratégico: Un enfoque de gerencia (p. 120), por F. D’Alessio, 2008, México D.F.: Pearson Educación. 


\subsection{Oportunidades y amenazas.}

Los principales problemas de la logística nacional están en: (a) la eficiencia logística, (b) la calidad y confiabilidad de la infraestructura, basadas en las dificultades con el sector terrestres; y, (c) la eficiencia del sector aduanero, debido a los procesos engorrosos y complicados (Mincetur, 2016). De este modo, considerando lo siguiente: la misión y visión de la empresa, el impacto que tiene el entorno externo en los clientes, proveedores y la empresa, y las problemáticas identificadas por el Mincetur se plantea las siguientes oportunidades que Ransa puede explotar en los años por venir y amenazas que la misma debe evitar o superar. Ver Tabla 10.

Tabla 10

Oportunidades y amenazas

\begin{tabular}{|ll|}
\hline $\mathbf{N}^{\circ}$ & \multicolumn{1}{c|}{ Oportunidades } \\
\hline O1 & Plan Nacional de infraestructura \\
O2 & Tratados de Libre Comercio \\
O3 & Reglas de la Haya - Visby y Hamburgo \\
O4 & Crecimiento económico en el Perú y América Latina \\
O5 & Tecnología, soporte de la actividad logística \\
O6 & Tendencias globales de consumo \\
\hline $\mathbf{N}^{\circ}$ & $\quad$ Amenazas \\
A1 & Falta de infraestructura nacional vial \\
A2 & La informalidad laboral en el Perú \\
A3 & Aumento de las exigencias medioambientales \\
A4 & Inestabilidad social y política del país \\
A5 & Corrupción en las licitaciones de proyectos de infraestructura \\
\hline
\end{tabular}

Nota. Las oportunidades y amenazas fueron aceptadas por los expertos que evaluaron las mismas en el Anexo 04.

\subsection{Matriz de evaluación de los factores externos (EFE)}

La siguiente tabla fue elaborada a partir de la recopilación de información de distintos expertos que laboran en Ransa, donde se analiza la importancia de distintas variables y la eficacia con la que responde la empresa (Ver anexo 04). Ver Tabla 11. 
Tabla 11

Matriz de evaluación de factores externos

Factores críticos para el éxito

Amenazas

1. Falta de infraestructura nacional vial

2. La informalidad laboral en el Perú

3. Aumento de las exigencias medioambientales

4. Inestabilidad social y política del país

5. Corrupción en las licitaciones de proyectos de infraestructura

Subtotal

\section{Oportunidades}

1. Plan Nacional de Infraestructura

2. Tratados de Libre Comercio

3. Reglas de la Haya - Visby y Hamburgo

4. Crecimiento Económico en el Perú y América Latina

5. Tecnología, soporte de la actividad logística

6. Tendencias globales de consumo

Subtotal

Total

Nota. Adaptado de El proceso estratégico: Un enfoque de gerencia (p. 126), por F. D’Alessio, 2008, México D.F.: Pearson Educación.

La Tabla 11 reporta un ponderado total de 2.62, resultado que posiciona a Ransa por encima del promedio, capitalizando oportunidades y reduciendo el impacto de las amenazas, por ello, se afirma que Ransa posee una alta respuesta frente a las oportunidades que brinda el entorno externo, así como los tratados de libre comercio (TLCs), el crecimiento económico en el Perú y América Latina, la tecnología enfocada en el soporte de la actividad logística y las tendencias globales de consumo, asumiendo además que la empresa tendrá una alta respuesta frente a la oportunidad ofrecida por el plan nacional de infraestructura; del mismo modo, se observa que la empresa tiene una baja respuesta a la amenaza que representa la falta de infraestructura vial, la informalidad laboral en el Perú, la inestabilidad social y política del país, y la corrupción en las licitaciones de proyectos de infraestructura. 


\section{Capítulo V. Análisis de la industria}

\subsection{Descripción del mercado (demanda) e industria (oferta)}

\section{a. La oferta}

En principio, de acuerdo con Blum Consultora Empresarial, los operadores logísticos se adaptan a las necesidades de cada cliente, manteniendo distintos niveles de integración (“Clasificación de los diferentes operadores logísticos,” 22 de junio del 2018). Los principales tipos de operadores logísticos presentes en el mercado nacional son los siguientes:

- Primera fase de proveedor logístico (1PL): Esta fase de la logística hace referencia al transporte de mercancías. Por su parte, el área logística de la empresa contratante conserva las actividades de operaciones y cuenta con sus propios almacenes.

- Segunda fase de proveedor logístico (2PL): En este caso, los operadores logísticos ofrecen el servicio de transporte, almacenamiento de productos y manejo de equipos de almacén. Por su parte, la empresa contratante coordina la flota de transporte y la preparación de los pedidos en el almacén.

- Tercera fase de proveedor logístico (3PL): En este caso, los operadores logísticos ofrecen la integración de servicios, proveen de flota de transporte y lugar de almacenaje, además, gestionan las operaciones de transporte y almacén. Por su parte, la empresa contratante mantiene el control global de todo el flujo de mercancías.

- Cuarta fase de proveedor logístico (4PL): Supervisan el funcionamiento de la logística con el objetivo de optimizar al máximo la eficiencia de la cadena de suministro a través de su amplio y especializado conocimiento y capacidad tecnológica; no tienen 
recursos físicos como camiones o almacenes. Suelen supervisar a los operadores 3PL subcontratados por la empresa.

Considerando los distintos tipos de operadores logísticos, el Informe de Demografía Empresarial en el Perú, señala que en el II trimestre del 2018, uno de los servicios que registró mayor variación neta fue el servicio de transporte y almacenamiento, con 126,415 empresas registradas y en funcionamiento, alcanzando un aumento neto de 3052 empresas respecto al trimestre anterior (INEI, 2018). Ver Tabla 12.

Tabla 12

Número de empresas según actividad económica, II trimestre 2018

\begin{tabular}{|c|c|c|c|c|c|c|c|}
\hline Actividad económica & Stock $1 /$ & Altas 2] & Bajas 31 & $\begin{array}{r}\text { Variación } \\
\text { Neta } 4 /\end{array}$ & $\begin{array}{r}\text { Tasa de } \\
\text { altas (\%) } 51\end{array}$ & $\begin{array}{r}\text { Tasa de } \\
\text { bajas (\%) } 61\end{array}$ & $\begin{array}{r}\text { Tasa neta } \\
(\%) 7\end{array}$ \\
\hline Total & 2379445 & 63748 & 27711 & 36037 & 2,7 & 1,2 & 1,5 \\
\hline Agricultura, ganaderia, silvicultura y pesca & 39321 & 1269 & 795 & 474 & 3,2 & 2,0 & 1,2 \\
\hline Explotación de minas y canteras & 16968 & 457 & 992 & -535 & 2,7 & 5,8 & $-3,2$ \\
\hline Industrias manufactureras & 187684 & 4573 & 2475 & 2098 & 2,4 & 1,3 & 1,1 \\
\hline Construcción & 67004 & 2887 & 1302 & 1585 & 4,3 & 1,9 & 2,4 \\
\hline Venta y reparación de vehículos & 65975 & 1882 & 830 & 1052 & 2,9 & 1,3 & 1,6 \\
\hline Comercio al por mayor & 218074 & 8492 & 4252 & 4240 & 3,9 & 1,9 & 1,9 \\
\hline Comercio al por menor & 789727 & 16764 & 5968 & 10796 & 2,1 & 0,8 & 1,4 \\
\hline Transporte y almacenamiento & 126415 & 5298 & 2246 & 3052 & 4,2 & 1,8 & 2,4 \\
\hline Actividades de alojamiento & 25002 & 496 & 201 & 295 & 2,0 & 0,8 & 1,2 \\
\hline Actividades de servicio de comidas y bebidas & 189163 & 5993 & 1485 & 4508 & 3,2 & 0,8 & 2,4 \\
\hline Información y comunicaciones & 55532 & 955 & 421 & 534 & 1,7 & 0,8 & 1,0 \\
\hline Servicios prestados a empresas & 243856 & 5866 & 2636 & 3230 & 2,4 & 1,1 & 1,3 \\
\hline Salones de belleza & 34318 & 1022 & 199 & 823 & 3,0 & 0,6 & 2,4 \\
\hline Otros servicios 81 & 320406 & 7794 & 3909 & 3885 & 2,4 & 1,2 & 1,2 \\
\hline
\end{tabular}

Nota. Tomado de "Demografía empresarial en el Perú, II Trimestre 2018," por F. Costa, 2018, Instituto Nacional de Estadística e Informática (INEI), p. 04. Recuperado de goo.gl/uNv7Sq 
Además, la publicación Perú Top Publicaciones; la cual lista a las 10.000 empresas más importantes del Perú por ingresos, afirma que los operadores logísticos más importantes en términos de ventas, expresados en miles de soles, son solo 3: Ransa con S/ 780.960, Neptunia con S/ 326.277, y Dinet con S/ 125.735. (“Cuáles son las empresas más importantes del sector logístico,” 03 de agosto de 2017). Cabe señalar que, bajo la clasificación de operadores logísticos, las tres empresas anteriormente mencionadas son de naturaleza 3PL.

Tras lo mencionado, se identifica a Ransa como un operador logístico 3PL, por lo que la evaluación de la industria, en el apartado 5.2, se desarrolla desde la posición de operadores logísticos 3PL. Además, se determina a las empresas con mayores ventas de toda la industria, colocando a Ransa entre los principales operadores logísticos capaces de responder a la demanda del mercado nacional.

\section{b. La demanda}

En principio, la Figura 08 muestra la densidad empresarial orientadas al comercio de bienes por cada región al término del año 2017; información que permite aproximar el número de empresas comerciales en todo el Perú. Además, identificamos que en la Provincia de Lima existen 32.6 empresas por cada 1,000 habitantes (INEI, 2017). 


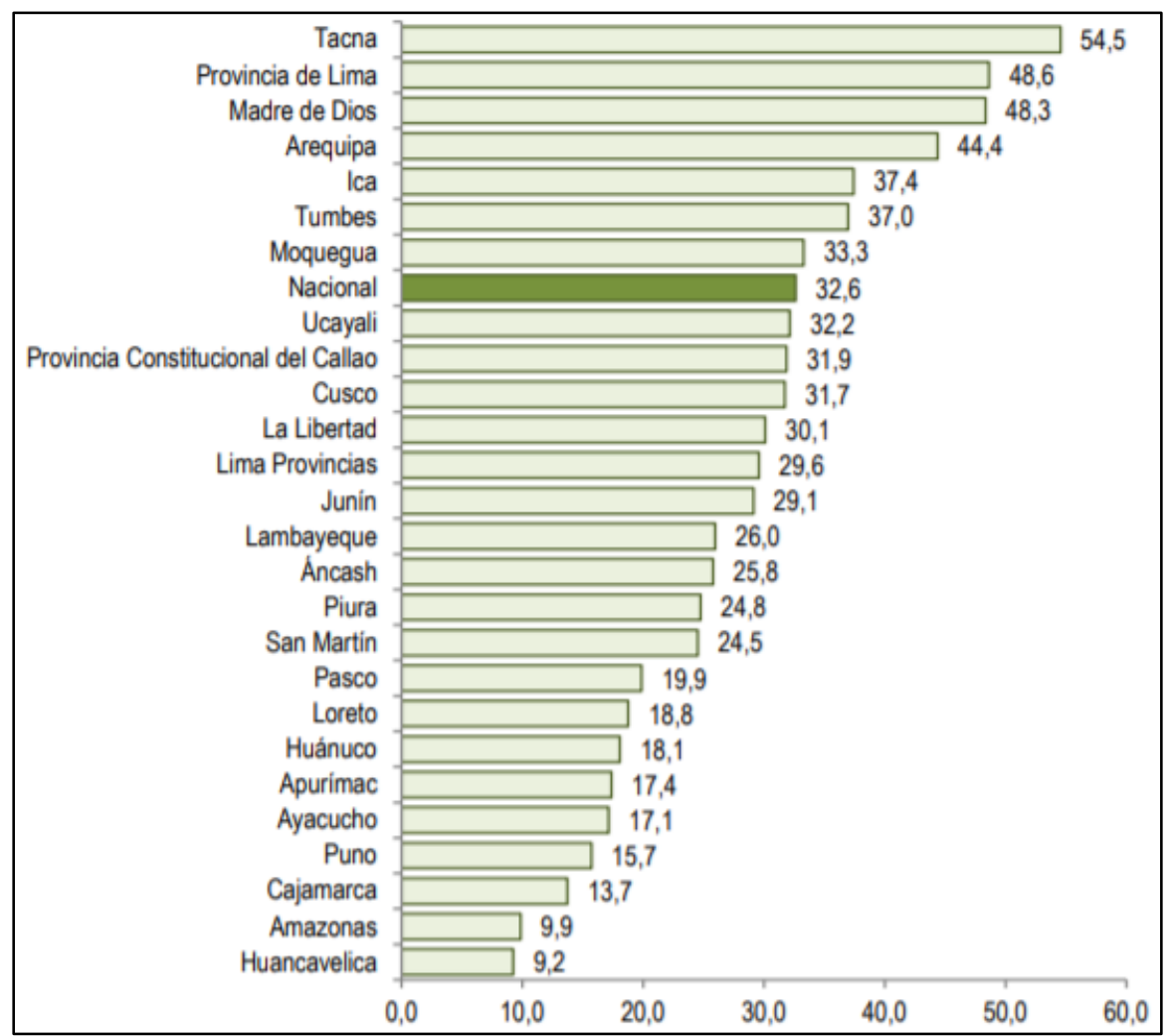

Figura 08. Densidad Empresarial de las empresas comerciales, según región (emp. por cada mil personas), 2017. Tomado de "Estructura Empresarial 2017" por el INEI, 2017. Recuperado de https://bit.ly/2GoR01O

En complemento, la Tabla 13 muestra la estructura del mercado nacional, señalando que el 0,6\% del mercado está conformado por grandes y medianas empresas, siendo éstos el mercado objetivo de la industria logística. Además, algunos pequeños empresarios suelen juntarse, formando conglomeraciones, con el fin de alcanzar grandes volúmenes de sus productos, convirtiéndose éstos en un mercado atractivo para la industria.

Tabla 13

Estructura empresarial

\begin{tabular}{|c|c|c|c|c|}
\hline \multirow{2}{*}{ Segmento empresarial } & \multirow{2}{*}{2016} & \multicolumn{2}{|c|}{2017} & \multirow{2}{*}{$\begin{array}{c}\text { Var \% } \\
2017 / 16\end{array}$} \\
\hline & & Absoluto & Porcentaje & \\
\hline Total & $2^{\prime} 124,280$ & $2 ’ 303,511$ & 100,00 & 8,4 \\
\hline Microempresa & $2^{\prime} 011,153$ & $2^{\prime} 183,121$ & 94,8 & 8,6 \\
\hline Pequeña empresa & 92,789 & 98,942 & 4,3 & 6,6 \\
\hline Gran y mediana empresa & 13,031 & 13,898 & 0,6 & 6,7 \\
\hline Administración pública & 7,307 & 7,550 & 0,3 & 3,3 \\
\hline
\end{tabular}

Nota. Tomado de "Perú: Estructura Empresarial, 2017”, por INEI, 2017. Recuperado de goo.gl/u4rUR7 
Por otro lado, en la Tabla 12 se observa que en el II trimestre del 2018 ingresaron al mercado 32,985 empresas de distintas industrias (sin incluir operadores logísticos), cifra que propone un aumento de potenciales clientes.

Sin embargo, el $95.0 \%$ de las empresas formales son microempresas, $4.3 \%$ pequeñas empresas y $0.2 \%$ medianas empresas. De este modo, el $39.3 \%$ de las pymes registraron ventas anuales menores a 2 UIT, mientras que un $26.9 \%$ reconoció ventas anuales por encima de 13 UIT (Ministerio de la Producción, 2015). Dicho esto, debe considerarse que la mayor parte de las empresas (existentes y nuevas) no están en condiciones de tercerizar sus operaciones logísticas, ya sea por falta de capital o porque no sea necesario.

Por último, es importante señalar que existen empresas que no están de acuerdo que la tercerización logística sea parte de un beneficio a largo plazo, perdiendo así miles de soles al año debido a sus ineficientes procesos logísticos, prácticas inadecuadas de almacenamiento y personal no calificado. Así, el porcentaje de empresas reacios al cambio asciende a 30\%. (Ramos, 2017).

En conclusión, de los 2`379,445 empresas solo el 5\% está en condiciones de tercerizar sus operaciones logísticas, de las cuales un $70 \%$ piensa en ello como beneficio a largo plazo. Además, cabe mencionar que las microempresas, las cuales representan el $95 \%$ del total de empresas, aunque no estén en condiciones de tercerizar sus operaciones logísticas, son las que mueven al 5\% de las empresas que sí están en condiciones de contratar un operador logístico; por lo que, al final del trayecto, son los operadores logísticos los beneficiados. 


\subsection{Descripción de las cinco fuerzas competitivas de la industria}

En el siguiente apartado se analiza cada una de las cinco fuerzas competitivas del sector logístico 3PL a través de la información recogida por medio de entrevistas a expertos de Ransa (ver Anexo 05). A continuación, se podrán observar tablas por cada una de las fuerzas competitivas, las cuales contienen factores críticos, peso de relevancia, impacto del factor y el valor final que determina la situación de la fuerza en la industria.

\subsubsection{Sustitutos.}

Ransa es un operador 3PL, es decir, gestiona los procesos logísticos de sus clientes y les ofrece una serie de ventajas competitivas.

De esta manera, las empresas pueden reducir sus costos, ya que no invierten en la implementación de un centro de distribución, sino que pagan al 3PL lo correspondiente al espacio que utilizan. Además, optimizan los tiempos, ya que asumen la gestión de los procesos logísticos y si se trata de querer operar en otros países, al trabajar con un 3PL se tiene la seguridad de que se dará de manera eficiente debido al conocimiento y experiencia en otros mercados (Ransa, 2018).

Es importante mencionar que los operadores logísticos 4PL se encargan de gestionar a los proveedores de los servicios logísticos 3PL que han sido subcontratados por la empresa cliente (Coyle, Bardi, EJ y Langley, \& CJ, 2003). Por lo tanto, el principal objetivo de un operador 4PL es generar valor a sus empresas clientes por medio del suministro de recursos de proveedores especializados que ofrezcan valor añadido. Es difícil encontrar un 4PL que pueda ofrecer todos los recursos (camiones, almacenes y capacidad tecnológica) debido a que su mayor fortaleza está en seleccionar y coordinar los recursos de otros operadores (3PL) que generen un valor mayor del que podría generar el proceso interno de las empresas clientes (Win, 2008). 
En ese sentido, la amenaza de productos sustitutos nace del servicio logístico no integral (1PL y 2PL). Cabe mencionar que estos servicios no ofrecen un valor agregado y muchas veces son administrados por empresas que no poseen amplia experiencia dentro de la industria (De La Torre, López, Luna, Meza, \& Mixán, 2016).

Por otro lado, de acuerdo con la Tabla 14, los siguientes factores: (a) propensión del consumidor a sustituir, (b) sustitutos con mejores precios y (c) facilidad de cambio del comprador, alcanzan la puntuación más alta (3), lo que significa que de no demonstrar la ventaja competitiva de contratar un servicio integrado 3PL, éstos evaluarán la opción de sustituir el servicio mencionado por un 1PL (solo transporte) y 2PL (transporte más almacenamiento), los cuales ofrecen alquiler de espacios, pero no gestionan los almacenes, responsabilizando a los cliente de mantener la función de administrar las tareas operativas y de contar con sus propio sistema de gestión.

Por último, que los clientes dejen de tercerizar el servicio 3PL para empezar a gestionar su propia cadena logística, implementando un centro de distribución o adquiriendo flota propia para el transporte de su mercadería, sería otra forma de sustituir el servicio mencionado; sin embargo, es una alternativa poco viable debido al nivel inversión y especialización que ello demanda. 
Tabla 14

Amenaza de servicios sustitutos

\begin{tabular}{|c|c|c|c|c|c|c|c|c|c|}
\hline Peso & Factores & ВАJA & 1 & 2 & 3 & 4 & 5 & ALTA & Valor \\
\hline $16.67 \%$ & $\begin{array}{l}\text { Propensión del consumidor a } \\
\text { sustituir }\end{array}$ & & & & 3 & & & & 0.44 \\
\hline $25.00 \%$ & Sustitutos con mejores precios & & & & 3 & & & & 0.71 \\
\hline $20.83 \%$ & $\begin{array}{l}\text { Facilidad de cambio del } \\
\text { comprador }\end{array}$ & & & & 3 & & & & 0.66 \\
\hline $20.83 \%$ & $\begin{array}{l}\text { Nivel percibido de diferenciación } \\
\text { del producto }\end{array}$ & & & 2 & & & & & 0.42 \\
\hline $16.67 \%$ & $\begin{array}{l}\text { Disponibilidad de sustitutos } \\
\text { cercanos }\end{array}$ & & & 2 & & & & & 0.33 \\
\hline $100 \%$ & & & & & & & & & 2.56 \\
\hline
\end{tabular}

Nota. La información de la presente tabla es el resultado promedio de las entrevistas realizadas a expertos de Ransa (ver Anexo 05).

\subsubsection{Potenciales.}

Actualmente, no existen barreras legales para iniciarse en la industria logística. Al contrario, El Estado Peruano promociona la inversión privada, la competitividad del mercado y el trato justo de todas las industrias (Ley $\mathrm{N}^{\circ} 757,1991$ ).

Sin embargo, la integración de servicios que ofrece un operador logístico como Ransa, representa una barrera para el ingreso de nuevos competidores. Por ejemplo, la empresa cuenta con profesionales bajo el perfil de líderes supply, quienes se encargan del manejo integral de la cadena logística, optimizando los recursos en bienestar del cliente y asegurando que la demanda del mismo esté cubierta en todo momento

Mientras tanto, la tecnología en la industria logística avanza a pasos agigantados y es necesario reinventarse e innovar para ofrecer un mejor servicio a los clientes. Considerando que UPS realiza inversiones anuales de más de mil millones de dólares, con la finalidad de innovar en las diferentes áreas del negocio logístico y de distribución, es claro que se tiene a un potencial competidor (Salamanca, 2017). Cabe mencionar que UPS es ampliamente conocida por su entrega de paquetes terrestres nacionales; además, ofrece servicios de envío nacional e 
internacional, rastreo, contratación de servicios de logística, integración de tecnología UPS y sustentabilidad (United Parcel Service [UPS], 2019).

Por lo mencionado anteriormente y los resultados mostrados en la Tabla 15, el factor de mayor relevancia e impacto es la inversión de capital que demanda ingresar a la industria de operadores logísticos, ya que ésta reflejará el grado de integración del servicio ofrecido.

Finalmente, el valor ponderado de 2.96 muestra que el ingreso de nuevos competidores es una amenaza que puede ir en aumento si no se pone atención en incrementar la calidad de los procesos logísticos y en su integración. Ver Tabla 15.

Tabla 15

Amenaza de nuevos competidores

\begin{tabular}{|c|c|c|c|c|c|c|c|c|c|}
\hline Peso & Factores & ВАJA & 1 & 2 & 3 & 4 & 5 & ALTA & Valor \\
\hline $20.83 \%$ & Economía a escala & & & & 3 & & & & 0.59 \\
\hline $21.67 \%$ & Diferenciación del producto & & & 2 & & & & & 0.51 \\
\hline $24.17 \%$ & Inversiones de capital & & & & 3 & & & & 0.81 \\
\hline $17.50 \%$ & Acceso a canales de distribución & & & & 3 & & & & 0.61 \\
\hline $15.83 \%$ & Barreras de entrada & & & & 3 & & & & 0.45 \\
\hline $100 \%$ & & & & & & & & & 2.96 \\
\hline
\end{tabular}

Nota. La información de la presente tabla es el resultado promedio de las entrevistas realizadas a expertos de Ransa (ver Anexo 05).

\subsubsection{Clientes.}

Los clientes con mayor poder de negociación en el sector son aquellos con mayores volúmenes (almacenaje) o con mayor frecuencia (transporte). En el caso de Ransa, el cliente más importante es Samsung con el $80 \%$ de sus ingresos por distribución; además, Samsung y Alicorp son clientes que ocupan un almacén cada uno.

Es importante mencionar que el principal servicio de los operadores logísticos es el almacenaje y es donde los clientes grandes (caso: alimentos, minería, etc.) “dominan” la 
negociación a la hora de contratar los servicios logísticos por los volúmenes ofrecidos. Sin embargo, los demás clientes de Ransa que no representan un alto porcentaje de ingresos por almacenaje, transporte y distribución, se rigen al cumplimiento de los términos y condiciones previamente negociadas por ambas partes. Al final, las exigencias de cada uno de los clientes se reflejan en los precios de los servicios contratados.

Por otro lado, la Tabla 16 muestra que el factor de mayor relevancia e impacto es el potencial cambio de operador logístico; factor que se valida, además, con el Anexo 06, el cual muestra el resultado de encuestas a clientes de la empresa, en el que se mencionan distintas deficiencias de los servicio que podrían desencadenar una caída de la cartera de clientes, por ejemplo: América Móvil requiere de mayor tecnología e innovación, así como la mejorar la capacidad de respuesta; Oster enfatiza que la empresa debe alinearse con las nuevas tendencias y requerimientos del mercado; Minera Yanacocha menciona resalta que la empresa debe enfocarse más en el cliente que en la reducción de costos, acentuando que ello es la razón por lo que la empresa sufre pérdida de clientes.

Es por ello que, con un valor ponderado de 3.13 (ver Tabla 16), el poder de negociación de los clientes alcanza a ser medio alto, lo que le convierte en un tema de interés para el área comercial; puesto que, de no ser tratado a tiempo y con cuidado, puede convertirse en una debilidad. 
Tabla 16

Poder de negociación de los clientes

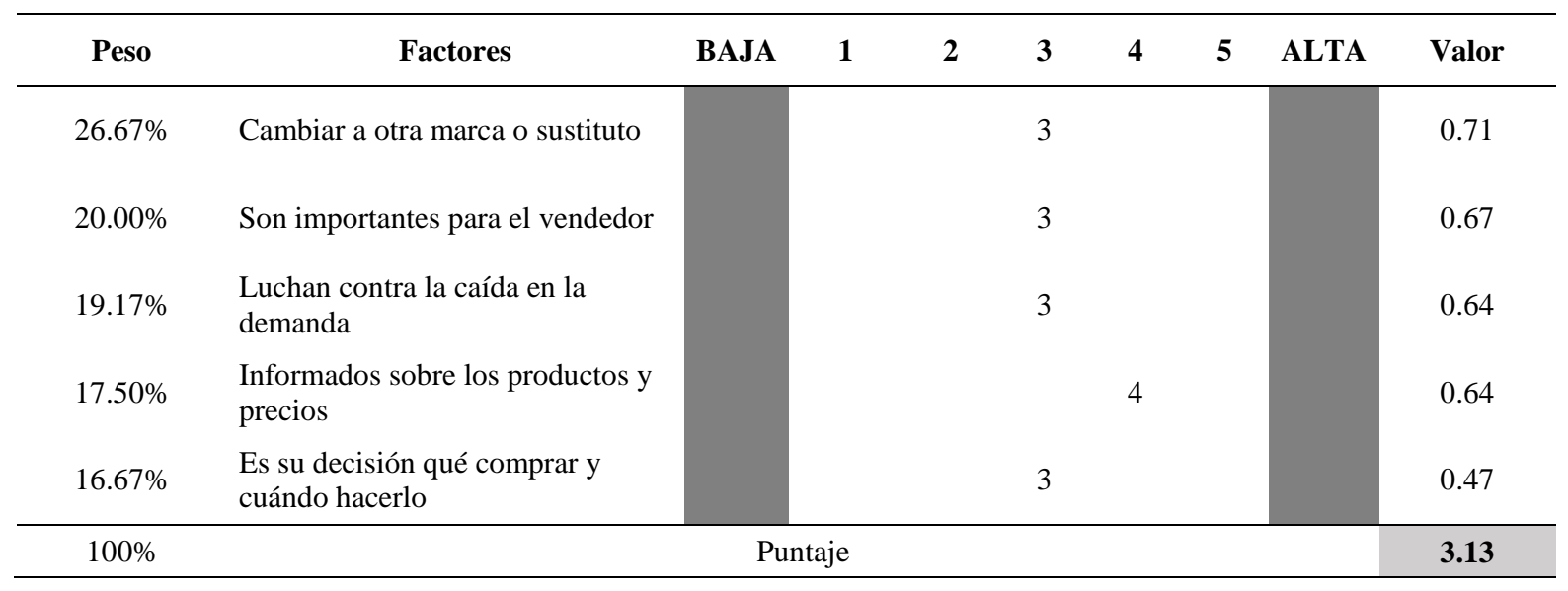

Nota. La información de la presente tabla es el resultado promedio de las entrevistas realizadas a expertos de Ransa (ver Anexo 05).

\subsubsection{Proveedores.}

La mayoría de los operadores logísticos subcontrata algunas operaciones que abarcan los servicios comerciales entre las unidades de negocio y los clientes. De este modo, los subcontratistas se convierten en los principales proveedores debido al involucramiento directo que tienen sobre la calidad del servicio. La importancia de subcontratar operaciones es la reducción de costos a través de un servicio especializado. (De La Torre et al, 2016).

En cuanto a lo mencionado, la Tabla 17 señala que la cantidad de proveedores y el poder que éstos tienen sobre los precios son los factores de mayor relevancia, ya que existen pocos proveedores que cumplen con los altos requerimientos establecidos por los operadores logísticos 3PL.

Sin embargo, considerando la entrevista realizada al Jefe de Servicios (ver Anexo 07), la negociación de tarifas con los proveedores, luego del vencimiento del contrato, significa un incremento del 1 o $2 \%$ a lo mucho; esto debido a que siempre hay nuevos proveedores dispuestos 
a negociar con la empresa, y perder la renovación del contrato involucra perder un gran

porcentaje de sus ventas debido a que cubren todas las operaciones de Ransa.

Por ello, el poder de negociación de los proveedores alcanza un valor ponderado de 2.99 (ver Tabla 17), valor que afirma que la industria de operadores logísticos 3PL tiene un poder de negociación medio, ya que la facultad de ofrecer un servicio integrado de alta calidad depende de terceros.

Tabla 17

Poder de negociación de los proveedores

\begin{tabular}{|c|c|c|c|c|c|c|c|c|c|}
\hline Peso & Factores & BAJA & 1 & 2 & 3 & 4 & 5 & ALTA & Valor \\
\hline $26.67 \%$ & $\begin{array}{l}\text { Cantidad de proveedores en la } \\
\text { industria }\end{array}$ & & & & 3 & & & & 0.80 \\
\hline $27.50 \%$ & $\begin{array}{l}\text { Poder de decisión en el precio por } \\
\text { parte del proveedor }\end{array}$ & & & & 3 & & & & 0.83 \\
\hline $25.00 \%$ & $\begin{array}{l}\text { Nivel de organización de los } \\
\text { proveedores }\end{array}$ & & & & 3 & & & & 0.71 \\
\hline $20.83 \%$ & Nivel de poder adquisitivo & & & & 3 & & & & 0.66 \\
\hline $100 \%$ & & & & & & & & & 2.99 \\
\hline
\end{tabular}

Nota. La información de la presente tabla es el resultado promedio de las entrevistas realizadas a expertos de Ransa (ver Anexo 05).

\subsubsection{Competencia en el mismo sector.}

De acuerdo con la Tabla 18, el factor de mayor relevancia e impacto es el número de competidores; sin embargo la cantidad de éstos, a la fecha, es moderada, por lo que su valor se justifica en el impacto que éstas tienen actualmente y en el potencial que pueden alcanzar; por ejemplo, entre los operadores logísticos 3PL que atienden el mercado nacional, tenemos los siguientes: Dinet, Neptunia y Ransa; empresas que, además, buscan desarrollar la calidad de la industria, como se mencionó anteriormente en el punto 4.1.5. 
Por otro lado, el factor de costos fijos impacta sobre el precio y la calidad de los servicios, influyendo finalmente en el factor de diferenciación; por ello, las empresas que brindan servicios integrados manejan mayores costos fijos debido a la alta calidad de sus operaciones, logrando así una alta diferenciación. Sin embargo, la Tabla 18 muestra que los costos fijos tienen mayor relevancia que la diferenciación, de modo que tercerizar operaciones especializadas ayuda a disminuir costos y aumentar la calidad.

Por último, el valor ponderado de 2.93 muestra una rivalidad media alta entre competidores debido al gran número de empresas que conforman la industria. Así, las empresas que ofrecen servicios logísticos no integrados compiten por precios, mientras que las empresas que ofrecen servicios integrados compiten por calidad. Ver Tabla 18.

Tabla 18

Rivalidad de los competidores

\begin{tabular}{|c|c|c|c|c|c|c|c|c|c|}
\hline Peso & Factores & BAJA & 1 & 2 & 3 & 4 & 5 & ALTA & Valor \\
\hline $26.67 \%$ & Gran número de competidores & & & & 3 & & & & 0.84 \\
\hline $20.00 \%$ & Costos fijos & & & & 3 & & & & 0.67 \\
\hline $17.50 \%$ & Falta de diferenciación & & & & 3 & & & & 0.44 \\
\hline $19.17 \%$ & Competidores diversos & & & & 3 & & & & 0.51 \\
\hline $16.67 \%$ & Barreras de salida & & & & 3 & & & & 0.47 \\
\hline $100 \%$ & \multicolumn{8}{|c|}{ Puntaje } & 2.93 \\
\hline
\end{tabular}

Nota. La información de la presente tabla es el resultado promedio de las entrevistas realizadas a expertos de Ransa (ver Anexo 05). 


\subsection{Análisis del grado de atractividad de la industria}

Tabla 19

Análisis de atractividad

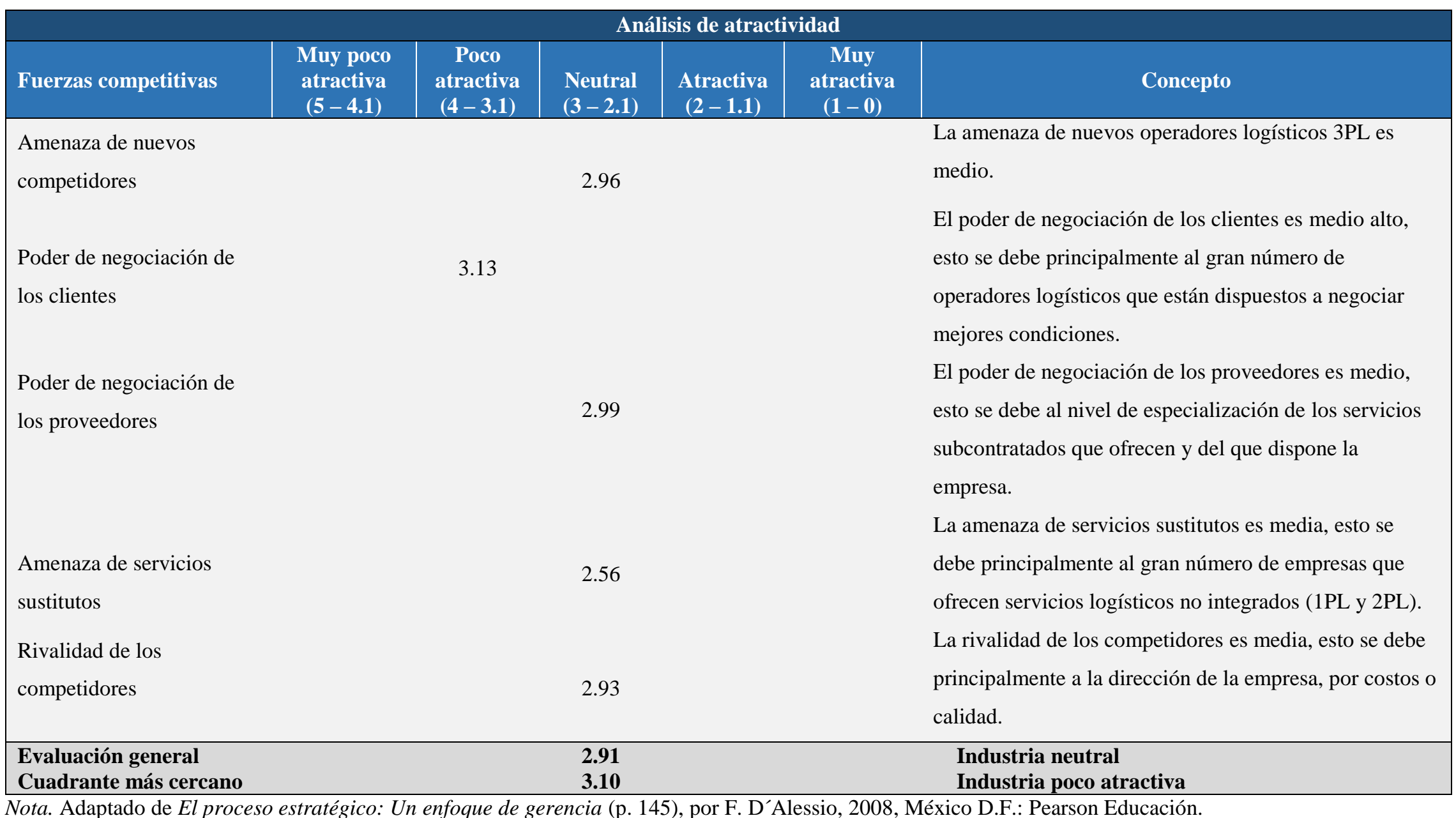


El resultado de la Tabla 19 muestra una industria neutral - poco atractiva; esto debido a la poca dificultad de ingresar a la industria ofreciendo servicios logísticos no integrados (1PL y 2PL) como el servicio de transporte, almacenamiento y distribución, ya que éstos por separado demandan menor desembolso de dinero; sin embargo, esta cara de la industria muestra mayor índice de competidores, restándole atractividad a la industria; mientras que para ofrecer un servicio logístico integrado (3PL) se necesita mayor inversión de dinero y tiempo, lo cual involucra infraestructura, flota de camiones, certificaciones, personal calificado, entre otros; reduciendo notablemente el índice de competidores.

Además, al existir en toda la industria gran cantidad de operadores logísticos, los clientes tienen cierto poder en hacer cumplir sus demandas, y de no estar satisfechos con lo recibido pueden buscar una nueva alternativa. La decisión depende de que si el cliente alcanza a percibir el valor diferencial de un servicio integrado y el impacto que éste tiene sobre sus operaciones, de no percibirlo puede finalmente inclinarse por otro operador logístico 3PL o por uno que brinde servicios atomizados (1PL o 2PL).

Es por ello por lo que, luego del análisis de la industria, la empresa debe desarrollar estrategias que estén orientadas en lo siguiente: incrementar la diferenciación de sus servicios y el nivel percibido sobre esta misma.

A continuación, en la Tabla 20, considerando todo lo mencionado anteriormente, se muestra las fortalezas y debilidades de Ransa frente a las fuerzas competitivas de la industria. 
Tabla 20

Ransa frente a las fuerzas competitivas

\begin{tabular}{|c|c|c|}
\hline Fuerzas competitivas de la industria & Fortalezas/debilidades & \\
\hline Poder de negociación de los clientes & Debilidad & 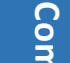 \\
\hline Poder de negociación de los proveedores & Deblidad potencial & 을. \\
\hline Amenaza de servicios sustitutos & Fortaleza & 응 \\
\hline Rivalidad de los competidores & Fortaleza potencial & ลํ. \\
\hline Amenaza de nuevos competidores & Fortaleza & \& \\
\hline
\end{tabular}

Primero, la empresa a través del área de Operaciones está responsabilizada en impulsar iniciativas que mejoren y diferencien sus servicios ofrecidos, creando valor en la cadena de suministros de sus clientes.

Al incrementar el valor de los servicios ofrecidos, la empresa hace frente a la problemática de que su servicio integral (3PL) sea remplazado por servicios atomizados (1PL o 2PL); asimismo, incrementa las barreras de entrada, relacionadas con la inversión tecnológica; y, por último, incrementa su nivel de competitividad, convirtiéndose en una amenaza para el resto de los operadores 3PL; sin embargo, de acuerdo con la Figura 03, se puede inferir que Ransa ha estado perdiendo cierto grado de diferenciación.

Es así como, considerando el nivel de integración de los servicios, el alcance geográfico, y la infraestructura de la empresa, se considera que Ransa, a través de Operaciones, está atacando a 3 de las 5 fuerzas de la industria, en la que dicha gestión, por el valor creado, puede considerarse una fortaleza para la empresa. 
Segundo, la empresa a través del área Comercial está responsabilizada de impulsar iniciativas que transmitan la diferenciación de sus servicios ofrecidos, incrementando el valor percibido de estos mismos.

Al incrementar el valor percibido de los servicios ofrecidos, la empresa hace frente a la problemática del poder de decisión de los clientes, reduciendo la posibilidad de que éstos consideren remplazar los servicios contratados. Por otro lado, debido al alcance geográfico y el nivel de especialización que demanda la industria, la empresa necesita tercerizar distintos servicios, por lo que el área Comercial está comprometida a negociar por ellos; sin embargo, con la exigencia que muestra el mercado, el nivel de especialización demandada será cada vez más alta, por lo que negociar por esos servicios demandará mayor cuidado.

Es así como, considerando la caída de las ventas en una industria en crecimiento (ver Figura 03), el resultado de la encuesta de satisfacción (ver Anexo 06) y la entrevista realizada al jefe de Gestión de Servicios (ver Anexo 07), se considera que Ransa, a través del área Comercial, está trabajando en 2 de las 5 fuerzas de la industria, gestión que aún no alcanza resultados óptimos, por lo que se le puede considerar como una debilidad.

\subsection{Matriz de perfil competitivo (MPC)}

De acuerdo con DÁlessio (2008), “el propósito de esta matriz es señalar cómo está una organización respecto del resto de competidores asociados al mismo sector, para que a partir de esa información la organización pueda inferir sus posibles estrategias” (p.145).

Además, D’Alessio (2008) señala que "las clasificaciones (valores) se refieren a fortalezas y debilidades de la organización, donde: 4=fortaleza mayor, 3=fortaleza menor, 
2=debilidad menor, 1=debilidad mayor. Los pesos de los factores clave de éxito deben sumar 1 y deben ser entre 6 y $12 ”($ p.146).

Para identificar y determinar a los competidores más importantes de Ransa Comercial, recurrimos a entrevistas personales con expertos de la organización, los cuales lideran los principales servicios de la Operación, conocen la gestión de la competencia y cuentan con amplia experiencia en el rubro logístico. De esta manera, en función de las variables tales como: cobertura, estándares de seguridad, experiencia, infraestructura, integración de la cadena, gestión comercial y orientación al cliente, se determinan a las empresas que constituyen como competencia de la organización. (Ver anexo 8)

En este sentido, se tuvo como resultado que las empresas que compiten directamente con Ransa son Neptunia y Dinet. Asimismo, esta información se contrasta con lo mencionado anteriormente en cuanto a los tres operadores logísticos más importantes del sector en términos de ventas, resultando las tres organizaciones como representativas.

Es así como, se aplica la herramienta MPC para evaluar la comparación de fortalezas y debilidades de las empresas mencionadas, las cuales se conectan entre sí en función de los Factores Clave para el Éxito (FCE), los cuales fueron validados por expertos de la organización y de la industria, quienes enumeraron un listado de factores y se eligieron aquellos de mayor repetición para efectos de la evaluación.

Respecto a los expertos de la industria, tenemos a personas que lideren servicios del rubro logístico, con puestos de jefatura o gerencia dentro de sus organizaciones y que cuentan con amplia experiencia en el mercado. 
De esta manera, para determinar la valoración de la Matriz de Perfil competitivo, consideramos solo la evaluación de los expertos ajenos a Ransa Comercial, de modo que los puntajes reflejen una percepción más certera. (Ver anexo 8)

Por consiguiente, la Tabla 21 indica que Ransa posee un alto manejo de (1) cobertura a nivel nacional de sus operaciones logísticas y (3) experiencia en la industria. Asimismo, Ransa mantiene un buen manejo de (2) altos estándares de seguridad en las operaciones logísticas, (4) infraestructura Logística, (5) nivel de integración de la cadena de suministro y (7) orientación al cliente, seguido por Dinet y Neptunia en base al puntaje.

Por ello, se puede afirmar que Ransa maneja aquellos factores críticos de gran influencia en la industria de operadores logísticos para prestar sus servicios, permitiendo a la empresa tener una ventaja sobre las demás. Por otro lado, es Neptunia quien posee mejor manejo del factor (6) gestión comercial, seguido por Ransa y Dinet en base al puntaje

Sobre el puntaje final ponderado se observa que Ransa, Dinet y Neptunia $(3.17,2.74$ y 2.47 respectivamente) se encuentran por encima del promedio de la industria, lo que significa que utilizan sus capacidades para aprovechar las oportunidades y evadir las amenazas presentes en la industria. 
Tabla 21

Matriz de perfil competitivo: Ransa, Neptunia y Dinet

\begin{tabular}{lccccccc}
\multicolumn{1}{c}{ Factores del éxito } & \multirow{2}{*}{ Peso } & \multicolumn{2}{c}{ RANSA } & \multicolumn{2}{c}{ NEPTUNIA } & DINET \\
\cline { 4 - 7 } & & Valor & Puntaje & Valor & Puntaje & Valor & Puntaje \\
\hline 1. Cobertura a nivel nacional de las oepraciones logísticas & 0.14 & 4 & 0.53 & 3 & 0.39 & 3 & 0.39 \\
2. Manejo de altos estándares de seguridad en las operaciones logísticas & 0.14 & 3 & 0.45 & 3 & 0.36 & 3 & 0.42 \\
3. Experiencia en la Industria & 0.13 & 4 & 0.52 & 3 & 0.34 & 3 & 0.39 \\
4. Infraestructura Logística & 0.13 & 3 & 0.44 & 3 & 0.36 & 3 & 0.34 \\
5. Nivel de integración de la cadena de suministro & 0.14 & 3 & 0.39 & 2 & 0.31 & 2 & 0.34 \\
6. Gestión Comercial & 0.16 & 2 & 0.38 & 2 & 0.38 & 3 & 0.42 \\
7. Orientación al cliente & 0.16 & 3 & 0.45 & 2 & 0.32 & 3 & 0.45 \\
\hline Total & $\mathbf{1 . 0 0}$ & & $\mathbf{3 . 1 7}$ & & $\mathbf{2 . 4 7}$ & & $\mathbf{2 . 7 4}$ \\
\hline
\end{tabular}

Nota. Los factores clave de éxito fueron planteados y evaluados por expertos de la industria de operadores logísticos (ver Anexo 05). Adaptado de El proceso estratégico: Un enfoque de gerencia (p. 147), por F. D’Alessio, 2008, México D.F.: Pearson Educación.

Por otro lado, de manera específica, Ransa debe implementar estrategias que mejoren el factor 6, considerado como debilidad menor, y refuercen los factores $2,4,5$ y 7 , considerados como fortalezas menores.

Respecto al valor ponderado de 3.17, Ransa se posiciona como el líder en la industria de operadores logísticos, seguido por Dinet (2.74) y Neptunia (2.47).

Por último, mejorar el nivel de integración de la cadena de suministros (FCE 5) está orientado a incrementar la diferenciación de los servicios y mejorar la gestión comercial y la orientación de la empresa hacia y para el cliente, mientras que el FEC 7 está orientada a incrementar el nivel percibido sobre la diferenciación de los servicios.

\subsection{Benchmarking y comparación con los líderes de la industria en cada uno de los factores claves de éxito (FCE)}

El mercado de operadores logísticos es una industria amplia y competitiva, debido a los distintos factores que exige el mercado y que determinan la calidad de los servicios. 
Asimismo, es importante mencionar que las empresas deberían tener la capacidad de atender los requerimientos de los clientes y adaptarse a sus necesidades.

En este sentido, en la Tabla 22, se realiza un análisis comparativo de las empresas que lideran la industria logística y son evaluadas en base a factores clave de éxito, tales como: cobertura, estándares de seguridad, experiencia en la industria, infraestructura logística y nivel de integración de la cadena logística. Los resultados de la evaluación permitirán identificar las prácticas superiores de las organizaciones o aquellas que deban potenciar, adoptando e implementando iniciativas similares a las demás empresas.

Tras la evaluación, ver Tabla 22, se concluye que Ransa es superior en términos de cobertura de operaciones, infraestructura logística y experiencia en la industria. 
Tabla 22

Benchmarking de los factores claves de éxito

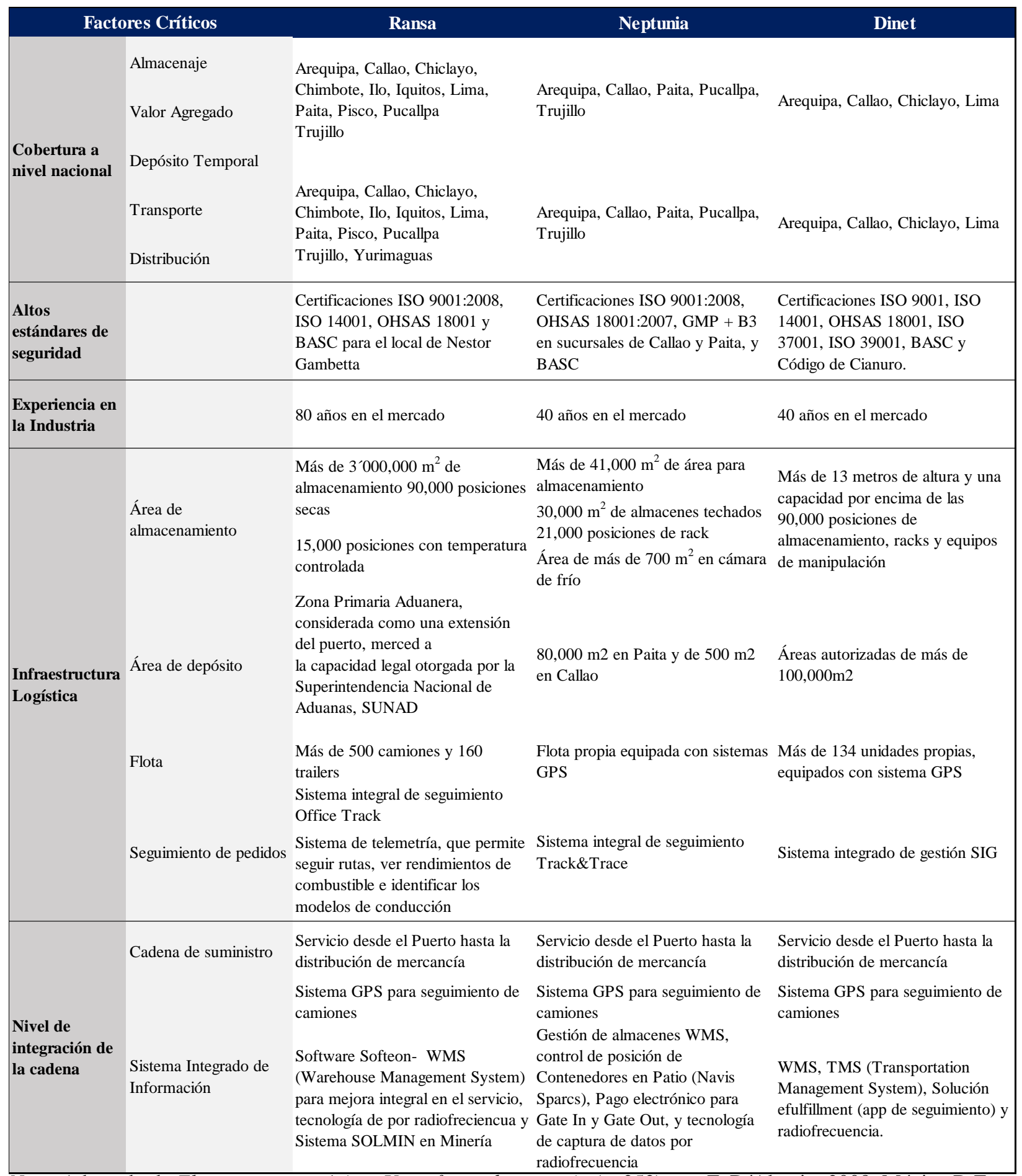

Nota. Adaptado de El proceso estratégico: Un enfoque de gerencia (p. 252), por F. D’Alessio, 2008, México D.F.: Pearson Educación. 


\section{Capítulo VI. Análisis interno}

\subsection{Descripción de las actividades de la cadena de valor de la empresa}

La cadena de valor es una herramienta que analiza el plan estratégico de las empresas, permitiendo identificar las funciones, actividades y, sobre todo, los procesos críticos; además, de cómo logran crear valor al interrelacionarse. Asimismo, permite identificar las ventajas competitivas desde el seno de la empresa (Porter, 1985). Bajo este concepto la Figura 09 muestra las actividades primarias y de apoyo de Ransa Comercial, cadena de valor enfocada en una organización que ofrece servicios logísticos.

\begin{tabular}{|c|c|c|c|c|c|c|}
\hline \multirow{6}{*}{ 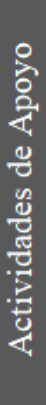 } & 1 & \multicolumn{5}{|c|}{ Gestión de Sistemas y TI } \\
\hline & 2 & \multicolumn{5}{|c|}{ Gestión de Recursos Humanos } \\
\hline & 3 & \multicolumn{5}{|c|}{ Gestión de Finanzas } \\
\hline & 4 & \multicolumn{5}{|c|}{ Gestión de Innovación y Consultoría } \\
\hline & 5 & \multicolumn{5}{|c|}{ Gestión de Calidad y Seguridad } \\
\hline & 6 & \multicolumn{5}{|c|}{ Gestión de Servicios } \\
\hline \multirow{3}{*}{ 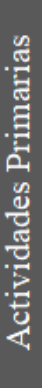 } & \multirow[t]{3}{*}{$\begin{array}{c}1 \\
\text { Comercial }\end{array}$} & \multicolumn{5}{|c|}{ Oneraciones } \\
\hline & & 2.1 & 2.2 & 2.3 & 2.4 & 2.5 \\
\hline & & Almacenaje & Distribución & Transporte & $\begin{array}{l}\text { Servicio de } \\
\text { Valor } \\
\text { Agregado }\end{array}$ & $\begin{array}{l}\text { Depósito } \\
\text { Temporal }\end{array}$ \\
\hline
\end{tabular}

Figura 09. Cadena de valor - Ransa 2019. Adaptado de "Competitive Advantage," por Porter, M. 1985. New York, EEUU: The Free Press

La cadena de valor de Ransa está conformada por dos actividades primarias (Comercial y Operaciones) y seis actividades secundarias (Gestión de Sistemas y TI, Gestión de Recursos Humanos, Gestión de Finanzas, Gestión Central de Negocios - Comercial, Gestión de Innovación y Consultoría, Gestión de Calidad y Seguridad, y Gestión de Servicios). 


\section{a. Actividades Primarias}

\section{Comercial}

Área que tiene como actividad principal reconocer oportunidades de negocio relacionados al sector logísticos; además, debe establecer las tarifas de los servicios, brindar soporte a los clientes, y crear relaciones efectivas con los mismos. Es así como, desde sus inicios, Ransa ha logrado incrementar su cartera de clientes, llegando a atender, a la fecha, a 20 sectores a nivel nacional.

El área con la que tiene mayor interacción es Operaciones, ya sea para dar solución a los clientes como para solicitar la cotización de un servicio. En este punto, los Jefes de Operaciones revisan la productividad y los costos relacionados para brindar la información; sin embargo, de acuerdo con las entrevistas realizadas a expertos del área de operaciones (ver Anexo 09), la pauta mencionada no se cumple, sino que los ejecutivos/gerentes comerciales ofrecen tarifas que no cubren los costos operativos o aceptan concesiones comerciales que afectan la rentabilidad del negocio.

Sin embargo, en el Anexo 10, se observa que las consideraciones y capacidades de atención, determinados en los contratos de los principales clientes, no se cumplen; lo que se define como relaciones contractuales débiles, escenario en el que, por un lado, se tiene el incumplimiento de los acuerdos por parte de la empresa, y, por otro lado, se tiene a clientes que llevan operando con Ransa desde hace varios años con los mismo acuerdos y contratos desactualizados, siendo la fuente que ralentiza la aplicación de contratos o acuerdos actualizados.

Por último, en el Anexo 06, se observa el resultado de la encuesta de satisfacción al cliente del 2018, realizada a 80 clientes y 117 contactos, la cual obtuvo un puntaje de $71.79 \%$, junto a comentarios que enfatizan en lo siguiente: mejorar la comunicación con el cliente, así 
como la agilidad y atención por parte del área comercial; disminuir los tiempos de acceso al personal como de las unidades de transporte de Ransa; e implementar iniciativas tecnológicas.

\section{Operaciones}

\section{Almacenaje}

El área de Operaciones dispone de la siguiente infraestructura logística: más de 3’000,000 m2 de almacenamiento, 90,000 posiciones secas y 15,000 posiciones a temperatura controlada a disposición de los clientes; cabe mencionar que la infraestructura logística incluye todos los activos fijos de la empresa. Además, el área cuenta con almacenes especializados por tipo de mercadería, un sistema de gestión de información integrado (WMS), almacenamiento de datos (RFID) y facturación.

Asimismo, como se mencionó anteriormente, la infraestructura logística de la empresa muestra presencia en las siguientes ciudades: Iquitos, Yurimaguas, Pucallpa, Mollendo, Ilo, Arequipa, Cajamarca, Pisco, Callao, Chimbote, Trujillo, Salaverry, Chiclayo y Paita.

El área con la que tiene mayor interacción es con el Comercial, ya sea para brindar la cotización de un servicio como para dar solución al cliente en temas puntuales. Además, tiene interacción con el área de TI para la configuración de sistemas, mantenimiento de software y antenas, entre otras actividades.

Por último, es importante mencionar que la presente área aún cuenta con operaciones manuales y que requieren de un gran número de personas asignado para cumplir con el servicio, escenario en el que muchas veces se tiene deficiencias (ver Anexo 11); sin embargo, con la apropiada implementación de tecnología avanzada, se puede reducir o eliminar el personal ocioso en algunas cuentas o utilizarlos en otros almacenes; del mismo modo, se puede reducir o eliminar procesos que no generen valor a la empresa. 


\section{Distribución y Transporte}

El área de Operaciones cuenta con las siguientes variables: experiencia, disponibilidad y, gracias a la infraestructura logística de la empresa, cobertura a nivel nacional; variables que, juntas, permiten alcanzar entregas de mercancía a tiempo, bajo estándares de seguridad y protección. Además, se tiene una flota de camiones en excelentes condiciones y con sistemas de seguridad y trazabilidad en el viaje (Office Truck).

El área con la que tiene mayor interacción es con el área Comercial, ya sea para brindar la cotización de un servicio como para dar solución al cliente en temas puntuales. Además, tiene interacción con el área de TI para la configuración y mantenimiento de sistemas, y con el área de Seguridad para controlar el ingreso y salida de las unidades.

\section{Depósito Temporal}

El área de Operaciones ofrece el servicio de descarga y embarque de carga suelta y carga rodante de contenedores exclusivos, y consolidados por DP World y APM Terminals en Callao y TPE en Paita, operando con toda la infraestructura de un almacén para recibir toda la mercadería directamente al arribo de las naves.

El área con la que tiene mayor interacción es con el área Comercial, ya sea para brindar la cotización de un servicio como para dar solución al cliente en temas puntuales. Además, tiene interacción con el área de TI para la configuración y mantenimiento de los sistemas.

\section{Servicio de Valor Agregado}

El área de Operaciones ofrece el servicio de valor agregado como solución para toda la cadena de suministro. Además, la calidad del servicio involucra contar con la infraestructura 
conveniente, tener personal capacitado en el manejo y transformación de mercadería, y la recuperación y re-empaque de productos de acuerdo al acuerdo de nivel de servicio.

El área con la que tiene mayor interacción es con el área Comercial, ya sea para brindar la cotización de un servicio como para dar solución al cliente en temas puntuales. Además, tiene interacción con el área de Servicios para el abastecimiento de materiales y herramientas.

Por otro lado, en el Anexo 12, se detalla un problema reiterativo en la organización que es el no contar con información fehaciente para la toma de decisiones; problema que tiene su origen en la diferencia de los gastos realizados mensualmente por las operaciones y lo registrado en los estados de resultados, problema que genera malas cargas en las partidas y, en efecto, genera partes de transferencia para regularizar lo mencionado.

Por último, como se observa en el Anexo 14, el hecho de contar con operaciones manuales conlleva a tener una alta estructura de costos operativos, ya sea de costos variables (costo de materiales) o costos fijos directos (gastos de personal).

\section{b. Actividades de Apoyo}

\section{Sistemas y TI}

Ransa cuenta con un sistema WMS, el cual permite controlar las operaciones de almacén y procesar las operaciones de recepción, ubicación, picking y despacho dentro de este mismo; además, permite acceder a información en tiempo real sobre las operaciones.

Existe una gran diferencia entre un WMS y un ERP, y Ransa se encarga de realizar esta comparación en sus presentaciones para nuevos clientes. La diferencia radica en lo siguiente: primero, un WMS está netamente enfocado en la gestión de almacenes, orientado hacia la 
optimización de procesos; y, segundo, ésta trabaja de la mano con un ERP, y brinda información a detalle de los productos, permitiendo mejorar el control de las operaciones.

Además, la empresa cuenta con sistemas de información propios integrados a sus clientes y el área de TI es la encargada de brindar soporte a las operaciones respecto a la integración, configuración y caídas del sistema.

El área con la que tiene mayor interacción es con el área de Operaciones, ya sea para dar solución a inconvenientes de los sistemas o usuarios actuales, así como para habilitar los centros de distribución para el ingreso de nuevos clientes respecto a conexión y cobertura, e implementación de los sistemas.

Sin embargo, existe un problema presente en la organización, el cual reside en la falta de integración de las operaciones con las áreas de apoyo (ver Anexo 13); problema identificado por los jefes de Operación (ver Anexo 09) que señalan que los tiempos de respuesta del área son bastante altos. En consecuencia, como muchas de las actividades dependen del soporte de TI para continuar con el flujo, se generan retrasos y reclamos por parte de los clientes.

\section{Recursos Humanos}

El área brinda soporte a las operaciones, a través de la evaluación y selección del personal idóneo, con experiencia y conocimiento del sector, considerando el presupuesto de la organización. Además, realiza la organización y planificación de capacitaciones y demás actividades dirigidas al personal.

En el 2018, los resultados de una encuesta de clima laboral, realizada a 600 colaboradores de Lima y Provincias, arrojaron un 82\% de aceptación (ver Anexo 15). Es así como los colaboradores que se muestran en desacuerdo consideran lo siguiente: no reciben información 
importante y oportuna sobre la empresa, no tienen libertad para expresar sus opiniones y que su superior inmediato no comunica claramente lo que espera de su trabajo.

Asimismo, el 18\% que no acepta el clima laboral considera lo siguiente: primero, la falta de interés por parte de la empresa en equilibrar la vida laboral y personal de sus colaboradores; segundo, la remuneración por debajo del mercado en puestos similares y no acorde al trabajo realizado; y, tercero, los insuficientes beneficios otorgados por la empresa.

Por otro lado, en una entrevista realizada a gerentes y jefes (ver Anexo 09), se establece que los tiempos de reclutamiento del personal es casi de dos meses, lo que retrasa la curva de aprendizaje y genera mayor carga laboral en los demás colaboradores, ocasionando que realicen horas extra para cumplir con los servicios. Escenario que puede o no estar relacionado a los resultados de la encuesta de clima laboral.

\section{Finanzas}

El área brinda soporte a las operaciones, a través de la administración, planificación y control de ejecución presupuestal. Además, son los encargados de enviar los resultados financieros de manera mensual a todas las gerencias, jefaturas y supervisores de operaciones.

De acuerdo con las entrevistas realizadas (ver Anexo 09), se menciona que los tiempos de envío de información deberían mejorar, ya que muchas veces los resultados se reciben con muy poco tiempo de anticipación de cara al Comité.

\section{Innovación y Consultoría}

El área brinda soporte a las operaciones, generando un valor agregado para los servicios actuales y generando ventajas competitivas. Además, lideran las implementaciones de los nuevos clientes y desarrollan iniciativas, mejoras y proyectos enfocados en la mejora continua. 
Innovación y consultoría se encuentra al pendiente de las nuevas tendencias del sector y comportamiento del mercado nacional; y gracias al respaldo de un Grupo económico que opera en diferentes sectores como lo es el Grupo Romero, Ransa Comercial cuenta con la capacidad para desarrollar proyectos innovadores en distintos sectores del mercado nacional.

\section{Calidad y Seguridad}

El área brinda soporte a las operaciones a través de un sistema integrado de gestión basado en estándares internacionales, cuyo sistema cubre los conceptos de calidad, seguridad, salud ocupacional y medio ambiente, cumpliendo con la legislación vigente y otros requisitos a los que la organización se ha suscrito voluntariamente y que tienen como objetivo fundamental la mejora continua de los procesos.

Ransa cuenta con una central de monitoreo y vigilancia CCTV. Adicionalmente, se tiene el "Premio Anual a la Excelencia en seguridad" brindado por la empresa Mapfre y promueven la campaña "Piensa, Vive y Actúa Seguro" entre los colaboradores. Además, cuenta con las certificaciones de ISO 9001, ISO 1400, OHSAS 18001, OEA y certificación de la DGAC.

El área con la que tienen mayor interacción es con Operaciones y, en las entrevistas realizadas a expertos de Operación (Ver anexo 09), se menciona la necesidad de que el área de Calidad se involucre mucho más en las implementaciones de nuevos clientes, debido a la importancia de los tiempos que toman los licenciamientos y las certificaciones.

\section{Servicios}

El área brinda soporte a las operaciones, a través del suministro de materiales, gestión de compras con proveedores y mantenimiento de la infraestructura. 
De acuerdo con las entrevistas realizadas (Ver anexo 09), es necesario mejorar los tiempos de respuesta, tiempos de entrega y actualizar la base de proveedores, ya que se ha presentado desabastecimiento de algunos materiales afectando la operación y la satisfacción al cliente, generando reclamos de su parte.

\subsection{Indicadores de cada una de las actividades de la cadena de valor}

En la Tabla 23, se presenta los indicadores establecidos para las actividades primarias de la cadena de valor, los cuales permiten realizar mediciones de eficiencia y eficacia en los procesos core del negocio.

De acuerdo con la Tabla 23, se observa que el proceso de gestión de Operaciones tiene distintos indicadores que no alcanzan las metas planteadas en el periodo evaluado, pero se encuentran muy cerca de éstas, es así como este proceso puede considerarse una fortaleza potencial de la empresa; mientras que el proceso de gestión Comercial no define metas sobre sus indicadores, por lo que este proceso puede considerarse una debilidad potencial de la empresa 
Tabla 23

Indicadores de actividades primarias

\begin{tabular}{|c|c|c|c|c|c|}
\hline Proceso & Indicador & Objetivo & Meta & $\begin{array}{l}\text { Frecuencia } \\
\text { de medición }\end{array}$ & 2018 \\
\hline \multirow{6}{*}{ Operaciones } & Exactitud de Inventario & $\begin{array}{l}\text { Medir la exactitud de los inventarios } \\
\text { físicos vs. los indicados en el sistema }\end{array}$ & $100 \%$ & Mensual & $97.84 \%$ \\
\hline & Productividad & $\begin{array}{l}\text { Medir la eficiencia de la operación } \\
\text { (Unidad de medida/h-h) }\end{array}$ & & Mensual & 261 \\
\hline & Fill Rate & $\begin{array}{l}\text { Medir el cumplimiento de las } \\
\text { entregas vs pedidos el cliente }\end{array}$ & $100 \%$ & Mensual & $100 \%$ \\
\hline & Incidencias & $\begin{array}{l}\text { Medir la cantidad de incidencias en el } \\
\text { servicio }\end{array}$ & 0 incidencias & Mensual & 5 \\
\hline & Merma & Medir el porcentaje de desperdicio & $0 \%$ & Mensual & $5 \%$ \\
\hline & On time delivery & $\begin{array}{c}\text { Medir el porcentaje de entrega a } \\
\text { tiempo }\end{array}$ & $99.5 \%$ & Mensual & $83.9 \%$ \\
\hline \multirow{3}{*}{ Comercial } & Esfuerzo Comercial & $\begin{array}{l}\text { Medir las ventas ganadas entre el } \\
\text { total (Abierto + Perdido + Ganado) }\end{array}$ & & Mensual & $10 \%$ \\
\hline & Win Rate & $\begin{array}{l}\text { Medir las ventas ganadas entre el } \\
\text { total (Perdido + Ganado) }\end{array}$ & & Mensual & $13 \%$ \\
\hline & Satisfacción del cliente & $\begin{array}{l}\text { Medir la satisfacción del cliente } \\
\text { respecto a los servicios }\end{array}$ & $90 \%$ & Anual & $71.79 \%$ \\
\hline
\end{tabular}

Nota. Adaptado de "Reporte de Control Presupuestal Ventas - Perú Logístico," por Control de Gestión, 2018. Recuperado de la Vicepresidencia de Finanzas.

Por otro lado, la Tabla 24 presenta el detalle de los indicadores establecidos en cada actividad de apoyo perteneciente a la cadena de valor, los cuales permiten controlar el desempeño de los procesos e identificar oportunidades de mejora.

Los procesos que alcanzaron y superaron la mayoría de las metas en el periodo evaluado son: gestión de Calidad y Seguridad, gestión de Innovación y Consultoría, y gestión de Sistemas y TI, procesos que pueden ser considerados como fortalezas potenciales de la empresa; mientras que los procesos que no alcanzaron las metas establecidas son: gestión de Recursos Humanos y gestión de Finanzas, procesos que pueden ser considerados como debilidades potenciales de la empresa (ver Tabla 24). 


\section{Tabla 24}

Indicadores de actividades de apoyo

\begin{tabular}{|c|c|c|c|c|c|}
\hline Proceso & Indicador & Objetivo & Meta & $\begin{array}{l}\text { Frecuencia } \\
\text { de medición }\end{array}$ & 2018 \\
\hline $\begin{array}{l}\text { Gestión de } \\
\text { Sistemas y TI }\end{array}$ & $\begin{array}{l}\mathrm{N}^{\circ} \text { de mantenimientos } \\
\text { preventivos realizados }\end{array}$ & $\begin{array}{l}\text { Medir el cumplimiento del plan } \\
\text { preventivo de mantenimiento del } \\
\text { servidor }\end{array}$ & 2 al año & Semestral & 2 \\
\hline \multirow{6}{*}{$\begin{array}{l}\text { Gestión de } \\
\text { Recursos } \\
\text { Humanos }\end{array}$} & Rotación de personal & $\begin{array}{l}\text { Medir la proporción de personal que } \\
\text { sale de la organización }\end{array}$ & $<=5 \%$ & Mensual & $3.14 \%$ \\
\hline & Vacaciones & $\begin{array}{l}\text { Medir el cumplimiento del plan de } \\
\text { vacaciones }\end{array}$ & $\begin{array}{c}<=30 \text { días } \\
(100 \%)\end{array}$ & Mensual & $\begin{array}{c}<=30 \text { días ( } 84 \%) \\
\text { entre } 30 \text { y } 45 \text { días (15\%) } \\
>45 \text { días ( } 1 \%)\end{array}$ \\
\hline & Horas Extra & $\begin{array}{l}\text { Medir las horas de sobretiempo del } \\
\text { personal }\end{array}$ & $\begin{array}{l}\text { Horas al } 25 \% \\
(90 \%)\end{array}$ & Mensual & $\begin{array}{l}\text { Horas } 25 \%(44 \%) \\
\text { Horas } 35 \%(21 \%) \\
\text { Horas } 100 \%(34 \%)\end{array}$ \\
\hline & Absentismo & $\begin{array}{l}\text { Medir la ausencia o abandono del } \\
\text { puesto de trabajo }\end{array}$ & $<=3 \%$ & Mensual & $4.97 \%$ \\
\hline & Tasa de sindicalización & $\begin{array}{l}\text { Medir el porcentaje de personal } \\
\text { sindicalizado }\end{array}$ & $<=10 \%$ & Mensual & $39.61 \%$ \\
\hline & Clima Laboral & $\begin{array}{c}\text { Medir el nivel de satisfacción del } \\
\text { personal }\end{array}$ & $90 \%$ & Anual & $82.00 \%$ \\
\hline $\begin{array}{l}\text { Gestión de } \\
\text { Finanzas }\end{array}$ & $\begin{array}{l}\text { Porcentaje de } \\
\text { cumplimiento de ejecución } \\
\text { de presupuesto }\end{array}$ & $\begin{array}{l}\text { Controlar la ejecución de gastos vs } \\
\text { plan }\end{array}$ & $<=100 \%$ & Mensual & $112 \%$ \\
\hline \multirow{3}{*}{$\begin{array}{l}\text { Gestión de } \\
\text { Innovación y } \\
\text { consultoría }\end{array}$} & $N^{\circ}$ de Servicios Mejorados & $\begin{array}{l}\text { Medir la cantidad de servicios } \\
\text { mejorados }\end{array}$ & 1 servicio al año & Anual & 1 \\
\hline & $\begin{array}{l}N^{\circ} \text { de Nuevos Servicios } \\
\text { Generados }\end{array}$ & $\begin{array}{l}\text { Medir la cantidad de nuevos } \\
\text { servicios mejorados }\end{array}$ & 1 servicio al año & Anual & 0 \\
\hline & $\begin{array}{c}N^{\circ} \text { de implementaciones } \\
\text { ejecutadas }\end{array}$ & $\begin{array}{c}\text { Medir la cantidad de } \\
\text { implementaciones de clientes }\end{array}$ & $\begin{array}{l}2 \text { servicios al } \\
\text { año }\end{array}$ & Semestral & 2 \\
\hline \multirow{4}{*}{$\begin{array}{l}\text { Gestión de } \\
\text { Calidad y } \\
\text { Seguridad }\end{array}$} & Accidentabilidad & Medir la cantidad de accidentes & 0 & Mensual & 0.86 \\
\hline & \multirow{3}{*}{ BPA } & \multirow{3}{*}{$\begin{array}{l}\text { Medir las Buenas Prácticas del } \\
\text { Almacén }\end{array}$} & \multirow{3}{*}{$92 \%$} & $C M \& R$ & $93.75 \%$ \\
\hline & & & & Droguería & $98 \%$ \\
\hline & & & & Perecederos & $96.90 \%$ \\
\hline
\end{tabular}

Nota. Adaptado de "Reporte de Control Presupuestal Ventas - Perú Logístico," por Control de Gestión, 2018. Recuperado de la Vicepresidencia de Finanzas. 


\subsection{Benchmarking y comparación con los líderes de la industria de cada una de las actividades de la cadena de valor}

El mercado de operadores logísticos es una industria amplia y competitiva, debido a los distintos factores de especialización que demanda la variedad de productos atendidos y exigida por las diferentes necesidades de cada cliente, los cuales buscan mejorar la gestión y generación de eficiencia de sus operaciones logísticas.

Por otro lado, empresas de distintas industrias se encuentran en continuo crecimiento, expandiendo su alcance geográfico dentro del territorio nacional; por lo que Ransa y otros operadores logísticos 3PL al ser socios estratégicos de algunas de estas empresas proliferantes, se encuentran comprometidos a respaldar y acompañar dicho crecimiento, formando parte de la experiencia y, sobre todo, proyectándose a potenciales clientes.

Sin embargo, estos operadores logísticos deben estar preparados para sumar valor lo más rápido posible a cada decisión realizada por sus clientes que involucren sus operaciones logísticas; por ello, es apropiado que estos operadores logísticos, por el número de operaciones gestionadas, cuenten con actividades de apoyo ampliamente desarrolladas dentro de toda su estructura organizacional.

Por último, la Tabla 25 presenta un análisis comparativo de las actividades de la cadena de valor, donde se recopila y analizan datos de Ransa y empresas similares que lideran la industria. El análisis permite identificar prácticas superiores que puedan ser adoptadas e implementadas dentro de Ransa, además de identificar brechas entre estas empresas 3PL, lo que permitirá plantear e implementar acciones necesarias y aplicables. 
Tabla 25

Benchmarking de la cadena de valor con los líderes del mercado

\begin{tabular}{|c|c|c|c|c|}
\hline \multirow{2}{*}{\multicolumn{2}{|c|}{\begin{tabular}{|c} 
Actividad \\
Depósito temporal
\end{tabular}}} & Ransa & Neptunia & Dinet \\
\hline & & Callao & Callao & Callao \\
\hline \multirow{36}{*}{ 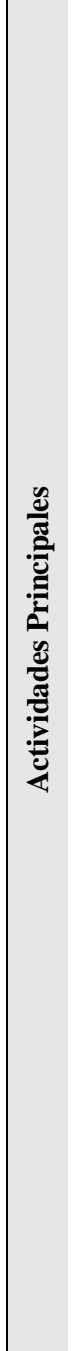 } & \multirow{12}{*}{ Transporte } & Arequipa & Arequipa & Arequipa \\
\hline & & Callao & Callao & Callao \\
\hline & & Chiclayo & & Chiclayo \\
\hline & & Chimbote & & \\
\hline & & & & \\
\hline & & Iquitos & & \\
\hline & & Lima & & Lima \\
\hline & & Paita & Paita & \\
\hline & & Pisco & & \\
\hline & & Pucallpa & Pucallpa & \\
\hline & & Trujillo & Trujillo & \\
\hline & & Yurimaguas & & \\
\hline & \multirow{10}{*}{ Almacenaje } & Arequipa & Arequipa & Arequipa \\
\hline & & Callao & Callao & Callao \\
\hline & & Chiclayo & & Chiclayo \\
\hline & & Chimbote & & \\
\hline & & Ilo & & \\
\hline & & Lima & & Lima \\
\hline & & Paita & Paita & \\
\hline & & Pisco & & \\
\hline & & Pucallpa & Pucallpa & \\
\hline & & Trujillo & Trujillo & \\
\hline & \multirow{3}{*}{$\begin{array}{l}\text { Servicio de valor } \\
\text { agregado }\end{array}$} & Callao & Callao & Callao \\
\hline & & Lima & & \\
\hline & & Paita & & \\
\hline & \multirow{11}{*}{ Distribución } & Arequipa & Arequipa & Arequipa \\
\hline & & Callao & Callao & Callao \\
\hline & & Chiclayo & & Chiclayo \\
\hline & & Chimbote & & \\
\hline & & & & \\
\hline & & Iquitos & & \\
\hline & & Lima & & Lima \\
\hline & & Paita & Paita & \\
\hline & & Pisco & & \\
\hline & & Pucallpa & Pucallpa & \\
\hline & & Trujillo & Trujillo & \\
\hline \multirow{7}{*}{ 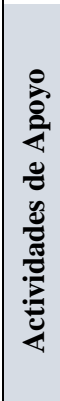 } & Gestión de sistemas y TI & Gerencia & Gerencia & Área esnecializada \\
\hline & Gectión de PPHH & Área esnecializada & Área esnecializado & Área esnecializada \\
\hline & Gestión de RRHH & Area espectantzada & Area espectantzada & Alea espectanzada \\
\hline & Gestión de finanzas & Gerencia & $\begin{array}{l}\text { Área integrada a la } \\
\text { administración }\end{array}$ & $\begin{array}{l}\text { Área integrada a la } \\
\text { administración }\end{array}$ \\
\hline & $\begin{array}{l}\text { Gestión de innovación y } \\
\text { consultoría }\end{array}$ & Área especializada & Área especializada & $\begin{array}{l}\text { Área integrada a la } \\
\text { administración }\end{array}$ \\
\hline & $\begin{array}{l}\text { Gestión de calidad y } \\
\text { seguridad }\end{array}$ & Gerencia & $\begin{array}{l}\text { Área integrada a la } \\
\text { administración }\end{array}$ & $\begin{array}{l}\text { Área integrada a la } \\
\text { administración }\end{array}$ \\
\hline & Gestión de Servicios & Gerencia & Gerencia & Gerencia \\
\hline
\end{tabular}

Nota. Adaptado de El proceso estratégico: Un enfoque de gerencia (p. 252), por F. D’Alessio, 2008, México D.F.: Pearson Educación. 
De acuerdo con lo mostrado en la Tabla 25, se hace evidente que Ransa es el operador logístico 3PL con mayor alcance geográfico sobre el territorio nacional, lo que le suma ventaja al negociar con empresas que se encuentren dentro de estas regiones o aledañas. Además, se observa que dispone de actividades de apoyo mayor desarrolladas frente a su competencia, lo que le permite alcanzar un mejor rendimiento en sus operaciones principales.

\subsection{Determinar las competencias de la empresa}

Ransa ofrece el proceso más completo de soluciones integrales logísticas en muchos departamentos del país, ofreciendo soluciones integrales a los procesos de sus clientes.

La Tabla 26 muestra los recursos y capacidades que Ransa ha ido ganando, mejorando y perfeccionando con el transcurso de los años.

\section{Tabla 26}

Identificación de recursos y capacidades

\begin{tabular}{|l|l|l|l}
\hline \multicolumn{4}{c}{ Recursos y Capacidades } \\
\hline Financieros & Organizativos & Humanos & Físicos \\
\hline Autofinanciamiento & $\begin{array}{l}\text { Marca y } \\
\text { reputación }\end{array}$ & $\begin{array}{l}\text { Personal } \\
\text { capacitado y } \\
\text { con } \\
\text { experiencia }\end{array}$ & $\begin{array}{l}\text { Materiales de } \\
\text { oficina }\end{array}$ \\
& $\begin{array}{l}\text { Cartera de } \\
\text { clientes de } \\
\text { diferentes } \\
\text { sectores } \\
\text { económicos }\end{array}$ & Innovación & $\begin{array}{l}\text { Infraestructura } \\
\text { propia y de } \\
\text { gran } \\
\text { envergadura }\end{array}$ \\
& $\begin{array}{l}\text { Sistema de } \\
\text { información } \\
\text { integrado a } \\
\text { sistemas de } \\
\text { clientes }\end{array}$ & $\begin{array}{l}\text { Cultura } \\
\text { Modo C }\end{array}$ & $\begin{array}{l}\text { Ubicación } \\
\text { estratégica }\end{array}$ \\
& & Calidad del & \\
& & servicio &
\end{tabular}




\begin{tabular}{|l|l|l|}
\hline \multicolumn{1}{|c|}{ Organizativos } & \multicolumn{1}{c|}{ Humanos } & \multicolumn{1}{c|}{ Físicos } \\
\hline Experiencia en la Industria & $\begin{array}{l}\text { Capacidad de desarrollar proyectos } \\
\text { innovadores }\end{array}$ & Infraestructura logística \\
$\begin{array}{l}\text { Cobertura a nivel nacional de las } \\
\text { operaciones logísticas }\end{array}$ & $\begin{array}{l}\text { Manejo de alto estándares de seguridad } \\
\text { en las operaciones logísticas }\end{array}$ \\
$\begin{array}{l}\text { Sistema de información integrado } \\
\text { a sistemas de clientes }\end{array}$ & \\
\hline
\end{tabular}

Nota. Adaptado de El proceso estratégico: Un enfoque de gerencia (p. 395), por F. D’Alessio, 2008, México D.F.: Pearson Educación.

Además, la empresa ofrece un asesoramiento personalizado en el diseño de la operación

logística de los clientes de cada sector económico, dado los años operando en el mercado.

Además, ofrece un servicio integral y flexible a las necesidades de los clientes (ver Tabla 27).

Tabla 27

Competencias de la empresa

\begin{tabular}{|l|l|}
\hline Competencias & \multicolumn{1}{c|}{ Ransa Comercial } \\
\hline Experiencia & $\begin{array}{l}\text { Ransa es el operador logístico del Perú con } 80 \text { años en el mercado y con } \\
\text { más de } 7,000 \text { colaboradores altamente capacitados. De esta manera, la } \\
\text { experiencia y el conocimiento le permite desarrollar los servicios acorde } \\
\text { a las expectativas y requerimientos de los clientes de cada sector } \\
\text { económico. }\end{array}$ \\
& $\begin{array}{l}\text { Ransa, al ser un 3PL es proveedor de los servicios logísticos básicos, } \\
\text { manejo de infomación y alta cobertura. De esta manera, un cliente } \\
\text { encuentra en la organización a su centro de distribución, de valor }\end{array}$ \\
agregado y de comercialización de sus productos. Además, se cuenta con \\
líderes supply, quienes velan por la integración y gestión de la cadena, \\
dando solución inmediata a las necesidades del cliente y siendo su nexo \\
con el área comercial y de operaciones. \\
Uno de los pilares de la organización es el Modo cliente o Modo C, lo \\
que implica poner al centro de todo al cliente. De esta manera, dado el \\
dianmismo del mercado, el ofrecer un servicio que se adapte a las \\
necesidades cambiantes de los clientes, es crucial. Por esta razon, Ransa \\
presta atención a sus clientes y les brinda soluciones en todo momento.
\end{tabular}

Nota. Adaptado de "Almacenaje, distribución y transporte," por Ransa, s.f., Servicios Logísticos. Recuperado de goo.gl/ohGCim 
Así, las competencias listadas permiten a Ransa gestionar y mejorar continuamente los procesos logísticos y la calidad de éstos, aumentando el impacto de la implementación de soluciones sobre toda la cadena logística de los clientes. Ver Tabla 27.

\subsection{Identificación y determinación de las ventajas competitivas de la empresa}

Desde su creación al presente, Ransa ha incrementado su lista de servicios ofrecidos a lo largo del territorio peruano, llegando a posicionarse como una de las principales empresas de la industria logística en el país; sin embargo, para mantener dicha posición, Ransa ha debido convertir sus recursos comunes en competencias que le permitan aprovechar las oportunidades y enfrentar las amenazas del entorno externo.

Es por ello por lo que, en la Tabla 28, se identifican los recursos comunes que Ransa convirtió en competencias o fortalezas, y se evalúan por medio de la matriz VRIO (Valioso, Raro, Inimitable y Organizado) con la finalidad de determinar su participación estratégica que representan en la empresa.

Tabla 28

Matriz VRIO

\begin{tabular}{|c|c|c|c|c|c|}
\hline Recursos & Valioso & Raro & Inimitable & Organizado & $\begin{array}{c}\text { Implicación } \\
\text { estratégica }\end{array}$ \\
\hline Experiencia en la Industria & $\mathrm{Si}$ & $\mathrm{Si}$ & $\mathrm{Si}$ & $\mathrm{Si}$ & $\begin{array}{l}\text { Ventaja Competitiva } \\
\text { Sostenible }\end{array}$ \\
\hline $\begin{array}{l}\text { Cobertura a nivel nacional de } \\
\text { las operaciones logísticas }\end{array}$ & $\mathrm{Si}$ & $\mathrm{Si}$ & No & $\mathrm{Si}$ & $\begin{array}{l}\text { Ventaja competitiva por } \\
\text { explotar }\end{array}$ \\
\hline $\begin{array}{l}\text { Sistema de información } \\
\text { integrado a sistemas de } \\
\text { clientes }\end{array}$ & $\mathrm{Si}$ & $\mathrm{Si}$ & No & No & $\begin{array}{l}\text { Ventaja competitiva } \\
\text { temporal }\end{array}$ \\
\hline $\begin{array}{l}\text { Capacidad de desarrollar } \\
\text { proyectos innovadores }\end{array}$ & $\mathrm{Si}$ & $\mathrm{Si}$ & No & $\mathrm{Si}$ & $\begin{array}{l}\text { Ventaja competitiva por } \\
\text { explotar }\end{array}$ \\
\hline Infraestructura logística & $\mathrm{Si}$ & $\mathrm{Si}$ & No & $\mathrm{Si}$ & $\begin{array}{l}\text { Ventaja competitiva por } \\
\text { explotar }\end{array}$ \\
\hline $\begin{array}{l}\text { Manejo de alto estándares de } \\
\text { seguridad en las operaciones } \\
\text { logísticas }\end{array}$ & $\mathrm{Si}$ & $\mathrm{Si}$ & No & $\mathrm{Si}$ & $\begin{array}{l}\text { Ventaja competitiva por } \\
\text { explotar }\end{array}$ \\
\hline
\end{tabular}


Nota. Adaptado de The Management of Organizations: Strategy, Structure, Behavior. por J. B. Barney \& R. Griffin, 1992, Boston, Estados Unidos: Houghton Mifflin Co.

Las ventajas definidas en la tabla anterior se sustentan en lo siguiente:

- Experiencia en la Industria: Tal como se mencionó anteriormente, Ransa cuenta con 80 años de experiencia en la gestión de operaciones de abastecimiento e implementación de soluciones logísticas integrales.

- Cobertura a nivel nacional de las operaciones logísticas: Tal como muestra en la Tabla 25, la empresa tiene mayor alcance geográfico de sus servicios, en comparación a los otros dos operadores 3PL que lideran la industria en términos de ventas.

- Infraestructura logística: Ransa cuenta con amplios espacios de almacenaje y depósito, los cuales se encuentran distribuidos en distintos departamentos del Perú; además, cuenta con flotas de camiones en excelentes condiciones y con sistemas de seguridad y trazabilidad en el viaje (Office Truck).

- Sistema de información integrado a sistemas de clientes: La empresa cuenta con los sistemas integrados de información para la gestión en los almacenes (WMS), almacenamiento de datos (RFID) y facturación.

- Capacidad de desarrollar proyectos innovadores: Los avances tecnológicos y las nuevas industrias crecientes dieron a Ransa la oportunidad de innovar soluciones logísticas con una visión integral.

- Manejo de alto estándares de seguridad en las operaciones logísticas: Cuenta con las certificaciones de ISO 9001, ISO 14001, OHSAS 18001 y BASC, que garantizan la seguridad y la calidad de las operaciones.

\subsection{Matriz de evaluación de los factores internos (EFI)}


La elaboración de la Matriz EFI (ver Tabla 29) se obtiene del promedio de las matrices del Anexo 16, alcanzando un peso ponderado en sus fortalezas y debilidades de 2.53 y 0.42 respectivamente, ponderados que indican que Ransa ha desarrollado más fortalezas que debilidades; además, el resultado ponderado final de la matriz asciende a 2.95, resultado que posiciona la estrategia general interna de Ransa por encima de la media, lo que significa que la empresa aprovecha apropiadamente sus fortalezas y soluciona o disminuye sus debilidades; sin embargo, la presencia de debilidades indica la necesidad de ajustar los procesos existentes, lo que permitirá establecer oportunidades de mejora interna, logrando atender de mejor manera las necesidades de los clientes.

Tabla 29

Matriz EFI - Ransa

\section{MATRIZ EFI}

\section{Factores internos clave}

Peso Calificación Ponderado

\section{Fortalezas}

1. Infraestructura logística

2. Experiencia en la industria

3. Cobertura a nivel nacional de las operaciones logísticas

4. Manejo de alto estándares de seguridad en las operaciones logísticas

5. Sistemas de información propios integrados al sistema de los clientes

6. Capacidad para desarrollar proyectos innovadores

Subtotal

\section{Debilidades}

1. Relaciones contractuales débiles

2. Deficiente asignación de recursos humanos en la gestión de almacenes

3. Información no fehaciente para la toma de decisiones

4. Falta de integración de las áreas de apoyo

5. Alta estructura de costos operativos

Subtotal
0.16

0.11

0.12

0.12

0.10

0.10

$0.10 \quad 3.0$

4.0

3.5

3.8

4.0

3.0

3.0

0.30

$\begin{array}{ll}3.0 & 0.30 \\ 2.53\end{array}$

0.62

0.38

0.45

0.48

0.30

0.06

2.0

0.12

0.05

1.3

0.07

$0.05 \quad 1.0$

0.05

0.07

0.12

0.07

1.8

0.07

0.42

\section{Total}

1.00

2.95

Nota. Adaptado de El proceso estratégico: Un enfoque de gerencia (p. 185), por F. D’Alessio, 2008, México D.F.: Pearson Educación. 


\section{Formulación de los objetivos y diseño de las estrategias}

Siguiendo el marco analítico para la formulación estratégica, en los capítulos previos se ha desarrollado la primera etapa conocida como la Etapa de insumos, obtenida de las matrices EFE, EFI y MPC, cuya información contenida sirve de insumo para la segunda etapa conocida como la Etapa del emparejamiento o del proceso estratégico, generada por el modelo de Océano Azul y las matrices FODA, PEYEA, BCG, IE y GE, cuya información compuesta de variables internas y externas es lo esencial para el diseño de las estrategias.

\subsection{Alcance y planeamiento de los objetivos estratégicos}

El alcance de los objetivos estratégicos propuestos para la empresa Ransa Comercial es definir las estrategias óptimas que mejoren el proceso de crecimiento y en consecuencia aumenten significativamente los ingresos.

\subsubsection{Objetivos estratégicos.}

Los objetivos estratégicos permiten definir una dirección para determinar el plan de acción de una empresa a largo plazo y se establecen metas específicas. De esta manera, se requiere evaluar el entorno mediante un análisis externo de identificación del grado de atractividad del negocio. Además, se requiere de un análisis interno que logre identificar la posición competitiva de la empresa.

Asimismo, los objetivos estratégicos con expresados en términos de crecimiento, a fin de determinar una meta de negocio en un periodo determinado, de rentabilidad, a fin de establecer un retorno sobre el capital invertido y de supervivencia, a fin de establecer el propósito de la empresa de continuar operando. 
A continuación, se realiza el planeamiento de los objetivos estratégicos.

- Objetivo estratégico 1. Incrementar el ingreso de la empresa como mínimo $6 \%$ cada año en el periodo $2020-2022$.

- Objetivo estratégico 2. Reducir los costos operativos de la empresa como mínimo en $6 \%$ en el periodo $2019-2022$.

- Objetivo estratégico 3. Desarrollar una cultura de enfoque al cliente en el periodo $2019-2022$.

\subsubsection{Análisis de los objetivos estratégicos.}

- Objetivo $\mathbf{N}^{\circ}$ 1: Incrementar el ingreso de la empresa como mínimo $6 \%$ cada año en el periodo $2020-2022$.

Para establecer el incremento de $6 \%$ en las ventas, se considera la tendencia positiva que muestra la industria en los últimos diez años, alcanzando un crecimiento promedio de 6,09\% (ver Figura 03 y 06). A ello, se agrega otras consideraciones, planteando dos escenarios para la proyección de las ventas de la empresa:

En el escenario optimista, luego de implementar las estrategias apropiadas, se evitará que el $6.84 \%$ de los clientes de Ransa, que sienten que la empresa a desmejorado (ver Anexo 06), abandonen la cartera de clientes al término de sus contratos o disminuyan sus volúmenes contratados; además, se recuperarán los contratos o volúmenes perdidos que afectaron la caída de las ventas, cifra que asciende a 1\% en el periodo 2017 (ver Figura 03). 
En el escenario conservador, luego de implementar las estrategias apropiadas, se evitará que el $6.84 \%$ de los clientes de Ransa, que sienten que la empresa a desmejorado (ver Anexo 06), abandonen la cartera de clientes al término de sus contratos o disminuyan sus volúmenes contratados; sin embargo, no se espera recuperar los contratos o volúmenes perdidos que afectaron la caída de las ventas, cifra que asciende a 1\% en el periodo 2017 (ver Figura 03), ya que éstos pueden estar comprometidos en nuevos contratos por un largo periodo.

Es así como, al ser el escenario conservador el más factible, se plantea el incremento de las ventas en un $6 \%$.

- Objetivo estratégico 2. Reducir los costos operativos de la empresa como mínimo en $6 \%$ en el periodo $2019-2022$.

Para establecer la reducción de los costos, se considera el exceso del 6\% de los sueldos y salarios (ver Anexo 14), exceso que representa el 4\% del total de los costos reales y resulta de la ineficiente gestión y asignación de recursos. A ello, se agrega otras consideraciones, planteando dos escenarios para la proyección de las ventas de la empresa:

En el escenario optimista, luego de implementar las estrategias apropiadas, se reducirán los costos operativos en un 9\%; cifra que, además del concepto de sueldos y salarios, considera el resto de los costos reales vs lo presupuestado en el periodo 2018, diferencia que excede en 5\% lo presupuestado (ver Anexo 14). 
En el escenario conservador, luego de implementar las estrategias apropiadas, se reducirán los costos operativos en un 6\%; cifra que, además del concepto de sueldos y salarios, considera conceptos en específico, tales como: gastos relacionados con el personal, servicios complementarios al personal, alquiler de inmuebles, transporte y fletes, gasto de vehículos, servicios de almacenaje, servicios de estiba y desestiba, servicios de montacarga, servicios de manipuleo y servicios de balanza. La diferencia de estos conceptos excede en $2 \%$ lo presupuestado en el periodo 2018 (ver Anexo 14).

Es así como, al ser el escenario conservador el más factible, se plantea la reducción de los costos operativos en un $6 \%$.

- Objetivo estratégico 3. Desarrollar una cultura de enfoque al cliente en el periodo $2019-2022$.

El enfoque de cliente se define como la cualidad de satisfacer profunda y permanentemente las preferencias y necesidades de los clientes; y, para ello, se requiere del abasto suficiente y oportuno de los mejores bienes y servicios, alcanzados por un centro de atención amable y ordenado (Salinas, 2008).

Además, la fortaleza financiera y operativa de una empresa está estrechamente relacionada con la satisfacción de sus clientes, quienes pueden decidir regresar, recomprar y recomendar la empresa (Salinas, 2008).

Sin embargo, los resultados del Anexo 06 señalan que un $6.8 \%$ de clientes no recomendarían a la empresa y que, además, sienten que ésta ha desmejorado sus 
servicios; también señala que un $14.53 \%$ es indiferente frente a recomendar a la empresa y que un $28.21 \%$ considera que Ransa no ha mejorado en los últimos años; situación que puede ocasionar lo siguientes escenarios: que no renueven sus contratos o que disminuyan los espacios contratados; escenarios que al final tendrían un impacto negativo sobre los ingresos.

Por ello, la empresa debe desarrollar una cultura de enfoque al cliente en el periodo 2019 - 2022, implementando iniciativas que incrementen la diferenciación y la percepción sobre éstas, cubriendo en el proceso las necesidades toda la cartera de clientes.

Como indicador de medición sobre el personal, se realizará seguimiento continuo a los colaboradores capacitados debidamente identificados (\% de personal capacitado). En complemento, como indicador de medición sobre los clientes, se utilizará el indicador NPS, el cual permite medir la lealtad de éstos. En este sentido, Ransa entrevista a los líderes de las cuentas donde indican su percepción respecto a los servicios, entrevista que consultará a los mismos si considera que el personal operativo y comercial se encuentran adaptados a sus necesidades, información que permitirá medir el avance de la cultura de enfoque al cliente, identificando a los colaboradores que se adapten con el objetivo.

\subsection{Diseño y formulación de estrategias}

La formulación de estrategias consiste en plantear respuestas a distintas incógnitas de cómo la empresa va a competir en la industria o cómo va a atraer y retener clientes, con el fin de alcanzar la visión de la empresa (Maldonado, 2014). 


\subsubsection{Modelo del océano azul}

El modelo del océano azul se ha convertido en un desafío para las compañías, quienes deben abandonar el océano rojo de la competencia y enfocarse en la creación de espacios seguros en el mercado, espacios donde la competencia no tenga relevancia. En vez de dividirse la demanda existente y compararse frecuentemente con la industria, el modelo del océano azul propone desarrollar el tamaño de la demanda y olvidarse de la competencia (Chan \& Mauborgne, 2005).

Sin embargo, considerando lo mencionado en los capítulos anteriores, la industria de operadores logísticos se encuentra en crecimiento como consecuencia de un incremento en la demanda de bienes y servicios en diferentes industrias, lo que ha generado el ingreso de nuevos operadores logísticos 1PL y 2PL, colocando a la industria dentro del concepto de océano rojo. Por ello, de acuerdo con la teoría de océanos rojos, la empresa debe enfocar sus recursos en desarrollar estrategias de diferenciación o de reducción de costos (Chan \& Mauborgne, 2012).

Cabe mencionar que las estrategias competitivas genéricas de Porter son: de liderazgo global en costos, de diferenciación y de enfoque o concentración (Porter, 1991); las mismas que se alinean a las estrategias propuestas por Chan \& Mauborgne en el escenario del océano rojo.

\subsubsection{Lienzo de la estrategia actual de la empresa}

El lienzo estratégico de Ransa está conformado por las siguientes variables: (a) servicio logístico integrado, (b) infraestructura propia, (c) infraestructura especializada, (d) actividades económicas atendidas, (e) cobertura del servicio, (f) relaciones contractuales, (g) procesos manuales, (h) tecnología avanzada, y (i) personal con experiencia/certificado. 
En la Figura 10, elaborada a partir del Anexo 17, se observa las variables identificadas, las cuales están valoradas en una escala del 0 al 10, donde 0 es nulo, 1 muy malo y 10 muy bueno.

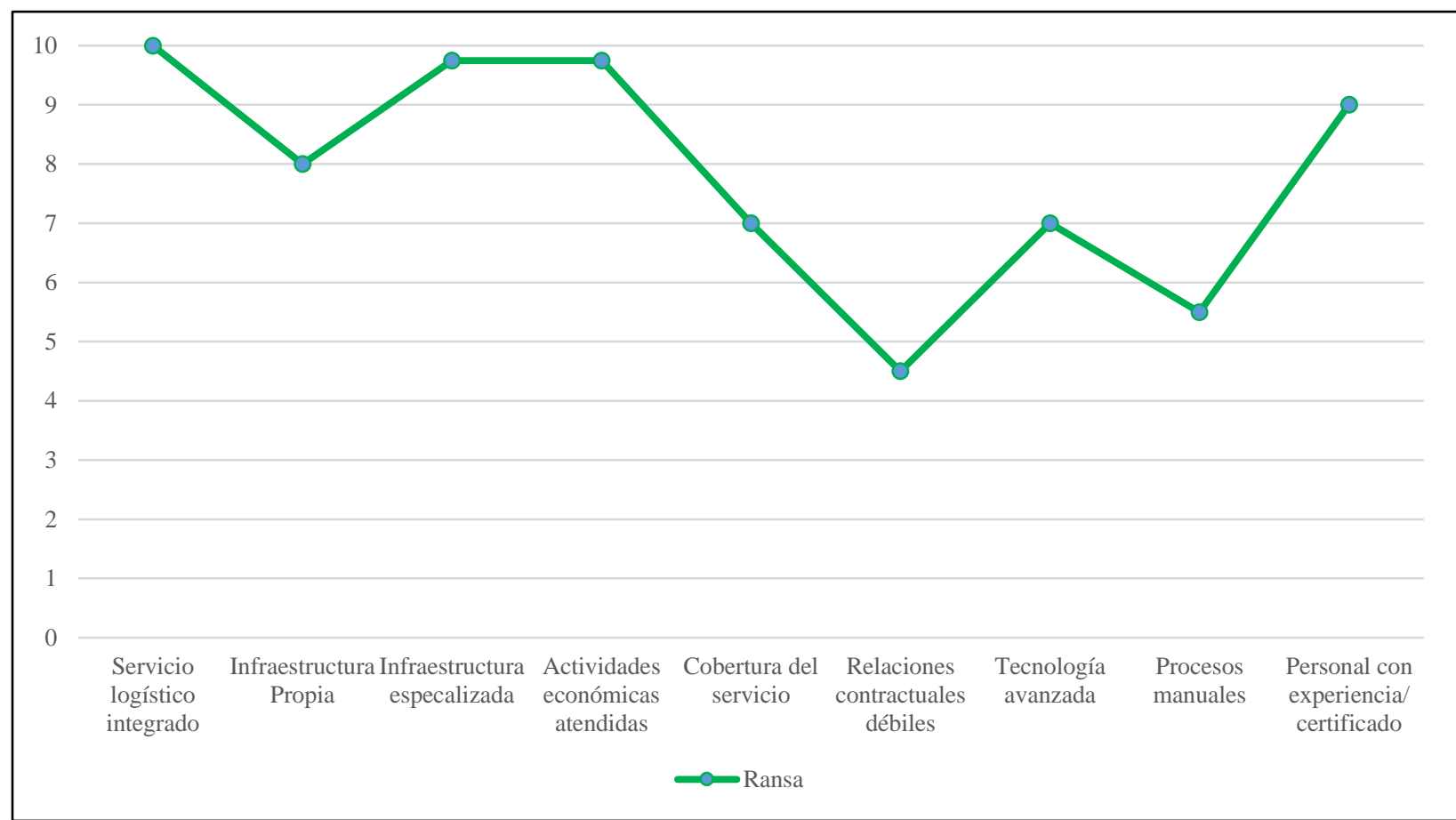

Figura 10. Lienzo del océano azul de la empresa. Adaptado de "La estrategia del océano azul," por Chan Kim W. \& Mauborgne, R. 2005. Bogotá, Colombia: Editorial Norma S.A. 


\subsubsection{Lienzo de la estrategia de la industria}

Para elaborar el lienzo estratégico de la industria se tomaron las mismas variables de la Figura 10 y se aplicó la valoración correspondiente. Ver Figura 11.

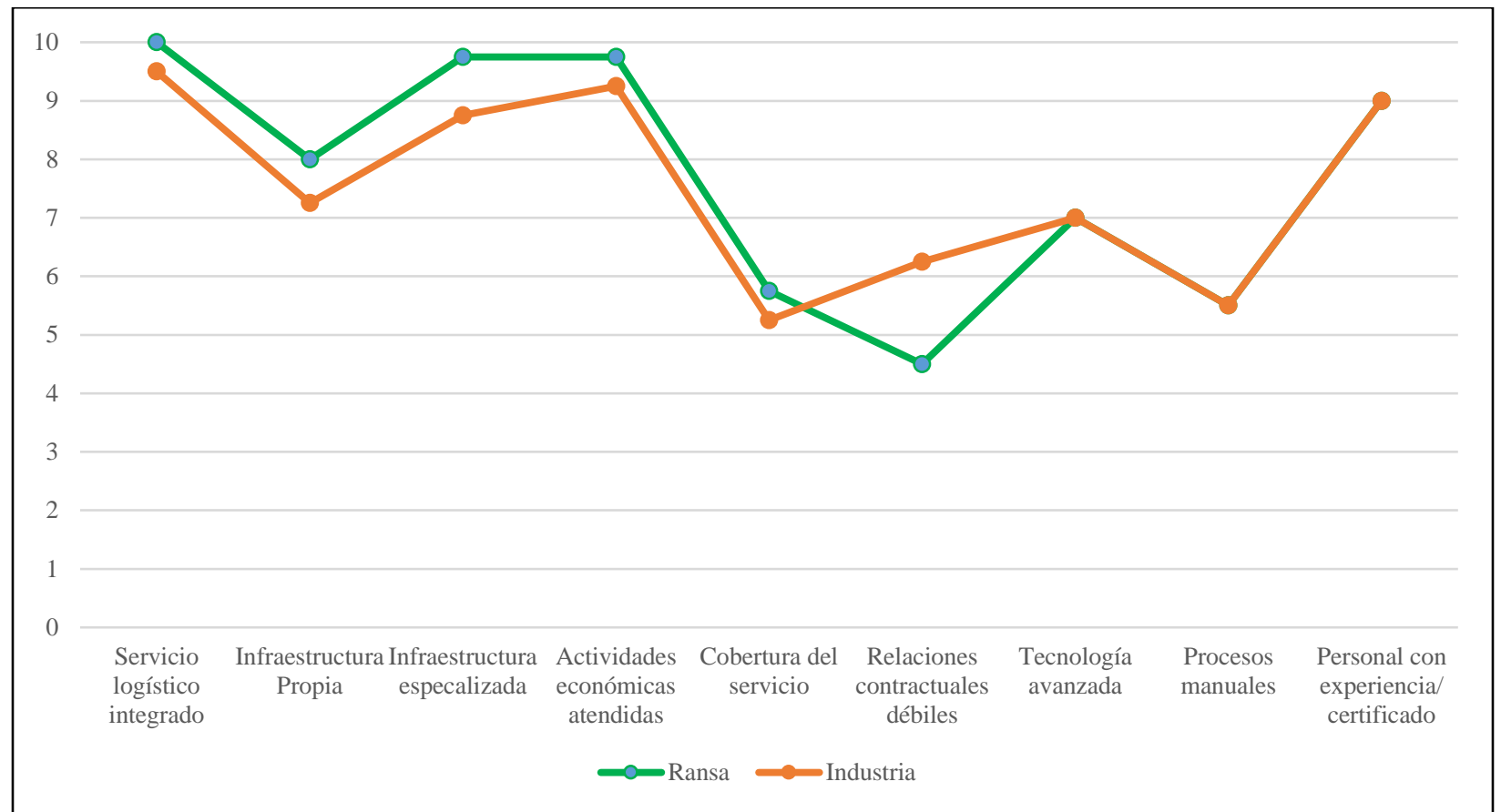

Figura 11. Lienzo del océano azul de la industria. Adaptado de "La estrategia del océano azul," por Chan Kim W. \& Mauborgne, R. 2005. Bogotá, Colombia: Editorial Norma S.A.

\subsubsection{Matriz (Eliminar, Reducir, Incrementar, Crear)}

La Tabla 30 muestra el esquema de las cuatro acciones.

Tabla 30

Esquema de las cuatro acciones

\begin{tabular}{|l|l|}
\hline $\begin{array}{l}\text { Reducir } \\
\text { - Reducir procesos manuales }\end{array}$ & $\begin{array}{l}\text { Crear } \\
\text { - Certificado de huella de carbono a clientes }\end{array}$ \\
\hline $\begin{array}{l}\text { Incrementar } \\
\text { - Personal con experiencia/certificado } \\
\text { - Tecnología avanzada }\end{array}$ & $\begin{array}{l}\text { Eliminar } \\
\text { - Relaciones contractuales débiles }\end{array}$ \\
\hline
\end{tabular}

Nota. Adaptado de La estrategia del océano azul (p. 42), por W. Chan Kim \& R. Mauborgne, 2005, Bogotá, Colombia: Editorial Norma S.A. 


\subsubsection{Lienzo de la nueva estrategia considerada}

Para elaborar este lienzo se tomó las variables originales y se añadió dos nuevas identificadas en la Tabla 30, y se mantiene la variable que fue situada en eliminar ya que en la industria aún se consideran, obteniendo de este modo una visión amplia de las variables evaluadas. Ver la Figura 12.

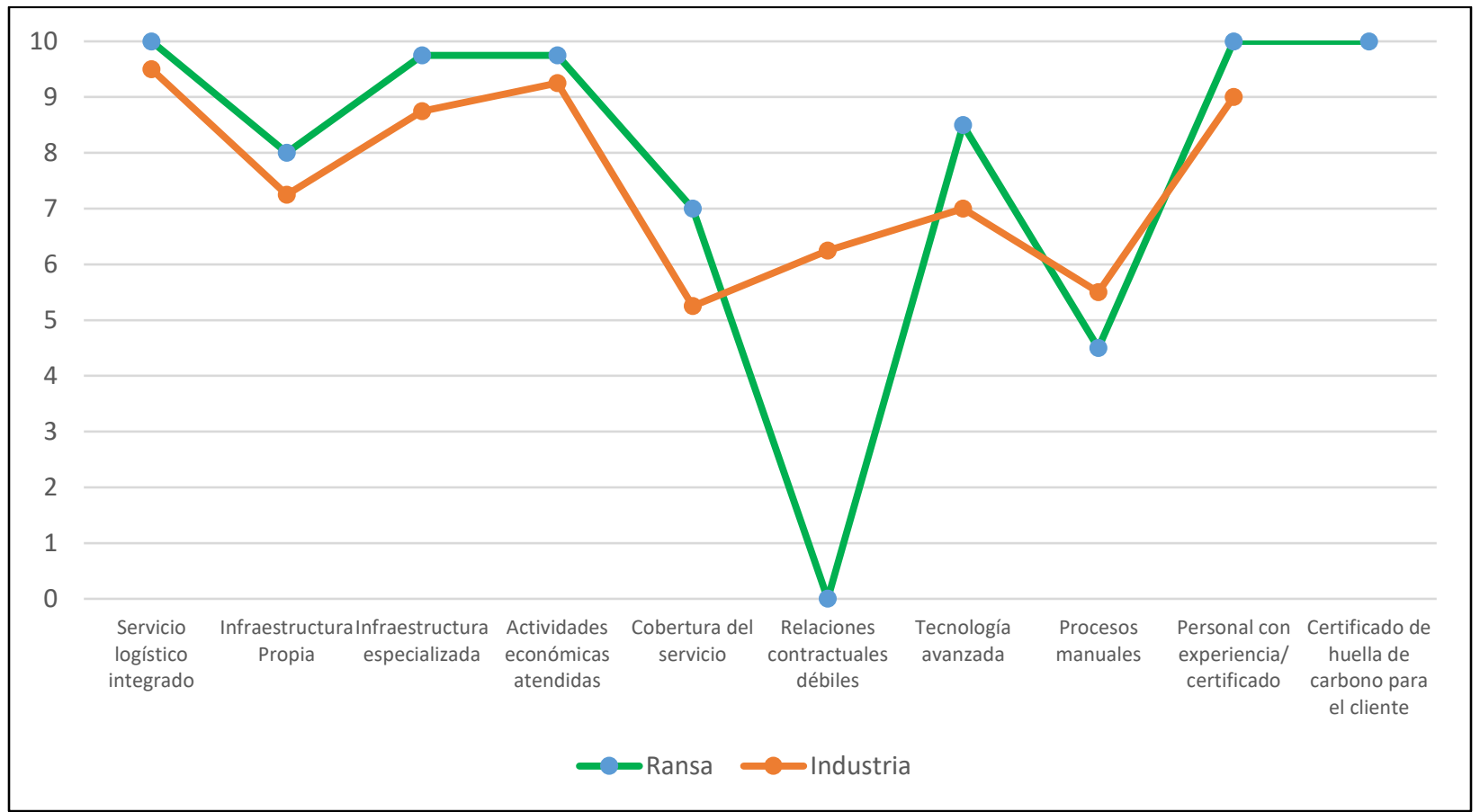

Figura 12. Lienzo del océano azul con estrategia considerada. Adaptado de "La estrategia del océano azul," por Chan Kim W. \& Mauborgne, R. 2005. Bogotá, Colombia: Editorial Norma S.A.

Cabe mencionar que el nivel de impacto de las cuatro acciones (ver Tabla 30) es definido por el criterio de los autores del presente Plan Estratégico.

\subsubsection{Matrices de formulación de estrategias}

\subsubsection{Matriz FODA}

La siguiente matriz se construye teniendo como base principal los conceptos obtenidos en las matrices EFE y EFI, cuya consolidación de variables permite definir cuatro tipos de estrategias, teniendo éstas un enfoque ofensivo, defensivo, adaptativo y de sobrevivencia. 
Tabla 31

Matriz FODA

\begin{tabular}{|c|c|c|}
\hline & FORTALEZAS - F & DEBILIDADES - D \\
\hline & $\begin{array}{l}\text { 1. Infraestructura logística } \\
\text { 2. Experiencia y posicionamiento en el sector } \\
\text { 3. Cobertura a nivel nacional de las operaciones logísticas } \\
\text { 4. Manejo de altos estándares de seguridad en las operaciones } \\
\text { logísticas } \\
\text { 5. Sistemas de información propios integrados al sistema de } \\
\text { los clientes } \\
\text { 6. Capacidad para desarrollar proyectos innovadores }\end{array}$ & $\begin{array}{l}\text { 1. Relaciones contractuales débiles } \\
\text { 2. Deficiente asignación de recursos humanos en la gestión de } \\
\text { almacenes. } \\
\text { 3. Información no fehaciente } \\
\text { 4. Falta de integración de las áreas de apoyo } \\
\text { 5. Alta estructura de costos operativos }\end{array}$ \\
\hline $\begin{array}{l}\text { OPORTUNIDADES - O } \\
\text { 1. Plan Nacional de Infraestructura } \\
\text { 2. Tratados de libre comercio } \\
\text { 3. Regla de la Haya - Visby y Hamburgo } \\
\text { 4. Crecimiento económico en el Perú y } \\
\text { América Latina } \\
\text { 5. Tecnología, soporte de la actividad } \\
\text { logística } \\
\text { 6.Tendencias globales de consumo }\end{array}$ & \begin{tabular}{l}
\multicolumn{1}{c}{ ESTRATEGIA OFENSIVA } \\
-Aumentar los centros de distribución para afianzar la \\
cobertura y mejorar el posicionamiento en las provincias con \\
mayor potencial comercial. $(O 1, O 4, F 2, F 3, F 6)$ \\
-Estandarizar la gestión de procesos y proyectos, logrando la \\
interoperabilidad. $(O 5, F 5, F 6)$ \\
- Asegurar el crecimiento sostenible de los clientes clave, \\
anticipando sus necesidades futuras. $(O 1, O 5, O 6, F 4, F 5)$
\end{tabular} & $\begin{array}{l}\text { ESTRATEGIA ADAPTATIVA } \\
\text {-Integrar los sistemas de información para lograr sinergia en las } \\
\text { operaciones. }(O 5, D 2, D 3) \\
\text {-Implementar acuerdos de nivel de servicio para todos los } \\
\text { clientes, estableciendo penalidades en caso se incumpla algún } \\
\text { acuerdo. }(O 5, D 1) \\
\text {-Impulsar la investigación y desarrollo de nuevas tecnologías } \\
\text { que mejoren la infraestructura logística de la organización. (OI, } \\
O 4, O 5, D 5) \\
\text {-Promocionar los servicios de tercerización logística en las } \\
\text { ferias y convenciones internacionales. }(O 2, O 3, D 5)\end{array}$ \\
\hline \begin{tabular}{l}
\multicolumn{1}{c}{ AMENAZAS - A } \\
1. Falta de infraestructura nacional vial \\
2. Informalidad laboral en el Perú \\
3. Aumento de las exigencias \\
medioambientales \\
4. Inestabilidad social y política del país \\
5.Corrupción en las licitaciones de \\
proyectos gubernamentales de \\
infraestructura
\end{tabular} & \begin{tabular}{l}
\multicolumn{1}{c}{ ESTRATEGIA DEFENSIVA } \\
-Desarrollar un clima laboral atractivo para los \\
colaboradores. $(A 2, F 2, F 4, F 6)$ \\
-Desarrollar un modelo de economía circular para operar de \\
manera eficiente sobre una base de respeto medioambiental. \\
$(A 3, F 2, F 6)$ \\
-Identificar clientes de menores volúmenes pero con gran \\
potencial de crecimiento y dirigir hacia ellos los esfuerzos del \\
área comercial $(A 2, A 4, F 2, F 5)$ \\
-No desarrollar proyectos basados en iniciativas \\
gubernamentales de infraestructura $(A 5, F 2, F 3)$
\end{tabular} & $\begin{array}{l}\text { ESTRATEGIA DE SUPERVIVENCIA } \\
\text {-Impulsar la cooperación entre las unidades de negocio para } \\
\text { lograr sinergia y eficiencia de los recursos compartidos. ( } A 2 \text {, } \\
A 4, D 2, D 3, D 4, D 5) \\
\text {-Implementar mejoras tecnológicas que disminuyan el costo } \\
\text { operativo. }(A 2, A 4, D 1, D 2, D 5)\end{array}$ \\
\hline
\end{tabular}

Nota. Adaptado de El proceso estratégico: Un enfoque de gerencia (p. 268), por F. D’Alessio, 2008, México D.F.: Pearson Educación. 
De acuerdo con la Tabla 31, se obtuvieron distintas estrategias, las cuales pueden ser alineadas por su naturaleza dentro del concepto de estrategias competitivas genéricas de Porter, siendo éstas las siguiente: diferenciación y liderazgo global en costos.

Es importante mencionar que la estrategia competitiva de liderazgo global en costos está relacionada a lo siguiente: implementación agresiva de instalaciones de escala eficiente, búsqueda permanente de la reducción de costos basada en la experiencia, control agresivo de los gastos variables y fijos, entre otras (Porter, 1991).

Además, 8 de 12 estrategias planteadas en el FODA se encuentran dentro de la estrategia competitiva de liderazgo global en costos, de las cuales 6 se orientan a alcanzar la eficiencia operativa a través de la implementación de tecnología y la reorganización de procesos basada en la experiencia. Ver Tabla 32.

Por ello, las estrategias genéricas obtenidas mediante la matriz FODA son de diferenciación y de eficiencia operativa.

Tabla 32

Estrategias del FODA frente a las estrategias competitivas genéricas

\begin{tabular}{|c|c|c|c|}
\hline $\mathrm{N}^{\circ}$ & Diferenciación & $\mathrm{N}^{\circ}$ & Eficiencia operativa \\
\hline 3 & $\begin{array}{l}\text { Asegurar el crecimiento sostenible de losclientes clave, } \\
\text { anticipando sus necesidades futuras } \\
\text { Desarrollar un modelo de economía circular para operar } \\
\text { de manera eficiente sobre una base de respeto } \\
\text { medioambiental } \\
\text { Impulsar la investigación y desarrollo de nuevas } \\
\text { tecnologías que mejoren la infraestructura logística de la } \\
\text { organización } \\
\text { Aumentar los centros de distribución para afianzar la } \\
\text { cobertura y mejorar el posicionamiento en las provincias } \\
\text { con mayor potencial comercial }\end{array}$ & 2 & $\begin{array}{l}\text { Estandarizar la gestión de procesos y proyectos, } \\
\text { logrando interoperabilidad } \\
\text { Identificar clientes de menores volúmenes pero con } \\
\text { gran potencial de crecimiento y dirigir hacia ellos los } \\
\text { efuerzos del área comercial } \\
\text { Desarrollar un clima laboral atractivo para los } \\
\text { colaboradores } \\
\text { No desarrollar proyectos basados en iniciativas } \\
\text { gibernamentales de infraestructura } \\
\text { Integrar los sistemas de información para lograr sinergia } \\
\text { en las operaciones } \\
\text { Implementar acuerdos de nivel de servicio para todos } \\
\text { los clientes, estableciendo penalidades en caso se } \\
\text { incumpla algún acuerdo } \\
\text { Impulsar la cooperación entre las unidades de negcio } \\
\text { para lograr sinergia y eficiencia de los recursos } \\
\text { compartidos } \\
\text { Implementar mejoras tecnológicas que disminuyan el } \\
\text { costo operativo }\end{array}$ \\
\hline
\end{tabular}




\subsubsection{Matriz PEYEA.}

La matriz de Posición Estratégica y Evaluación de la Acción es una herramienta que permite a Ransa determinar la estrategia más adecuada.

El análisis de la matriz se enfoca en la posición global de Ransa a través de cuatro dimensiones determinantes. Primero, como dimensiones internas se tiene la Fortaleza Financiera (FF) y la Ventaja Competitiva (VC) con calificaciones que van del +1(menor puntuación) al +6 (mayor puntuación). Segundo, como dimensiones externas se tiene la Estabilidad del Entorno (EE) y la Fortaleza de la Industria (FI) con calificaciones que van del -1 (mejor puntuación) al -6 (menor puntuación). Ver la Tabla 33.

Para la elaboración de la Matriz PEYEA se aplicó la Ficha Técnica del Anexo 18 a especialistas de Ransa, donde se obtuvo valoraciones similares en las variables de cada dimensión. Asimismo, la dimensión de Fortaleza Financiera (FF) se complementó con data de la empresa. Ver el Anexo 19.

A continuación, en la Tabla 33, se observa la valoración promediada de cada variable, lo que permite tener una primera vista detallada de la posición de las dimensiones. 
Tabla 33

\section{Matriz PEYEA}

\begin{tabular}{|c|c|c|c|c|c|c|c|c|}
\hline \multicolumn{9}{|c|}{ Dimensiones y variables de la Matriz PEYEA } \\
\hline \multicolumn{9}{|l|}{ Fortaleza Financiera (FF) } \\
\hline ROE & Bajo & 1 & 2 & 3 & 4 & 5 & 6 & Alto \\
\hline ROA & Bajo & 1 & 2 & 3 & 4 & 5 & 6 & Alto \\
\hline Liquidez & Desbalanceado & 1 & 2 & 3 & 4 & 5 & 6 & Solida \\
\hline Endeudamiento & Alto & 1 & 2 & 3 & 4 & 5 & 6 & Bajo \\
\hline Flujo de caja & Bajo & 1 & 2 & 3 & 4 & 5 & 6 & Alto \\
\hline Facilidad de salida del mercado & Difícil & 1 & 2 & 3 & 4 & 5 & 6 & Fácil \\
\hline Riesgo involucrado en el negocio & Alto & 1 & 2 & 3 & 4 & 5 & 6 & Bajo \\
\hline Rotación de inventarios & Lento & 1 & 2 & 3 & 4 & 5 & 6 & Rápido \\
\hline $\begin{array}{l}\text { Economías de escala y de } \\
\text { experiencia }\end{array}$ & Baja & 1 & 2 & 3 & 4 & 5 & 6 & Alta \\
\hline \multicolumn{9}{|c|}{ Promedio: 2.67} \\
\hline \multicolumn{9}{|l|}{ Fortaleza de la Industria (FI) } \\
\hline Potencial de crecimiento & Bajo & 1 & 2 & 3 & 4 & 5 & 6 & Alto \\
\hline Potencial de utilidades & Bajo & 1 & 2 & 3 & 4 & 5 & 6 & Alto \\
\hline Estabilidad financiera & Bajo & 1 & 2 & 3 & 4 & 5 & 6 & Alto \\
\hline Conocimiento tecnológico & Simple & 1 & 2 & 3 & 4 & 5 & 6 & Complejo \\
\hline Utilización de recursos & Ineficiente & 1 & 2 & 3 & 4 & 5 & 6 & Eficiente \\
\hline Intensidad de capital & Bajo & 1 & 2 & 3 & 4 & 5 & 6 & Alto \\
\hline Facilidad de entrada al mercado & Fácil & 1 & 2 & 3 & 4 & 5 & 6 & Difícil \\
\hline $\begin{array}{l}\text { Productividad / utilización de la } \\
\text { capacidad }\end{array}$ & Baja & 1 & 2 & 3 & 4 & 5 & 6 & Alta \\
\hline $\begin{array}{l}\text { Poder de negociación de los } \\
\text { clientes }\end{array}$ & Bajo & 1 & 2 & 3 & 4 & 5 & 6 & Alto \\
\hline \multicolumn{9}{|c|}{ Promedio: 4.67} \\
\hline \multicolumn{9}{|l|}{ Ventajas Competitivas (VC) } \\
\hline Participación de mercado & Grande & -1 & -2 & -3 & -4 & -5 & -6 & Pequeña \\
\hline Calidad del producto & Superior & -1 & -2 & -3 & -4 & -5 & -6 & Inferior \\
\hline Ciclo de vida del producto & Temprano & -1 & -2 & -3 & -4 & -5 & -6 & Avanzado \\
\hline Ciclo de reemplazo del producto & Fijo & -1 & -2 & -3 & -4 & -5 & -6 & Variable \\
\hline Lealtad al consumidor & Alto & -1 & -2 & -3 & -4 & -5 & -6 & Bajo \\
\hline $\begin{array}{l}\text { Utilización de la capacidad de los } \\
\text { competidores }\end{array}$ & Alto & -1 & -2 & -3 & -4 & -5 & -6 & Bajo \\
\hline Conocimiento tecnológico & Alto & -1 & -2 & -3 & -4 & -5 & -6 & Bajo \\
\hline Integración vertical & Alto & -1 & -2 & -3 & -4 & -5 & -6 & Bajo \\
\hline $\begin{array}{l}\text { Velocidad de introducción de } \\
\text { nuevos productos }\end{array}$ & Rápida & -1 & -2 & -3 & -4 & -5 & -6 & Lenta \\
\hline \multicolumn{9}{|c|}{ Promedio: -2.22} \\
\hline \multicolumn{9}{|l|}{ Estabilidad del Entorno (EE) } \\
\hline Cambios tecnológicos & Pocos & -1 & -2 & -3 & -4 & -5 & -6 & Muchos \\
\hline
\end{tabular}




\begin{tabular}{|c|c|c|c|c|c|c|c|c|}
\hline Tasa de inflación & Baja & -1 & -2 & -3 & -4 & -5 & -6 & Alta \\
\hline Variabilidad de la demanda & Pequeña & -1 & -2 & -3 & -4 & -5 & -6 & Grande \\
\hline $\begin{array}{l}\text { Rango de precios de los productos } \\
\text { competitivos }\end{array}$ & Estrecho & -1 & -2 & -3 & -4 & -5 & -6 & Amplio \\
\hline Barreras de entrada al mercado & Muchas & -1 & -2 & -3 & -4 & -5 & -6 & Pocas \\
\hline Rivalidad / presión competitiva & Baja & -1 & -2 & -3 & -4 & -5 & -6 & Alta \\
\hline $\begin{array}{l}\text { Elasticidad de precios de la } \\
\text { demanda }\end{array}$ & Inelástica & -1 & -2 & -3 & -4 & -5 & -6 & Elástica \\
\hline Presión de los productos sustitutos & Baja & -1 & -2 & -3 & -4 & -5 & -6 & Alta \\
\hline
\end{tabular}

Nota. Adaptado de El proceso estratégico: Un enfoque de gerencia (p. 284), por F. D’Alessio, 2008, México D.F.: Pearson Educación.

La postura de Ransa en sus estrategias deben ser agresivas debido a la a la ubicación del vector (ver Figura 13), señalando que la empresa tiene una estabilidad financiera aceptable que le ha permitido desarrollar ventajas competitivas dentro de una industria estable y creciente. El cuadrante indica que la empresa está en la facultad de aprovechar las oportunidades del mercado, aumentar su participación en la industria, y desarrollar nuevas ventajas competitivas o perfeccionar las existentes. Por ello, las estrategias apropiadas que el cuadrante establece son: intensivas, diversificación concéntrica, integración vertical, y liderazgo en costos. Este último puede lograse mediante la construcción de instalaciones eficientes, control o reajuste agresivo de costos, disminución de gastos en I\&D, publicidad y ventas.

Por otro lado, el vector se encuentra muy cerca del cuadrante de estrategias competitivas, debido a la baja estabilidad del entorno. El cuadrante indica que la empresa también se encuentra en la posibilidad de mejorar su fuerza de ventas, mejorar o ampliar su línea de productos, aumentar su productividad, disminuir costos, y proteger su ventaja competitiva. Por ello, las estrategias opcionales que el cuadrante establece son: fusión concéntrica, fusión conglomerado, reconversión, y diferenciación. Este último puede lograse mediante el desarrollo de productos únicos en diseño, marca, calidad, y valor agregado. 


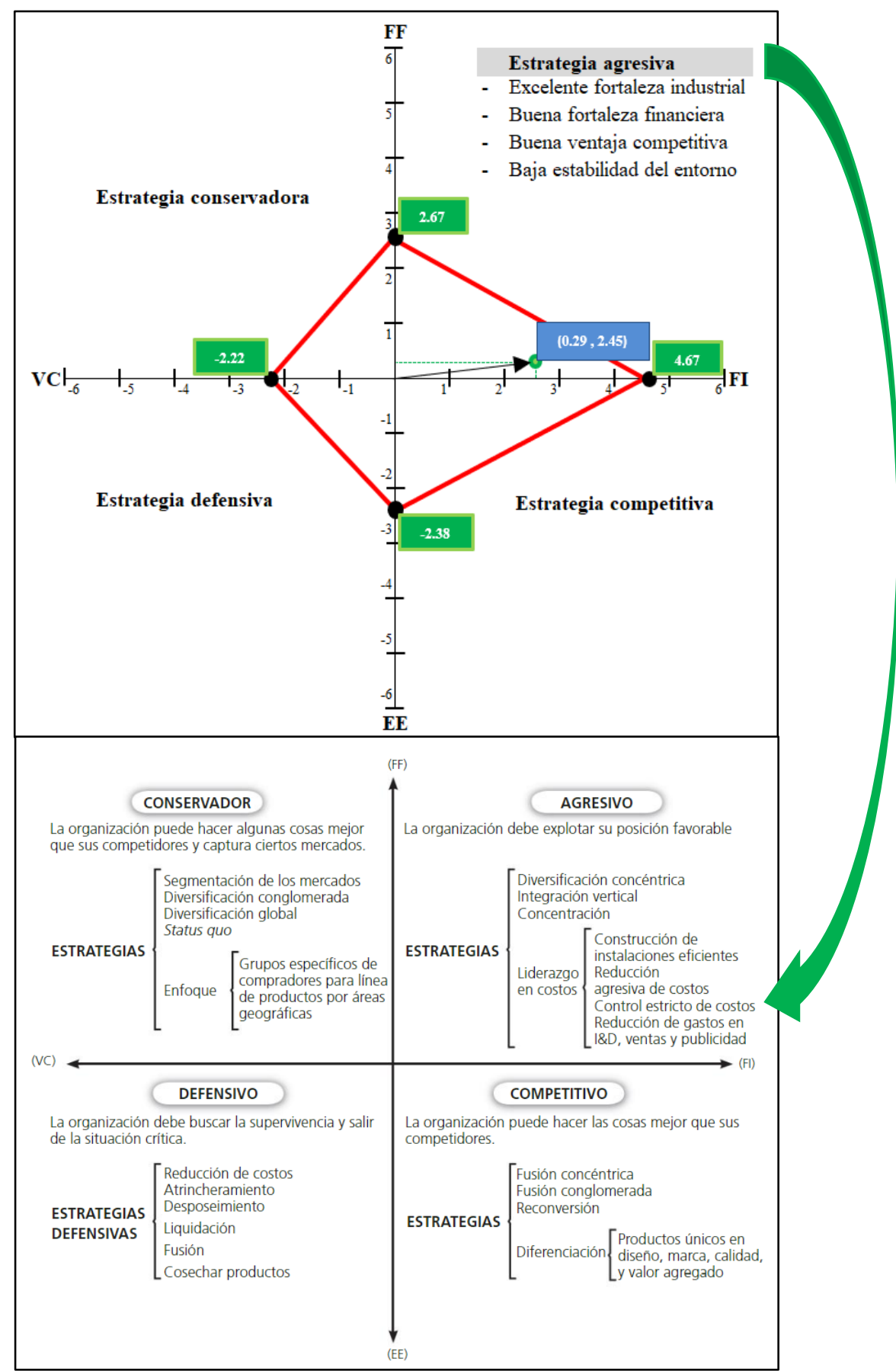

Figura 13. Matriz PEYEA. Adaptado de "El proceso estratégico: Un enfoque de gerencia," por F. D'Alessio, 2008. México D.F.: Pearson Educación. 


\subsubsection{Matriz Interna Externa (IE)}

La matriz Interna Externa es una herramienta que permite evaluar a la empresa, tomando en cuenta sus factores internos (eje "x") y externos (eje "y"), obteniendo una coordenada que se puede graficar y ubicar en cualquiera de los 9 cuadrantes de dicha matriz.

Así, la Figura 14 posiciona a Ransa Comercial S.A. en el cuadrante V - Promedio Medio, cuadrante donde la empresa debe desarrollarse selectivamente para mejorar, utilizando estrategias de penetración de mercado y desarrollo de productos.

Por otro lado, el punto de intersección se encuentra cerca al cuadrante IV - Fuerte Medio, cuadrante donde la empresa debe invertir selectivamente y construir, indicando como alternativa la implementación de estrategias de desarrollo de mercados y de integración. 


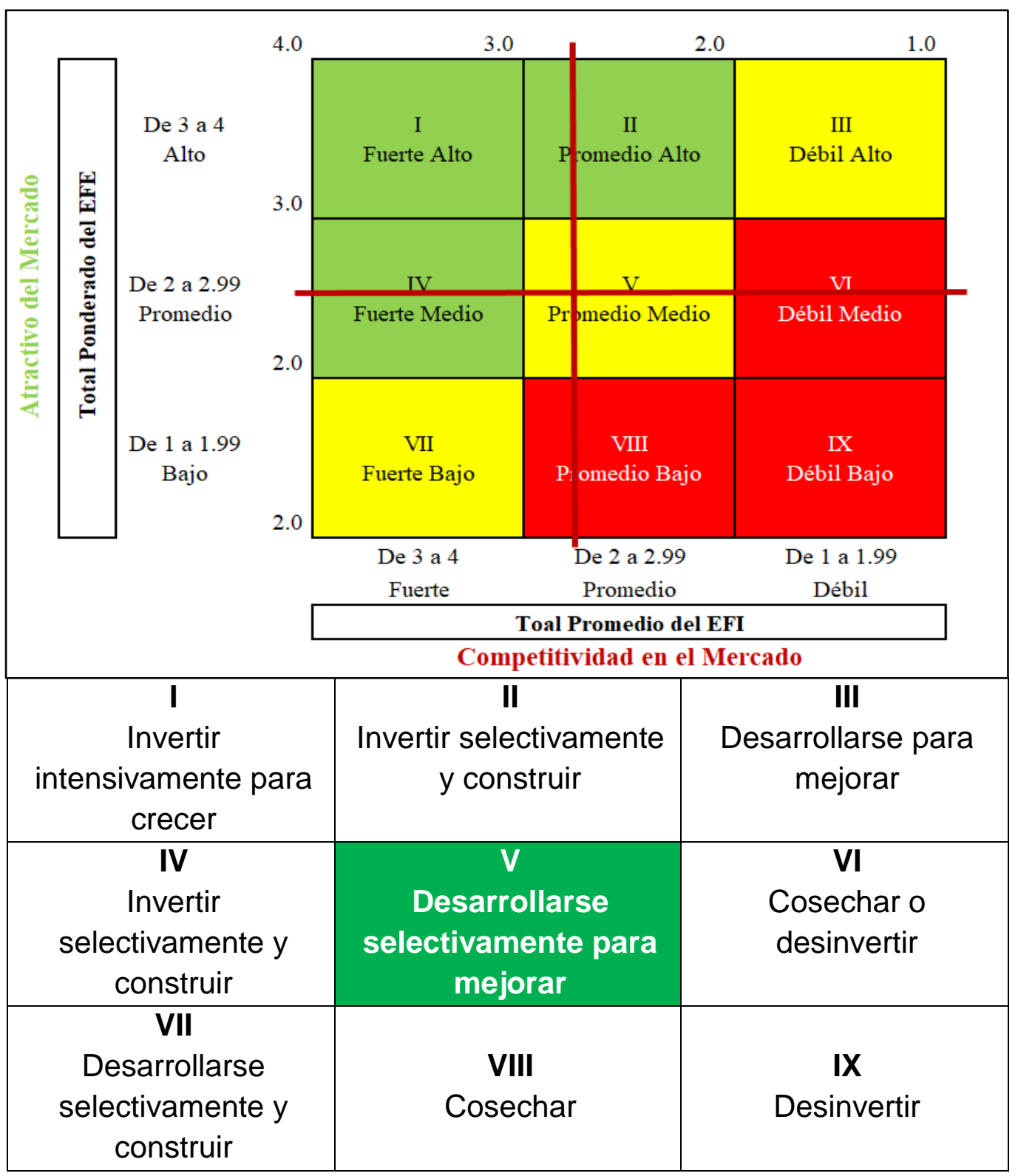

Figura 14. Matriz Interna Externa. Adaptado de "El proceso estratégico: Un enfoque de gerencia," por F. D’Alessio, 2008. México D.F.: Pearson Educación.

\subsubsection{Matriz Boston Consulting Group (BCG).}

La matriz BCG es una herramienta gráfica que permite analizar los servicios de la empresa en contraste a la industria, determinando si el servicio es signo de interrogación (cuadrante I), estrella (cuadrante II), vacas lecheras (cuadrante III), perros (cuadrante IV). 
Para la elaboración de esta matriz no se cuenta con la información necesaria. Sin embargo, de acuerdo con la Figura 04, el ciclo de vida de los servicios (transporte, almacenaje y distribución) se encuentran en la etapa de madurez y crecimiento lento, etapas relacionadas al cuadrante de vacas lecheras, debido a que generan altos ingresos sin hacer uso excesivo de caja.

Las estrategias adecuadas para el cuadrante de vacas lechereas son: desarrollo de producto y diversificación concéntrica. Sin embargo, éstas no serán tomadas en cuenta en la Matriz de decisión (ver Tabla 34) debido a la falta de información apropiada para elaborar matriz BCG. Ver Figura 15.

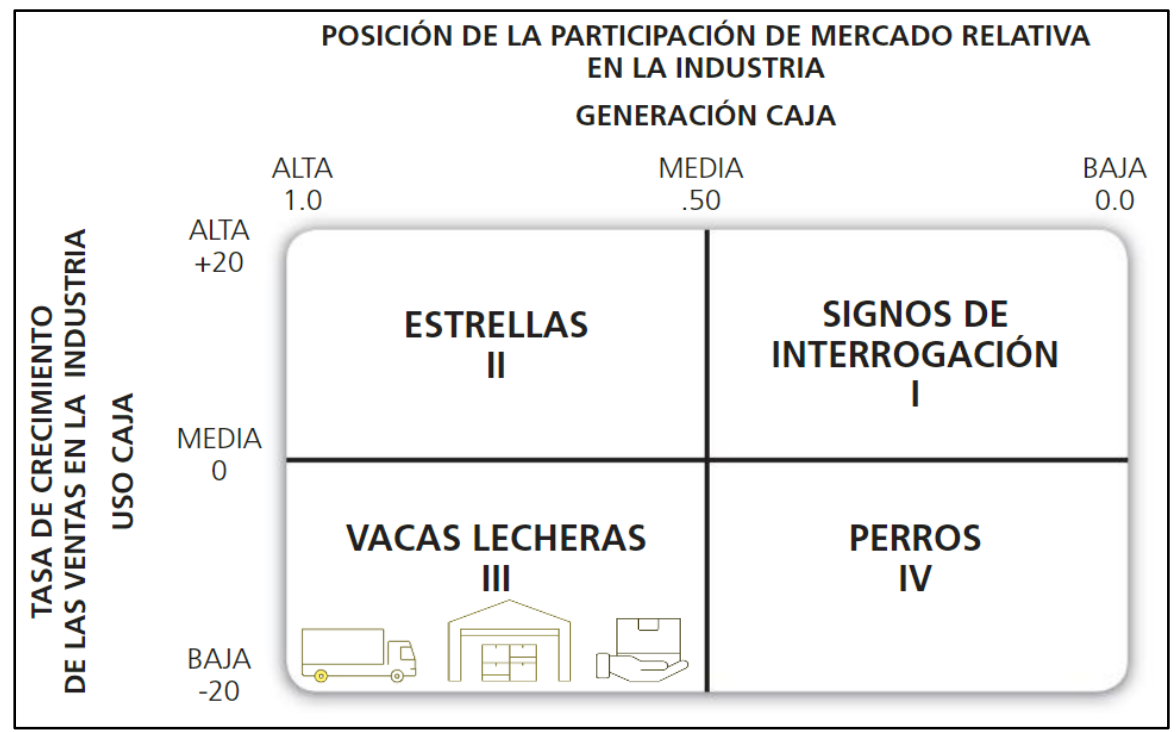

Figura 15. Matriz BCG. Adaptado de "El proceso estratégico: Un enfoque de gerencia,” por F. D’Alessio, 2008. México D.F.: Pearson Educación.

\subsubsection{Matriz de la Gran Estrategia}

Esta herramienta permite evaluar y afinar la selección de estrategias para la empresa. La matriz evalúa el crecimiento del mercado (rápido o lento) y la posición competitiva de la empresa (fuerte o débil). 
Primero, la matriz EFE y EFI muestran resultados muy arriba del promedio, resultados que indican que Ransa Comercial S.A. cuenta con una fuerte posición competitiva. Segundo, la matriz PEYEA indica que la empresa ha desarrollado importantes ventajas competitivas en una industria estable y en crecimiento. Tercero, la matriz IE coloca a la empresa en el cuadrante VPromedio Medio, indicando un alto nivel competitivo en un mercado atractivo. Cuarto, de acuerdo con la Figura 03, la industria ha mostrado un crecimiento estable en los últimos 10 años. Por ello, se concluye que la empresa se ubica en el Cuadrante I. Ver Figura 16.

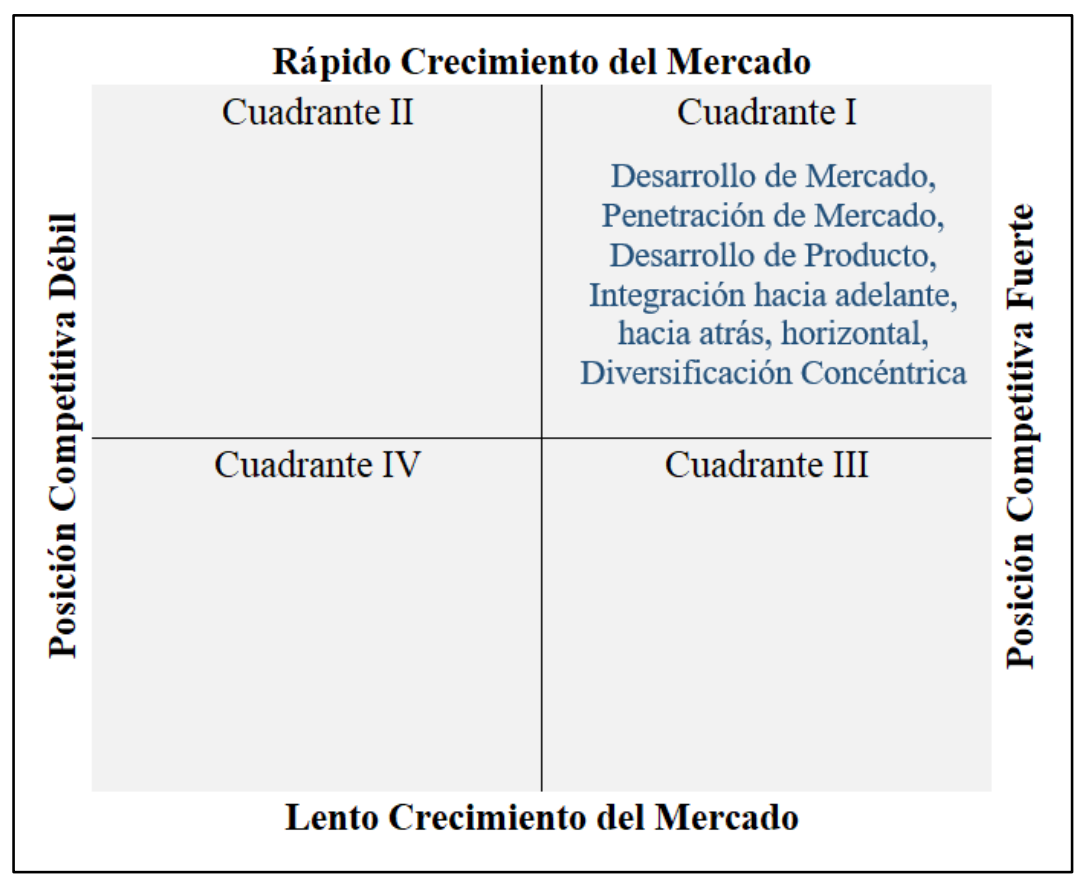

Figura 16. Matriz de la Gran Estrategia. Adaptado de "El proceso estratégico: Un enfoque de gerencia," por F. D'Alessio, 2008. México D.F.: Pearson Educación.

\subsection{Resumen de las estrategias formuladas}

Todas las estrategias planteadas en la etapa de emparejamiento o del proceso estratégico, obtenidas del modelo del Océano Azul y las matrices FODA, PEYEA, BCG, IE y GE, se colocan en una matriz (ver Tabla 34), la cual permite observar las repeticiones de estas estrategias, pasando a retener a las que se repitan más veces. 
Tabla 34

Matriz de decisión

\begin{tabular}{|c|c|c|c|c|c|c|c|}
\hline Estrategias destacadas & $\begin{array}{c}\text { Modelo } \\
\text { Océano } \\
\text { Azul }\end{array}$ & $\begin{array}{l}\text { Matriz } \\
\text { FODA }\end{array}$ & $\begin{array}{l}\text { Matriz } \\
\text { PEYEA }\end{array}$ & $\begin{array}{c}\text { Matriz } \\
\text { IE }\end{array}$ & $\begin{array}{c}\text { Matriz } \\
\text { BCG }\end{array}$ & $\begin{array}{c}\text { Matriz } \\
\text { GE }\end{array}$ & Total \\
\hline 1 Penetración de Mercado & & & & $\mathrm{X}$ & & $\mathrm{X}$ & 2 \\
\hline 2 Desarrollo de Mercado & & & & & & $\mathrm{X}$ & 1 \\
\hline 3 Desarrollo de Producto & $\mathrm{X}$ & & & $\mathrm{X}$ & & $\mathrm{X}$ & 3 \\
\hline 4 Integración vertical hacia atrás & & & $\mathrm{X}$ & & & $\mathrm{X}$ & 2 \\
\hline 5 Integración vertical hacia adelante & & & $\mathrm{X}$ & & & $\mathrm{X}$ & 2 \\
\hline 6 Integración horizontal & & & & & & $\mathrm{X}$ & 1 \\
\hline 7 Diversificación Concéntrica & & & $\mathrm{X}$ & & & $\mathrm{X}$ & 2 \\
\hline 8 Concentración & & & $\mathrm{X}$ & & & & 1 \\
\hline 9 Diferenciación & $\mathrm{X}$ & $\mathrm{X}$ & & & & & 2 \\
\hline 10 Eficiencia operativa & $\mathrm{X}$ & $\mathrm{X}$ & $\mathrm{X}$ & & & & 3 \\
\hline
\end{tabular}

Nota. Adaptado de El proceso estratégico: Un enfoque de gerencia (p. 332), por F. D’Alessio, 2008, México D.F.: Pearson Educación.

De este modo, las estrategias seleccionadas son: eficiencia operativa, desarrollo de producto y diferenciación. Cabe mencionar que este último es seleccionado entre las demás porque según la matriz PEYEA, la posición estratégica de la empresa se encuentra cerca del cuadrante competitivo, el cual recomienda entre sus estrategias la de diferenciación (ver Figura 15). Por otro lado, las estrategias no seleccionadas son: penetración de mercado, integración vertical hacia atrás, integración vertical hacia delante, diversificación concéntrica, desarrollo de mercado, integración horizontal y concentración. Ver Tabla 34. 


\section{Selección de la estrategia}

Sobre este punto es imposible identificar de manera concluyente las estrategias que

brindarán óptimos resultados o asegurar por lo menos que éstas funcionarán (David, 2013). Sin embargo, se puede identificar las estrategias de mayor desempeño y analizar sus resultados.

\subsection{Método factores estratégicos claves.}

\subsubsection{Criterios de selección.}

Después de identificar las estrategias de mayor repetición en la matriz de decisión es importante filtrarlas una vez más, aplicando los criterios planteados por Rumelt: consistencia, consonancia, ventaja y factibilidad. Ver Figura 17.

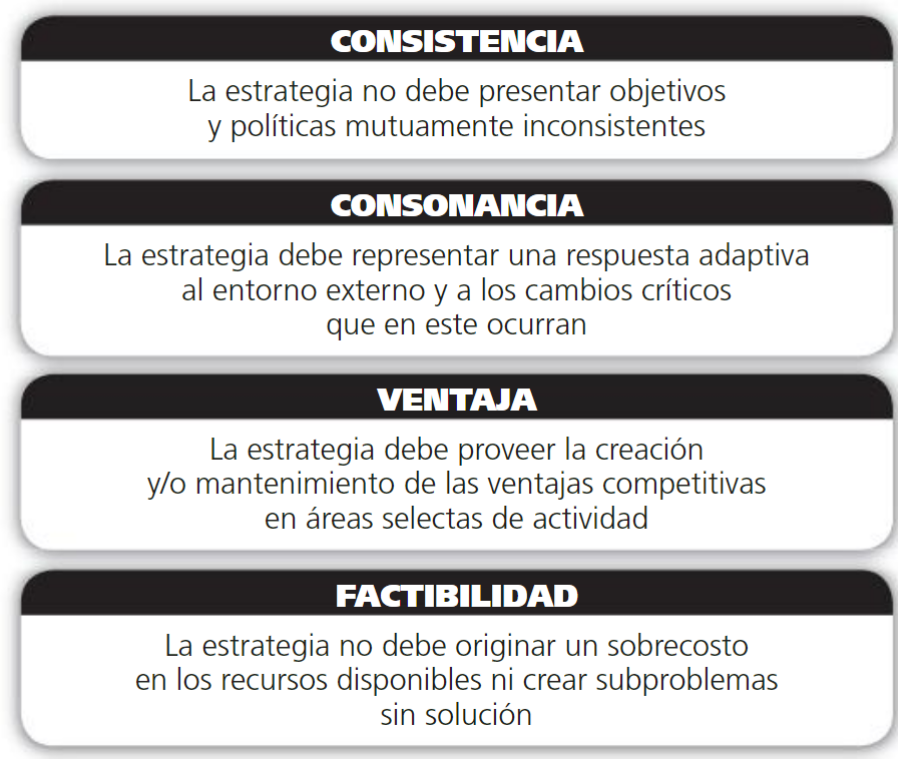

Figura 17. Criterios de selección de estrategias. Tomado de "El proceso estratégico: Un enfoque de gerencia,” por F. D'Alessio, 2008. México D.F.: Pearson Educación. 


\subsubsection{Matriz de selección.}

Establecidos los criterios, se evalúan las estrategias retenidas en la matriz de decisión en la matriz de Rumelt (ver Tabla 35), identificando a aquellas estrategias que cumplen con los cuatro criterios y descartando a aquellas que no.

Tabla 35

Matriz Rumelt

\begin{tabular}{|c|c|c|c|c|c|}
\hline Estrategias & 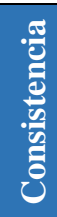 & 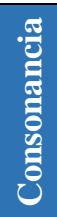 & 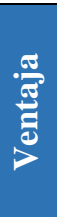 & 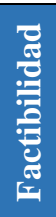 & Se acepta \\
\hline 1. Eficiencia operativa & SI & SI & SI & SI & SI \\
\hline 2. Diferenciación & SI & SI & SI & SI & SI \\
\hline 3. Desarrollo de producto & SI & SI & SI & SI & SI \\
\hline
\end{tabular}

Nota. Adaptado de El proceso estratégico: Un enfoque de gerencia (p. 354), por F. D’Alessio, 2008, México D.F.: Pearson Educación.

Así, la Tabla 35 muestra que las tres estrategias evaluadas cumplen con las características inherentes de los criterios, sosteniendo que pueden ser aceptadas y seleccionadas.

\subsection{Método de escenarios}

Esta es una herramienta que identifica acontecimientos que pueden ocurrir en el futuro y define supuestos para que la empresa esté preparada.

\subsubsection{Descripción de escenarios considerados.}

En este punto se identifican los posibles escenarios a los que Ransa Comercial S.A. se puede enfrentar, siendo éstos: el más probable y el menos probable. A continuación, se muestran las consideraciones: 


$\begin{array}{ll}\text { Horizonte temporal } & : 2019-2022 \\ \text { Grupo de interés } & : \text { Stakeholders internos } \\ \text { Factores clave } & : \text { Ver Tabla } 36 \\ \text { Escenarios propuestos } & : \text { Ver Tabla } 37\end{array}$

Tabla 36

Factores clave del entorno

\begin{tabular}{|l|l|}
\hline \multicolumn{1}{|c|}{ Aspecto } & \\
\hline $\begin{array}{l}\text { Político - } \\
\text { Gubernamental }\end{array}$ & $\begin{array}{l}\text { Plan Nacional de Infraestructura } \\
\text { Acuerdos Comerciales } \\
\text { Informalidad }\end{array}$ \\
\hline Económico & Empresas activas \\
\hline Legal & Fomento de la competitividad \\
\hline Cultural & Tasa de desempleo \\
\hline Tecnológico & Automatización y almacenes robotizados, IoT y bienes sensorizados y Big Data \\
\hline Ecológico & Responsabilidad ambiental \\
\hline
\end{tabular}

Una vez determinados los factores clave del entorno externo (ver Tabla 36) se los evalúa bajo dos escenarios supuestos, el más y el menos probable (ver Tabla 37).

Es importante mencionar que la Tabla 37 analiza el efecto de los factores clave que se consideran más significativos y su respectivo impacto de los escenarios considerados. 
Tabla 37

Escenarios propuestos

\begin{tabular}{|c|c|c|c|}
\hline Aspecto & Factores Clave & Más Probable & Menos Probable \\
\hline \multirow{3}{*}{$\begin{array}{c}\text { Político - } \\
\text { Gubernamental }\end{array}$} & $\begin{array}{l}\text { Plan Nacional de } \\
\text { Infraestructura }\end{array}$ & $\begin{array}{l}\text { Incumplimiento del plan, } \\
\text { manteniendo los costos } \\
\text { logísticos. }\end{array}$ & $\begin{array}{l}\text { Cumplimiento del plan, } \\
\text { reduciendo los costos } \\
\text { logísticos. }\end{array}$ \\
\hline & Acuerdos Comerciales & $\begin{array}{c}\text { Aumentan las oportunidades } \\
\text { de la industria }\end{array}$ & $\begin{array}{c}\text { Se mantienen las } \\
\text { oportunidades de la } \\
\text { industria }\end{array}$ \\
\hline & Informalidad & $\begin{array}{l}\text { Aumento de la informalidad } \\
\text { y competencia desleal }\end{array}$ & $\begin{array}{l}\text { Reducción de la } \\
\text { informalidad y } \\
\text { competencia desleal }\end{array}$ \\
\hline Económico & Empresas activas & Incremento de la demanda & $\begin{array}{c}\text { No impacta en el nivel de } \\
\text { la demanda }\end{array}$ \\
\hline Legal & $\begin{array}{l}\text { Fomento de la } \\
\text { competitividad }\end{array}$ & $\begin{array}{l}\text { Incremento del índice de } \\
\text { competitividad }\end{array}$ & $\begin{array}{l}\text { No impacta en el índice de } \\
\text { competitividad }\end{array}$ \\
\hline Cultural & Tasa de desempleo & $\begin{array}{c}\text { Disminuye la tasa, } \\
\text { aumentando la demanda de } \\
\text { bienes y servicios }\end{array}$ & $\begin{array}{l}\text { Aumente la tasa, } \\
\text { disminuyendo la demanda } \\
\text { de bienes y servicios }\end{array}$ \\
\hline Tecnológico & $\begin{array}{c}\text { Automatización y } \\
\text { almacenes robotizados, } \\
\text { IoT y bienes sensorizados } \\
\text { y Big Data }\end{array}$ & $\begin{array}{c}\text { Optimiza los procesos } \\
\text { logísticos }\end{array}$ & $\begin{array}{l}\text { No tenga impacto } \\
\text { significativo en los } \\
\text { procesos logísticos }\end{array}$ \\
\hline Ecológico & $\begin{array}{l}\text { Responsabilidad } \\
\text { ambiental }\end{array}$ & $\begin{array}{l}\text { Mejora la percepción de los } \\
\text { stakeholders }\end{array}$ & $\begin{array}{l}\text { No impacta en la } \\
\text { percepción de los } \\
\text { stakeholders }\end{array}$ \\
\hline
\end{tabular}

Nota. El texto escrito en color rojo representa escenarios negativos.

\section{Escenario - Más Probable}

Los factores que presentan un impacto negativo en este escenario se encuentran en el aspecto político - gubernamental. Por su lado, el potencial aumento de la informalidad, concepto que involucra la competencia desleal, generaría la incursión de sustitutos para los servicios pertenecientes a la logística no integral. Sin embargo, si bien estos servicios no son los mismos que Ransa ofrece en la calidad de logística integral, podrían ser atractivos para clientes que se encuentran perdiendo ventas, estableciendo relaciones contractuales con estos proveedores basados en un menor precio, incluso si aquello implica reducir la calidad de sus servicios. 
Por otro lado, el incumplimiento o cumplimiento a media del Plan Nacional de Infraestructura, provocaría que los costos de operación se mantengan constantes, debido a que la industria de operadores logísticos lleva años operando en las condiciones actuales; por ello, el impacto no sería notorio, todo lo contrario de que si éste fuera realizado por completo.

Por último, los otros factores muestran impactos favorables para la estrategia de eficiencia operativa, diferenciación y desarrollo de producto.

\section{Escenario - Menos Probable}

El factor que presenta el mayor impacto negativo en este escenario se encuentra en el aspecto político - gubernamental, ya que de incumplirse el plan nacional de infraestructura resultaría en una reducción de los altos costos logísticos para las empresas de la industria, sobre todo para aquellas que alcanzan mayor territorio nacional. Cabe mencionar, que estos costos tienen un alto impacto sobre el precio de los productos, en un rango del 30\% al 40\% ("Altos costos logísticos afectan exportaciones peruanas," 04 de marzo de 2015).

Los otros factores con efecto negativo impactan sobre la demanda, operatividad de los procesos y la percepción de los stakeholders. En estos casos el impacto negativo no sería significativo, ya que éste puede ser solucionado por la empresa, desarrollando estrategias de eficiencia operativa, diferenciación y desarrollo de producto.

\subsubsection{Comparación de estrategias con escenarios.}

De acuerdo con la Tabla 38, se muestra el comparativo de los escenarios y las estrategias identificadas anteriormente; mostrando, además, que la estrategia de eficiencia operativa resulta "muy favorable" para el escenario más probable, dado que las ventas se incrementarían y los costos se reducirían significativamente, incrementando la rentabilidad de la empresa y generando 
un efecto dominó en las potenciales inversiones que la empresa podría desarrollar en relación a la estrategia mencionada, lo cual mejoraría la competitividad de ésta en relación al concepto de "liderazgo en costos"; por otro lado, en el escenario menos probable la estrategia de eficiencia operativa permanece siendo "muy favorable", dado que el impacto de reducir la informalidad disminuiría la competencia desleal de los productos sustitutos y en consecuencia las ventas de los servicios actuales de Ransa se mantendrían o aumentarían, reflejando el mismo comportamiento sobre la rentabilidad de la empresa.

Tabla 38

Comparativo de estrategias con escenarios propuesto

\section{Estrategia}

Eficiencia operativa

Diferenciación

Desarrollo de producto
Más Probable Muy favorable

Favorable

Favorable
Menos Probable

Muy favorable

Favorable

Favorable

Además, bajo el mismo sentido, las estrategias de diferenciación y desarrollo de producto resultan "favorables" en el escenario más probable y menos probable, ofreciendo ambas estrategias resultados aceptables.

\subsection{Matriz de planeación estratégica cuantitativa (MPEC)}

Esta herramienta toma como entradas el resultado de los insumos de la primera etapa y el resultado del emparejamiento de la segunda etapa, permitiendo evaluar y seleccionar objetivamente las estrategias. De este modo, la matriz CPE evalúa la atractividad de las estrategias retenidas en la matriz de decisión frente a las oportunidades, amenazas, fortalezas y debilidades de la empresa. Ver la Tabla 39.

Para completar la matriz Cuantitativa de Planeamiento Estratégico se tuvo asistencia de Magnolia Padilla, subgerente de Operaciones. 
Tabla 39

Matriz cuantitativa del planeamiento estratégico (MCPE)

\begin{tabular}{|c|c|c|c|c|c|c|c|}
\hline \multirow[b]{2}{*}{ Matriz EFI } & \multirow[b]{2}{*}{ Peso } & \multicolumn{2}{|c|}{$\begin{array}{l}\text { Eficiencia } \\
\text { operativa }\end{array}$} & \multicolumn{2}{|c|}{ Diferenciación } & \multicolumn{2}{|c|}{$\begin{array}{l}\text { Desarrollo de } \\
\text { producto }\end{array}$} \\
\hline & & Calif. & $\mathbf{P} \times \mathbf{C}$ & Calif. & $\mathbf{P} \times \mathbf{C}$ & Calif. & $\mathbf{P} \times \mathbf{C}$ \\
\hline \multicolumn{8}{|l|}{ Fortalezas } \\
\hline 1. Infraestructura logística & 0.16 & 4 & 0.64 & 4 & 0.64 & 4 & 0.64 \\
\hline $\begin{array}{l}\text { 2. Experiencia y posicionamiento en el sector } \\
\text { 3. Cobertura a nivel nacional de las operaciones }\end{array}$ & 0.11 & 4 & 0.44 & 4 & 0.44 & 4 & 0.44 \\
\hline logísticas & 0.12 & 4 & 0.48 & 4 & 0.48 & 4 & 0.48 \\
\hline $\begin{array}{l}\text { 4. Manejo de altos estándares de seguridad en las } \\
\text { operaciones logísticas }\end{array}$ & 0.12 & 4 & 0.48 & 3 & 0.36 & 4 & 0.48 \\
\hline $\begin{array}{l}\text { 5. Sistemas de información propios integrados al } \\
\text { sistema de los clientes } \\
\text { 6. Capacidad para desarrollar proyectos }\end{array}$ & 0.10 & 4 & 0.40 & 3 & 0.30 & 3 & 0.30 \\
\hline innovadores & 0.10 & 4 & 0.40 & 1 & 0.10 & 3 & 0.30 \\
\hline \multicolumn{8}{|l|}{ Debilidades } \\
\hline 1. Relaciones contractuales débiles & 0.06 & 3 & 0.18 & 2 & 0.12 & 3 & 0.18 \\
\hline $\begin{array}{l}\text { 2. Deficiente asignación de recursos humanos en } \\
\text { la gestión de almacenes }\end{array}$ & 0.05 & 4 & 0.20 & 1 & 0.05 & 2 & 0.10 \\
\hline 3. Información no fehaciente & 0.05 & 3 & 0.15 & 1 & 0.05 & 1 & 0.05 \\
\hline 4. Falta de integración de las áreas de apoyo & 0.07 & 3 & 0.21 & 1 & 0.07 & 2 & 0.14 \\
\hline 5. Alta estructura de costos operativos & 0.07 & 4 & 0.28 & 1 & 0.07 & 2 & 0.14 \\
\hline Sumatoria de F y D & 1 & & 3.86 & & 2.68 & & 3.25 \\
\hline Matriz EFE & Peso & & & & & & \\
\hline \multicolumn{8}{|l|}{ Oportunidades } \\
\hline 1. Plan Nacional de Infraestructura & 0.12 & 4 & 0.48 & 1 & 0.12 & 4 & 0.48 \\
\hline 2. Tratados de Libre Comercio & 0.10 & 4 & 0.40 & 4 & 0.40 & 4 & 0.40 \\
\hline $\begin{array}{l}\text { 3. Reglas de la Haya - Visby y Hamburgo } \\
\text { 4. Crecimiento Económico en el Perú y América }\end{array}$ & 0.04 & 4 & 0.16 & 4 & 0.16 & 4 & 0.16 \\
\hline Latina & 0.11 & 4 & 0.44 & 4 & 0.44 & 4 & 0.44 \\
\hline 5. Tecnología, soporte de la actividad logística & 0.10 & 4 & 0.40 & 4 & 0.40 & 4 & 0.40 \\
\hline 6. Tendencias globales de consumo & 0.10 & 4 & 0.40 & 1 & 0.10 & 4 & 0.40 \\
\hline \multicolumn{8}{|l|}{ Amenazas } \\
\hline 1. Falta de infraestructura nacional vial & 0.11 & 1 & 0.11 & 1 & 0.11 & 1 & 0.11 \\
\hline 2. La informalidad laboral en el Perú & 0.10 & 1 & 0.10 & 4 & 0.40 & 1 & 0.10 \\
\hline 3. Aumento de las exigencias medioambientales & 0.05 & 1 & 0.05 & 4 & 0.20 & 1 & 0.05 \\
\hline 4. Inestabilidad social y política del país & 0.11 & 1 & 0.11 & 1 & 0.11 & 1 & 0.11 \\
\hline $\begin{array}{l}\text { 5. Corrupción en las licitaciones de proyectos } \\
\text { gubernamentales de infraestructura }\end{array}$ & 0.07 & 1 & 0.07 & 1 & 0.07 & 1 & 0.07 \\
\hline Sumatoria de O y A & 1 & & 2.72 & & 2.51 & & 2.72 \\
\hline Suma Total & 2 & & 6.58 & & 5.19 & & 5.97 \\
\hline
\end{tabular}

Nota. Adaptado de El proceso estratégico: Un enfoque de gerencia (p. 340), por F. D’Alessio, 2008, México D.F.: Pearson Educación.

El resultado de la matriz MCPE indica que la estrategia de eficiencia operativa alcanza la puntuación más alta con 6.58, seguida de la estrategia de desarrollo de producto con 5.97 puntos. De este modo, se obtienen las estrategias más apropiadas para alcanzar los objetivos propuestos. 


\subsection{Descripción de estrategia seleccionada}

La estrategia de eficiencia operativa, implica que Ransa Comercial S.A. debe hacer seguimiento y monitoreo a los procesos que estén generando sobretiempo y sobrecostos en las operaciones de cada uno de sus principales servicios ofrecidos, siendo estos los servicios de transporte, almacenaje y distribución.

Siendo así, se deben implementar acciones enfocadas en lo siguiente: (a) obtención de información fehaciente, en tiempo real, de las operaciones de cada cliente; (b) colaboración del equipo de trabajo; y (c) eliminación de actividades improductivas. Estas acciones ofrecerán una propuesta de valor que involucre la implementación de proyectos de mejora de procesos y uso de tecnología que permita agilizar el flujo en el almacén y un monitoreo proactivo de las unidades de transporte y distribución, impactando en la disminución del costo operativo.

\subsection{Descripción de estrategia contingente}

La estrategia de desarrollo de producto, implica que Ransa Comercial S.A. debe desarrollar nuevas competencias y capacidades para cumplir con las nuevas exigencias del mercado, buscando crear o mejorar las características o atributos de los principales servicios ofrecidos.

Las primeras acciones alineadas a esta estrategia son: (a) sumar a la experiencia profesional de los colaboradores diversas capacitaciones y certificaciones, logrando así un mayor rendimiento dentro de las operaciones; (b) implementar tecnología avanzada que permita a la empresa presentar dimensiones distintas de sus servicios ofrecidos; y (c) añadir valor social o emocional al producto final. 


\section{Implantación de la estrategia}

\subsection{Mapa de la estrategia}

El mapa de la estrategia es una herramienta de gestión que convierte la estrategia en objetivos relacionados, los cuales se miden a través de indicadores y se ligan a planes de acción que alinean el comportamiento de la organización (Fernández, 2001).

De acuerdo con la Figura 18, se especifica lo siguiente.

Perspectiva financiera: Se consideran los objetivos específicos: rentabilidad, incrementar el nivel de ventas y reducir los costos operativos.

Perspectiva del cliente: Se consideran los objetivos específicos: mejorar el servicio ofrecido y la gestión comercial.

Estos objetivos se determinaron en base a los resultados de las encuestas a clientes en donde se evaluó la percepción de éstos en cuanto al soporte comercial que reciben, arrojando los siguientes resultados: solo el $30.23 \%$ de los clientes alcanza a recibir apoyo comercial, señalando además que éstos suelen tener tiempos de respuesta muy altos; el $27.91 \%$ señala que la empresa debe ser más proactiva y brindar nuevas soluciones; el $48.84 \%$ señala que la gestión de reclamos debe mejorar los tiempos de respuesta. Ver Anexo 06.

Por otro lado, la evaluación de Ransa frente al entendimiento de las necesidades de los clientes obtuvo los siguientes resultandos: el $27.91 \%$ señala que la empresa debe realizar visitas operativas para comprender mejor las necesidades; el 23. $26 \%$ señala que la empresa debe brindar soluciones innovadoras para adaptar sus servicios las necesidades de cada cliente. Ver Anexo 06. 
Perspectiva de procesos internos: Se consideran los objetivos específicos: Optimizar procesos, recursos y mejorar la visibilidad y trazabilidad.

Estos objetivos se determinaron en base a los resultados de las encuestas a clientes en donde se evaluó el acceso a información de los servicios contratados, arrojando los siguientes resultados: el 41.86\% indica que no reciben indicadores de gestión ni cuentan con visibilidad; el 27.91\% indica que se mejore la actualización y presentación de los indicadores y el plan de acción sobre éstos; el $41.86 \%$ indica que la empresa debe brindar más alternativas de solución respecto a sus procesos. (Ver anexo 06)

Perspectiva del aprendizaje y crecimiento: Se consideran los objetivos específicos: Crear una cultura de calidad e innovación, y potenciar el liderazgo.

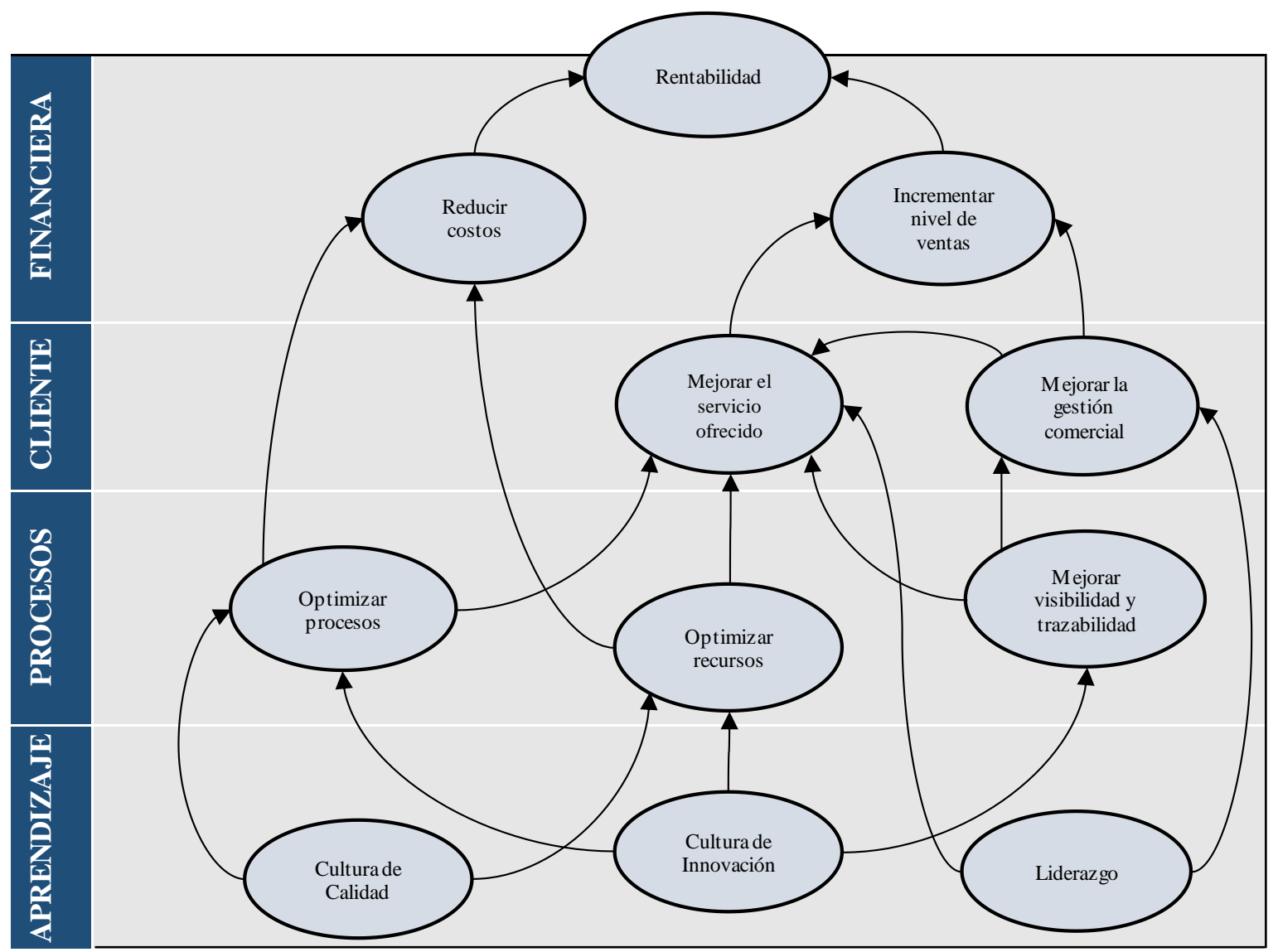

Figura 18. Mapa estratégico. Adaptado de "El Balanced Scorecard: ayudando a implantar la estrategia", por A. Fernández, 2001, Recuperado de https://bit.ly/2Wj1r2H 


\subsection{Objetivos específicos según el mapa de la estrategia}

De acuerdo con el mapa de la estrategia, la Tabla 40 desarrolla los objetivos específicos considerados en cada perspectiva.

Tabla 40

Objetivos específicos

\section{Objetivos Específicos}

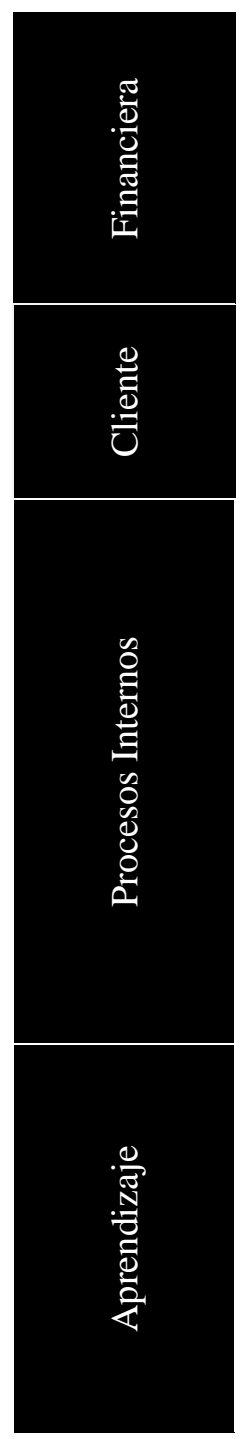

Incrementar el nivel de ventas

Reducir los gastos de personal

Reducir los costos operativos (manipuleo, materiales, mantenimiento, etc.)

Mejorar los servicios ofrecidos

Mejorar la gestión comercial

Estandarizar la gestión de procesos y proyectos, logrando la interoperabilidad

Implementar mejoras tecnológicas que disminuyan el costo operativo

Impulsar la cooperación entre las unidades de negocio para lograr sinergia y eficiencia de los recursos compartidos.

Desarrollar un modelo de economía circular para operar de manera eficiente sobre una base de respeto medioambiental

Desarrollar un clima laboral atractivo para los colaboradores

Desarrollar la habilidad de liderazgo en los colaboradores con personal a cargo

Desarrollar una cultura de calidad

Desarrollar una cultura de innovación 


\subsection{Indicadores para cada uno de los objetivos específicos}

En la Tabla 41 se establece los indicadores de cada uno de los objetivos específicos, indicadores que serán medidos y controlados periódicamente.

Tabla 41

Indicadores asociados a los objetivos específicos

Objetivos Específicos

Indicadores

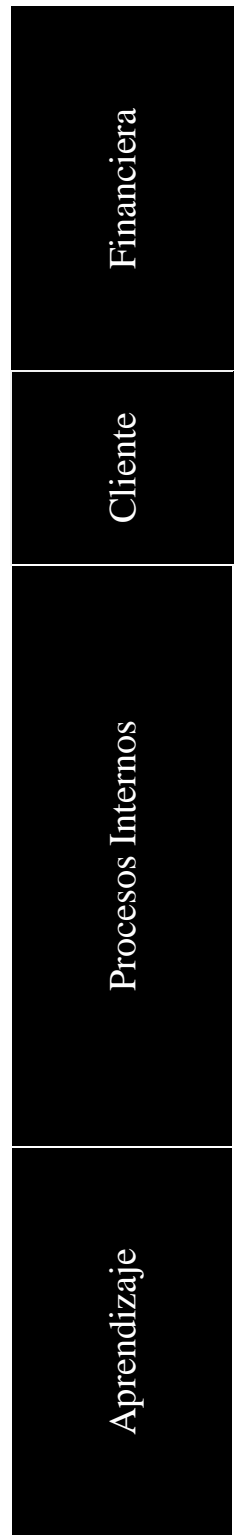

\begin{tabular}{|l|} 
Incrementar el nivel de ventas \\
\hline Reducir los gastos de personal
\end{tabular}

Crecimiento de ventas

[(GP año 1 - GP año 0) / (GP año 0$)] \times 100 \%, \mathrm{GP}=$ Gastos de personal

Reducir los costos operativos (manipuleo, materiales, mantenimiento, etc.)

[(CO año 1 - CO año 0) / (CO año 0$)] \times 100 \%, C O=$ Costos operativos

Mejorar el servicio ofrecido

Mejorar la gestión comercial

Porcentaje de clientes satisfechos

Estandarizar la gestión de procesos y proyectos, logrando la interoperabilidad

Cantidad de procesos operativos mapeados, Implementar mejoras tecnológicas que disminuyan el costo operativo

Cantidad de proyectos $y$ mejoras implementadas

Impulsar la cooperación entre las unidades de negocio

Horas extras / Horas trabajadas para lograr sinergia y eficiencia de los recursos compartidos.

Cantidad de equipos utilizados

Desarrollar un modelo de economía circular para operar de manera eficiente sobre una base de respeto medioambiental

Cantidad de iniciativas de iniciativas implementadas

Desarrollar un clima laboral atractivo para los colaboradores

Desarrollar la habilidad de liderazgo en los colaboradores con personal a cargo

Desarrollar una cultura de calidad

Cumplimiento de las 5S

Desarrollar una cultura de innovación

Ideas del personal implementadas / Ideas totales 


\subsection{Metas para cada uno de los objetivos específicos}

En la Tabla 42 se indica las metas fijadas a cada uno de los objetivos específicos, metas que serán medidas y controladas por los indicadores establecidos (ver Tabla 41).

Tabla 42

Metas asociadas a los objetivos específicos

Objetivos Específicos

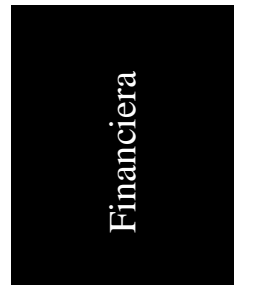

$\stackrel{0}{\frac{1}{0}}$

0
0
0
0
0
0
0
0
0
0

\begin{tabular}{|c|c|c|}
\hline Objetivos Específicos & Unidades & Meta \\
\hline Incrementar el nivel de ventas & $\%$ & $3 \%$ \\
\hline Reducir los gastos de personal & $\%$ & $1 \%$ \\
\hline $\begin{array}{l}\text { Reducir los costos operativos (manipuleo, materiales, } \\
\text { mantenimiento, etc.) }\end{array}$ & $\%$ & $0.5 \%$ \\
\hline Mejorar el servicio ofrecido & \multirow{2}{*}{$\%$} & \multirow{2}{*}{$6.84 \%$} \\
\hline Mejorar la gestión comercial & & \\
\hline $\begin{array}{l}\text { Estandarizar la gestión de procesos y proyectos, logrando } \\
\text { la interoperabilidad }\end{array}$ & $\%$ & $87 \%$ \\
\hline $\begin{array}{l}\text { Implementar mejoras tecnológicas que disminuyan el costo } \\
\text { operativo }\end{array}$ & $\%$ & $98 \%$ \\
\hline \multirow{2}{*}{$\begin{array}{l}\text { Impulsar la cooperación entre las unidades de negocio para } \\
\text { lograr sinergia y eficiencia de los recursos compartidos. }\end{array}$} & $\%$ & $<=5 \%$ \\
\hline & $\%$ & $95 \%$ \\
\hline $\begin{array}{l}\text { Desarrollar un modelo de economía circular para operar de } \\
\text { manera eficiente sobre una base de respeto } \\
\text { medioambiental }\end{array}$ & $\%$ & $50 \%$ \\
\hline $\begin{array}{l}\text { Desarrollar un clima laboral atractivo para los } \\
\text { colaboradores }\end{array}$ & \multirow{2}{*}{$\%$} & \multirow{2}{*}{$90 \%$} \\
\hline $\begin{array}{l}\text { Desarrollar la habilidad de liderazgo en los colaboradores } \\
\text { con personal a cargo }\end{array}$ & & \\
\hline Desarrollar una cultura de calidad & $\%$ & $90 \%$ \\
\hline Desarrollar una cultura de innovación & $\%$ & $>=20 \%$ \\
\hline
\end{tabular}




\subsection{Iniciativas (acciones a llevar a cabo para cada uno de los objetivos específicos) estrategias, programas, políticas, reglas, procedimientos}

En la Tabla 43 se ha definido 17 iniciativas, pudiendo impactar cada una en más de un objetivo específico. El análisis se realiza evaluando las iniciativas con cada uno de los objetivos; si la iniciativa tiene algún grado de impacto (bajo, medio, alto) sobre el objetivo, la casilla de intersección se marca con una $x$. Por último, se suma verticalmente las casillas marcadas y se determina el total por iniciativa, priorizando las iniciativas de mayor resultado. 
Tabla 43

Iniciativas asociadas a los objetivos específicos

\begin{tabular}{|c|c|c|c|c|c|c|c|c|}
\hline Objetivos Específicos & $\begin{array}{l}\text { Retomar } \\
\text { relaciones } \\
\text { con } \\
\text { antiguos } \\
\text { clientes y } \\
\text { definir } \\
\text { acciones } \\
\text { para } \\
\text { ampliar la } \\
\text { cartera }\end{array}$ & $\begin{array}{c}\text { Co-crear } \\
\text { un nuevo } \\
\text { proceso } \\
\text { de } \\
\text { cotizacio } \\
\text { nes más } \\
\text { agil, sin } \\
\text { fricciones } \\
\text { y } \\
\text { centrado } \\
\text { en los } \\
\text { clientes } \\
\end{array}$ & $\begin{array}{c}\text { Elaborar } \\
\text { instructivos } \\
\text { de uso de } \\
\text { materiales, } \\
\text { equipos, } \\
\text { sistemas, } \\
\text { etc }\end{array}$ & $\begin{array}{c}\text { Utilizar } \\
\text { NPS para } \\
\text { medir la } \\
\text { lealtad de } \\
\text { los clientes }\end{array}$ & $\begin{array}{c}\text { Elaborar } \\
\text { planes de } \\
\text { contingenci } \\
\text { a antes } \\
\text { situaciones } \\
\text { de riesgo }\end{array}$ & $\begin{array}{c}\text { Implement } \\
\text { ar Power } \\
\text { BI para } \\
\text { compartir } \\
\text { indicadores } \\
\text {, análisis y } \\
\text { planes }\end{array}$ & $\begin{array}{l}\text { Implementar } \\
\text { Softeon } \\
\text { WMS para la } \\
\text { gestión de } \\
\text { almacenes }\end{array}$ & $\begin{array}{l}\text { Implement } \\
\text { ar Drivin } \\
\text { para la } \\
\text { gestión de } \\
\text { transporte }\end{array}$ \\
\hline Incrementar el nivel de ventas & $\mathrm{X}$ & $\mathrm{X}$ & & $\mathrm{X}$ & & $\mathrm{X}$ & $\mathrm{X}$ & $\mathrm{X}$ \\
\hline $\begin{array}{l}\text { Reducción y mejoramiento de } \\
\text { los costos operativos }\end{array}$ & & & $\mathrm{X}$ & & & & & \\
\hline $\begin{array}{l}\text { Conocer a los clientes e } \\
\text { incrementar su lealtad }\end{array}$ & & & & $\mathrm{X}$ & $\mathrm{X}$ & $\mathrm{X}$ & & \\
\hline $\begin{array}{l}\text { Ofrecer procesos } \\
\text { automatizados }\end{array}$ & & & & & & $\mathrm{X}$ & $\mathrm{X}$ & $\mathrm{X}$ \\
\hline $\begin{array}{l}\text { Estandarizar la gestión de } \\
\text { procesos y proyectos }\end{array}$ & & $\mathrm{X}$ & & & & & $\mathrm{X}$ & $\mathrm{X}$ \\
\hline $\begin{array}{l}\text { Impulsar la investigación y } \\
\text { desarrollo de nuevas } \\
\text { tecnologías }\end{array}$ & & & & & & & $\mathrm{X}$ & $\mathrm{X}$ \\
\hline $\begin{array}{l}\text { Implementar mejoras } \\
\text { tecnológicas que disminuyan } \\
\text { el costo operativo }\end{array}$ & & & & & & $\mathrm{X}$ & $\mathrm{X}$ & $\mathrm{X}$ \\
\hline \multicolumn{9}{|l|}{$\begin{array}{l}\text { Desarrollar un modelo de } \\
\text { economía circular }\end{array}$} \\
\hline $\begin{array}{l}\text { Integrar los sistemas de } \\
\text { información }\end{array}$ & & & & & & & $\mathrm{X}$ & $\mathrm{X}$ \\
\hline $\begin{array}{l}\text { Estandarizar los procesos } \\
\text { operativos de las unidades de } \\
\text { negocio }\end{array}$ & & & $\mathrm{X}$ & & & & & \\
\hline $\begin{array}{l}\text { Impulsar la cooperación entre } \\
\text { las unidades de negocio }\end{array}$ & & & & & $\mathrm{X}$ & & & \\
\hline \multicolumn{9}{|l|}{$\begin{array}{l}\text { Desarrollar un clima laboral } \\
\text { atractivo para los } \\
\text { colaboradores }\end{array}$} \\
\hline $\begin{array}{l}\text { Desarrollar la habilidad de } \\
\text { liderazgo de colaboradores } \\
\text { con un equipo a cargo }\end{array}$ & & & & & $\mathrm{X}$ & & & \\
\hline $\begin{array}{l}\text { Disponer de colaboradores } \\
\text { que identifiquen y gestionen } \\
\text { iniciativas sostenibles }\end{array}$ & & & $\mathrm{X}$ & & & & & \\
\hline \multirow[t]{2}{*}{$\begin{array}{l}\text { Disponer de colaboradores } \\
\text { que gestionen proyectos }\end{array}$} & & $\mathrm{X}$ & & & $\mathrm{X}$ & $\mathrm{X}$ & $\mathrm{X}$ & $\mathrm{X}$ \\
\hline & 1 & 3 & 3 & 2 & 4 & 5 & 7 & 7 \\
\hline
\end{tabular}




\begin{tabular}{|c|c|c|c|c|c|c|c|c|c|}
\hline $\begin{array}{l}\text { Objetivos } \\
\text { Específicos }\end{array}$ & $\begin{array}{l}\text { Uso de RF } \\
\text { anillos en } \\
\text { almacén }\end{array}$ & $\begin{array}{c}\text { Implemear } \\
\text { MS } \\
\text { Planner } \\
\text { para la } \\
\text { gestión de } \\
\text { tareas y } \\
\text { proyectos }\end{array}$ & $\begin{array}{l}\text { Implement } \\
\text { ar Área de } \\
\text { mejora } \\
\text { Operativa }\end{array}$ & $\begin{array}{c}\text { Implement } \\
\text { ar } \\
\text { proyectos } \\
\text { bajo la } \\
\text { metodolog } \\
\text { ía lean }\end{array}$ & $\begin{array}{l}\text { Implementar } \\
\text { aplicativo } \\
\text { para } \\
\text { compartir } \\
\text { recursos } \\
\text { entre } \\
\text { almacenes }\end{array}$ & $\begin{array}{c}\text { Implementar } \\
\text { talleres de } \\
\text { integración } \\
\text { del personal }\end{array}$ & $\begin{array}{c}\text { Desarrollar } \\
\text { un programa } \\
\text { de Liderazgo } \\
\text { para } \\
\text { Supervisores } \\
\text {, Jefes y Sub } \\
\text { Gerentes }\end{array}$ & $\begin{array}{c}\text { Capacitar } \\
\text { al personal } \\
\text { en la } \\
\text { metología } \\
\text { lean six } \\
\text { sigma }\end{array}$ & $\begin{array}{l}\text { Capacitar al } \\
\text { personal en } \\
\text { metologías } \\
\text { ágiles }\end{array}$ \\
\hline $\begin{array}{l}\text { Incrementar el nivel } \\
\text { de ventas }\end{array}$ & $\mathrm{X}$ & & & & & & & & \\
\hline $\begin{array}{l}\text { Reducción y } \\
\text { mejoramiento de los } \\
\text { costos operativos }\end{array}$ & & & & & $X$ & & & $X$ & \\
\hline $\begin{array}{l}\text { Conocer a los clientes } \\
\text { e incrementar su } \\
\text { lealtad }\end{array}$ & & & & & & & & & \\
\hline $\begin{array}{l}\text { Ofrecer procesos } \\
\text { automatizados }\end{array}$ & $\mathrm{X}$ & & $\mathrm{X}$ & & & & & & \\
\hline $\begin{array}{l}\text { Estandarizar la } \\
\text { gestión de procesos y } \\
\text { proyectos }\end{array}$ & $X$ & $X$ & & $X$ & & & & & $X$ \\
\hline $\begin{array}{l}\text { Impulsar la } \\
\text { investigación y } \\
\text { desarrollo de nuevas } \\
\text { tecnologías }\end{array}$ & $X$ & & $X$ & & & & & & $X$ \\
\hline $\begin{array}{l}\text { Implementar mejoras } \\
\text { tecnológicas que } \\
\text { disminuyan el costo } \\
\text { operativo }\end{array}$ & $X$ & & $X$ & $X$ & $X$ & & & $X$ & $X$ \\
\hline $\begin{array}{l}\text { Desarrollar un } \\
\text { modelo de economía } \\
\text { circular }\end{array}$ & & & $\mathrm{X}$ & & & & & & \\
\hline $\begin{array}{l}\text { Integrar los sistemas } \\
\text { de información para } \\
\text { lograr sinergia en las } \\
\text { operaciones }\end{array}$ & & & & & & & & & \\
\hline $\begin{array}{l}\text { Estandarizar los } \\
\text { procesos operativos } \\
\text { de las unidades de } \\
\text { negocio }\end{array}$ & & & $X$ & $X$ & & & & $X$ & \\
\hline $\begin{array}{l}\text { Impulsar la } \\
\text { cooperación entre las } \\
\text { unidades de negocio }\end{array}$ & & & $X$ & & $X$ & & & & \\
\hline $\begin{array}{l}\text { Desarrollar un clima } \\
\text { laboral atractivo para } \\
\text { los colaboradores }\end{array}$ & & & & & & $X$ & $X$ & & \\
\hline $\begin{array}{l}\text { Desarrollar la } \\
\text { habilidad de } \\
\text { liderazgo de } \\
\text { colaboradores con un } \\
\text { equipo a cargo }\end{array}$ & & $X$ & $X$ & & & $X$ & $X$ & & \\
\hline $\begin{array}{l}\text { Disponer de } \\
\text { colaboradores que } \\
\text { identifiquen y } \\
\text { gestionen iniciativas } \\
\text { sostenibles }\end{array}$ & & & $X$ & $X$ & $X$ & & & $X$ & \\
\hline \multirow[t]{2}{*}{$\begin{array}{l}\text { Disponer de } \\
\text { colaboradores que } \\
\text { gestionen proyectos }\end{array}$} & $\mathrm{X}$ & $X$ & $X$ & & $X$ & & & & $\mathrm{X}$ \\
\hline & 6 & 3 & 9 & 4 & 5 & 2 & 2 & 4 & 4 \\
\hline
\end{tabular}




\subsection{Responsable de cada una de las iniciativas}

En la Tabla 44 se observa las iniciativas determinadas en la tabla anterior (ver Tabla 43), ordenadas de acuerdo con el resultado calculado. Además, se muestra los responsables asociados a cada una de las iniciativas.

Tabla 44

Responsables de iniciativa

\section{Iniciativas}

Retomar relaciones con antiguos clientes y definir acciones para ampliar la cartera

Co-crear un nuevo proceso de cotizaciones más ágil, sin fricciones y centrado en los clientes

Elaborar instructivos de uso de materiales, equipos, sistemas, etc.

Ofrecer certificado online a los clientes con resultado de huella de carbono

Utilizar NPS para medir la lealtad de los clientes

Elaborar planes de contingencia antes situaciones de riesgo que puedan afectar el flujo del servicio

Implementar Power BI para compartir indicadores, análisis y planes

Implementar Softeon WMS para la gestión de almacenes

Implementar Drivin para la gestión de transporte

Uso de RF anillos en almacén

Implementar MS Planner para la gestión de tareas y proyectos

Implementar Área de mejora Operativa

Implementar proyectos bajo la metodología lean

Implementar aplicativo para compartir recursos entre almacenes

Implementar talleres de integración del personal

Desarrollar un programa de Liderazgo para Supervisores, Jefes y Sub Gerentes

Capacitar al personal en la metodología lean six sigma

Capacitar al personal en metodologías ágiles

\section{Responsables}

Área Comercial

Área Comercial, Cotizaciones, Operaciones, TI, Finanzas y Compras

Área de Operaciones

Área de Calidad

Área Comercial

Área de Operaciones, RRHH, Servicios y TI

Área de Operaciones y Comercial

Área de Operaciones, Comercial y TI

Área de Operaciones, Comercial y TI

Área de Operaciones, Comercial y TI

Área de Operaciones

Área de Operaciones y RRHH

Área de Operaciones

Área de Operaciones y TI

Área de Operaciones y RRHH

Área de Operaciones y RRHH

Área de Operaciones y RRHH

Área de Operaciones y RRHH 


\subsection{Presupuesto de cada una de las iniciativas}

Se han presupuestado cada una de las iniciativas y a continuación, se detallarán las actividades relacionadas a las mismas:

\section{Retomar relaciones con antiguos clientes y definir acciones para ampliar la}

cartera: Tal como figura en la Tabla 45, esta iniciativa involucra la contratación de Ejecutivos de Negocios Junior que logren potenciar las relaciones con los clientes, generando visitas y propuestas atractivas para recuperarlos u obtener nuevas licitaciones.

Tabla 45

Costo Ejecutivo de Negocios Junior

\begin{tabular}{|ccccccc|}
\multicolumn{1}{c}{ Perfil } & Sueldo Básico & Adicional & $\begin{array}{c}\text { Costo } \\
\text { Empresa Mes }\end{array}$ & $\begin{array}{c}\text { Costo Empresa } \\
\text { Año }\end{array}$ & Cantidad & Costo Total \\
\hline $\begin{array}{c}\text { Ejecutivo de } \\
\text { Negocios Jr. }\end{array}$ & S/ 4,000 & S/ 2,000 & S/ 6,000 & S/ 80,000 & 2 & S/ 160,000 \\
& & & & & & S/ 160,000 \\
\hline
\end{tabular}

Co-crear un nuevo proceso de cotizaciones más ágil, sin fricciones y centrado

en los clientes: Es importante que los líderes de las áreas de Cotizaciones, TI, Operaciones, Finanzas y Servicios trabajen en conjunto y desarrollen un nuevo de proceso para obtener las cotizaciones de manera más rápida, tomando en cuenta que los posibles clientes exigen inmediatez para obtener las propuestas. De esta manera, tal como figura en la Tabla 46, se generarán reuniones semanales durante un mes para desarrollar la idea. 
Tabla 46

Costo de horas dedicadas al nuevo proceso de cotización

\begin{tabular}{|c|c|c|c|c|c|c|c|c|c|c|}
\hline Perfil & \multicolumn{2}{|c|}{ Sueldo Básico } & \multicolumn{2}{|c|}{ Adicional } & \multicolumn{2}{|c|}{$\begin{array}{c}\text { Costo } \\
\text { Empresa Mes }\end{array}$} & \multirow{2}{*}{$\begin{array}{c}\text { Dedicación } \\
\text { proyecto }\end{array}$} & \multirow{2}{*}{$\begin{array}{c}\text { Duración } \\
1 \text { mes }\end{array}$} & \multicolumn{2}{|c|}{$\begin{array}{l}\text { Costo Total } \\
\text { (horas } \\
\text { dedicadas) }\end{array}$} \\
\hline $\begin{array}{l}\text { Jefe de } \\
\text { Cotizaciones }\end{array}$ & $\mathrm{S} /$ & 7,000 & $\mathrm{~S} /$ & 3,500 & S/ & 10,500 & & & $\mathrm{~S} /$ & 1,615 \\
\hline Jefe de TI & $\mathrm{S} /$ & 7,000 & $\mathrm{~S} /$ & 3,500 & $\mathrm{~S} /$ & 10,500 & 1 día a la semana & $1 \mathrm{mes}$ & $\mathrm{S} /$ & 1,615 \\
\hline $\begin{array}{l}\text { Jefe de } \\
\text { Almacenes }\end{array}$ & $\mathrm{S} /$ & 7,000 & $\mathrm{~S} /$ & 3,500 & S/ & 10,500 & 1 día a la semana & 1 mes & S/ & 1,615 \\
\hline $\begin{array}{l}\text { Jefe de } \\
\text { Distribución }\end{array}$ & $\mathrm{S} /$ & 7,000 & $\mathrm{~S} /$ & 3,500 & S/ & 10,500 & 1 día a la semana & 1 mes & S/ & 1,615 \\
\hline $\begin{array}{l}\text { Analista de } \\
\text { Finanzas }\end{array}$ & $\mathrm{S} /$ & 3,000 & $\mathrm{~S} /$ & 1,500 & S/ & 4,500 & 1 día a la semana & 1 mes & $\mathrm{S} /$ & 692 \\
\hline \multirow[t]{2}{*}{$\begin{array}{l}\text { Jefe de } \\
\text { Servicios }\end{array}$} & $\mathrm{S} /$ & 7,000 & $\mathrm{~S} /$ & 3,500 & $\mathrm{~S} /$ & 10,500 & 1 día a la semana & 1 mes & $\mathrm{S} /$ & 1,615 \\
\hline & & & & & & & & & $\mathrm{S} /$ & 8,769 \\
\hline
\end{tabular}

Utilizar NPS para medir la lealtad de los clientes: Es importante contar con un indicador que mida la lealtad de los clientes basándose en las recomendaciones que dan a través de encuestas y entrevistas. De esta manera, como en la Tabla 47, dos semanas al año serán asignadas a realizar esta actividad.

Tabla 47

Costo de horas dedicadas a NPS

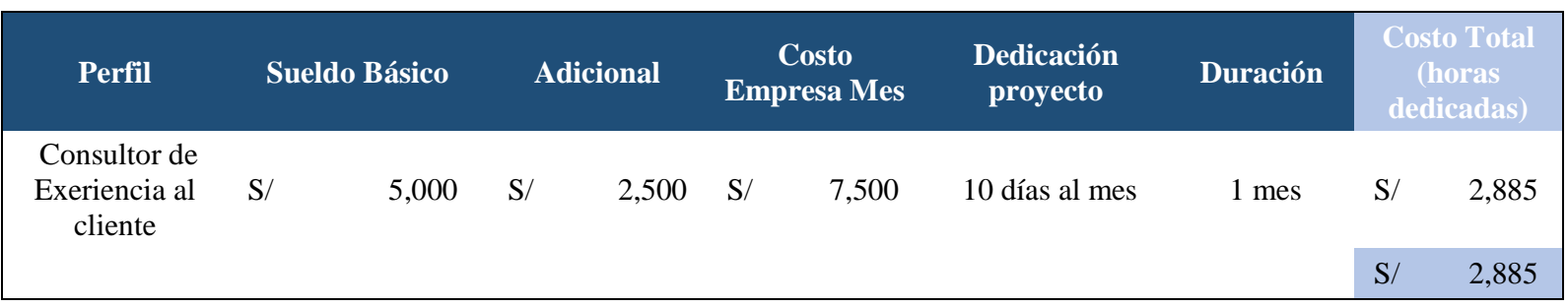

Implementar Área de mejora Operativa: Es importante contar con un equipo que desarrolle los proyectos, iniciativas y mejoras en las Operaciones, logrando optimizar procesos, reducir tiempos y aumentar la productividad. Por esta razón, tal como figura en la Tabla 48 y 49, se propone la contratación de ocho personas para la implementación del área, así como los equipos necesarios para operar. 
Tabla 48

Personal del área de Mejora Operativa

\begin{tabular}{|c|c|c|c|c|c|c|c|c|c|c|c|}
\hline Perfil & \multicolumn{2}{|c|}{ Sueldo Básico } & \multicolumn{2}{|c|}{ Adicional } & \multicolumn{2}{|c|}{$\begin{array}{c}\text { Costo } \\
\text { Empresa Mes }\end{array}$} & \multicolumn{2}{|c|}{$\begin{array}{c}\text { Costo Empresa } \\
\text { Año }\end{array}$} & Cantidad & \multicolumn{2}{|c|}{ Costo Total } \\
\hline $\begin{array}{c}\text { Supervisor de } \\
\text { Mejora } \\
\text { Operativa }\end{array}$ & S/ & 4,500 & S/ & 2,250 & $\mathrm{~S} /$ & 6,750 & $\mathrm{~S} /$ & 90,000 & 1 & $\mathrm{~S} /$ & 90,000 \\
\hline $\begin{array}{l}\text { Analista de } \\
\text { Mejora } \\
\text { Operativa }\end{array}$ & S/ & 3,200 & $\mathrm{~S} /$ & 1,600 & S/ & 4,800 & $\mathrm{~S} /$ & 64,000 & 1 & S/ & 64,000 \\
\hline $\begin{array}{c}\text { Practicante de } \\
\text { Mejora } \\
\text { Operativa }\end{array}$ & $\mathrm{S} /$ & 1,100 & & & $\mathrm{~S} /$ & 1,100 & $\mathrm{~S} /$ & 14,300 & 6 & S/ & 85,800 \\
\hline & & & & & & & & & & $\mathrm{S} /$ & 239,800 \\
\hline
\end{tabular}

Tabla 49

Equipos del área de Mejora Operativa

\begin{tabular}{|ccccccr|}
\hline Equipo/Inmueble & \multicolumn{2}{c}{ Costo } & Cantidad & \multicolumn{2}{c|}{ Costo Total } \\
\hline $\begin{array}{c}\text { Alquiler } \\
\text { Contenedor 40" }\end{array}$ & S/ & 1,000 & 2 & S/ & 2,000 \\
Laptop & S/ & 1,900 & 2 & S/ & 3,800 \\
Mouse & S/ & 30 & 2 & S/ & 60 \\
$\begin{array}{c}\text { Impresora } \\
\text { Multifuncional } \\
\text { Equipo de } \\
\text { cómputo (incluye } \\
\text { teclado y mouse) }\end{array}$ & S/ & 125 & 1 & S/ & 125 \\
\hline
\end{tabular}

Implementar aplicativo para compartir recursos entre almacenes: El objetivo

de estas iniciativas es evitar horas ociosas y horas extras, logrando mayor eficiencia en las operaciones (Ver tabla 50 y 51). 
Tabla 50

Inversión aplicativo web y móvil

\begin{tabular}{|c|c|c|c|c|c|}
\hline Descripción & & Costo & Cantidad & & Costo Total \\
\hline $\begin{array}{l}\text { Desarrollo de } \\
\text { aplicación móvil } \\
\text { Android }\end{array}$ & $\mathrm{S} /$ & 8,500 & 1 & S/ & 8,500 \\
\hline $\begin{array}{l}\text { Desarrollo de } \\
\text { aplicación móvil } \\
\text { iOS. }\end{array}$ & $\mathrm{S} /$ & 9,500 & 1 & $\mathrm{~S} /$ & 9,500 \\
\hline \multirow[t]{4}{*}{$\begin{array}{c}\text { Desarrollo de } \\
\text { administrador Web }\end{array}$} & $\mathrm{S} /$ & 21,500 & 1 & $\mathrm{~S} /$ & 21,500 \\
\hline & & & Subtotal & $\mathrm{S} /$ & 39,500 \\
\hline & & & IGV (18\%) & $\mathrm{S} /$ & 7,110 \\
\hline & & & & S/ & 46,610 \\
\hline
\end{tabular}

Tabla 51

Costo servicio de soporte

\begin{tabular}{cccccccc|} 
Descripción & \multicolumn{2}{c}{ Costo } & Cantidad & Costo Mes & \multicolumn{2}{c|}{ Costo Total } \\
$\begin{array}{c}\text { Servicio de } \\
\text { soporte }\end{array}$ & S/ & 700 & 1 & 700 & S/ & 8,400 \\
\cline { 4 - 7 } & & & & & & S/ & 8,400 \\
\hline
\end{tabular}

\section{Implementar Power BI para compartir indicadores, análisis y planes: El}

objetivo de esta iniciativa es contar con una plataforma que permita compartir KPI's acordados con los clientes de almacenaje y distribución, determinando tendencias y planes. Además, es importante que se tenga acceso vía web y app móvil.

Asimismo, se generarían accesos para todos los usuarios que el cliente requiera, personalizando las vistas. Por esta razón, tal como figura en la Tabla 52 y 53 se contempla una capacitación en Power BI y la adquisión de licencias. 
Tabla 52

Costo Curso Power Bi

\begin{tabular}{|ccccccc|}
\hline Descripción & \multicolumn{2}{c}{ Inversión } & \multicolumn{2}{c|}{ Cantidad } & \multicolumn{2}{c|}{$\begin{array}{c}\text { Inversión } \\
\text { Total }\end{array}$} \\
$\begin{array}{c}\text { Curso Power } \\
\text { BI Pro Analista }\end{array}$ & S/ & \multirow{2}{*}{990} & & 3 & S/ & 2,970 \\
\cline { 3 - 6 } & & & & & S/ & 2,970 \\
& & & & & \\
\hline
\end{tabular}

Tabla 53

Costo Licencia Power Bi

\begin{tabular}{|c|c|c|c|c|c|c|}
\hline \multirow{3}{*}{$\begin{array}{l}\text { Licencia Power } \\
\text { BI }\end{array}$} & & Costo & Cantidad & Costo Mes & \multicolumn{2}{|c|}{ Costo Total } \\
\hline & S/ & 34 & 1 & 34 & $\mathrm{~S} /$ & 408 \\
\hline & & & & & $\mathrm{S} /$ & 408 \\
\hline
\end{tabular}

Implementar Softeon WMS para la gestión de almacenes: En Ransa aún se tienen clientes manuales, es decir no cuentan con un sistema eficiente para gestionar sus operaciones y emitir reportes. Por esta razón, dada la importancia del caso, se considera la implementación de un WMS en las diferentes cuentas.

En la Tabla 54 se puede observar por año los clientes contemplados para la implementación de Softeon WMS, así como la inversión. De igual manera, en la Tabla 55 se tiene el recurrente anual. 
Tabla 54

Inversión Softeon WMS

\begin{tabular}{|c|c|c|c|c|c|c|c|c|c|}
\hline Año & Cuenta & Descripción & \multicolumn{2}{|c|}{ Inversión } & Cantidad & \multicolumn{4}{|c|}{ Inversión Total } \\
\hline \multirow{4}{*}{2019} & \multirow{4}{*}{ Sodexo } & $\begin{array}{c}\text { Configuración } \\
\text { del Sistema }\end{array}$ & $\mathrm{S} /$ & 61,200 & 1 & $\mathrm{~S} /$ & 61,200 & \multirow{4}{*}{ S/ } & \multirow{4}{*}{79,621} \\
\hline & & Licencias & $\mathrm{S} /$ & 752 & 5 & $\mathrm{~S} /$ & 3,759 & & \\
\hline & & WIFI & $\mathrm{S} /$ & 9,775 & 1 & $\mathrm{~S} /$ & 9,775 & & \\
\hline & & Puntos de Red & $\mathrm{S} /$ & 977 & 5 & S/ & 4,887 & & \\
\hline \multirow{4}{*}{2020} & \multirow{4}{*}{ Hilti } & $\begin{array}{l}\text { Configuración } \\
\text { del Sistema }\end{array}$ & $\mathrm{S} /$ & 61,200 & 1 & S/ & 61,200 & \multirow{4}{*}{ S/ } & \multirow{4}{*}{79,621} \\
\hline & & Licencias & S/ & 752 & 5 & $\mathrm{~S} /$ & 3,759 & & \\
\hline & & WIFI & $\mathrm{S} /$ & 9,775 & 1 & S/ & 9,775 & & \\
\hline & & Puntos de Red & $\mathrm{S} /$ & 977 & 5 & S/ & 4,887 & & \\
\hline \multirow{4}{*}{2021} & \multirow{4}{*}{$\mathrm{J} \& \mathrm{~J}$} & $\begin{array}{l}\text { Configuración } \\
\text { del Sistema }\end{array}$ & S/ & 61,200 & 1 & S/ & 61,200 & \multirow{4}{*}{ S/ } & \multirow{4}{*}{79,621} \\
\hline & & Licencias & $\mathrm{S} /$ & 752 & 5 & $\mathrm{~S} /$ & 3,759 & & \\
\hline & & WIFI & $\mathrm{S} /$ & 9,775 & 1 & S/ & 9,775 & & \\
\hline & & Puntos de Red & $\mathrm{S} /$ & 977 & 5 & S/ & 4,887 & & \\
\hline \multirow{5}{*}{2022} & \multirow{5}{*}{ Delosi } & $\begin{array}{l}\text { Configuración } \\
\text { del Sistema }\end{array}$ & $\mathrm{S} /$ & 61,200 & 1 & S/ & 61,200 & \multirow{5}{*}{ S/ } & \multirow{4}{*}{79,621} \\
\hline & & Licencias & $\mathrm{S} /$ & 752 & 5 & S/ & 3,759 & & \\
\hline & & WIFI & $\mathrm{S} /$ & 9,775 & 1 & S/ & 9,775 & & \\
\hline & & Puntos de Red & $\mathrm{S} /$ & 977 & 5 & S/ & 4,887 & & \\
\hline & & & & & & $\mathrm{S} /$ & & & 318,486 \\
\hline
\end{tabular}

Tabla 55

Recurrente anual Softeon WMS

\begin{tabular}{|cccr|}
\hline Año & Cuenta & \multicolumn{2}{c|}{$\begin{array}{c}\text { Recurrente } \\
\text { anual }\end{array}$} \\
\hline 2019 & Sodexo & S/ & 3,230 \\
2020 & Hilti & S/ & 6,460 \\
2021 & J\&J & S/ & 9,690 \\
2022 & Delosi & S/ & 12,920 \\
\cline { 3 - 4 } & & S/ & 22,610 \\
\hline
\end{tabular}


Implementar Drivin para la gestión de transporte: En importante contar con un sistema para transporte y distribución que permita revisar en tiempo real el recorrido de los conductores y tomar acciones en caso no se logre cumplir con lo planificado sin afectar a los clientes. Además, que permita la planificación de rutas, cumpliendo con las entregas en tiempo y forma, y que genere reportes o indicadores. Por esta razón, tal como figura en la Tabla 56, se propone invertir en el sistema Drivin.

Tabla 56

Inversión Drivin

\begin{tabular}{|lccccccc|}
\hline Año & Cuenta & \multicolumn{2}{c}{ Inversión } & Cantidad & \multicolumn{2}{l|}{ Inversión Total } \\
\hline 2020 & Varias & S/ & 70,000 & & 1 & S/ & 70,000 \\
\cline { 4 - 7 } & & & & & S/ & 70,000 \\
\hline
\end{tabular}

Uso de RF anillos en almacén: El RF anillos es una herramienta que permite a los trabajadores operar con manos libres. Además, aumenta la productividad, es de fácil manejo y es adaptable a cualquier tipo de operación. De esta manera, tal como figura en la tabla 57, se está considerando la inversión de RF anillos en los clientes que ya cuentan con Softeon.

Tabla 57

Inversión RF anillos

\begin{tabular}{|cccccccc|}
\hline Año & Cuenta & \multicolumn{2}{c}{ Inversión } & Cantidad & \multicolumn{2}{c|}{ Inversión Total } \\
\hline 2019 & Listo, Oriflame & S/ & 9,775 & 15 & S/ & 146,620 \\
2020 & $\begin{array}{c}\text { Arcor, Industrias } \\
\text { del Espino }\end{array}$ & S/ & 9,775 & 20 & S/ & 195,493 \\
\cline { 5 - 7 } & & & & & S/ & 342,113 \\
\hline
\end{tabular}




\section{Desarrollar un programa de Liderazgo para Supervisores, Jefes y Sub}

\section{Gerentes, y capacitar al personal en la metodología lean six sigma y en metodologías}

ágiles: La gerencia de RHH debe definir las competencias y capacidades requeridas por los colaboradores y desarrollar el plan de capacitación. Además, debe desglosar los servicios ofrecidos con el fin de hallar posibles falencias en competencias o capacidades requeridas, incluyéndolas en el plan.

Dentro del plan propuesto, tal como figura en la tabla 58, se contempla la inversión en un programa de liderazgo dirigido a supervisores, jefes y gerentes.

Tabla 58

Inversión en Programa de Liderazgo

\begin{tabular}{|c|c|c|c|c|c|c|c|c|c|}
\hline Año & Zona & Cant Personal & $\begin{array}{c}\text { Cant Personal } \\
(50 \%)\end{array}$ & \multicolumn{2}{|c|}{ Precio } & \multicolumn{4}{|c|}{ Inversión Total } \\
\hline \multirow{4}{*}{2019} & Callao & 1883 & 941.5 & S/ & 150 & S/ & 141,225 & \multirow{3}{*}{$\mathrm{S} /$} & \multirow{2}{*}{197,700} \\
\hline & Lima & 753 & 376.5 & $\mathrm{~S} /$ & 150 & S/ & 56,475 & & \\
\hline & Zona Sur & 176 & 88 & $\mathrm{~S} /$ & 150 & $\mathrm{~S} /$ & 13,200 & & \\
\hline & Zona Norte I & 228 & 114 & $\mathrm{~S} /$ & 150 & S/ & 17,100 & & \\
\hline \multirow[t]{4}{*}{2020} & Zona Norte II & 132 & 66 & $\mathrm{~S} /$ & 150 & $\mathrm{~S} /$ & 9,900 & $\mathrm{~S} /$ & 45,825 \\
\hline & Zona Centro & 21 & 10.5 & $\mathrm{~S} /$ & 150 & S/ & 1,575 & & \\
\hline & Zona Selva & 54 & 27 & $\mathrm{~S} /$ & 150 & $\mathrm{~S} /$ & 4,050 & & \\
\hline & & & & & & $\mathrm{S} /$ & & & 243,525 \\
\hline
\end{tabular}

Asimismo, tal como muestra la tabla 59, se proponen capacitaciones en Lean Six Sigma, una metodología de mejora de procesos que proporciona herramientas eficientes para la optimización. 
Tabla 59

Inversión en capacitación metodología Lean Six Sigma

\begin{tabular}{|c|c|c|c|c|c|c|c|c|}
\hline Año & Zona & $\begin{array}{l}\text { Personal a } \\
\text { capacitar }\end{array}$ & \multicolumn{2}{|c|}{ Precio } & \multicolumn{4}{|c|}{ Inversión Total } \\
\hline \multirow{2}{*}{2019} & Callao & 33 & S/ & 1,150 & S/ & 38,333 & \multirow{2}{*}{ S/ } & \multirow{2}{*}{57,500} \\
\hline & Lima & 17 & S/ & 1,150 & S/ & 19,167 & & \\
\hline \multirow{2}{*}{2020} & Callao & 33 & S/ & 1,150 & S/ & 38,333 & \multirow{2}{*}{ S/ } & \multirow{2}{*}{57,500} \\
\hline & Lima & 17 & S/ & 1,150 & S/ & 19,167 & & \\
\hline \multirow{3}{*}{2021} & Callao & 33 & S/ & 1,150 & S/ & 38,333 & \multirow{2}{*}{ S/ } & \multirow{2}{*}{57,500} \\
\hline & Lima & 17 & S/ & 1,150 & S/ & 19,167 & & \\
\hline & & & & & S/ & & & 2,500 \\
\hline
\end{tabular}

Finalmente, tal como figura en la tabla 60 , se proponen capacitaciones en metodología ágiles que permitan a los colaboradores gestionar los proyectos con flexibilidad e inmediatez.

Tabla 60

Inversión en capacitación metodologías Ágiles

\begin{tabular}{|c|c|c|c|c|c|c|c|c|}
\hline Año & Zona & $\begin{array}{l}\text { Personal a } \\
\text { capacitar }\end{array}$ & \multicolumn{2}{|c|}{ Precio } & \multicolumn{4}{|c|}{ Inversión Total } \\
\hline \multirow{2}{*}{2020} & Callao & 33 & $\mathrm{~S} /$ & 1,500 & $\mathrm{~S} /$ & 50,000 & \multirow[t]{2}{*}{ S/ } & \multirow{2}{*}{75,000} \\
\hline & Lima & 17 & $\mathrm{~S} /$ & 1,500 & $\mathrm{~S} /$ & 25,000 & & \\
\hline \multirow{2}{*}{2021} & Callao & 33 & S/ & 1,500 & $\mathrm{~S} /$ & 50,000 & \multirow{2}{*}{$\mathrm{S} /$} & \multirow{2}{*}{75,000} \\
\hline & Lima & 17 & S/ & 1,500 & $\mathrm{~S} /$ & 25,000 & & \\
\hline \multirow{3}{*}{2022} & Callao & 33 & S/ & 1,500 & S/ & 50,000 & \multirow[t]{2}{*}{$\mathrm{S} /$} & \multirow[t]{2}{*}{75,000} \\
\hline & Lima & 17 & $\mathrm{~S} /$ & 1,500 & $\mathrm{~S} /$ & 25,000 & & \\
\hline & & & & & S/ & & & 25,000 \\
\hline
\end{tabular}

En la Tabla 61 se muestra el resumen del presupuesto anual para cada una de las iniciativas que se han detallado anteriormente: 
Tabla 61

Presupuesto de las iniciativas

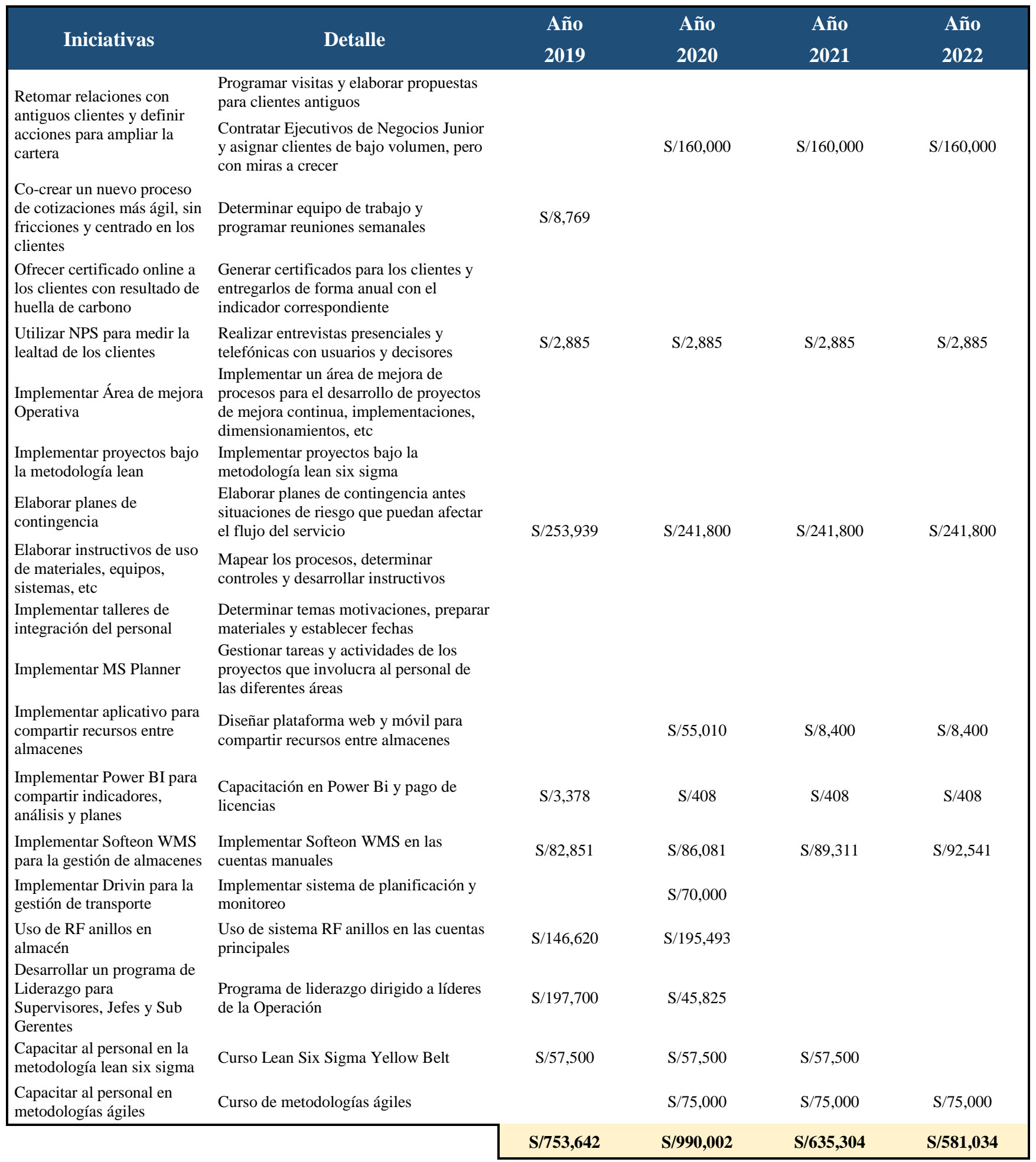




\subsection{Cronograma de cada una de las iniciativas}

En la Tabla 62 se muestra el cronograma de la implementación de las iniciativas, iniciando el año 2019 y siendo revaluadas al final de cada periodo, con el fin de ajustarlas o darlas de baja remplazándolas por otras.

Tabla 62

Cronograma de las iniciativas

\begin{tabular}{|c|c|c|c|c|c|}
\hline Iniciativas & Responsables & $\begin{array}{l}\text { Año } \\
2019\end{array}$ & $\begin{array}{l}\text { Año } \\
2020\end{array}$ & $\begin{array}{l}\text { Año } \\
2021\end{array}$ & $\begin{array}{l}\text { Año } \\
2022\end{array}$ \\
\hline $\begin{array}{l}\text { Retomar relaciones con antiguos clientes } \\
\text { y definir acciones para ampliar la cartera }\end{array}$ & Área Comercial & & & & \\
\hline $\begin{array}{l}\text { Co-crear un nuevo proceso de } \\
\text { cotizaciones mas agil }\end{array}$ & $\begin{array}{l}\text { Área Comercial, Cotizaciones, } \\
\text { Operaciones, TI, Finanzas y Compras }\end{array}$ & & & & \\
\hline Ofrecer certificado de huella de carbono & Área Calidad & & & & \\
\hline $\begin{array}{l}\text { Utilizar NPS para medir la lealtad de los } \\
\text { clientes }\end{array}$ & Área Comercial & & & & \\
\hline Implementar Área de mejora Operativa & Área de Operaciones y RRHH & & & & \\
\hline $\begin{array}{l}\text { Implementar proyectos bajo la } \\
\text { metodología lean }\end{array}$ & Área de Operaciones & & & & \\
\hline Elaborar planes de contingencia & $\begin{array}{l}\text { Área de Operaciones, RRHH, } \\
\text { Servicios y TI }\end{array}$ & & & & \\
\hline $\begin{array}{l}\text { Elaborar instructivos de uso de } \\
\text { materiales, equipos, sistemas, etc }\end{array}$ & Área de Operaciones & & & & \\
\hline $\begin{array}{l}\text { Implementar talleres de integración del } \\
\text { personal }\end{array}$ & Área de Operaciones y RRHH & & & & \\
\hline $\begin{array}{l}\text { Implemetar MS Planner para la gestión } \\
\text { de tareas }\end{array}$ & Área de Operaciones & & & & \\
\hline $\begin{array}{l}\text { Implementar aplicativo para compartir } \\
\text { recursos }\end{array}$ & Área de Operaciones y TI & & & & \\
\hline Implementar Power BI & Área de Operaciones y Comercial & & & & \\
\hline Implementar Softeon WMS & Área de Operaciones, Comercial y TI & & & & \\
\hline $\begin{array}{l}\text { Implementar Drivin para la gestión de } \\
\text { transporte }\end{array}$ & Área de Operaciones, Comercial y TI & & & & \\
\hline Uso de RF anillos en almacén & Área de Operaciones, Comercial y TI & & & & \\
\hline Desarrollar un programa de Liderazgo & Área de Operaciones y RRHH & & & & \\
\hline $\begin{array}{l}\text { Capacitar al personal en la metodología } \\
\text { lean six sigma }\end{array}$ & Área de Operaciones y RRHH & & & & \\
\hline $\begin{array}{l}\text { Capacitar al personal en metodologías } \\
\text { ágiles }\end{array}$ & Área de Operaciones y RRHH & & & & \\
\hline
\end{tabular}

Nota. Adaptado de A guide Project Management Body of Knowledge [PMBOK] (p. 219), Sexta edición, por Project Management Institute [PMI], 2017, Newtown Square, Pennsylvania, EEUU: PMI, Inc. 


\section{Capítulo X. Evaluación}

En este último capítulo se evalúa la conveniencia de aplicar las estrategias que han sido desarrolladas y seleccionadas anteriormente, complementando la evaluación cualitativa con un análisis financiero, teniendo como base un análisis simultáneo de la aplicación y no aplicación de las iniciativas.

\subsection{Evaluación cualitativa}

Sobre este punto es imposible identificar de manera concluyente las estrategias que brindarán óptimos resultados o asegurar por lo menos que éstas funcionarán (David, 2013). Sin embargo, se puede identificar las estrategias de mayor desempeño y analizar sus resultados.

\subsubsection{Criterios de evaluación.}

Después de seleccionar las estrategias (principal y de contingencia) es importante evaluarlas una vez más, aplicando los criterios planteados por Rumelt: consistencia, consonancia, ventaja y factibilidad. Ver Figura 19.

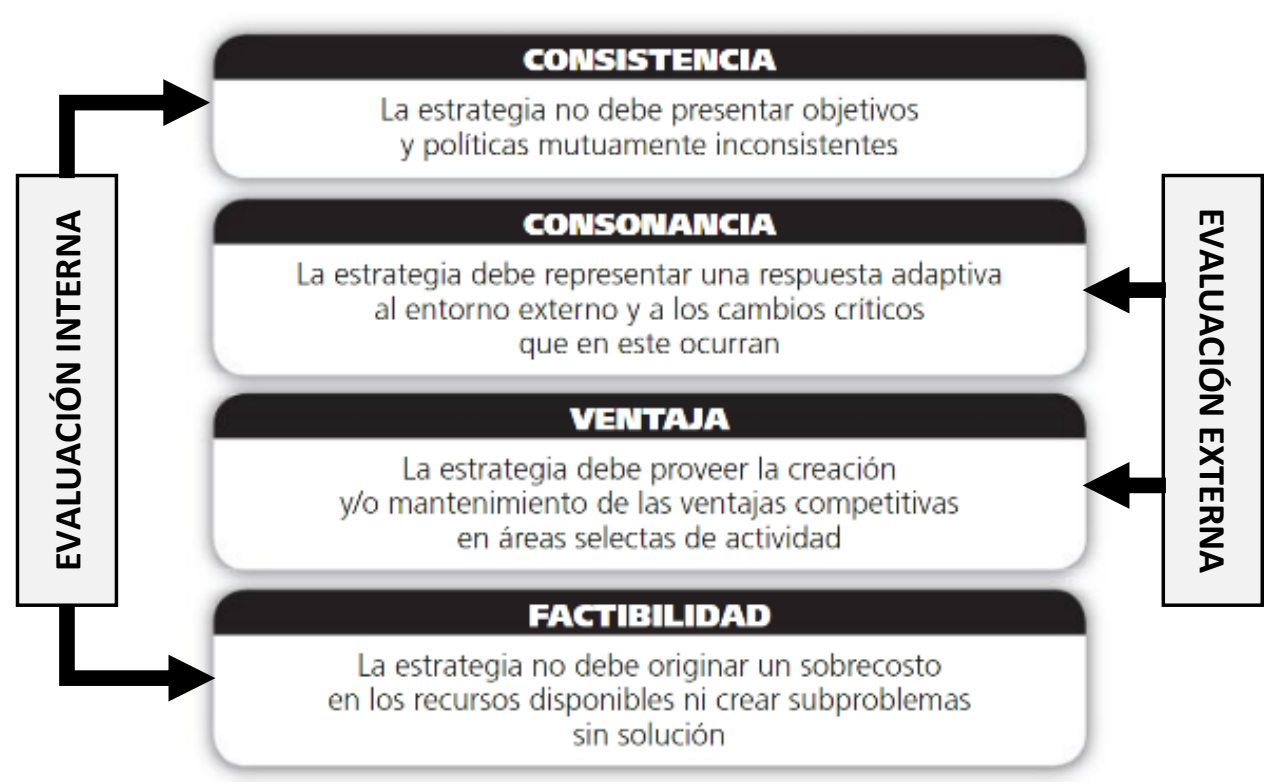

Figura 19. Criterios de evaluación de estrategias. Tomado de "El proceso estratégico: Un enfoque de gerencia,” por F. D’Alessio, 2008. México D.F.: Pearson Educación. 


\subsubsection{Comparación de la estrategia con los criterios.}

A continuación, se evalúan las estrategias seleccionadas bajo los criterios de Rumelt.

\section{Consistencia}

La estrategia de eficiencia operativa implica la creación de nuevas competencias en el personal operativo y la implementación de tecnología de vanguardia (infraestructura y softwares), para que juntas optimicen el tiempo de los procesos y reduzcan la tasa de incidencias, mejorando la calidad de los servicios y reduciendo los costos; y, de ese modo, fortalecer la posición Top de la empresa dentro de la industria. Esta estrategia se encuentra alineada a la visión de la empresa, que se puede corroborar en el siguiente extracto "Ser una organización de clase mundial posicionada entre los primeros operadores de Latinoamérica...”; de igual modo, la estrategia se alinea con la misión de la empresa, que se valida con el siguiente extracto "Mejorar el nivel de la logística en los países en los que trabajamos...” y “... mediante el uso de nuestra tecnología avanzada y manteniendo motivados a nuestros colaboradores como principal clave de nuestro éxito"; por tanto, se considera que la estrategia es consecuente a los objetivos de Ransa.

La estrategia de desarrollo de producto implica sumar a la experiencia profesional de los colaboradores diversas capacitaciones y certificaciones, logrando así un mayor rendimiento dentro de las operaciones; todo ello en sincronía con la implementación de tecnología de vanguardia que permite a la empresa en conjunto presentar dimensiones distintas de sus servicios ofrecidos, enfocado en la obtención y recuperación de clientes. Esta estrategia se encuentra alineada con la visión de la empresa, que se puede corroborar en el siguiente extracto "Ser una organización de clase mundial posicionada entre los primeros operadores de Latinoamérica...”; asimismo, la estrategia se alinea con la misión de la empresa, que se valida con el siguiente 
extracto "Mejorar el nivel de la logística en los países en los que trabajamos..."; por tanto, se considera que la estrategia es consecuente a los objetivos de Ransa.

\section{Consonancia}

La estrategia de eficiencia operativa implica agilizar el tiempo de las operaciones de cada uno de los servicios brindados por Ransa en los mercados que opera, ellos a través de la implementación de tecnología de vanguardia que optimicen el tiempo de los procesos y reduzcan la tasa de incidencias, mejorando así la calidad de los servicios y reduciendo los costos. Esta estrategia es una respuesta adaptada al entorno externo, bajo un escenario competitivo, en el cual debe mejorar constantemente los servicios prestados para conservar a sus clientes, recuperar a los perdidos, y ganar nuevos.

La estrategia de desarrollo de producto implica aprovechar la demanda creciente que existe en el país, reflejado en el crecimiento de la población, del consumo y de las empresas. Por ello, primero se debe crear nuevas competencias y capacidades en los colaboradores y en la empresa (infraestructura y software), y segundo se debe mejorar o desarrollar nuevas y atractivas características o atributos sobre los servicios prestados. Así, mientras la estrategia se ejecute, ésta complementará la estrategia de eficiencia operativa ganando nuevos clientes y evitando la pérdida de los existentes.

\section{Factibilidad}

Las iniciativas propuestas para el cumplimiento de los objetivos específicos se enfocan en la creación de nuevas competencias y capacidades a nivel de empresa, las que serán alcanzadas a través de pequeñas, medianas y grandes inversiones. Primero, en inversiones pequeñas se tiene todo lo referido a capacitaciones y certificaciones del personal; segundo, las inversiones 
medianas se orientan al acondicionamiento de tecnología de vanguardia dentro de los almacenes

y centros de distribución; tercero, las inversiones grandes convergen en la construcción, equipamiento y funcionamiento nuevos centros de distribución. Cabe resaltar, que las condiciones y posibilidades de la empresa abarcan los tres tipos de inversiones, teniendo antecedentes en cada una de ellas. Así, se considera que las estrategias de penetración de mercado y desarrollo de mercado son factibles.

\section{Ventaja}

La estrategia de eficiencia operativa y de desarrollo de producto se orientan a la creación de nuevas competencias y capacidades, mejorando los servicios prestados y desarrollando nuevas propuestas, lo que permitirá a la empresa fortalecer vínculos con sus clientes e incrementar su participación en la industria; es decir, estas estrategias en un inicio mejoran las ventajas competitivas de la empresa y terminan creando nuevas ventajas competitivas a través de una mejora en la gestión de las operaciones, lo que, en consecuencia, agiliza las operaciones de los servicios prestados (nuevos y existentes) y reduce los costos de operación.

\subsection{Evaluación financiera de la estrategia}

La evaluación financiera de las estrategias indicadas permitirá identificar si las ganancias y los costos generadas por éstas son o no de beneficio para la empresa, en comparación a un escenario vegetativo donde la empresa no aplica estrategias. Ver Tabla 63.

\subsubsection{Proyección de estados financieros (situación actual y con la nueva estrategia).}

Para la proyección de estados financieros sin estrategia o en estado vegetativo, bajo un escenario conservador, los ingresos por ventas se determinarán sobre un promedio porcentual calculado de las ventas efectuadas en los últimos tres años (2016, 2017 y 2018). Ver Anexo 20. 
De igual modo, para la proyección de estados financieros con estrategia se tomará en cuenta el índice de crecimiento promedio más los resultados esperados de la aplicación de las iniciativas planteadas que involucran reducción de costos operativos y aumento de ventas a través de inversiones en activos, capacitaciones, entre otras.

Los supuestos para el primer escenario (sin estrategias o estado vegetativo) es:

- De acuerdo con la tendencia negativa de la empresa en los últimos años respecto a sus ventas totales (año 2015, -10\%; 2016, -1\%; 2017, -1\%; 2018, -11\%) dentro de una industria creciente (ver Figura 03), y en consideración a la apreciación de los clientes sobre los servicios de Ransa (ver Anexo 06), se considera bajo un enfoque conservador que la empresa continuará en los próximos cuatro años con la tasa promedio decreciente de los últimos tres años que muestran sus principales servicios: transporte $-8.84 \%$, almacenaje $-3.63 \%$, distribución $+1.12 \%$, otros servicios $+3.13 \%$. Ver Anexo 20.

- A consecuencia de la caída de los ingresos por ventas, los Costos Variables se proyectan a través de un reajuste promedio proporcional a los ingresos por venta en los principales servicios: transporte $76.47 \%$, almacenamiento $10.05 \%$, distribución 61.64\%, otros servicios 53.46\%. Ver Anexo 20.

Los supuestos para el segundo escenario (con estrategias) son:

- Para la proyección de las ventas no se consideran relaciones ajenas al negocio para evitar que el precio varíe convenientemente hacia determinados clientes, estableciendo de esta manera un único precio ponderado por servicio. 
- El ingreso por ventas se mantiene fijo en el 2019 respecto al 2018, esto debido a que el primer año de proyección se busca fortalecer lazos con los clientes existentes, evitando que reduzcan la contratación de servicios o se retiren de la cartera de clientes.

- Los costos variables por servicio, al igual que los precios, se han ponderado y promediado.

- La reducción de costos variables por concepto de mano de obra es de S/8,789 (en miles); el cual será reducido de manera incremental, en los años evaluados, en la cantidad de S/2,197 (en miles); costo que se distribuye en los servicios de acuerdo con la participación que éstos tienen dentro de los costos variables. 
Tabla 63

Proyección de ventas y costos, sin y con estrategia, en miles de soles (000)

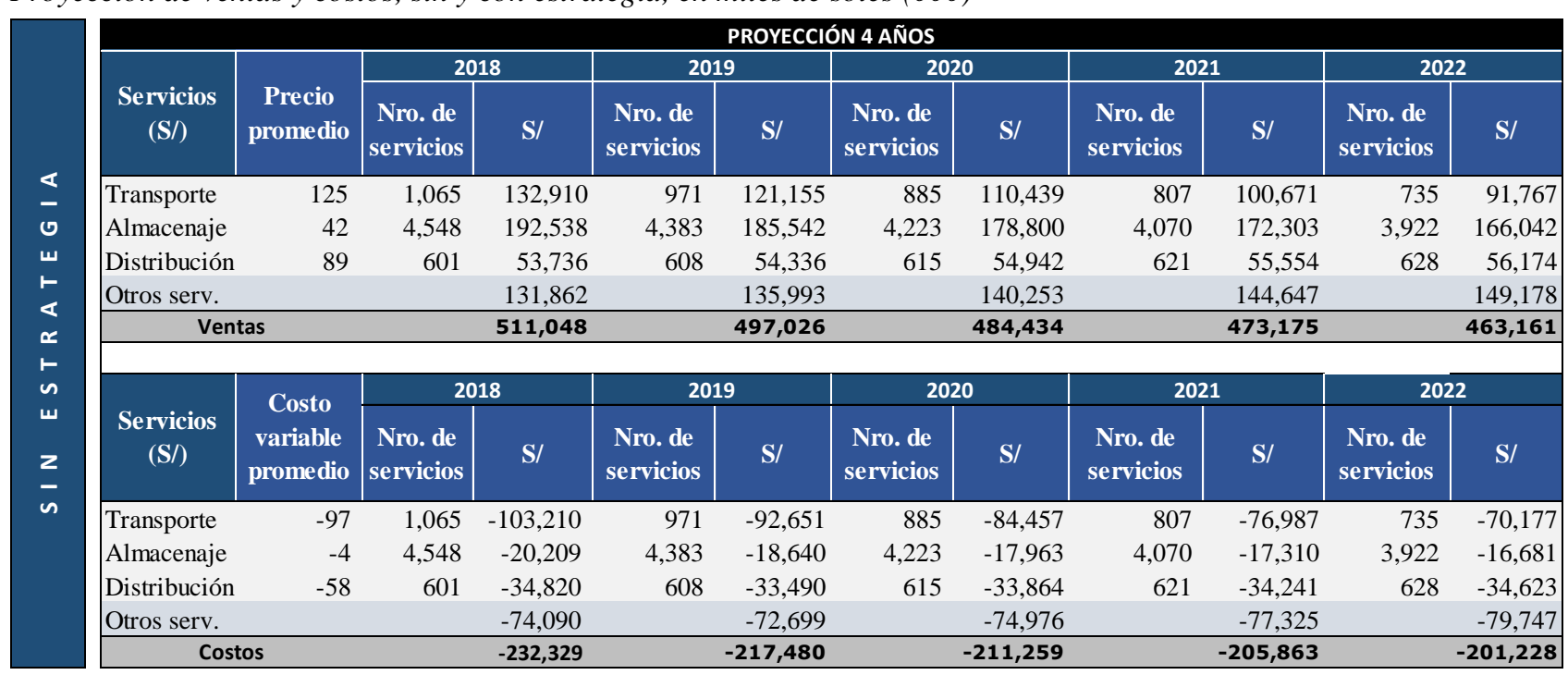

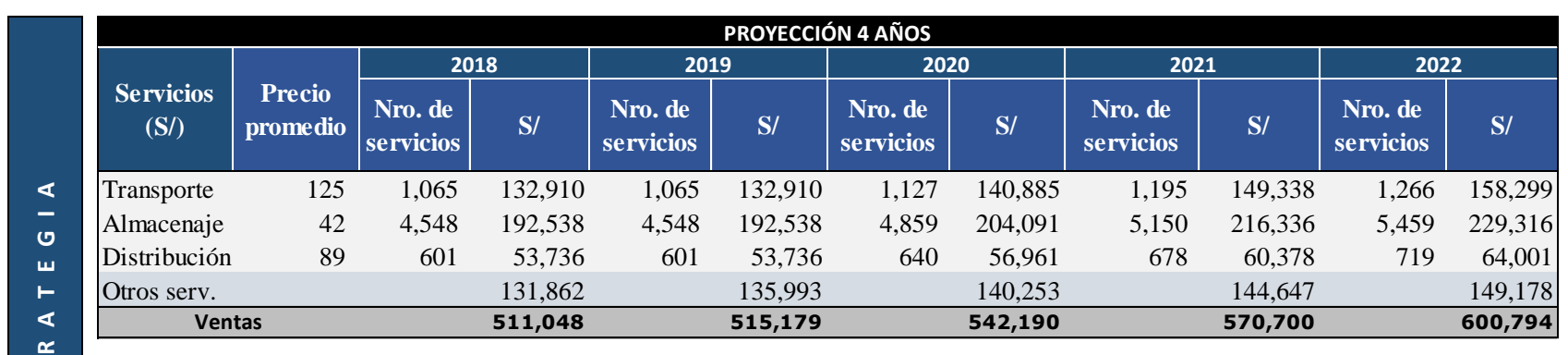

\begin{tabular}{|c|c|c|c|c|c|c|c|c|c|c|c|c|c|c|c|}
\hline \multirow[b]{2}{*}{$\begin{array}{c}\text { Servicios } \\
\text { (S/) }\end{array}$} & \multirow{2}{*}{$\begin{array}{c}\text { Costo } \\
\text { variable } \\
\text { promedio } \\
\text { (año 0) }\end{array}$} & \multicolumn{2}{|c|}{2018} & \multirow[b]{2}{*}{$\begin{array}{c}\text { CV } \\
\text { promedio } \\
\text { (1er año) }\end{array}$} & \multicolumn{2}{|c|}{2019} & \multirow[b]{2}{*}{$\begin{array}{c}\text { CV } \\
\text { promedio } \\
\text { (2do año) }\end{array}$} & \multicolumn{2}{|c|}{2020} & \multirow[b]{2}{*}{$\begin{array}{c}\text { CV } \\
\text { promedio } \\
\text { (3er año) }\end{array}$} & \multicolumn{2}{|c|}{2021} & \multirow[b]{2}{*}{$\begin{array}{c}\text { CV } \\
\text { promedio } \\
\text { (4to año) }\end{array}$} & \multicolumn{2}{|c|}{2022} \\
\hline & & $\begin{array}{c}\text { Nro. de } \\
\text { servicios }\end{array}$ & S/ & & $\begin{array}{c}\text { Nro. de } \\
\text { servicios }\end{array}$ & S/ & & $\begin{array}{l}\text { Nro. de } \\
\text { servicios }\end{array}$ & S/ & & $\begin{array}{c}\text { Nro. de } \\
\text { servicios }\end{array}$ & S/ & & $\begin{array}{c}\text { Nro. de } \\
\text { servicios }\end{array}$ & S/ \\
\hline Transporte & -97 & 1,065 & $-103,210$ & -94.97 & 1,065 & $-101,146$ & -93.07 & 1,127 & $-104,894$ & -91.21 & 1,195 & $-108,998$ & -89.39 & 1,266 & $-113,165$ \\
\hline Almacenaje & -4 & 4,548 & $-20,209$ & -4.35 & 4,548 & $-19,805$ & -4.27 & 4,859 & $-20,736$ & -4.18 & 5,150 & $-21,539$ & -4.10 & 5,459 & $-22,374$ \\
\hline Distribuciór & -58 & 601 & $-34,820$ & -56.78 & 601 & $-34,123$ & -55.64 & 640 & $-35,611$ & -54.53 & 678 & $-36,971$ & -53.44 & 719 & $-38,422$ \\
\hline Otros serv. & & & $-74,090$ & & & $-72,699$ & & & $-74,976$ & & & $-77,325$ & & & $-79,747$ \\
\hline Red. de cos & & & & & & 2,197 & & & 2,197 & & & 2,197 & & & 2,197 \\
\hline Costo Var & able Total & & $\begin{array}{l}-232,329 \\
\end{array}$ & & & $-225,576$ & & & $\begin{array}{l}-234,019 \\
\end{array}$ & & & $-242,635$ & & & $-251,511$ \\
\hline
\end{tabular}




\subsubsection{Estado de resultados (situación actual y con la nueva estrategia).}

En principio, la Tabla 64 presenta el estado de resultados proyectado sin estrategia o en estado vegetativo para el periodo 2019 - 2022, escenario donde solo factura de acuerdo con sus estrategias aplicadas hasta finales del 2018. Cabe mencionar que los conceptos de Costos Fijos Directos (CFD) e Indirectos (CFI) se proyectaron a través de una constante promedio proporcional de los ingresos de los últimos tres años, constante que varía de acuerdo con los principales servicios ofrecidos por Ransa (transporte CFD 22.88\% y CFI 7.99\%, almacenamiento CFD 66.08\% y CFI 16.56\%, distribución CFD 22.42\% y CFI 6.47\%, otros servicios CFD 22.89\% y CFI 6.84\%). Sin embargo, los conceptos de gastos de administración, gastos de venta, I/E operativos, dividendos recibidos e ingresos y gastos financieros, se mantienen constantes de acuerdo con el Estado de Resultados del año 2018. 
Tabla 64

Estado de resultados proyectados sin estrategia en miles de soles (000)

\begin{tabular}{|c|c|c|c|c|c|c|c|}
\hline ESTADO DE RESUUTADO & & & & AÑOS & & & \\
\hline ESIADU DE KESULIADU & $2016 \mathrm{R}$ & 2017 R & $2018 R$ & 2019 P & $2020 P$ & $2021 P$ & $2022 P$ \\
\hline Ingreso por Ventas & 546,115 & 522,250 & 511,048 & 497,026 & 484,434 & 473,175 & 463,161 \\
\hline Ventas Internas & -371 & -225 & -149 & -149 & -149 & -149 & -149 \\
\hline Costo Variables & $-233,191$ & $-231,856$ & $-232,329$ & $-217,480$ & $-211,259$ & $-205,863$ & $-201,228$ \\
\hline MARGEN DE CONTRIBUCIÓN & 312,553 & 290,169 & 278,570 & 279,397 & 273,027 & 267,164 & 261,784 \\
\hline & $57.23 \%$ & $55.56 \%$ & $54.51 \%$ & $56.21 \%$ & $56.36 \%$ & $56.46 \%$ & $56.52 \%$ \\
\hline Costos Fijos Directos & $-223,798$ & $-208,294$ & $-189,671$ & $-193,656$ & $-187,860$ & $-182,474$ & $-177,475$ \\
\hline Costos Fijos Indirectos & $-60,933$ & $-59,889$ & $-50,353$ & $-53,232$ & $-51,589$ & $-50,073$ & $-48,674$ \\
\hline UTILIDAD BRUTA & 27,822 & 21,986 & 38,546 & 32,509 & 33,577 & 34,617 & 35,635 \\
\hline & $5.09 \%$ & $4.21 \%$ & $7.54 \%$ & $6.54 \%$ & $6.93 \%$ & $7.32 \%$ & $7.69 \%$ \\
\hline Gasto de Administración & $-1,443$ & $-1,301$ & $-1,342$ & $-1,342$ & $-1,342$ & $-1,342$ & $-1,342$ \\
\hline Gastos de Venta & $-3,236$ & $-2,880$ & $-3,347$ & $-3,347$ & $-3,347$ & $-3,347$ & $-3,347$ \\
\hline I/E operativos & 868 & $-7,986$ & $-2,260$ & $-2,260$ & $-2,260$ & $-2,260$ & $-2,260$ \\
\hline UTILIDAD OPERATIVA & 24,011 & 9,819 & 31,597 & 25,560 & 26,628 & 27,668 & 28,686 \\
\hline n & $4.40 \%$ & $1.88 \%$ & $6.18 \%$ & $5.14 \%$ & $5.50 \%$ & $5.85 \%$ & $6.19 \%$ \\
\hline Dividendos recibidos & 12,088 & 13,901 & 15,069 & 15,069 & 15,069 & 15,069 & 15,069 \\
\hline Ingresos Financieros & 1,079 & 1,240 & 1,938 & 1,938 & 1,938 & 1,938 & 1,938 \\
\hline Gastos Financieros & $-14,089$ & $-14,667$ & $-15,363$ & $-15,363$ & $-15,363$ & $-15,363$ & $-15,363$ \\
\hline UTILIDAD ANTES DE IMPUESTOS & 23,089 & 10,293 & 33,241 & 27,204 & 28,272 & 29,312 & 30,330 \\
\hline & $4.23 \%$ & $1.97 \%$ & $6.50 \%$ & $5.47 \%$ & $5.84 \%$ & $6.19 \%$ & $6.55 \%$ \\
\hline Impuesto a la Renta & $-6,811$ & $-3,037$ & $-9,806$ & $-8,025$ & $-8,340$ & $-8,647$ & $-8,947$ \\
\hline UTILIDAD NETA & 16,278 & 7,257 & 23,435 & 19,179 & 19,932 & 20,665 & 21,383 \\
\hline & $2.98 \%$ & $1.39 \%$ & $4.59 \%$ & $3.86 \%$ & $4.11 \%$ & $4.37 \%$ & $4.62 \%$ \\
\hline Depreciación y amortización & $-15,068$ & $-13,557$ & $-12,860$ & $-12,860$ & $-12,860$ & $-12,860$ & $-12,860$ \\
\hline EBITDA & 39,079 & 23,376 & 44,457 & 38,420 & 39,488 & 40,528 & 41,546 \\
\hline
\end{tabular}

Además, el presente escenario muestra una tendencia creciente en sus utilidades neta, resultado de un ajuste de Costos Variables y Costos Fijos Directos e Indirectos ante la caída de las ventas; sin embargo, los Gastos de Administración y de Ventas no muestran alto grado de sensibilidad frente a la caída de las ventas (año 2016, 2017 y 2018) por lo que en la proyección mantienen la cifra del último año cerrado. Por último, el escenario muestra, año tras año, un EBITDA cuya tendencia refleja la de la utilidad neta, ascendiendo a S/38,420 (en miles) en el primer año proyectado y a S/41,546 (en miles) en el último.

Por otro lado, en la Tabla 65, se aprecia el estado de resultados proyectado con la aplicación de las iniciativas en el periodo 2019 - 2022, escenario donde se muestra un aumento 
del nivel de ventas y un mayor control sobre el manejo de los costos del servicio y de operación, que permiten alcanzar un margen bruto mayor a lo proyectado sin estrategias respecto a cada año. Cabe señalar que la proyección de los CFD y CFI se proyectan a través de una constante promedio proporcional $(39.33 \%$ y $11.36 \%$ respectivamente) de los ingresos en los últimos tres años, costos que además incluyen lo presupuestado.

Por último, continuando con el segundo escenario, ésta presenta mayor Utilidad Neta en el año 2020, 2021 y 2022, como consecuencia de la nueva tendencia positiva que siguen los ingresos por ventas, fruto de la implementación de las iniciativas formuladas anteriormente; además, el EBITDA muestra una tendencia que refleja la de la utilidad neta, ascendiendo a S/37,730 (en miles) en el primer año y S/54,316 (en miles) en el último. 
Tabla 65

Estado de resultados proyectados con estrategia en miles de soles (000)

\begin{tabular}{|c|c|c|c|c|c|c|c|c|}
\hline \multirow{2}{*}{\multicolumn{2}{|c|}{ ESTADO DE RESULTADO }} & \multicolumn{7}{|c|}{ AÑOS } \\
\hline & & 2016 R & 2017 R & $2018 R$ & 2019 P & $2020 P$ & $2021 P$ & $2022 P$ \\
\hline & Ingreso por Ventas & 546,115 & 522,250 & 511,048 & 515,179 & 542,190 & 570,700 & 600,794 \\
\hline & Ventas Internas & -371 & -225 & -149 & -149 & -149 & -149 & -149 \\
\hline & Costo Variables & $-233,191$ & $-231,856$ & $-232,329$ & $-225,576$ & $-234,019$ & $-242,635$ & $-251,511$ \\
\hline & MARGEN DE CONTRIBUCIÓN & 312,553 & 290,169 & 278,570 & 289,454 & 308,022 & 327,916 & 349,134 \\
\hline & & $57.23 \%$ & $55.56 \%$ & $54.51 \%$ & $56.19 \%$ & $56.81 \%$ & $57.46 \%$ & $58.11 \%$ \\
\hline & Costos Fijos Directos & $-223,798$ & $-208,294$ & $-189,671$ & $-199,560$ & $-210,024$ & $-221,067$ & $-232,252$ \\
\hline & Costos Fijos Indirectos & $-60,933$ & $-59,889$ & $-50,353$ & $-57,764$ & $-60,548$ & $-63,732$ & $-67,262$ \\
\hline & UTILIDAD BRUTA & 27,822 & 21,986 & 38,546 & 32,129 & 37,450 & 43,117 & 49,619 \\
\hline & & $5.09 \%$ & $4.21 \%$ & $7.54 \%$ & $6.24 \%$ & $6.91 \%$ & $7.56 \%$ & $8.26 \%$ \\
\hline $\bar{u}$ & Gasto de Administración & $-1,443$ & $-1,301$ & $-1,342$ & $-1,917$ & $-1,965$ & $-2,064$ & $-2,156$ \\
\hline 山 & Gastos de Venta & $-3,236$ & $-2,880$ & $-3,347$ & $-3,098$ & $-3,411$ & $-3,582$ & $-3,763$ \\
\hline$\varangle$ & I/E operativos & 868 & $-7,986$ & $-2,260$ & $-2,260$ & $-2,260$ & $-2,260$ & $-2,260$ \\
\hline$\stackrel{\propto}{上}$ & UTILIDAD OPERATIVA & 24,011 & 9,819 & 31,597 & 24,855 & 29,813 & 35,210 & 41,441 \\
\hline$\backsim$ & & $4.40 \%$ & $1.88 \%$ & $6.18 \%$ & $4.82 \%$ & $5.50 \%$ & $6.17 \%$ & $6.90 \%$ \\
\hline $\mathbf{z}$ & Dividendos recibidos & 12,088 & 13,901 & 15,069 & 15,069 & 15,069 & 15,069 & 15,069 \\
\hline S & Ingresos Financieros & 1,079 & 1,240 & 1,938 & 1,938 & 1,938 & 1,938 & 1,938 \\
\hline & Gastos Financieros & $-14,089$ & $-14,667$ & $-15,363$ & $-15,363$ & $-15,363$ & $-15,363$ & $-15,363$ \\
\hline & UTILIDAD ANTES DE IMPUESTOS & 23,089 & 10,293 & 33,241 & 26,499 & 31,457 & 36,854 & 43,085 \\
\hline & & $4.23 \%$ & $1.97 \%$ & $6.50 \%$ & $5.14 \%$ & $5.80 \%$ & $6.46 \%$ & $7.17 \%$ \\
\hline & Impuesto a la Renta & $-6,811$ & $-3,036$ & $-9,806$ & $-7,817$ & $-9,280$ & $-10,872$ & $-12,710$ \\
\hline & UTILIDAD NETA & 16,278 & 7,257 & 23,435 & 18,682 & 22,177 & 25,982 & 30,375 \\
\hline & & $2.98 \%$ & $1.39 \%$ & $4.59 \%$ & $3.63 \%$ & $4.09 \%$ & $4.55 \%$ & $5.06 \%$ \\
\hline & Depreciación y amortización & $-15,068$ & $-13,557$ & $-12,860$ & $-12,875$ & $-12,875$ & $-12,875$ & $-12,875$ \\
\hline & EBITDA & 39,079 & 23,376 & 44,457 & 37,730 & 42,688 & 48,085 & 54,316 \\
\hline
\end{tabular}

\subsubsection{Balance general (situación actual y con la nueva estrategia).}

El estado de situación financiera proyectado durante el periodo 2019 - 2022 sin

estrategia, refleja las políticas ineficientes aplicadas por la empresa, políticas que se muestran a

través de una constante promedio de crecimiento o decrecimiento en cada uno de los conceptos.

Ver Tabla 66.

Por ejemplo, las cuentas por cobrar de la empresa es un concepto que en su mayor parte engloba cifras por exceso de procesos al tramitar el recibo y al efectuar la cobranza, lo que incrementa el ciclo de cobro y en consecuencia infla las cifras de la cuenta mencionada; sin 
embargo, dentro del periodo evaluado, se observa como ésta disminuye año a año debido a la caída que sufren las ventas y al cobro de la misma.

Finalmente, este escenario trabaja bajo el supuesto de que la empresa no realiza inversiones en proyectos o adquiere inmuebles, maquinarias y equipos; generando que la cuenta de efectivo y equivalente de efectivo sufra un considerable incremento de liquidez. 
Tabla 66

Estado de situación financiera proyectado sin estrategia, en miles de soles (000)

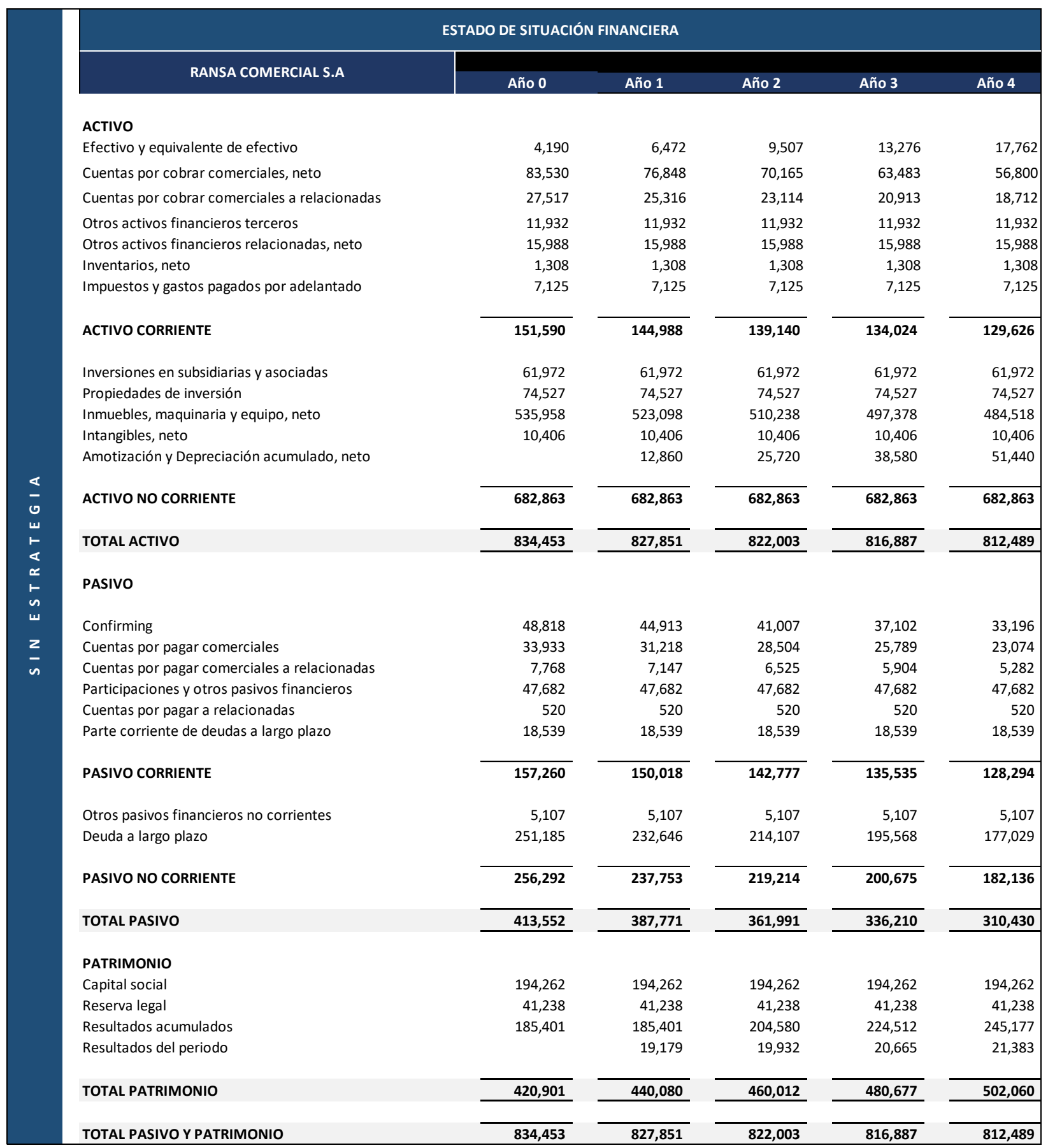


Por otro lado, el escenario con la aplicación de estrategias proyecta las mismas constantes de crecimiento o decrecimiento por concepto, adicionando a éstos los resultados esperados; mostrando, de esta manera, una mejora continua y progresiva de año a año. Ver Tabla 67.

Además, en el presente escenario, las iniciativas planteadas no desarrollan millonarias inversiones o renovaciones de inmuebles, maquinarias y equipos; generando que la cuenta de efectivo y equivalente de efectivo sufra un considerable incremento de liquidez, similar al escenario sin estrategia. 
Tabla 67

Estado de situación financiera proyectado con estrategia, en miles de soles (000)

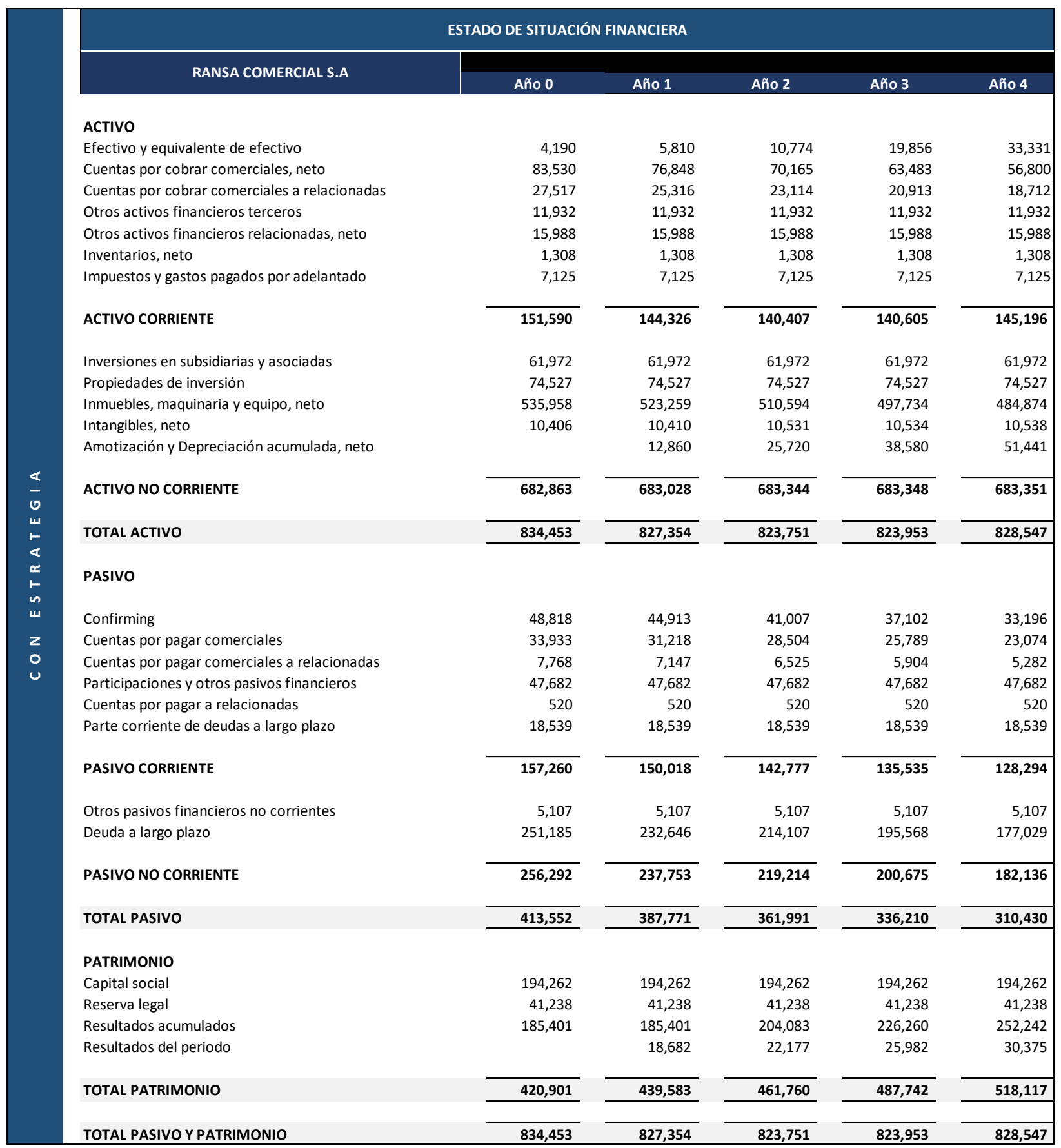




\subsubsection{Flujo de efectivo (situación actual y con la nueva estrategia).}

El flujo de efectivo proyectado sin estrategias expone la generación de efectivo de las actividades de operación como producto de las acciones e iniciativas desarrolladas por la empresa hasta finales del 2018. Ver Tabla 68.

Tabla 68

Flujo de efectivo proyectado sin estrategia

\begin{tabular}{|c|c|c|c|c|}
\hline \multirow{2}{*}{ FLUJO DE EFECTIVO } & \multicolumn{4}{|c|}{ AÑOS } \\
\hline & 2019 & 2020 & 2021 & 2022 \\
\hline \multicolumn{5}{|l|}{ ACTIVIDADES DE OPERACIÓN } \\
\hline EFECTIVO INICIAL & 4,190 & 6,472 & 9,507 & 13,276 \\
\hline (+) Cobranza a clientes & 505,910 & 493,318 & 482,059 & 472,045 \\
\hline (-) Pago a proveedores & $-239,925$ & $-233,703$ & $-228,307$ & $-223,673$ \\
\hline (-) Pagos relacionados a las operaciones & $-249,603$ & $-242,164$ & $-235,261$ & $-228,864$ \\
\hline (-) Otros pagos relacionados a las operaciones & $-7,570$ & $-7,570$ & $-7,570$ & $-7,570$ \\
\hline (-) Pago de impuesto & $-8,025$ & $-8,340$ & $-8,647$ & $-8,947$ \\
\hline $\begin{array}{l}\text { Flujo y equivalente de efectivo netro proveniente de } \\
\text { las actividades de operación }\end{array}$ & 786 & 1,540 & 2,273 & 2,990 \\
\hline \multicolumn{5}{|l|}{ ACTIVIDADES DE INVERSIÓN } \\
\hline (-) Adq. de inmuebles, maquinaria y equipo & - & - & - & - \\
\hline (-) Ventas internas & -149 & -149 & -149 & -149 \\
\hline (+) Dividendos recibidos & 15,069 & 15,069 & 15,069 & 15,069 \\
\hline $\begin{array}{l}\text { Efectivo y equivalente de efectivo neto utilizado en las } \\
\text { actividades de inversión }\end{array}$ & 14,920 & 14,920 & 14,920 & 14,920 \\
\hline \multicolumn{5}{|l|}{ ACTIVIDADES DE FINANCIAMIENTO } \\
\hline$(+)$ Ingresos financieros & 1,938 & 1,938 & 1,938 & 1,938 \\
\hline (-) Gastos Financieros & $-15,363$ & $-15,363$ & $-15,363$ & $-15,363$ \\
\hline $\begin{array}{l}\text { Flujo y equivalente de efectivo netro proveniente de } \\
\text { las actividades de financiamiento }\end{array}$ & 13,425 & 13,425 & 13,425 & 13,425 \\
\hline Efectivo y equivalente de efectivo al final del ejercicio & 6,472 & 9,507 & 13,276 & 17,762 \\
\hline $\begin{array}{l}\text { Efectivo y equivalente de efectivo al final del ejercicio } \\
\text { acumulado }\end{array}$ & 6,472 & 15,979 & 29,255 & 47,016 \\
\hline
\end{tabular}


De acuerdo con la información mostrada en la Tabla 68, el efectivo y equivalente de efectivo al final del ejercicio muestra una clara tendencia positiva dentro del periodo 2019 2020, siendo el resultado de un ajuste de costos en consecuencia a la caída de ventas y a la no adquisición y renovación de activos fijos e intangibles.

Por su parte, la Tabla 69 muestra el flujo de efectivo con estrategias consideras los montos de inversión que se presupuestaron anteriormente.

Tabla 69

Flujo de efectivo proyectado con estrategia

\begin{tabular}{|c|c|c|c|c|}
\hline \multirow{2}{*}{ FLUJO DE EFECTIVO } & \multicolumn{4}{|c|}{ AÑOS } \\
\hline & 2019 & 2020 & 2021 & 2022 \\
\hline \multicolumn{5}{|l|}{ ACTIVIDADES DE OPERACIÓN } \\
\hline EFECTIVO INICIAL & 4,190 & 5,810 & 10,774 & 19,856 \\
\hline (+) Cobranza a clientes & 524,062 & 551,074 & 579,584 & 609,678 \\
\hline (-) Pago a proveedores & $-248,020$ & $-256,464$ & $-265,080$ & $-273,956$ \\
\hline (-) Pagos relacionados a las operaciones & $-260,039$ & $-273,287$ & $-287,513$ & $-302,229$ \\
\hline (-) Otros pagos relacionados a las operaciones & $-7,896$ & $-8,258$ & $-8,528$ & $-8,800$ \\
\hline (-) Pago de impuesto & $-7,817$ & $-9,280$ & $-10,872$ & $-12,710$ \\
\hline $\begin{array}{l}\text { Flujo y equivalente de efectivo netro proveniente de } \\
\text { las actividades de operación }\end{array}$ & 290 & 3,785 & 7,591 & 11,983 \\
\hline \multicolumn{5}{|l|}{ ACTIVIDADES DE INVERSIÓN } \\
\hline (-) Adq. de inmuebles, maquinaria y equipo & -161 & -195 & - & \\
\hline (-) Adq. de activos intangibles & -4 & -120 & -4 & -4 \\
\hline (-) Ventas internas & -149 & -149 & -149 & -149 \\
\hline (+) Dividendos recibidos & 15,069 & 15,069 & 15,069 & 15,069 \\
\hline $\begin{array}{l}\text { Efectivo y equivalente de efectivo neto utilizado en las } \\
\text { actividades de inversión }\end{array}$ & 14,755 & 14,604 & 14,916 & 14,916 \\
\hline \multicolumn{5}{|l|}{ ACTIVIDADES DE FINANCIAMIENTO } \\
\hline$(+)$ Ingresos financieros & 1,938 & 1,938 & 1,938 & 1,938 \\
\hline (-) Gastos Financieros & $-15,363$ & $-15,363$ & $-15,363$ & $-15,363$ \\
\hline $\begin{array}{l}\text { Flujo y equivalente de efectivo netro proveniente de } \\
\text { las actividades de financiamiento }\end{array}$ & 13,425 & 13,425 & 13,425 & 13,425 \\
\hline Efectivo y equivalente de efectivo al final del ejercicio & 5,810 & 10,774 & 19,856 & 33,331 \\
\hline $\begin{array}{l}\text { Efectivo y equivalente de efectivo al final del ejercicio } \\
\text { acumulado }\end{array}$ & 5,810 & 16,584 & 36,441 & 69,772 \\
\hline
\end{tabular}


Finalmente, de acuerdo con la información mostrada en la Tabla 69, el efectivo y equivalente de efectivo al final del ejercicio muestra una clara tendencia positiva dentro del periodo 2019 - 2020, siendo el resultado del incremento de las ventas, reducción de costos de operación, y de la moderada inversión o adquisición y renovación de activos fijos e intangibles.

\subsubsection{Evaluación financiera (VAN, TIR y ratios financieros).}

Para una apropiada evaluación financiera es importante medir el rendimiento esperado del presente proyecto, considerando su nivel de riesgo; por ello, utilizando la ecuación del CAPM (Capital Asset Pricing Model), fórmula que relaciona el rendimiento de los activos y el riesgo no diversificable, se obtiene el COK (Costo de Oportunidad del Capital).

Para calcular el COK para Ransa Comercial S.A. se utiliza información basada en el mercado de los EE.UU. Ver Tabla 70.

Primero, la beta desapalancada de la industria estudiada en USA, mencionada por Demodaran, asciende a 0.87, la cual debe apalancarse aplicando la fórmula de $\boldsymbol{\beta}_{\mathbf{a}}=\boldsymbol{\beta}_{\mathbf{d}}$ $*(\mathbf{1}+(\mathbf{D} / \mathbf{C}) *(\mathbf{1}-\mathbf{T})$, resultado que da una beta apalancada de 1.61

Segundo, se aplica la siguiente fórmula: $\mathbf{K e}=\mathbf{R f}+\boldsymbol{\beta}_{\mathbf{a}} *(\mathbf{R m}-\mathbf{R f})$, en el que la tasa libre de riesgo $(R f)$ es representada por los bonos del tesoro público americano a 5 años (T-Bond), la cual asciende a 1.19\% en el periodo ajustado a la evaluación del presente plan estratégico; la prima por riesgo de mercado $(R m-R f)$ es representada por el exceso de retorno del índice S\&P500 sobre la tasa libre de riesgo, el cual ha sido seleccionado por ser uno de los más representativos del mercado americano, ascendiendo a $7.62 \%$ en el mismo periodo anteriormente mencionado. 
Tercero, obtenido el Ke o COK $\mathrm{EEUU}$ se aplica la siguiente suma: $\mathbf{C O K} \mathbf{P E R U}=\mathbf{C O K} \mathbf{E E U U}+$

Riesgo País, alcanzando el costo de capital para la empresa, el cual asciende a $14.52 \%$.

Tabla 70

Cálculo del COK

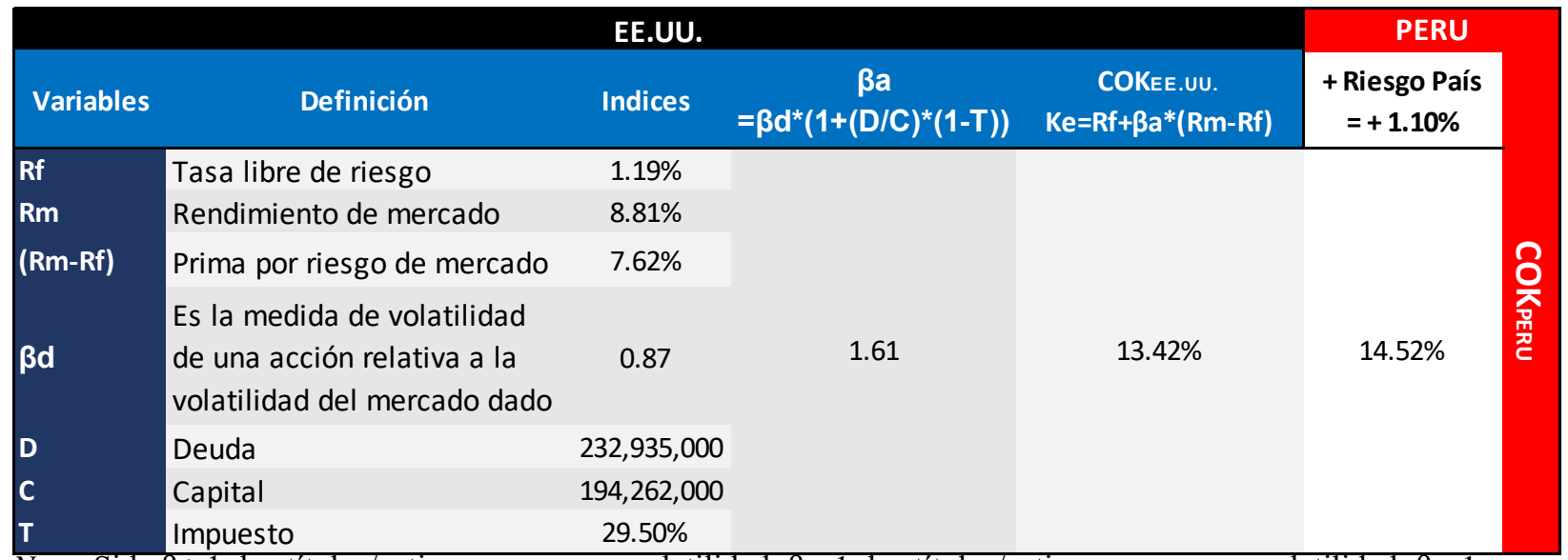

Nota. Si la $\beta_{\mathrm{a}}>1$, los títulos/activos con mayor volatilidad; $\beta_{\mathrm{a}}<1$, los títulos/activos con menor volatilidad; $\beta_{\mathrm{a}}=1$, activos sin riesgo.

Obtenido el COK Perú se calcula el WACC, conocido como el Costo Promedio Ponderado de Capital (CPPC), a través de la siguiente fórmula: WACC = Ke x [E/E+D] + Kd x [D/E+D] x (1-T); donde $\mathrm{Ke}=\mathrm{COK}_{\text {Perú }}, \mathrm{E}=$ equity o capital de la empresa, $\mathrm{D}=$ deuda financiera de la empresa, $\mathrm{Kd}=$ costo de la deuda, y $\mathrm{T}=$ impuesto a la renta.

Es así que la Tabla 71 detalla la información necesaria para el cálculo apropiado del WACC, fórmula que termina de la siguiente manera: 14.52\%x[S/194MM/S/427MM] + $\{[8.41 \% x[90 \mathrm{MM} / 427 \mathrm{MM}]+8.87 \% x[141 \mathrm{MM} / 427 \mathrm{MM}]+11.47 \% \times[1 \mathrm{MM} / 427 \mathrm{MM}]] \times(1-29.50 \%]\}$, logrando un WACC igual a 9.95\%. 
Tabla 71

Cálculo del WACC

\begin{tabular}{|c|c|c|}
\hline Entidad financiera & Deuda & $\begin{array}{c}\text { Tasa de interés } \\
\text { (Kd) }\end{array}$ \\
\hline Banistmo S.A. (ex - HSBC Panamá S.A. Xb) & $90,124,197.17$ & $8.41 \%$ \\
\hline Bank of Nova Scotia & $141,623,738.41$ & $8.87 \%$ \\
\hline IBM del Perú S.A. & $1,187,064.43$ & $11.47 \%$ \\
\hline Deuda Financiera Total & $232,935,000.00$ & \\
\hline Variables & s/ & $\%$ \\
\hline $\mathbf{T}$ & & $29.50 \%$ \\
\hline Ke & & $14.52 \%$ \\
\hline Equity & $194,262,000.00$ & \\
\hline Total D + E & $427,197,000.00$ & \\
\hline \multicolumn{3}{|c|}{$W A C C=K e \times[E /(E+D)]+K d \times(1-T) \times[D /(E+D)]$} \\
\hline WA & $9.95 \%$ & \\
\hline
\end{tabular}

Nota. Adaptado de Estados financieros separados, por Ransa Comercial S.A., 2018, Recuperado de la Vicepresidencia de Finanzas.

Obtenido el WACC se procede a calcular el VAN (Valor Actual Neto) y la TIR (Tasa Interna de Retorno), ambos de la diferencia de los flujos (c/s estrategia). Ver Tabla 72.

Tabla 72

Cálculo del VAN y la TIR

\section{FLUJOS}

Flujo de efectivo o equivalente de efectivo acumulado con estrategia Flujo de efectivo o equivalente de efectivo acumulado con estrategia Flujo de efectivo o equivalente de efectivo incremental

\begin{tabular}{lr|}
\hline WACC & $9.95 \%$ \\
VAN & 18,278 \\
TIR & $61.97 \%$ \\
\hline
\end{tabular}

Nota. Flujos de efectivo y VAN expresados en miles de soles. Las inversiones realizas en los distintos años del periodo de evaluación (2019-2022) se encuentran ajustadas a través del WACC en una sola inversión al año 0, valor presente.

El VAN hallado asciende a S/18,278 MM, mayor a cero, lo que indica que la inversión produce ganancias por encima de la rentabilidad exigida por los accionistas; asimismo, la TIR 
alcanzada es de $61.97 \%$, mayor al WACC, lo que indica que el proyecto devuelve lo invertido más una ganancia adicional. Por ello, considerando la atractividad del proyecto, éste debe ser aceptado.

Por otro lado, continuando con el análisis financiero, es importante complementar y reforzar la información hallada en la Tabla 72, esto a través de distintos ratios financieros que permiten evaluar el resultado de la gestión de Ransa con y sin estrategia dentro del periodo evaluado. Ver Tabla 73.

Tabla 73

Ratios financieros con y sin estrategias

\begin{tabular}{|l|cc|cc|cc|cc|}
\hline \multirow{2}{*}{\multicolumn{1}{c}{ Indicadores Financieros }} & \multicolumn{2}{c|}{2019} & \multicolumn{2}{c|}{2020} & \multicolumn{2}{c|}{2021} & \multicolumn{2}{c|}{2022} \\
\cline { 2 - 9 } & S.E & C.E. & S.E & C.E. & S.E & C.E. & S.E & C.E. \\
\hline Razones de liquidez & & & & & & & & \\
Liquidez general & 0.9665 & 0.9621 & 0.9745 & 0.9834 & 0.9889 & 1.0374 & 1.0104 & 1.1317 \\
Prueba ácida & 0.9577 & 0.9533 & 0.9654 & 0.9500 & 0.9792 & 1.0278 & 1.0002 & 1.1215 \\
Prueba defensiva & 0.0431 & 0.0387 & 0.0666 & 0.0492 & 0.0979 & 0.1465 & 0.1384 & 0.2598 \\
Razones de gestión & & & & & & & & \\
Margen bruto & $6.54 \%$ & $6.24 \%$ & $6.93 \%$ & $6.91 \%$ & $7.32 \%$ & $7.56 \%$ & $7.69 \%$ & $8.26 \%$ \\
Margen operativo & $5.14 \%$ & $4.82 \%$ & $5.50 \%$ & $5.50 \%$ & $5.85 \%$ & $6.17 \%$ & $6.19 \%$ & $6.90 \%$ \\
Margen neto & $3.86 \%$ & $3.63 \%$ & $4.11 \%$ & $4.09 \%$ & $4.37 \%$ & $4.55 \%$ & $4.62 \%$ & $5.06 \%$ \\
Razones de rentabilidad & & & & & & & & \\
ROE & $4.36 \%$ & $4.25 \%$ & $4.33 \%$ & $4.80 \%$ & $4.30 \%$ & $5.33 \%$ & $4.26 \%$ & $5.86 \%$ \\
ROA & $2.32 \%$ & $2.26 \%$ & $2.42 \%$ & $2.69 \%$ & $2.53 \%$ & $3.15 \%$ & $2.63 \%$ & $3.67 \%$ \\
Razones de solvencia & & & & & & & & \\
Endeudamiento patrimonial & 0.88 & 0.88 & 0.79 & 0.78 & 0.70 & 0.69 & 0.62 & 0.60 \\
Endeudamiento de los activos & 0.53 & 0.53 & 0.56 & 0.56 & 0.59 & 0.59 & 0.62 & 0.63 \\
\hline
\end{tabular}

Nota. S.E. significa sin estrategia y C.E. significa con estrategia.

El análisis de los resultados mostrados en la Tabla 73 afirman lo siguiente:

La prueba liquidez general o prueba corriente, en el escenario con estrategia, indica que por cada S/1.00 que se debe, se tiene S/0.96 para respaldar la deuda; sin embargo, al cuarto 
año la empresa dispone de $\mathrm{S} / 1.13$ para cubrir cada $\mathrm{S} / 1.00$ de su deuda. Del mismo modo, en el escenario sin estrategia la empresa dispone de S/0.97 en el primer año y de S/1.01 en el último.

La prueba ácida, siendo más exigente que la prueba anterior, indica que por cada $\mathrm{S} / 1.00$ que se debe, se tiene S/0.95 para respaldar la deuda; sin embargo, al cuarto año la empresa dispone de S/1.12 para cubrir cada S/1.00 de su deuda. Del mismo modo, en el escenario sin estrategia la empresa dispone de S/0.96 en el primer año y de S/1.00 en el último.

La prueba defensiva, siendo la más exigente, indica que por cada $\mathrm{S} / 1.00$ que se debe, se tiene S/0.03 para respaldar la deuda; sin embargo, al cuarto año la empresa dispone de S/0.25 para cubrir cada S/1.00 de su deuda. Del mismo modo, en el escenario sin estrategia la empresa dispone de S/0.04 en el primer año y de S/0.14 en el último.

El margen bruto, muestra que ambos escenarios siguen una tendencia positiva; esto debido a que el escenario sin estrategias se ajustan los costos tras la disminución de ventas; mientras que en el escenario con estrategias mejora la gestión y distribución de recursos, alcanzando un margen bruto de $8.26 \%$, superior al $7.69 \%$ perteneciente al margen bruto del primer escenario en el último año proyectado.

El margen operativo y neto, presenta una tendencia creciente en ambos escenarios, siendo más significativo en el escenario con estrategias implementadas; es decir, que éste cuenta con mayores márgenes fruto de la implementación de iniciativas, alcanzando en el último los márgenes de $6.90 \%$ y $5.06 \%$ respectivamente, superiores a los márgenes de $6.19 \%$ y $4.62 \%$ pertenecientes al primer escenario.

El endeudamiento patrimonial junto al endeudamiento de los activos, en el escenario con estrategia, indican que el patrimonio de la empresa se encuentra comprometido en un $88 \%$ 
con sus acreedores; sobre todo porque existe un margen del $47 \%$ de activos totales financiados con el patrimonio, no comprometidos con acreedores; sin embargo, al cuarto año el patrimonio de la empresa solo está comprometido en un $60 \%$ con sus acreedores y solo el $37 \%$ de activos totales se encuentran financiados por el patrimonio.

\section{La rentabilidad neta sobre el patrimonio y la rentabilidad neta sobre los activos}

muestran una tendencia creciente en los escenarios con y sin estrategias, siendo más significativo el escenario con iniciativas implementadas; alcanzando en el último año del periodo evaluado márgenes de $5.86 \%$ y $3.67 \%$ respectivamente. 


\section{Conclusiones y Recomendaciones}

\section{Conclusiones}

La empresa Ransa se ha enfocado en los últimos años en diversificar su cartera de servicios prestados y de expandir su alcance geográfico, buscando en un inicio lograr determinada rentabilidad a través de sus ventas, como única variable controlada, estrategia que ha funcionado a la empresa hasta la fecha; sin embargo, Ransa no ha enfocado los recursos necesarios en la búsqueda de controlar sus costos totales, estrategia que complementaría a la aplicada: por lo que, considerando la opinión de expertos en operaciones logísticas junto a la opinión de los clientes, se determina que Ransa debe enfocarse en iniciativas que le permitan reducir sus costos y, paralelamente, mejorar sus servicios.

Bajo este enfoque el Plan Estratégico obtenido del presente trabajo permite concluir en lo siguiente:

Que, en principio, la industria de operadores logísticos se encuentra en la etapa de crecimiento debido al índice creciente que muestra en los últimos diez años, fruto de una alta demanda por el servicio que ha provocado un alto nivel de competencia en la industria, colocándola dentro del concepto del océano rojo, escenario donde explotan la demanda y alinean todo su sistema de actividades a una preferencia estratégica: diferenciación o bajo costo.

Por ello, la empresa como participante de una industria aún en crecimiento, pero con un alto nivel de competencia, es indispensable que sepa reconocer las oportunidades que brinda el mercado y así ser los primeros en implementar iniciativas que exploten los beneficios de éstas; de igual modo, es indispensable que la empresa reconozca los escenarios que amenacen la 
industria e implemente adecuadamente iniciativas que disminuyan o mitiguen el impacto de éstas; sin embargo, Ransa no debe desperdiciar recursos en iniciativas inapropiadas.

Es así como Ransa, consciente del escenario en el que se encuentra la industria, ha propuesto una visión y práctica de valores que la alinean parcialmente con la industria, ello debido a la floja misión elaborada por la empresa que tiene como único foco al cliente.

Por otro lado, para alcanzar la visión y misión ajustada, es importante desarrollar las siguientes iniciativas: creación de nuevas competencias en el personal que les permita reconocer y solucionar problemas de modo apropiado; restructuración de áreas de la empresa que dificulten operaciones que tienen impacto directo en los flujos de caja e incrementen los costos innecesariamente; desarrollo de propuestas más atractivas sobre sus servicios prestados, rompiendo el equilibrio entre valor y costo, con el objeto de reducir o mitigar la salida de clientes de su cartera. Iniciativas que complementan la implementación apropiada de tecnología avanzada.

Por último, los resultados de la aplicación de las iniciativas, alineadas a las estrategias seleccionadas, muestran una viabilidad y rentabilidad para su aceptación y aplicación. 


\section{Recomendaciones}

A continuación, se enunciarán las recomendaciones que se consideran a raíz del presente trabajo.

- Es importante el compromiso de los involucrados en la implementación del presente plan estratégico 2019 - 2022, con el objeto de impulsar las ventas y reducir los costos a través de iniciativas que cambiarán los procesos, las políticas y las costumbres ineficientes relacionadas a la prestación de los servicios evaluados.

- Modificar la estructura organizacional a través de la reingeniería enfocada hacia el bienestar de los colaboradores y clientes, rediseñando las labores, el trabajo y los procesos; la misma que además debe mejorar los costos, calidad, servicio al cliente, y respuesta por parte de la empresa.

- Es fundamental evaluar minuciosamente, la viabilidad y rentabilidad de implementar las iniciativas identificadas en el modelo de océano azul.

- Realizar apropiadamente el seguimiento y el control de los indicadores definidos, con el fin de conocer oportunamente si se debe continuar, reajustar o cambiar la iniciativa.

- Elaborar un plan de acción para cada una de las iniciativas seleccionadas, respetando el cronograma planteado, siendo necesario que los responsables de cada una de las iniciativas trabajen en conjunto a través de su área responsable de proyectos. 
- Evaluar el nivel de impacto de las iniciativas en los otros servicios de la empresa (depósito temporal, on site, servicio de valor agregado, entre otros) y ajustar los estados financieros del Capítulo X.

- Es indispensable ajustar el Plan Estratégico dentro de un escenario que atraviesa una pandemia causada por la enfermedad SARS-CoV-2 (COVID-19), la cual ha impactado en todas las industrias, afectando significativamente la economía nacional. 


\section{Índice de Figuras}

Figura 01. Costos logísticos como porcentaje del PBI..............................13

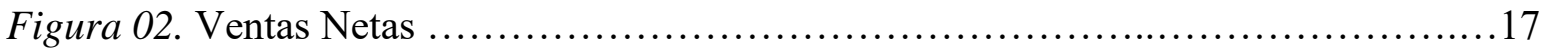

Figura 03. Comparativo de ventas Ransa Comercial SA y Producto Bruto Interno de la

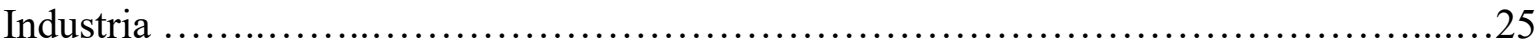

Figura 04. Ventas de los servicios principales de Ransa Comercial SA ..................26

Figura 05. Organigrama corporativo de Ransa 2018 ..............................28

Figura 06. Producto Bruto Interno según actividad económica ........................29

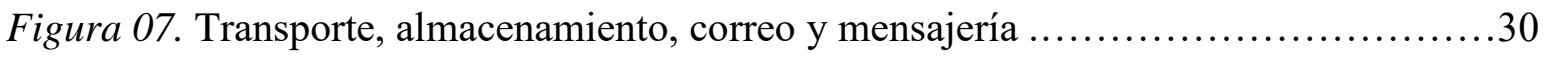

Figura 08. Densidad Empresarial de las empresas comerciales, según región .............64

Figura 09. Cadena de valor - Ransa 2019 ....................................... 83

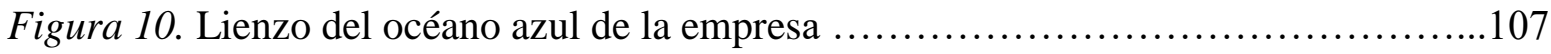

Figura 11. Lienzo del océano azul de la industria ................................ 108

Figura 12. Lienzo del océano azul con la estrategia considerada ........................109

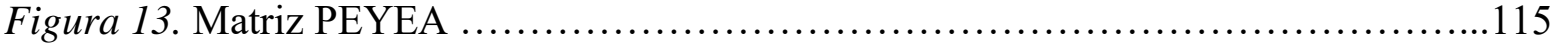

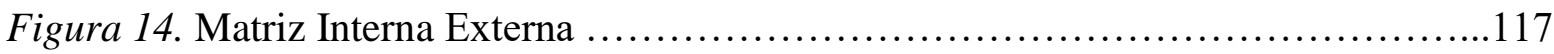

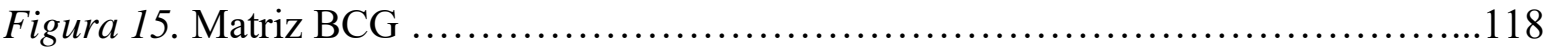

Figura 16. Matriz de la Gran Estrategia ........................................... 119

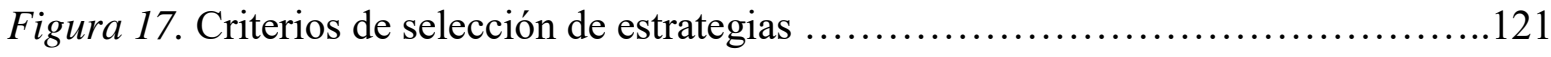

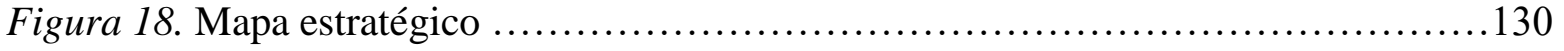

Figura 19. Criterios de evaluación de estrategias ................................... 149 


\section{Índice de Tablas}

Tabla 01. Niveles de estructura para operaciones logística por países ....................14

Tabla 02. Costos Variables, Costos Fijos Directos e Indirectos por servicio .................20

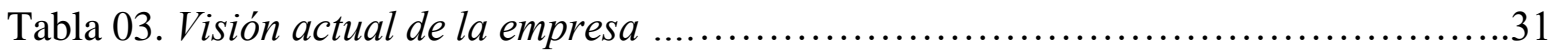

Tabla 04. Misión actual de la empresa ............................................33

Tabla 05. Misión propuesta para la empresa ...................................... 34

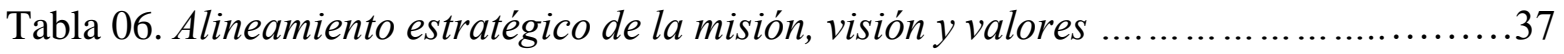

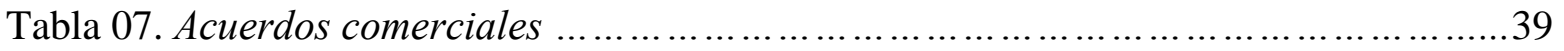

Tabla 08. Cantidad de empresa entrantes y salientes $(2015-2017)$....................42

Tabla 09. Impacto del entorno externo en los clientes, los proveedores y la empresa ........58

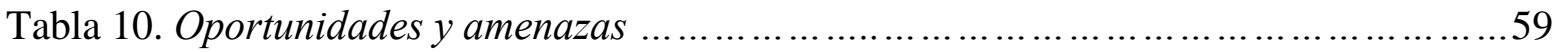

Tabla 11. Matriz de evaluación de factores externos ....................................6 60

Tabla 12. Número de empresas según actividad económica, II trimestre 2018 ............62

Tabla 13. Estructura empresarial .................................................... 64

Tabla 14. Amenaza de servicios sustitutos .........................................68

Tabla 15. Amenaza de nuevos competidores .............................................69

Tabla 16. Poder de negociación de los clientes ......................................71

Tabla 17. Poder de negociación de los proveedores .................................72

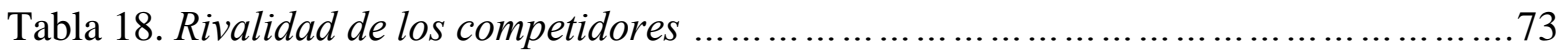

Tabla 19. Análisis de atractividad ................................................... 74

Tabla 20. Ransa frente a las fuerzas competitivas .......................................76

Tabla 21. Matriz de perfil competitivo: Ransa, Neptunia y Dinet .........................80

Tabla 22. Benchmarking de los factores claves de éxito .................................... 82 
Tabla 23. Indicadores de actividades primarias ....................................... 92

Tabla 24. Indicadores de actividades de apoyo ...........................................93

Tabla 25. Benchmarking de la cadena de valor con los líderes del mercado ...............95

Tabla 26. Identificación de recursos y capacidades .................................96

Tabla 27. Competencias de la empresa ..........................................97

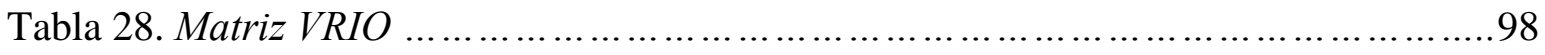

Tabla 29 Matriz EFI - Ransa ......................................................... 100

Tabla 30. Esquema de las cuatro acciones ....................................... 108

Tabla 31. Matriz FODA …......................................................... 110

Tabla 32. Estrategias del FODA frente a las estrategias competitivas genéricas ...........111

Tabla 33. Matriz PEYEA ............................................................. 113

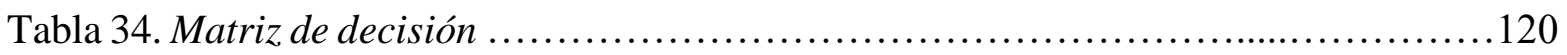

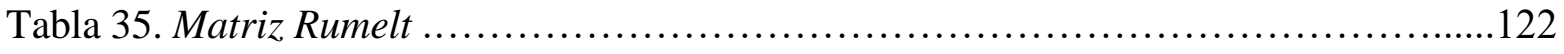

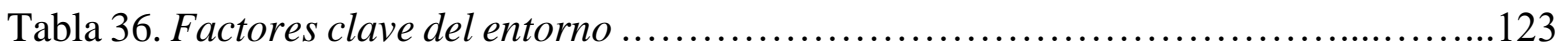

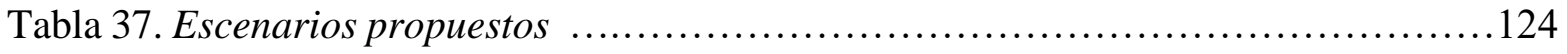

Tabla 38. Comparativo de estrategias con escenarios propuestos ........................126

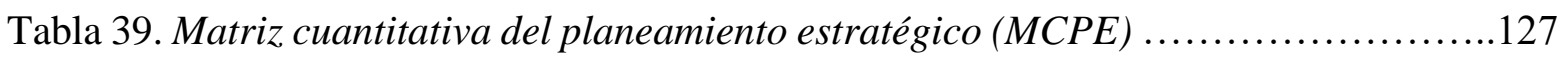

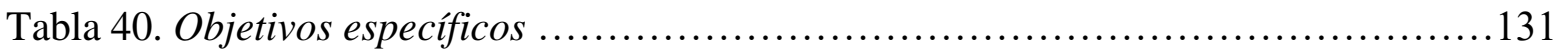

Tabla 41. Indicadores asociados a los objetivos específicos ............................... 132

Tabla 42. Metas asociadas a los objetivos específicos ..............................133

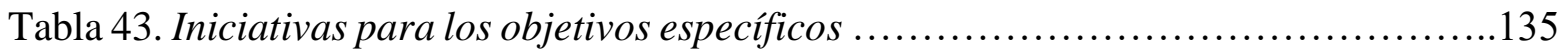

Tabla 44. Responsables de iniciativas ............................................ 137

Tabla 45. Costo de Ejecutivos de Negocios Junior ...................................... 138 
Tabla 46. Costo de horas dedicadas al nuevo proceso de cotización

Tabla 47. Costo de horas dedicadas a NPS

Tabla 48. Personal de área de Mejora Operativa

Tabla 49. Equipos de área de Mejora Operativa

Tabla 50. Inversión de aplicativo web y móvil

Tabla 51. Costo de servicio de soporte

Tabla 52. Costo de Power Bi

Tabla 53. Costo de Licencia Power Bi

Tabla 54. Inversión Softeon WMS

Tabla 55. Recurrente anual Softeon WMS

Tabla 56. Inversión Drivin

Tabla 57. Inversión $R F$ anillos

Tabla 58. Inversión en Programa de Liderazgo

Tabla 59. Inversión en capacitación metodología Lean Six Sigma 146

Tabla 60. Inversión en capacitación metodologías Ágiles 146

Tabla 61. Presupuesto de las iniciativas 147

Tabla 62. Cronograma de las iniciativas 148

Tabla 63. Proyección de ventas y costos sin y con estrategia .155

Tabla 64. Estado de resultados proyectado sin estrategia .157

Tabla 65. Estado de resultados proyectado con estrategia

Tabla 66. Estado de situación financiera proyectado sin estrategia 161

Tabla 67. Estado de situación financiera proyectado con estrategia 163

Tabla 68. Flujo de efectivo proyectado sin estrategia .164 


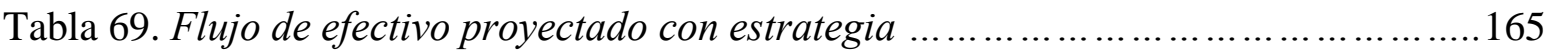

Tabla 70. Cálculo del COK ........................................................ 167

Tabla 71. Cálculo del WACC .................................................. 168

Tabla 72. Cálculo del VAN y la TIR ................................................ 168

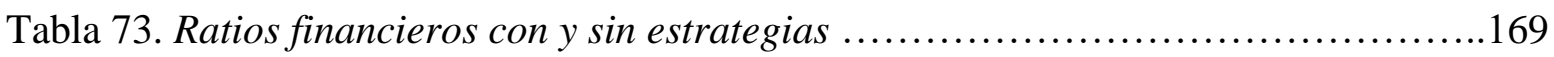




\section{Anexos}

\section{Anexo 01. Implementación WMS Sodexo}

A continuación, se presenta el cronograma del proyecto WMS Sodexo, desarrollado en el año 2019.

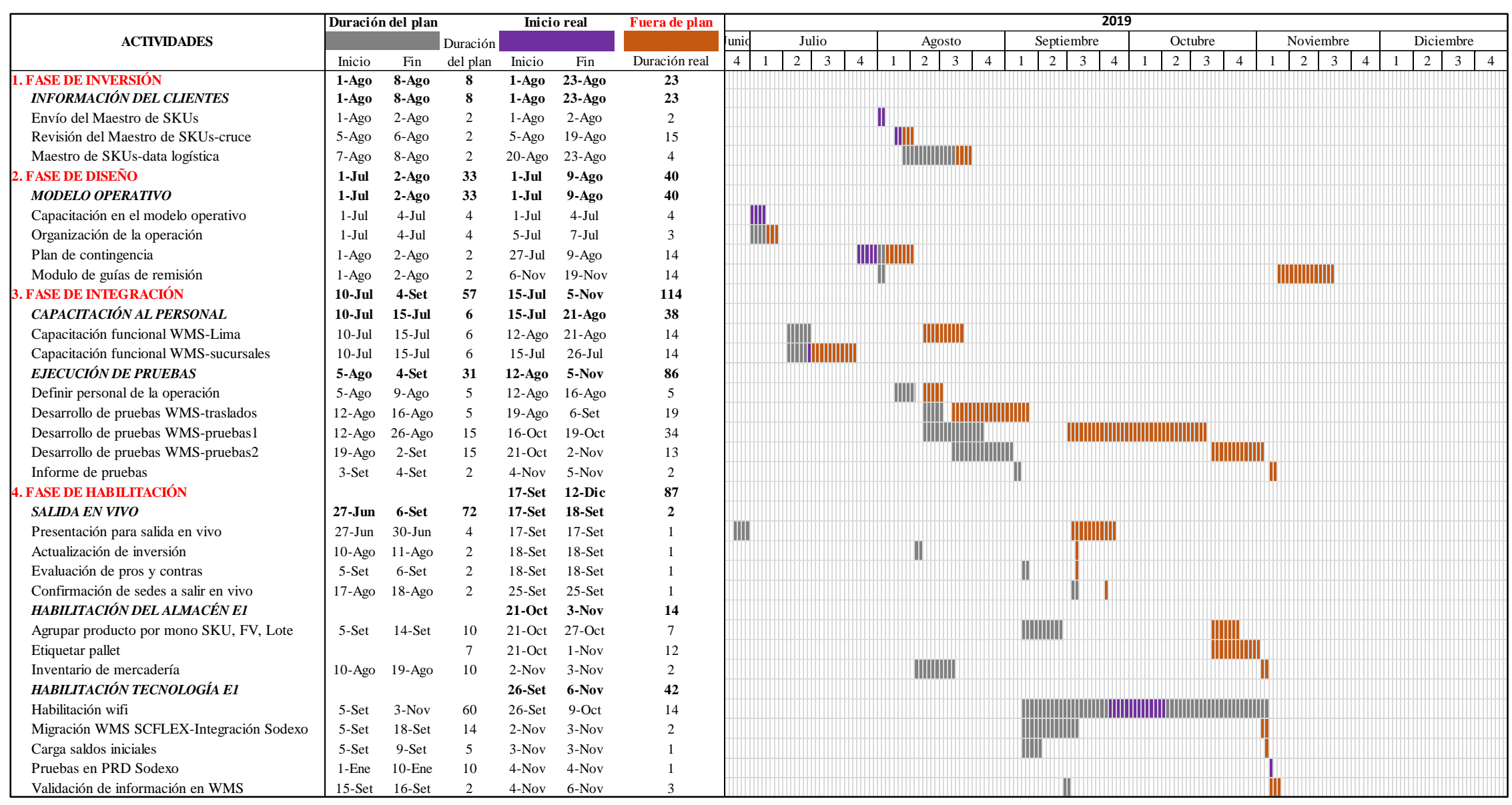




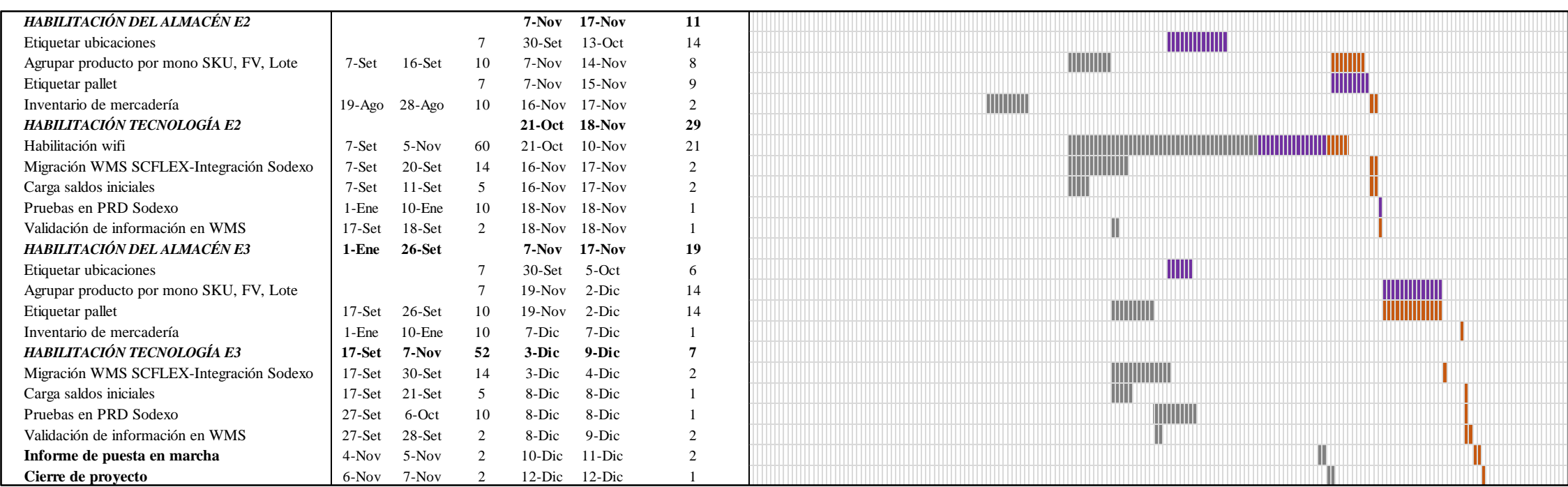

Nota. Dentro del cronograma de actividades, se observa tres distintos colores, que significan lo siguiente: color gris, cronograma establecido al inicio del proyecto; color morado, inicio y desarrollo real del proyecto, dentro del cronograma establecido; color marrón, inicio y desarrollo real del proyecto, fuera del cronograma establecido.

Como se observa en el cronograma de implementación WMS Sodexo, el cierre del proyecto debió llevarse a cabo los días 6 y 7 de noviembre, cosa que ocurrió el día 12 de diciembre, alcanzando 1 mes de retraso en la entrega del proyecto. 


\section{Anexo 02. Business Blueprint (BBP)}

A continuación, se muestra el documento estándar que debe presentarse para solicitar cambios en los proyectos.

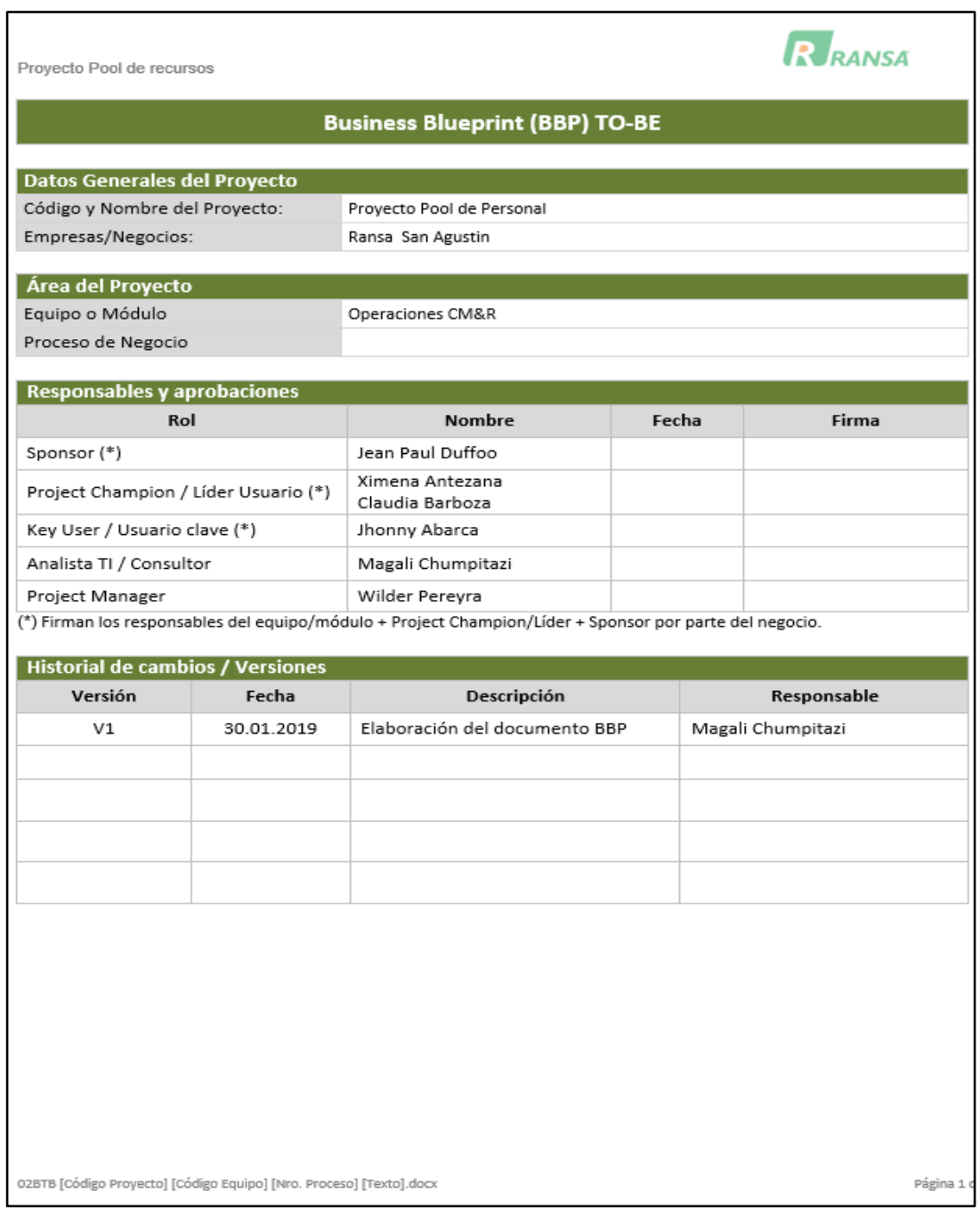

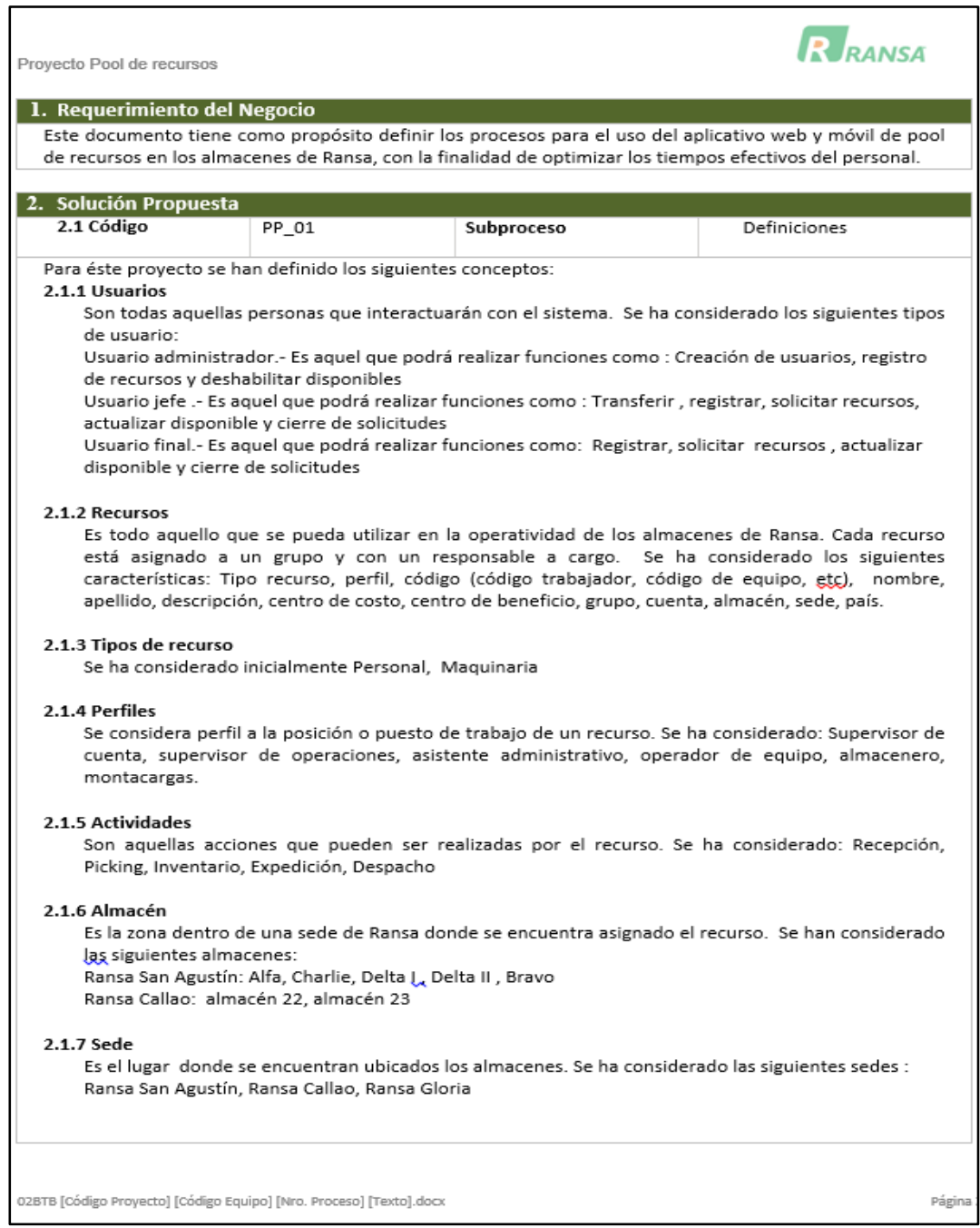




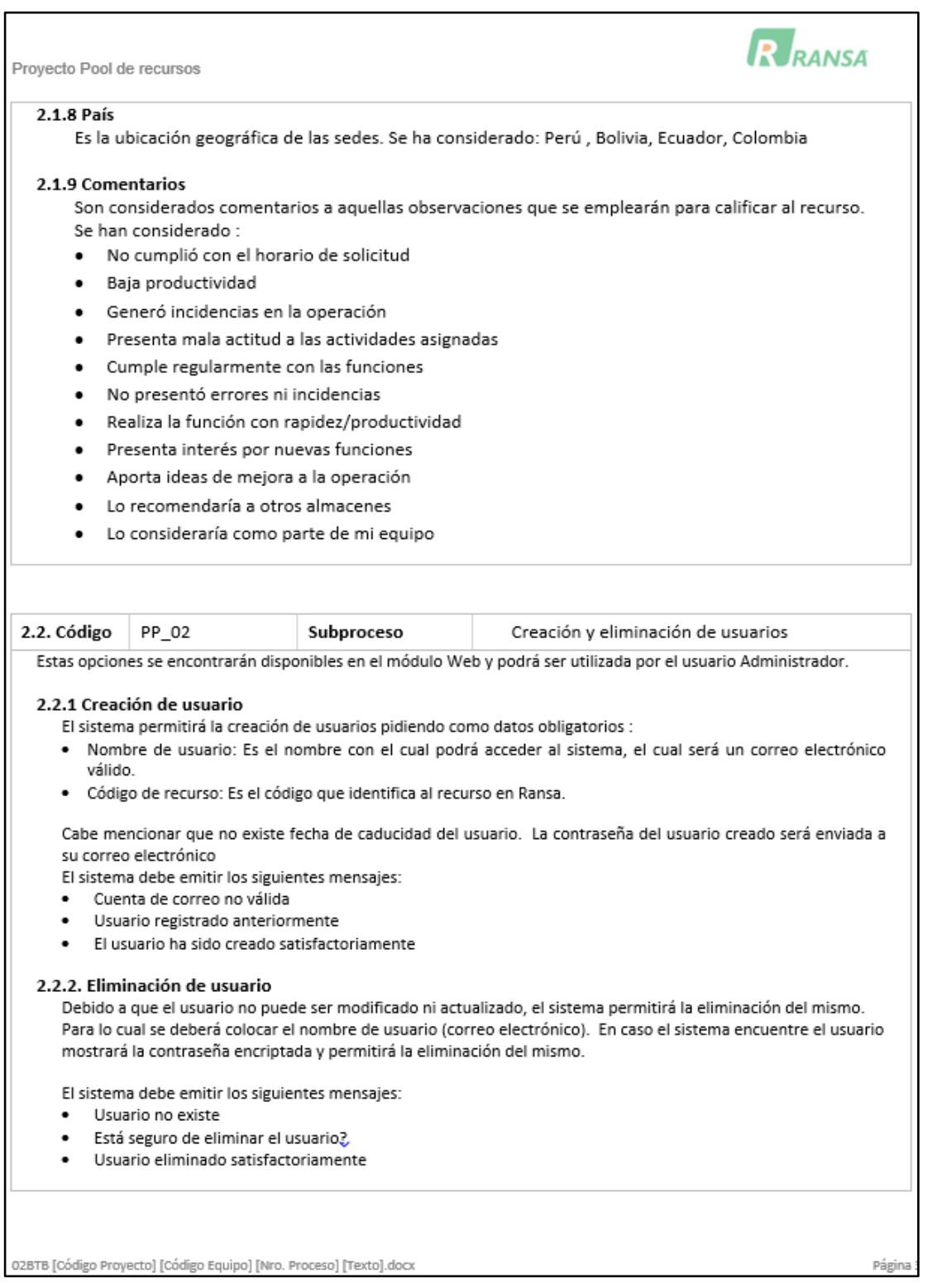

\begin{tabular}{|c|c|c|c|}
\hline \multicolumn{4}{|c|}{ Proyecto Pool de recursos } \\
\hline 2.3. Código & PP_03 & Subproceso & Registro de recursos \\
\hline \multicolumn{4}{|c|}{$\begin{array}{l}\text { Esta opción se encontrará disponible tanto en módulo web como en móvil y podrá ser utilizada por ambos usuarios } \\
\text { administrador y finales. } \\
\text { Mediante ésta opción se podrá inscribir a los recursos que podrán ser utilizados en los almacenes. Para lo cual se } \\
\text { deberá registrar : } \\
\text { - Campos obligatorios : Nombre, apellidos, código, perfil, almacén, actividad } \\
\text { Campo opcional : foto }\end{array}$} \\
\hline 2.4. Código & PP_04 & Subproceso & Modificar / Eliminar / Transferir recursos \\
\hline \multicolumn{4}{|c|}{ Esta opción se encontrará disponible en módulo web y podrá ser utilizada por los usuarios jefe y final. } \\
\hline \multicolumn{4}{|c|}{$\begin{array}{l}\text { - Seleccionar el código del recurso. } \\
\text { - Mostrará los datos como: nombre, apellidos, perfil, record actual. }\end{array}$} \\
\hline $\begin{array}{l}\text { Modific } \\
\text { : Per } \\
\text { - Per } \\
\text { - Se } \\
\text { a. } \\
\text { b. }\end{array}$ & $\begin{array}{l}\text { r recurso } \\
\text { vitirá actu } \\
\text { nitirá agré } \\
\text { lostrarán I } \\
\text { Está segur }\end{array}$ & $\begin{array}{l}\text { os del recurso } \\
\text { mensajes: } \\
\text { ar el recurso? } \\
\text { isfactoriamente }\end{array}$ & \\
\hline \multicolumn{3}{|c|}{$\begin{array}{l}\text { - Permite eliminar el recurso } \\
\text { Se mostrarán los siguientes mensajes: } \\
\text { a. Está seguro de eliminar el recurso? } \\
\text { b. Recurso eliminado satisfactoriamente }\end{array}$} & \\
\hline $\begin{array}{l}\text { Transfe } \\
\text { - } \text { Per } \\
\text { - } \text { Del } \\
\text { tra } \\
\text { - Se } \\
\text { ing } \\
\text { - Se } \\
\text { a. } \\
\text { b. }\end{array}$ & $\begin{array}{l}\text { r recursos } \\
\text { iecerealiza } \\
\text { erá indicar } \\
\text { ferir dich } \\
\text { ebe envia } \\
\text { sta a su gr } \\
\text { ostrarán I }\end{array}$ & $\begin{array}{l}\text { encia del recurso; } \\
\text { atransferir el rec } \\
\text { al nuevo encarga } \\
\text { mensajes: } \\
\text { ir el recurso? } \\
\text { isfactoriamente }\end{array}$ & $\begin{array}{l}\text { ón sólo puede ser utilizada por el usuario jefe. } \\
\text { ismo podrá seleccionar la actividad con la que se va a } \\
\text { po. Y sólo si el encargado acepta el recurso entonces }\end{array}$ \\
\hline 2.4. Código & PP_04 & Subproceso & Actualización disponible \\
\hline \multicolumn{4}{|c|}{$\begin{array}{l}\text { Esta opción se encontrará disponible tanto en módulo web como en móvil y podrá ser utilizada por todos los } \\
\text { usuarios ( administrador, jefe y final) }\end{array}$} \\
\hline \multicolumn{4}{|c|}{$\begin{array}{l}\text { Mediante ésta opción se podrá colocar al recurso como disponible para que pueda ser solicitado. La pantalla debe } \\
\text { mostrar: }\end{array}$} \\
\hline \multicolumn{4}{|c|}{$\begin{array}{l}\text { - Grilla de recursos asignados a su grupo con columnas: nombre o descripción, perfil, caja selección, horas } \\
\text { inicio disponible, hora fin disponible, } \\
\text { - Si marca la columna selección, el sistema permitirá actualizar la disponibilidad del recurso. } \\
\text { - Los recursos que no se hayan marcado se mostrarán inhabilitados para los demás usuarios. }\end{array}$} \\
\hline \multicolumn{4}{|c|}{ 028тв [Código Proyecto] [ [ódidigo Equipo] [Nro. Proceso] [Trexto].dooc } \\
\hline
\end{tabular}




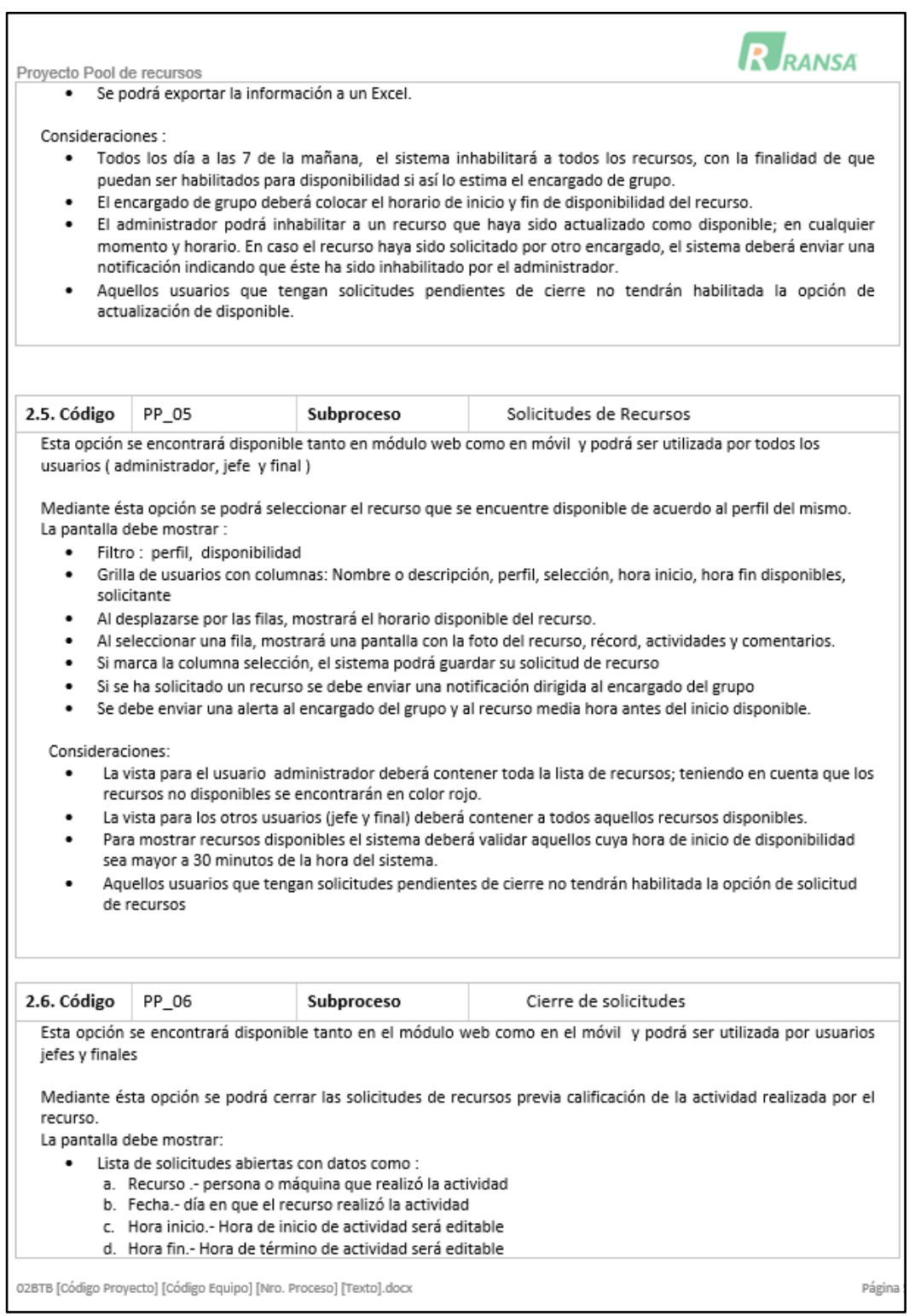

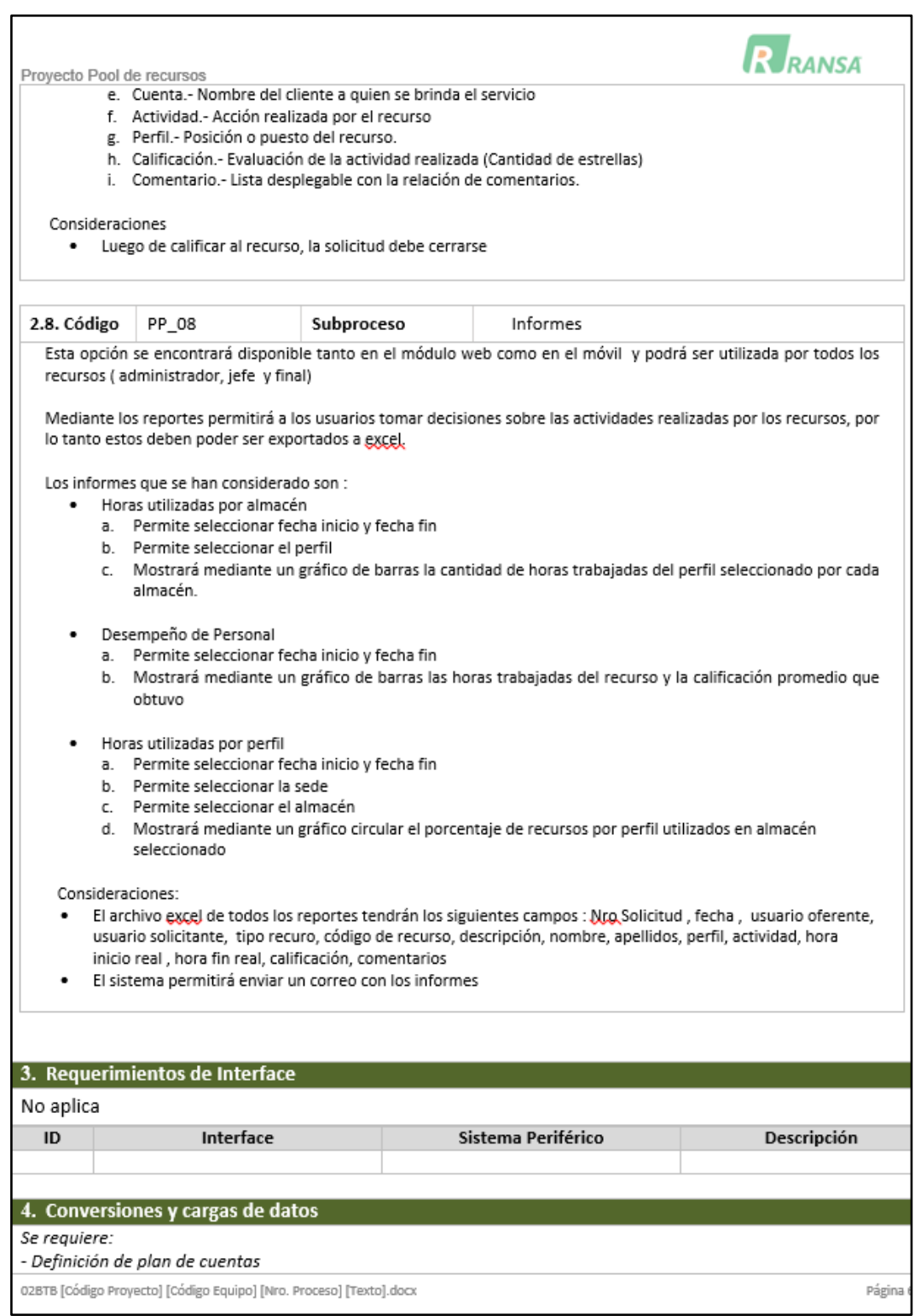




\section{Anexo 03. Gestión de Proyectos en 5 pasos (P5P)}

A continuación, se presenta el proceso de gestión de proyectos.
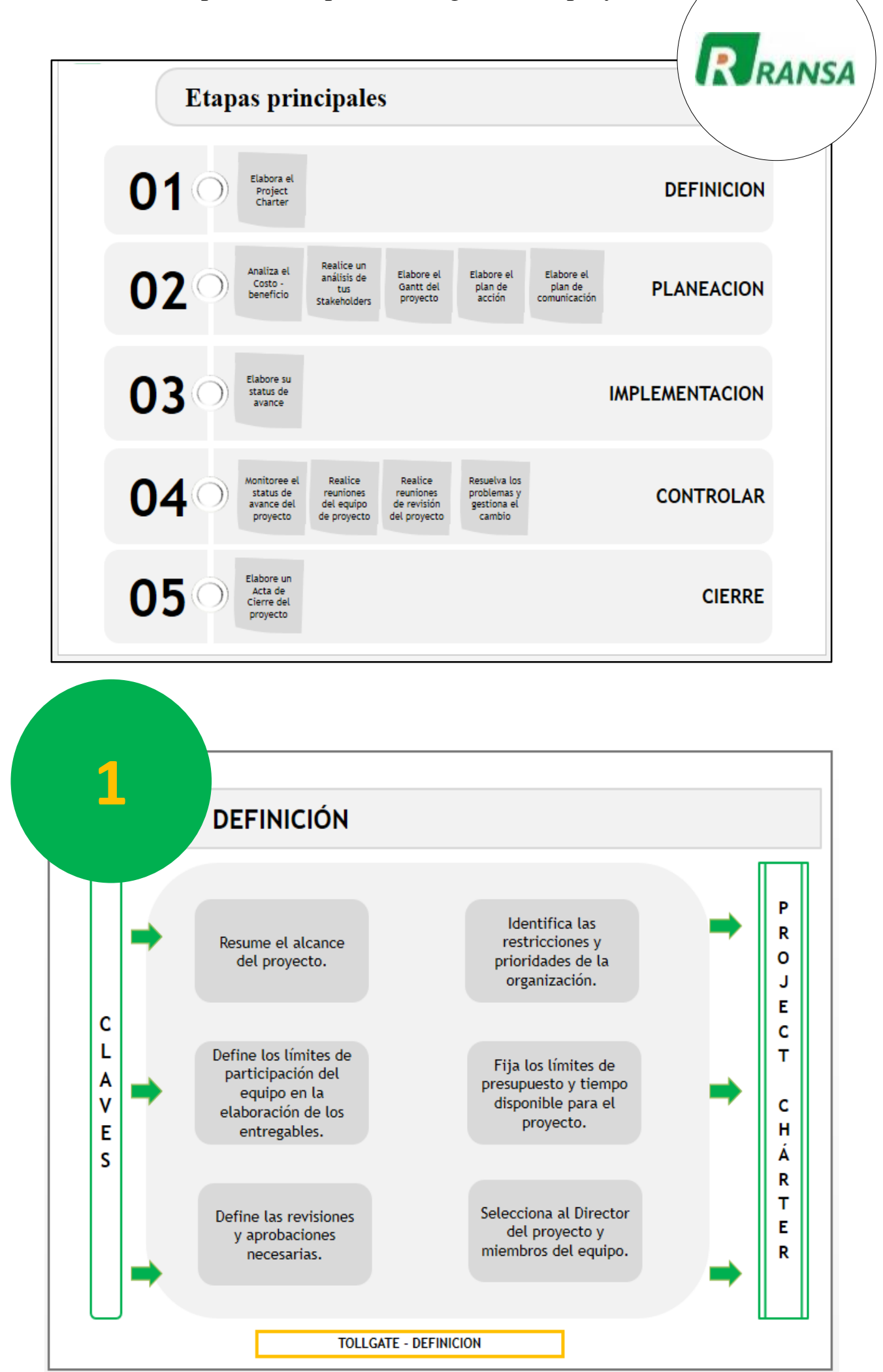


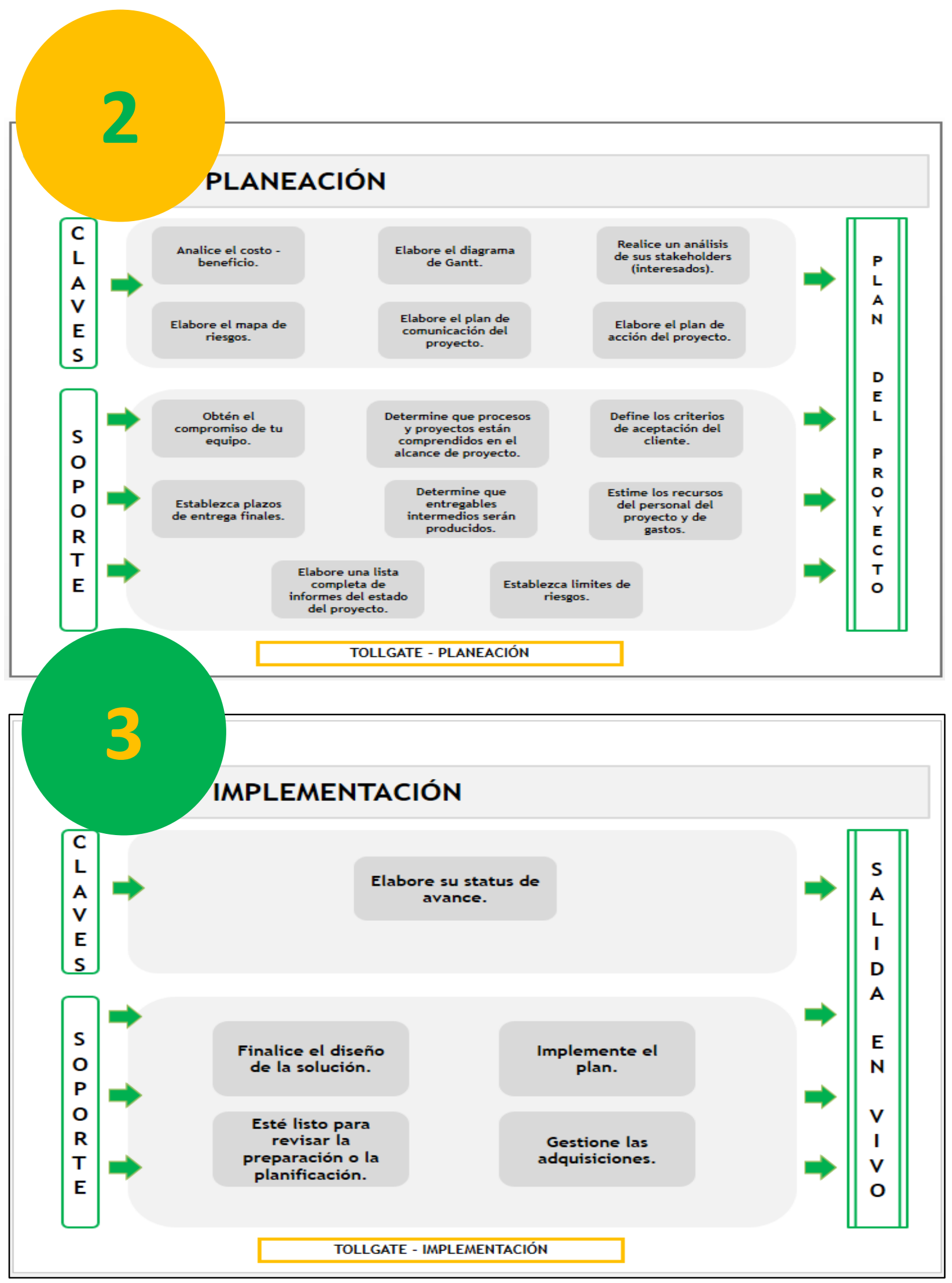




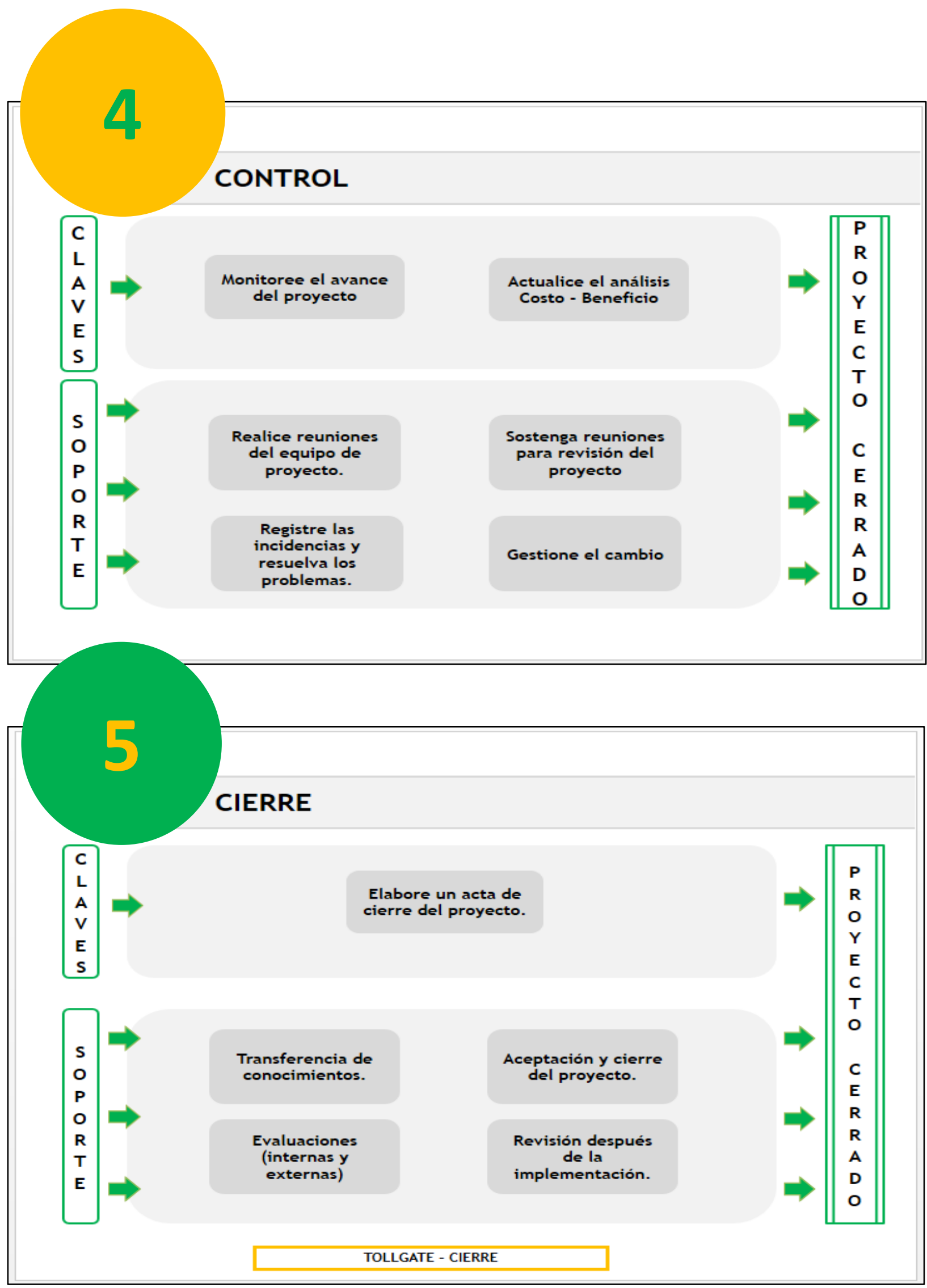


Anexo 04. Ficha técnica - Matriz de evaluación de los factores externos por expertos de Ransa

\section{Presentación}

Buen día, antes de comenzar queremos agradecerle por recibirnos y brindarnos su tiempo para llevar a cabo esta entrevista. Dicho esto, la información que nos brinde será de uso estricto para el desarrollo de nuestra tesis.

\section{Objetivos de investigación}

Conocer al detalle el nivel de importancia e impacto que tienen los factores externos capitalizando oportunidades y evitando amenazas.

\section{Método de devaluación}

Primero, asignar un peso de 0.00 (menos importante) a 1.00 (más importante) a cada uno de los siguientes factores, el peso dado representa la importancia relativa para alcanzar el éxito en la industria logística, sumando al final todos los pesos 1.00. Segundo, asignar una calificación de 1 (respuesta mala), 2 (respuesta media), 3 (respuesta superior a la media), y 4 (respuesta superior), basándose en la eficacia de las estrategias de Ransa. Las calificaciones pertenecen a Ransa y los pesos a la industria.

\section{Guía de entrevista}

\begin{tabular}{|c|c|c|c|}
\hline \multicolumn{4}{|c|}{ GUÍA ENTREVISTA $\mathbf{N}^{\circ} 1$} \\
\hline \multicolumn{4}{|l|}{$\begin{array}{l}\text { Nombre: Samaniego Cruz, Sheryl } \\
\text { Cargo: Jefe de Operaciones de CM\&R }\end{array}$} \\
\hline Factores críticos para el éxito & Peso & Calificación & Ponderado \\
\hline \multicolumn{4}{|l|}{ Amenazas } \\
\hline 1. Falta de infraestructura nacional vial & 0.1 & 2 & 0.2 \\
\hline 2. La informalidad laboral en el Perú & 0.1 & 2 & 0.2 \\
\hline 3. Aumento de las exigencias medioambientales & 0.05 & 1 & 0.05 \\
\hline 4. Inestabilidad social y política del país & 0.12 & 2 & 0.24 \\
\hline 5. Corrupción en las licitaciones de proyectos de infraestructura & 0.08 & 2 & 0.16 \\
\hline \multicolumn{4}{|l|}{ Oportunidades } \\
\hline 1. Plan Nacional de Infraestructura & 0.11 & 4 & 0.44 \\
\hline 2. Tratados de Libre Comercio & 0.1 & 3 & 0.3 \\
\hline 3. Reglas de la Haya - Visby y Hamburgo & 0.04 & 3 & 0.12 \\
\hline 4. Crecimiento Económico en el Perú y América Latina & 0.1 & 4 & 0.4 \\
\hline 5. Tecnología, soporte de la actividad logística & 0.1 & 3 & 0.3 \\
\hline 6. Tendencias globales de consumo & 0.1 & 3 & 0.3 \\
\hline Total & 1 & & 2.71 \\
\hline
\end{tabular}


GUÍA ENTREVISTA $\mathbf{N}^{\circ} \mathbf{2}$

Nombre: Diaz Cespedes, Edwin

Cargo: Jefe de Operaciones de CM\&R

\begin{tabular}{|lccc|}
\hline Factores críticos para el éxito & Peso & Calificación & Ponderado \\
\hline Amenazas & & & \\
1. Falta de infraestructura nacional vial & 0.12 & 2 & 0.24 \\
2. La informalidad laboral en el Perú & 0.1 & 1 & 0.1 \\
3. Aumento de las exigencias medioambientales & 0.04 & 1 & 0.04 \\
4. Inestabilidad social y política del país & 0.1 & 2 & 0.2 \\
5. Corrupción en las licitaciones de proyectos de infraestructura & 0.07 & 2 & 0.14 \\
Oportunidades & & & \\
1. Plan Nacional de Infraestructura & 0.13 & 4 & 0.52 \\
2. Tratados de Libre Comercio & 0.1 & 3 & 0.3 \\
3. Reglas de la Haya - Visby y Hamburgo & 0.04 & 2 & 0.08 \\
4. Crecimiento Económico en el Perú y América Latina & 0.11 & 3 & 0.33 \\
5. Tecnología, soporte de la actividad logística & 0.1 & 3 & 0.3 \\
6. Tendencias globales de consumo & 0.09 & 3 & 0.27 \\
Total & $\mathbf{1}$ & & $\mathbf{2 . 5 2}$ \\
\hline
\end{tabular}

\section{GUÍA ENTREVISTA N ${ }^{\circ} 3$}

Nombre: Vittoria Figueroa, Giacomo

Cargo: Jefe de Operaciones de CM\&R

\begin{tabular}{|lccc|}
\hline Factores críticos para el éxito & Peso & Calificación & Ponderado \\
\hline Amenazas & & & \\
1. Falta de infraestructura nacional vial & 0.1 & 2 & 0.2 \\
2. La informalidad laboral en el Perú & 0.09 & 1 & 0.09 \\
3. Aumento de las exigencias medioambientales & 0.05 & 1 & 0.05 \\
4. Inestabilidad social y política del país & 0.12 & 2 & 0.24 \\
5. Corrupción en las licitaciones de proyectos de infraestructura & 0.07 & 2 & 0.14 \\
Oportunidades & & & \\
1. Plan Nacional de Infraestructura & 0.12 & 3 & 0.36 \\
2. Tratados de Libre Comercio & 0.1 & 3 & 0.3 \\
3. Reglas de la Haya - Visby y Hamburgo & 0.04 & 3 & 0.12 \\
4. Crecimiento Económico en el Perú y América Latina & 0.11 & 4 & 0.44 \\
5. Tecnología, soporte de la actividad logística & 0.1 & 3 & 0.3 \\
6. Tendencias globales de consumo & 0.1 & 4 & 0.4 \\
Total & $\mathbf{1}$ & & $\mathbf{2 . 6 4}$ \\
\hline
\end{tabular}


Anexo 05. Matriz de evaluación de las cinco fuerzas competitivas de la industria por expertos de Ransa

\section{Objetivos de investigación}

Conocer al detalle el nivel de Ransa Comercial en cada una de las variables de las cinco fuerzas competitivas de la industria.

\section{Perfil de los participantes}

a. Trabajador del área de logística y operaciones.

b. Estar laborando en la empresa como mínimo 3 años.

c. Tener experiencia en la industria como mínimo 5 años

d. Con conocimiento de la industria de operadores logísticos modernos y tradicionales.

\section{Guía de entrevista}

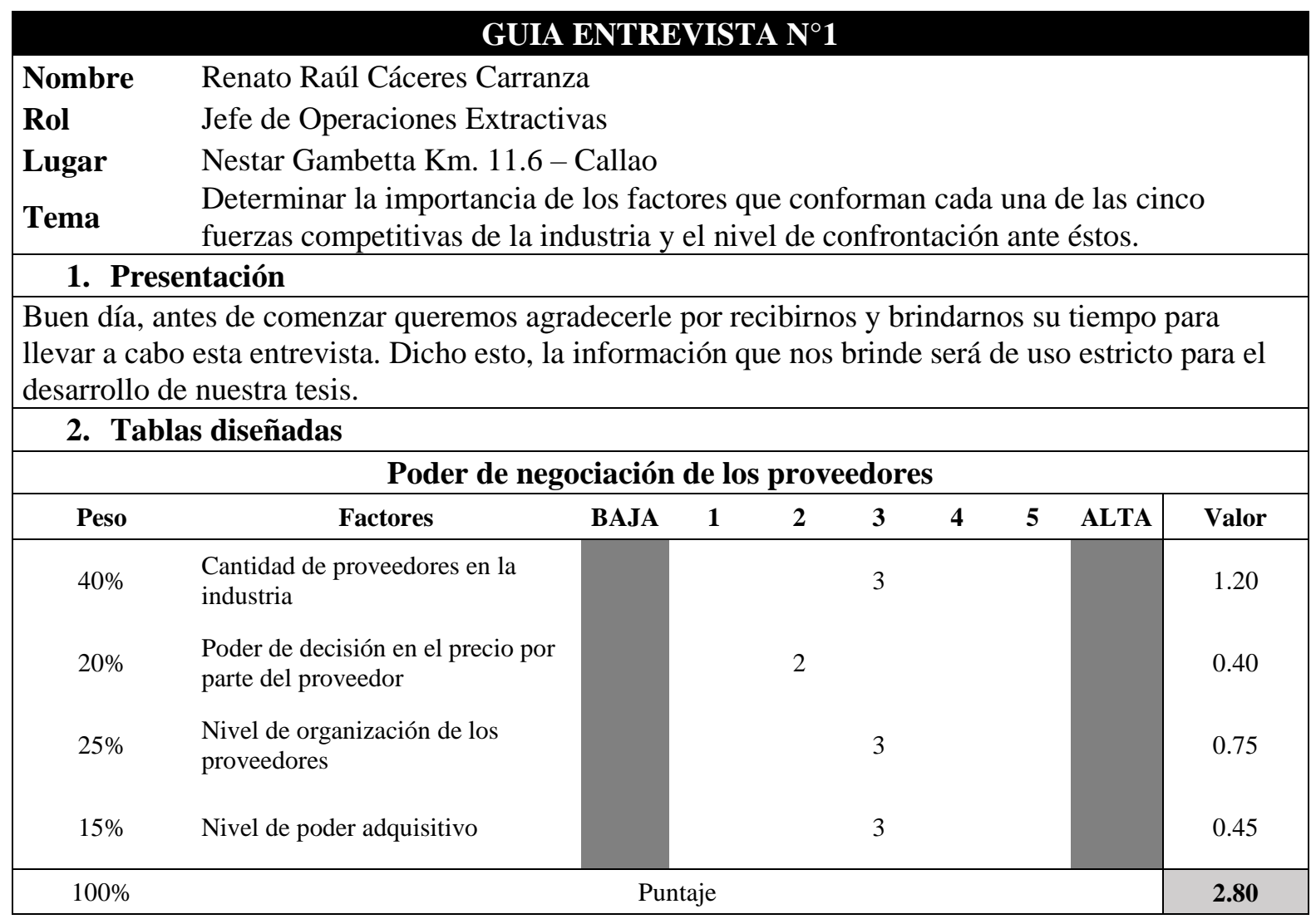




\begin{tabular}{|c|c|c|c|c|c|c|c|c|c|}
\hline \multicolumn{10}{|c|}{ Poder de negociación de los clientes } \\
\hline Peso & Factores & BAJA & 1 & 2 & 3 & 4 & 5 & ALTA & Valor \\
\hline $40 \%$ & Cambiar a otra marca o sustituto & & & & & 4 & & & 1.60 \\
\hline $25 \%$ & Son importantes para el vendedor & & & & 3 & & & & 0.75 \\
\hline $15 \%$ & $\begin{array}{l}\text { Luchan contra la caída en la } \\
\text { demanda }\end{array}$ & & & & 3 & & & & 0.45 \\
\hline $10 \%$ & $\begin{array}{l}\text { Informados sobre los productos y } \\
\text { precios }\end{array}$ & & & & & 4 & & & 0.40 \\
\hline $10 \%$ & $\begin{array}{l}\text { Es su decisión qué comprar y } \\
\text { cuándo hacerlo }\end{array}$ & & & 2 & & & & & 0.20 \\
\hline $100 \%$ & & & & & & & & & 3.40 \\
\hline \multicolumn{10}{|c|}{$\begin{array}{l}\text { Puntaje } \\
\text { devos competidores }\end{array}$} \\
\hline Peso & Factores & BAJA & 1 & 2 & 3 & 4 & 5 & ALTA & Valor \\
\hline $30 \%$ & Economía a escala & & & & 3 & & & & 0.90 \\
\hline $15 \%$ & Diferenciación del producto & & & 2 & & & & & 0.30 \\
\hline $25 \%$ & Inversiones de capital & & & & & 4 & & & 1.00 \\
\hline $15 \%$ & Acceso a canales de distribución & & & & & 4 & & & 0.60 \\
\hline $15 \%$ & Barreras de entrada & & & & 3 & & & & 0.45 \\
\hline $100 \%$ & & & & & & & & & 3.25 \\
\hline \multicolumn{10}{|c|}{ Amenaza de productos $\mathrm{s}$} \\
\hline Peso & Factores & BAJA & 1 & 2 & 3 & 4 & 5 & ALTA & Valor \\
\hline $10 \%$ & $\begin{array}{l}\text { Propensión del consumidor a } \\
\text { sustituir }\end{array}$ & & & & 3 & & & & 0.30 \\
\hline $25 \%$ & Sustitutos con mejores precios & & & 2 & & & & & 0.50 \\
\hline $30 \%$ & Facilidad de cambio del comprador & & & & & 4 & & & 1.20 \\
\hline $20 \%$ & $\begin{array}{l}\text { Nivel percibido de diferenciación } \\
\text { del producto }\end{array}$ & & & & 3 & & & & 0.60 \\
\hline $15 \%$ & $\begin{array}{l}\text { Disponibilidad de sustitutos } \\
\text { cercanos }\end{array}$ & & & 2 & & & & & 0.30 \\
\hline $100 \%$ & & & & & & & & & 2.90 \\
\hline \multicolumn{10}{|c|}{ Rivalidad de competidores existentes } \\
\hline Peso & Factores & BAJA & 1 & 2 & 3 & 4 & 5 & ALTA & Valor \\
\hline $30 \%$ & Gran número de competidores & & & & & 4 & & & 1.20 \\
\hline $20 \%$ & Costos fijos & & & & & 4 & & & 0.80 \\
\hline $10 \%$ & Falta de diferenciación & & & & 3 & & & & 0.30 \\
\hline $25 \%$ & Competidores diversos & & & 2 & & & & & 0.50 \\
\hline $15 \%$ & Barreras de salida & & & 2 & & & & & 0.30 \\
\hline $100 \%$ & \multicolumn{8}{|c|}{ Puntaje } & 3.10 \\
\hline
\end{tabular}




\section{GUÍA ENTREVISTA $\mathbf{N}^{\circ} 2$}

\begin{tabular}{ll} 
Nombre & Ramsés Manuel Cubas Gonzales \\
Rol & Jefe de Gestión de Operaciones \\
Lugar & Av. Argentina 2833 - Callao \\
Tema & $\begin{array}{l}\text { Determinar la importancia de los factores que conforman cada una de las cinco } \\
\text { fuerzas competitivas de la industria y el nivel de confrontación ante éstos. }\end{array}$ \\
\hline \multicolumn{2}{|c}{ 1. Presentación }
\end{tabular}

Buen día, antes de comenzar queremos agradecerle por recibirnos y brindarnos su tiempo para llevar a cabo esta entrevista. Dicho esto, la información que nos brinde será de uso estricto para el desarrollo de nuestra tesis.

2. Tablas diseñadas

\begin{tabular}{|c|c|c|c|c|c|c|c|c|c|}
\hline \multicolumn{10}{|c|}{ Poder de negociación de los proveedores } \\
\hline Peso & Factores & BAJA & 1 & 2 & 3 & 4 & 5 & ALTA & Valor \\
\hline $25 \%$ & $\begin{array}{l}\text { Cantidad de proveedores en la } \\
\text { industria }\end{array}$ & & & & 3 & & & & 0.75 \\
\hline $25 \%$ & $\begin{array}{l}\text { Poder de decisión en el precio por } \\
\text { parte del proveedor }\end{array}$ & & & & & 4 & & & 1.00 \\
\hline $25 \%$ & $\begin{array}{l}\text { Nivel de organización de los } \\
\text { proveedores }\end{array}$ & & & & 3 & & & & 0.75 \\
\hline $25 \%$ & Nivel de poder adquisitivo & & & & & & 5 & & 1.25 \\
\hline \multirow{2}{*}{\multicolumn{10}{|c|}{ Poder de negociación de los clientes }} \\
\hline & & & & & & & & & \\
\hline Peso & Factores & BAJA & 1 & 2 & 3 & 4 & 5 & ALTA & Valor \\
\hline $20 \%$ & Cambiar a otra marca o sustituto & & & 2 & & & & & 0.40 \\
\hline $20 \%$ & Son importantes para el vendedor & & & & 3 & & & & 0.60 \\
\hline $20 \%$ & $\begin{array}{l}\text { Luchan contra la caída en la } \\
\text { demanda }\end{array}$ & & & 2 & & & & & 0.40 \\
\hline $20 \%$ & $\begin{array}{l}\text { Informados sobre los productos y } \\
\text { precios }\end{array}$ & & & & & 4 & & & 0.80 \\
\hline $20 \%$ & $\begin{array}{l}\text { Es su decisión qué comprar y } \\
\text { cuándo hacerlo }\end{array}$ & & & & & 4 & & & 0.80 \\
\hline $100 \%$ & & & & & & & & & 3.00 \\
\hline \multicolumn{10}{|c|}{ Amenaza de nuevos competidores } \\
\hline Peso & Factores & BAJA & 1 & 2 & 3 & 4 & 5 & ALTA & Valor \\
\hline $5 \%$ & Economía a escala & & & 2 & & & & & 0.10 \\
\hline $30 \%$ & Diferenciación de producto & & & 2 & & & & & 0.06 \\
\hline $40 \%$ & Inversiones de capital & & & & 3 & & & & 1.20 \\
\hline $5 \%$ & Acceso a canales de distribución & & & & 3 & & & & 0.15 \\
\hline $20 \%$ & Barreras de entrada & & & 2 & & & & & 0.40 \\
\hline $100 \%$ & \multicolumn{8}{|c|}{ Puntaje } & 1.91 \\
\hline
\end{tabular}




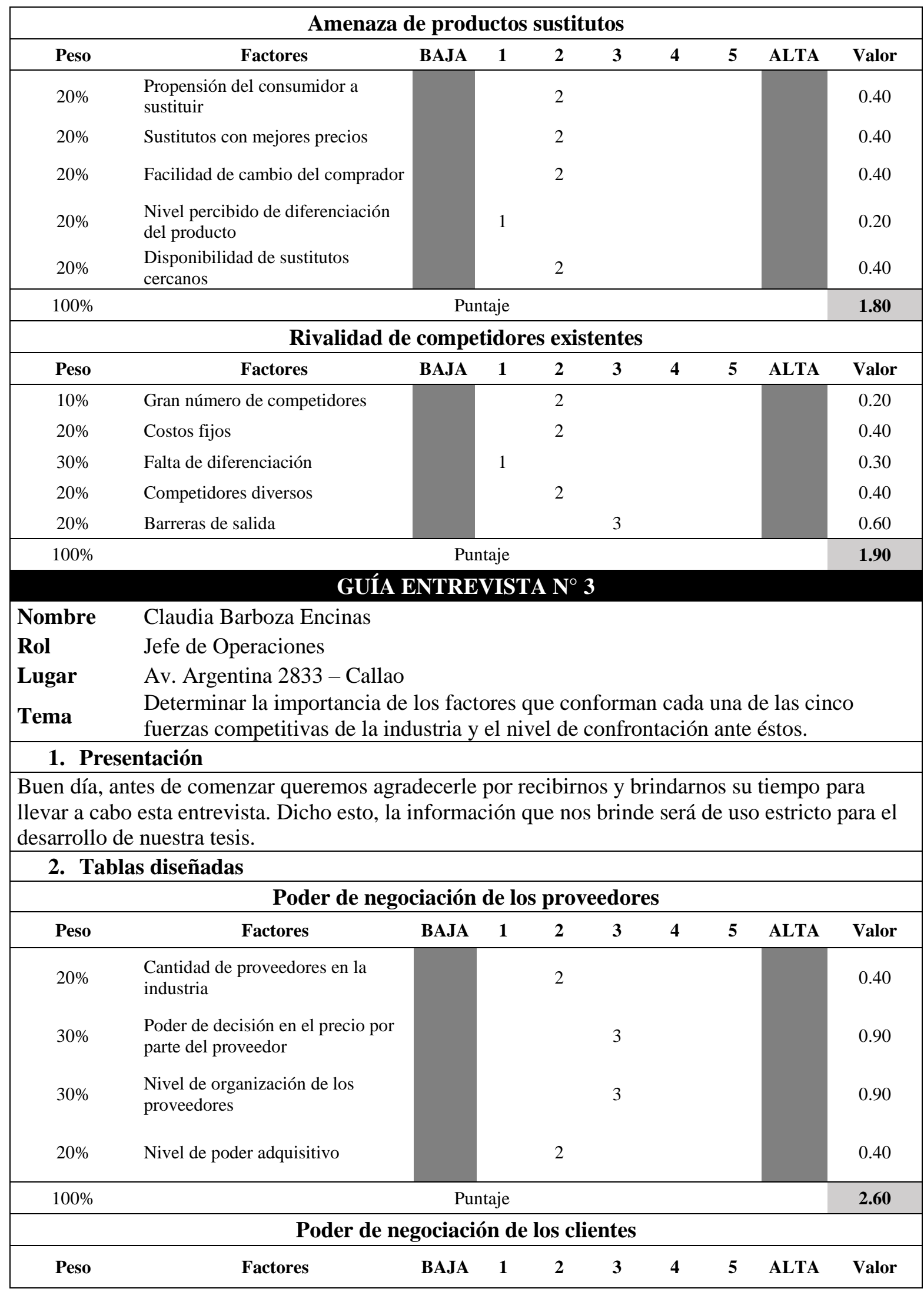




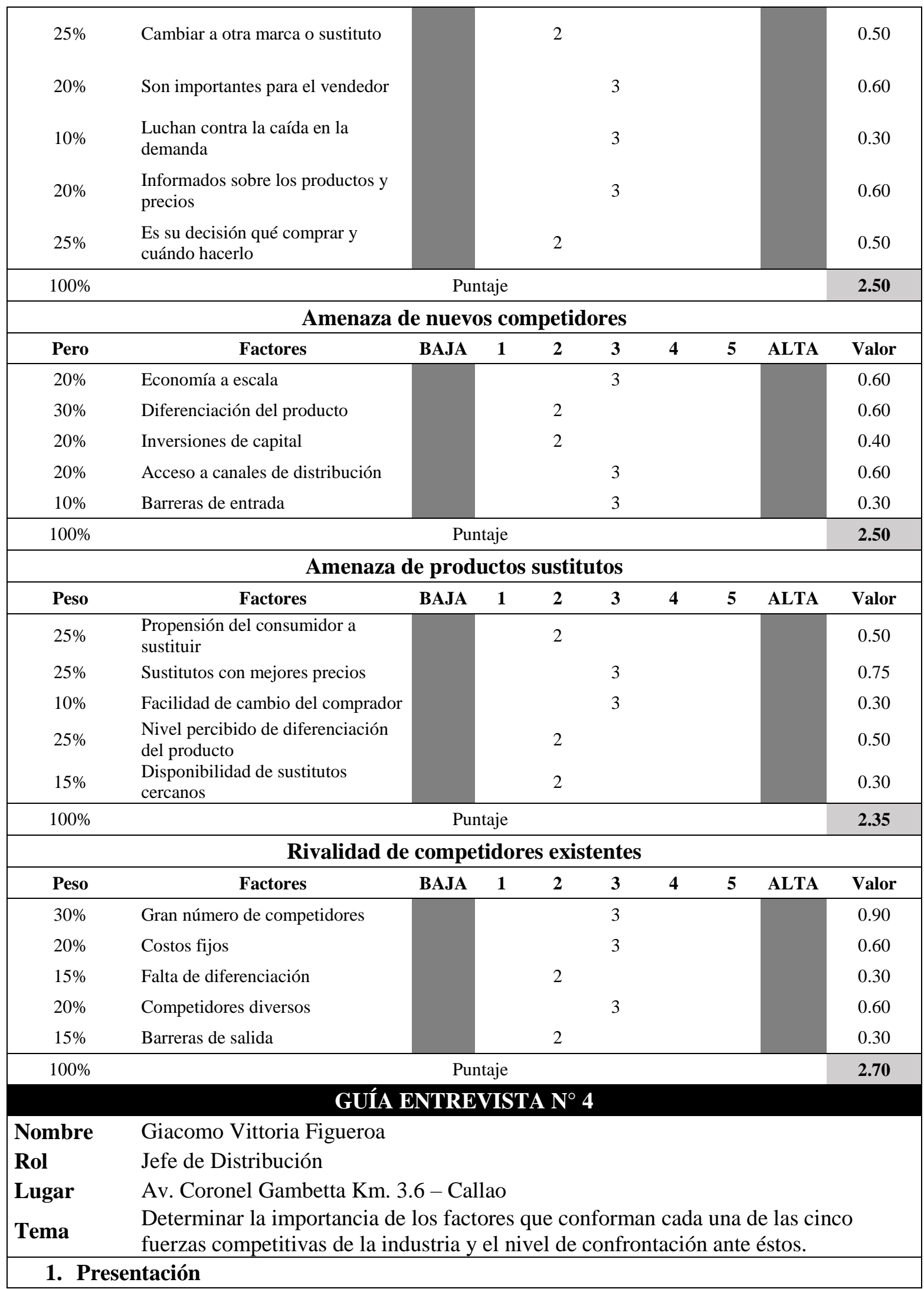


Buen día, antes de comenzar queremos agradecerle por recibirnos y brindarnos su tiempo para llevar a cabo esta entrevista. Dicho esto, la información que nos brinde será de uso estricto para el desarrollo de nuestra tesis.

2. Tablas diseñadas

\section{Poder de negociación de los proveedores}

\begin{tabular}{|c|c|c|c|c|c|c|c|c|c|}
\hline Peso & Factores & BAJA & 1 & 2 & 3 & 4 & 5 & ALTA & Valor \\
\hline $25 \%$ & $\begin{array}{l}\text { Cantidad de proveedores en la } \\
\text { industria }\end{array}$ & & & 2 & & & & & 0.50 \\
\hline $30 \%$ & $\begin{array}{l}\text { Poder de decisión en el precio por } \\
\text { parte del proveedor }\end{array}$ & & & & 3 & & & & 0.90 \\
\hline $25 \%$ & $\begin{array}{l}\text { Nivel de organización de los } \\
\text { proveedores }\end{array}$ & & & & 3 & & & & 0.75 \\
\hline $20 \%$ & Nivel de poder adquisitivo & & & 2 & & & & & 0.40 \\
\hline $100 \%$ & & Pun & & & & & & & 2.55 \\
\hline \multicolumn{10}{|c|}{ Poder de negociación de los clientes } \\
\hline Pesto & Factores & BAJA & 1 & 2 & 3 & 4 & 5 & ALTA & Valor \\
\hline $30 \%$ & Cambiar a otra marca o sustituto & & & 2 & & & & & 0.60 \\
\hline $20 \%$ & Son importantes para el vendedor & & & & 3 & & & & 0.60 \\
\hline $10 \%$ & $\begin{array}{l}\text { Luchan contra la caída en la } \\
\text { demanda }\end{array}$ & & & & 3 & & & & 0.30 \\
\hline $20 \%$ & $\begin{array}{l}\text { Informados sobre los productos y } \\
\text { precios }\end{array}$ & & & & 3 & & & & 0.60 \\
\hline $20 \%$ & $\begin{array}{l}\text { Es su decisión qué comprar y } \\
\text { cuándo hacerlo }\end{array}$ & & & 2 & & & & & 0.40 \\
\hline $100 \%$ & & Pun & & & & & & & 2.50 \\
\hline \multicolumn{10}{|c|}{ Amenaza de nuevos competidores } \\
\hline Peso & Factores & BAJA & 1 & 2 & 3 & 4 & 5 & ALTA & Valor \\
\hline $20 \%$ & Economía a escala & & & & 3 & & & & 0.60 \\
\hline $25 \%$ & Diferenciación del producto & & & 2 & & & & & 0.50 \\
\hline $20 \%$ & Inversiones de capital & & & 2 & & & & & 0.40 \\
\hline $20 \%$ & Acceso a canales de distribución & & & & 3 & & & & 0.60 \\
\hline $15 \%$ & Barreras de entrada & & & & 3 & & & & 0.45 \\
\hline $105 \%$ & & Pun & & & & & & & 2.55 \\
\hline \multicolumn{10}{|c|}{ Amenaza de productos sustitutos } \\
\hline Peso & Factores & BAJA & 1 & 2 & 3 & 4 & 5 & ALTA & Valor \\
\hline $20 \%$ & $\begin{array}{l}\text { Propensión del consumidor a } \\
\text { sustituir }\end{array}$ & & & 2 & & & & & 0.40 \\
\hline $20 \%$ & Sustitutos con mejores precios & & & & 3 & & & & 0.60 \\
\hline $20 \%$ & Facilidad de cambio del comprador & & & & 3 & & & & 0.60 \\
\hline $20 \%$ & $\begin{array}{l}\text { Nivel percibido de diferenciación } \\
\text { del producto }\end{array}$ & & & 2 & & & & & 0.40 \\
\hline $20 \%$ & $\begin{array}{l}\text { Disponibilidad de sustitutos } \\
\text { cercanos }\end{array}$ & & & 2 & & & & & 0.40 \\
\hline
\end{tabular}




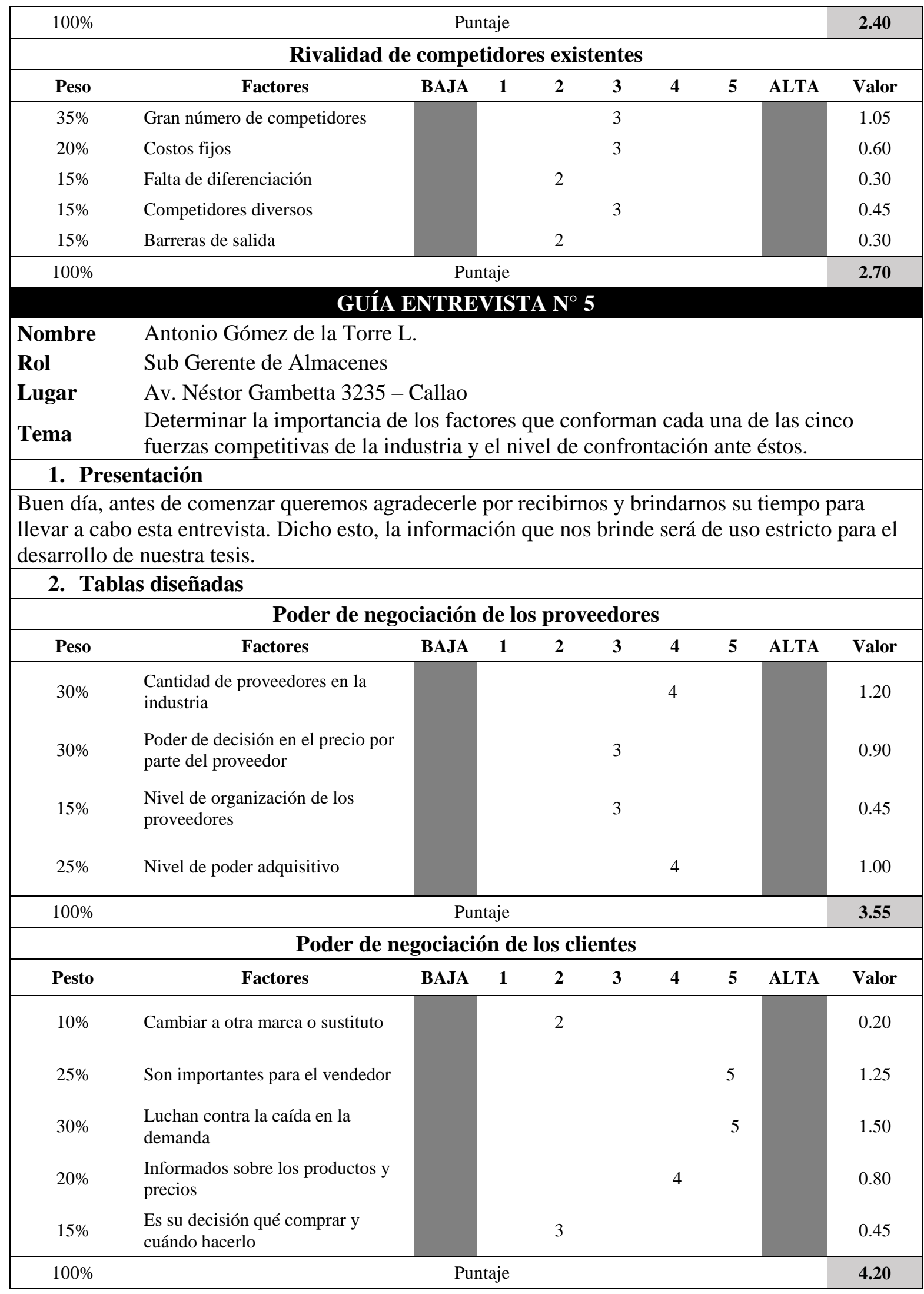




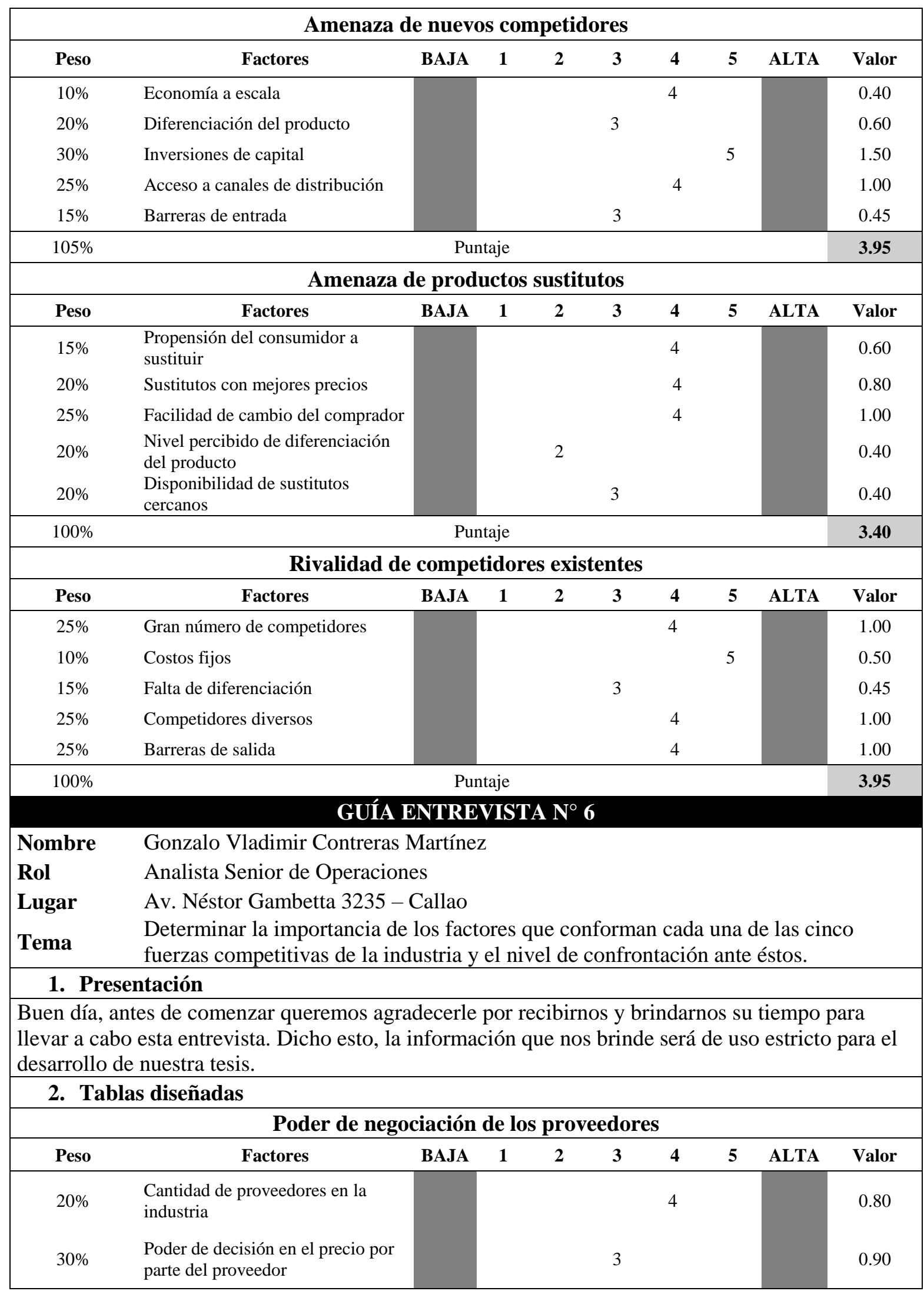




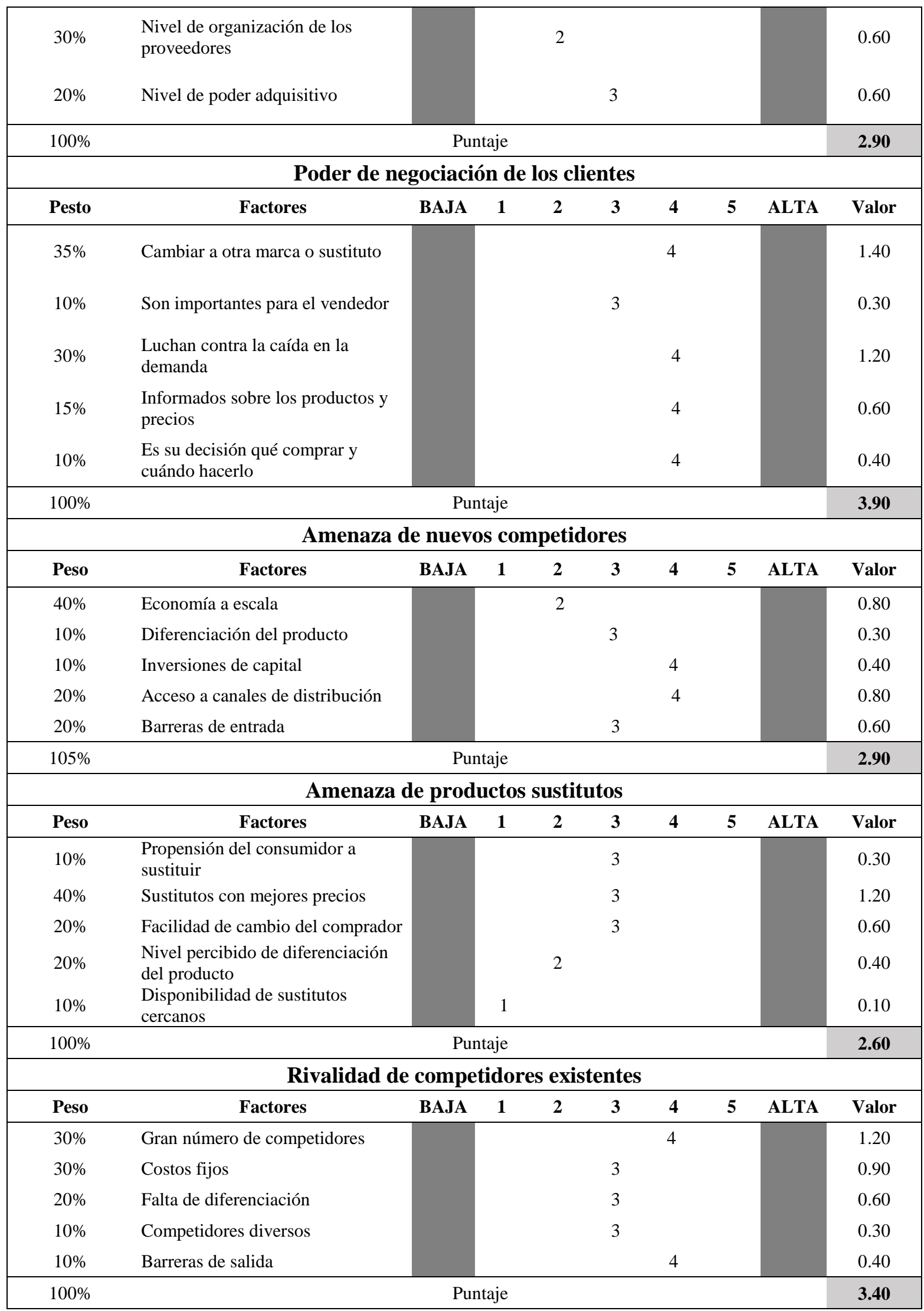




\section{Anexo 06. Encuesta de satisfacción a los clientes}

A continuación, en la siguiente página se presenta las respuestas de los clientes de Ransa acerca de los servicios subcontratados, en el cual se puede apreciar la calificación numérica de cada una de las variables evaluadas del 1 al 10 (siendo: $1=$ muy malo, $10=$ muy bueno), números acompañados por el sustento profesional del entrevistado.

Cabe señalar que no todos los clientes o entrevistados subcontratan toda la cadena de servicios de Ransa.

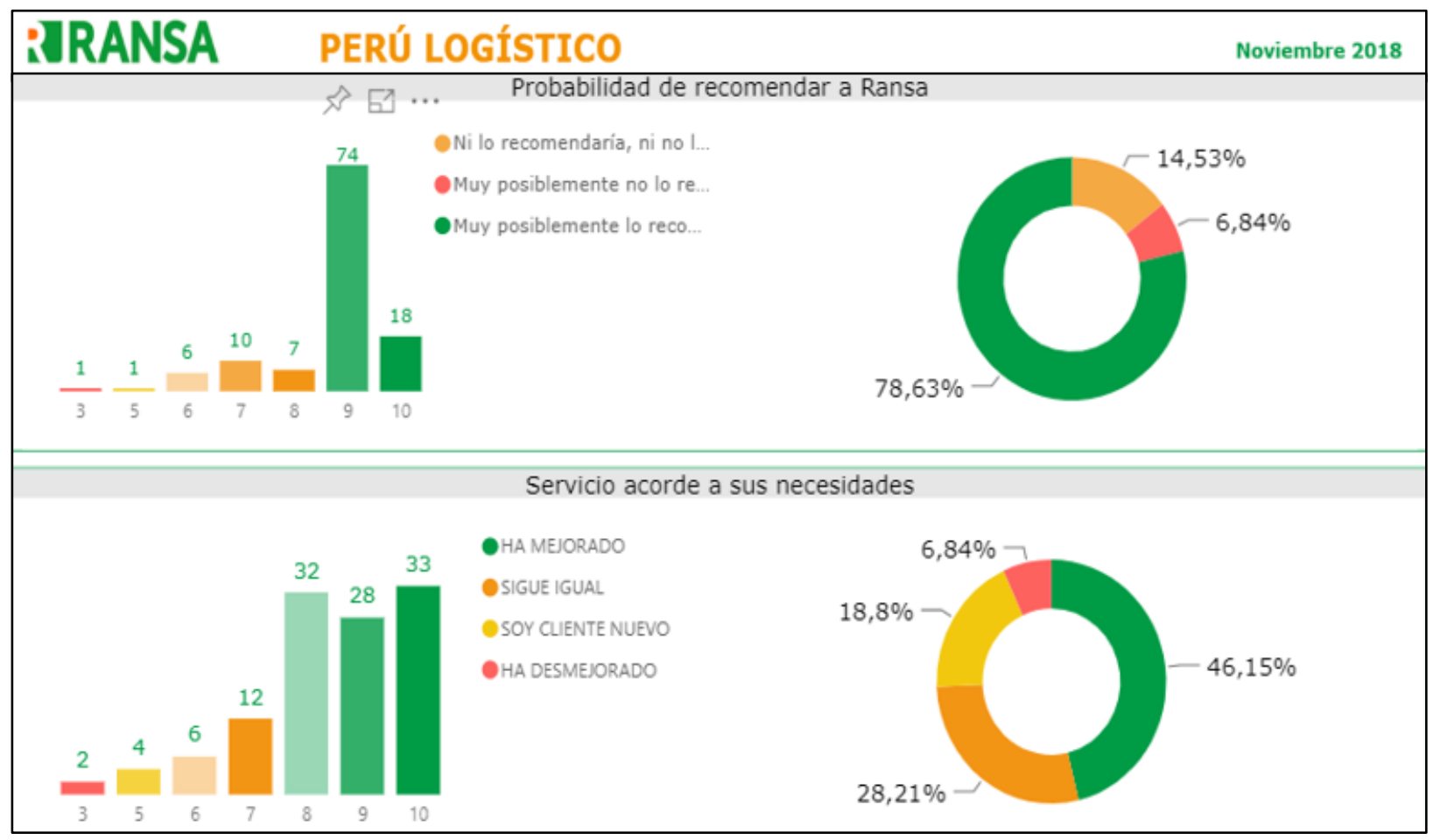




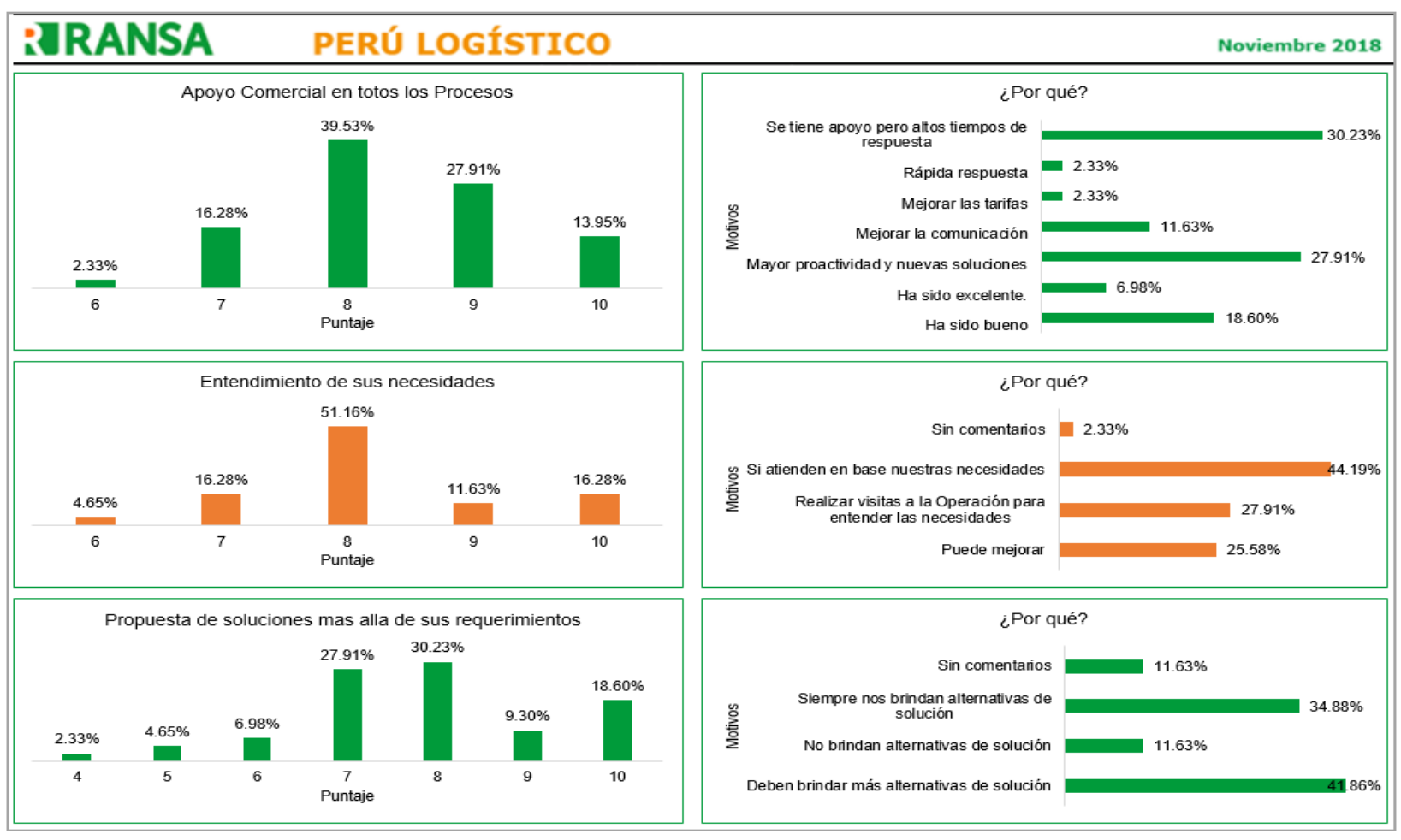

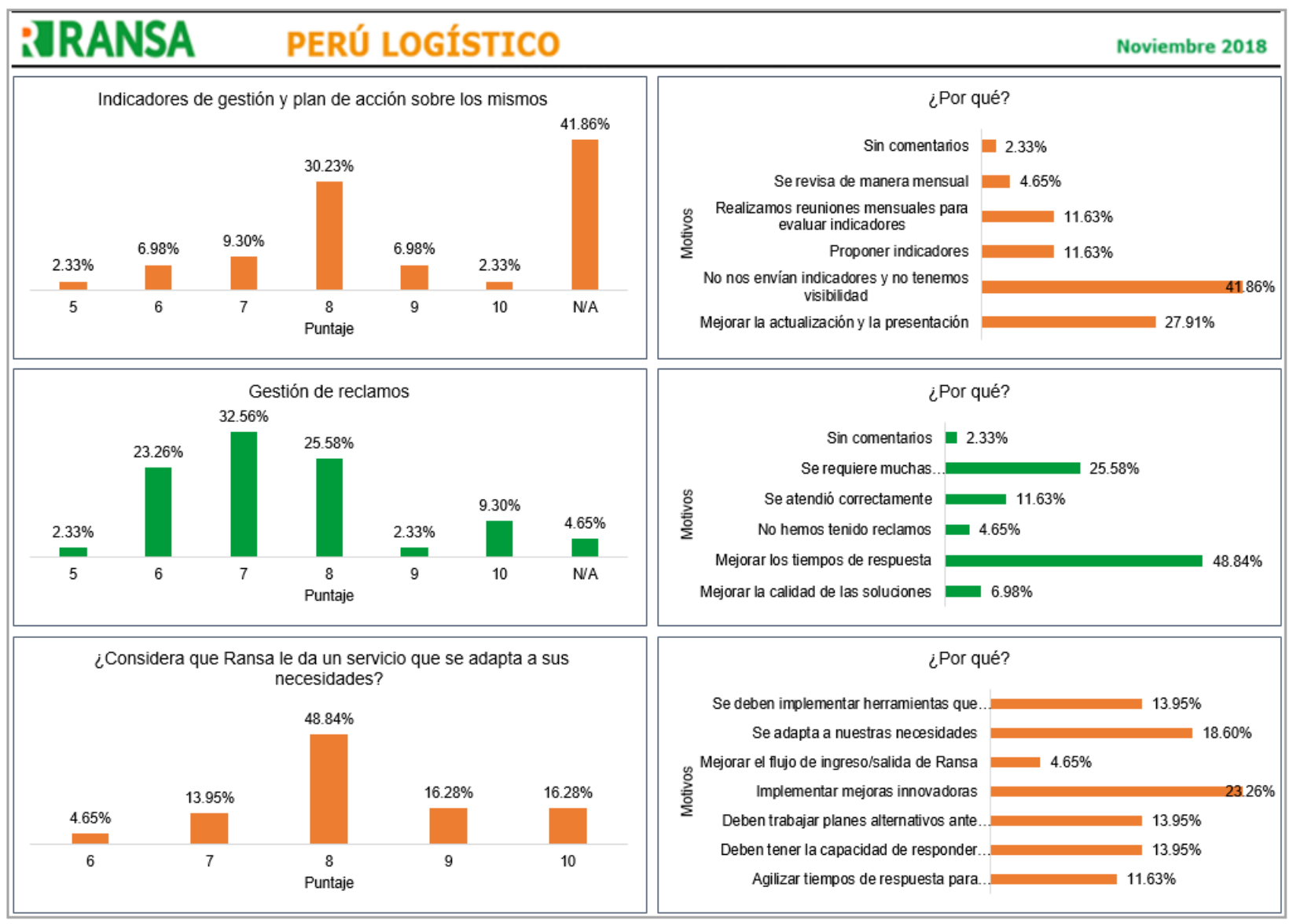




\section{Anexo 07. Entrevista a Experto de Ransa (Servicios)}

Objetivo: Recabar información acerca de los proveedores de la empresa, la evolución de precios y el impacto en las operaciones.

Entrevistado: Bruno Benavides

Cargo: Jefe de Gestión de Servicios

\section{1. ¿Con qué proveedores trabaja la empresa y que servicios se subcontratan?}

Las operaciones de almacenaje, transporte, distribución y maquila requieren de jornaleros para actividades como clasificación de mercadería, estiba y desestiba, armado de packs, forrado de mercadería, etiquetado, entre otros.

Los proveedores con los que trabajamos son Escoser, F\&B y Estrategias Corporativas.

Además, respecto a la compra de materiales, tenemos proveedores por contrato que nos abastecen de etiquetas, strech film, cajas, útiles de oficina, etc

\section{2. ¿Cuánto tiempo vienen trabajando con sus proveedores?}

Aproximadamente 3 años, pero de igual manera tenemos un backup en caso no logren abastecernos. Además, en el año gestionamos reuniones con nuevos proveedores y se gestiona la homologación para que cuando se requiera hacer una solicitud estén habilitados.

\section{Respecto a las tarifas, ¿Cuál ha sido la evolución? ¿Considera que ellos tienen poder de negociación?}

Cuando se renuevan los contratos se negocian las tarifas y generalmente se tiene un incremento del 1 o $2 \%$, por esta razón es que se escuchan las propuestas de otros proveedores y se homologan. Además, considero que el poder de negociación es medio porque dejar de trabajar con Ransa significaría perder un gran porcentaje de su venta, ya que ellos abastecen a todos nuestros servicios en todas las sedes. Sin embargo, en el mercado no se tiene una gran cantidad de proveedores con la capacidad de atención de los que tenemos actualmente. 


\section{¿Cuáles son los requisitos que los proveedores deben de cumplir para trabajar con la empresa?}

Primero, deben tener la capacidad suficiente para atender a todas nuestras operaciones. Además, es importante que dentro de su cartera de clientes se tengan empresas del sector que puedan asegurarnos que tienen experiencia en los servicios que requerimos. De igual manera, ellos deben contar con sus propios implementos (reglas, cuchillas, tocas, casco) para operar y se debe tener a un encargado en las sedes para la coordinación, validación y liquidación. 


\section{Anexo 08. Ficha Técnica - Matriz de perfil competitivo del grupo estratégico por expertos de} Ransa

Las matrices fueron evaluadas por expertos de Ransa, es decir, por altos funcionarios de la empresa con la experiencia y el conocimiento necesario de la industria logística. Por otro lado, para la evaluación también se consideró a expertos del sector, es decir, altos funcionarios de empresas del rubro logístico.

\section{Presentación}

Buen día, antes de comenzar queremos agradecerle por recibirnos y brindarnos su tiempo para llevar a cabo esta entrevista. Dicho esto, la información que nos brinde será de uso estricto para el desarrollo de nuestra tesis.

\section{Objetivos de investigación}

Conocer al detalle el nivel de importancia e impacto que tienen los factores de éxito dentro de la industria de operadores logísticos.

\section{Método de devaluación}

Primero, asignar un peso de 0.00 (menos importante) a 1.00 (más importante) a cada uno de los siguientes factores, el peso dado representa la importancia relativa para alcanzar el éxito de Ransa, sumando al final todos los pesos 1.00. Segundo, asignar una calificación de 1 (baja) a 4 (alta). Las calificaciones pertenecen a Ransa y los pesos a la industria.

\section{Guía de entrevista}

A continuación, se muestran las matrices evaluadas por expertos de la organización: 
Nombre: Julio Robles Soria

Puesto: Gerente de Distribución

Diseño de tabla: Matriz de Perfil Competitivo

\begin{tabular}{|c|c|c|c|c|c|c|c|}
\hline \multirow{2}{*}{ Factores del éxito } & \multirow[t]{2}{*}{ Peso } & \multicolumn{2}{|c|}{ RANSA } & \multicolumn{2}{|c|}{ NEPTUNIA } & \multicolumn{2}{|c|}{ DINET } \\
\hline & & Valor & Puntaje & Valor & Puntaje & Valor & Puntaje \\
\hline 1. Cobertura a nivel nacional de las oepraciones logísticas & 0.18 & 4 & 0.72 & 4 & 0.72 & 4 & 0.72 \\
\hline 2. Manejo de altos estándares de seguridad en las operaciones logísticas & 0.16 & 4 & 0.64 & 3 & 0.48 & 3 & 0.48 \\
\hline 3. Experiencia en la Industria & 0.18 & 4 & 0.72 & 4 & 0.72 & 2 & 0.36 \\
\hline 4. Infraestructura Logística & 0.18 & 4 & 0.72 & 2 & 0.36 & 2 & 0.36 \\
\hline 5. Nivel de integración de la cadena de suministro & 0.10 & 3 & 0.30 & 3 & 0.30 & 3 & 0.30 \\
\hline 6. Gestión Comercial & 0.10 & 2 & 0.20 & 3 & 0.30 & 2 & 0.20 \\
\hline 7. Orientación al cliente & 0.10 & 3 & 0.30 & 3 & 0.30 & 3 & 0.30 \\
\hline Total & 1.00 & & 3.60 & & 3.18 & & 2.72 \\
\hline
\end{tabular}

Total

GRÍA ENTREVISTA $\mathrm{N}^{\circ} 2$

Nombre: $\quad$ Magnolia Padilla

Puesto: $\quad$ Sub Gerente de Operaciones - Secos

Diseño de tabla: Matriz de Perfil Competitivo

\begin{tabular}{|c|c|c|c|c|c|c|c|}
\hline \multirow{2}{*}{ Factores del éxito } & \multirow[t]{2}{*}{ Peso } & \multicolumn{2}{|c|}{ RANSA } & \multicolumn{2}{|c|}{ NEPTUNIA } & \multicolumn{2}{|c|}{ DINET } \\
\hline & & Valor & Puntaje & Valor & Puntaje & Valor & Puntaje \\
\hline 1. Cobertura a nivel nacional de las oepraciones logísticas & 0.18 & 4 & 0.72 & 4 & 0.72 & 4 & 0.72 \\
\hline 2. Manejo de altos estándares de seguridad en las operaciones logísticas & 0.15 & 4 & 0.60 & 3 & 0.45 & 3 & 0.45 \\
\hline 3. Experiencia en la Industria & 0.15 & 4 & 0.60 & 4 & 0.60 & 4 & 0.60 \\
\hline 4. Infraestructura Logística & 0.15 & 3 & 0.45 & 3 & 0.45 & 3 & 0.45 \\
\hline 5. Nivel de integración de la cadena de suministro & 0.15 & 3 & 0.45 & 3 & 0.45 & 3 & 0.45 \\
\hline 6. Gestión Comercial & 0.12 & 2 & 0.24 & 3 & 0.36 & 2 & 0.24 \\
\hline 7. Orientación al cliente & 0.10 & 3 & 0.30 & 3 & 0.30 & 3 & 0.30 \\
\hline Total & 1.00 & & 3.36 & & 3.33 & & 3.21 \\
\hline
\end{tabular}

\begin{tabular}{|c|c|c|c|c|c|c|c|}
\hline $\begin{array}{ll}\text { Nombre: } & \text { Jose Luis Linares Lorenzo } \\
\text { Puesto: } & \text { Sub Gerente de Operaciones - Perecederos } \\
\text { Diseño de tabla: } & \text { Matriz de Perfil Competitivo }\end{array}$ & RÍA EI & VISTA & & & & & \\
\hline \multirow{2}{*}{ Factores del éxito } & \multirow[t]{2}{*}{ Peso } & \multicolumn{2}{|c|}{ RANSA } & \multicolumn{2}{|c|}{ NEPTUNIA } & \multicolumn{2}{|c|}{ DINET } \\
\hline & & Valor & Puntaje & Valor & Puntaje & Valor & Puntaje \\
\hline 1. Cobertura a nivel nacional de las oepraciones logísticas & 0.17 & 4 & 0.68 & 3 & 0.51 & 3 & 0.51 \\
\hline 2. Manejo de altos estándares de seguridad en las operaciones logísticas & 0.14 & 4 & 0.56 & 3 & 0.42 & 3 & 0.42 \\
\hline 3. Experiencia en la Industria & 0.15 & 4 & 0.60 & 3 & 0.45 & 3 & 0.45 \\
\hline 4. Infraestructura Logística & 0.17 & 4 & 0.68 & 4 & 0.68 & 3 & 0.51 \\
\hline 5. Nivel de integración de la cadena de suministro & 0.17 & 3 & 0.51 & 3 & 0.51 & 3 & 0.51 \\
\hline 6. Gestión Comercial & 0.10 & 3 & 0.30 & 3 & 0.30 & 3 & 0.30 \\
\hline 7. Orientación al cliente & 0.10 & 3 & 0.30 & 3 & 0.30 & 3 & 0.30 \\
\hline Total & 1.00 & & 3.63 & & 3.17 & & 3.00 \\
\hline \multicolumn{8}{|c|}{ GRÍA ENTREVISTA $\mathrm{N}^{\circ} 4$} \\
\hline $\begin{array}{ll}\text { Nombre: } & \text { Giacomo Vittoria } \\
\text { Puesto: } & \text { Jefe de Distribución } \\
\text { Diseño de tabla: } & \text { Matriz de Perfil Competitivo } \\
\end{array}$ & & & & & & & \\
\hline \multirow{2}{*}{ Factores del éxito } & \multirow[t]{2}{*}{ Peso } & \multicolumn{2}{|c|}{ RANSA } & \multicolumn{2}{|c|}{ NEPTUNIA } & \multicolumn{2}{|c|}{ DINET } \\
\hline & & Valor & Puntaje & Valor & Puntaje & Valor & Puntaje \\
\hline 1. Cobertura a nivel nacional de las oepraciones logísticas & 0.16 & 4 & 0.64 & 3 & 0.48 & 3 & 0.48 \\
\hline 2. Manejo de altos estándares de seguridad en las operaciones logísticas & 0.16 & 4 & 0.64 & 3 & 0.48 & 3 & 0.48 \\
\hline 3. Experiencia en la Industria & 0.16 & 4 & 0.64 & 3 & 0.48 & 3 & 0.48 \\
\hline 4. Infraestructura Logística & 0.16 & 4 & 0.64 & 2 & 0.32 & 2 & 0.32 \\
\hline 5. Nivel de integración de la cadena de suministro & 0.12 & 3 & 0.36 & 3 & 0.36 & 3 & 0.36 \\
\hline 6. Gestión Comercial & 0.12 & 2 & 0.24 & 2 & 0.24 & 2 & 0.24 \\
\hline 7. Orientación al cliente & 0.12 & 3 & 0.36 & 3 & 0.36 & 3 & 0.36 \\
\hline Total & 1.00 & & 3.52 & & 2.72 & & 2.72 \\
\hline
\end{tabular}


A continuación, se muestran las matrices evaluadas por expertos de la industria:

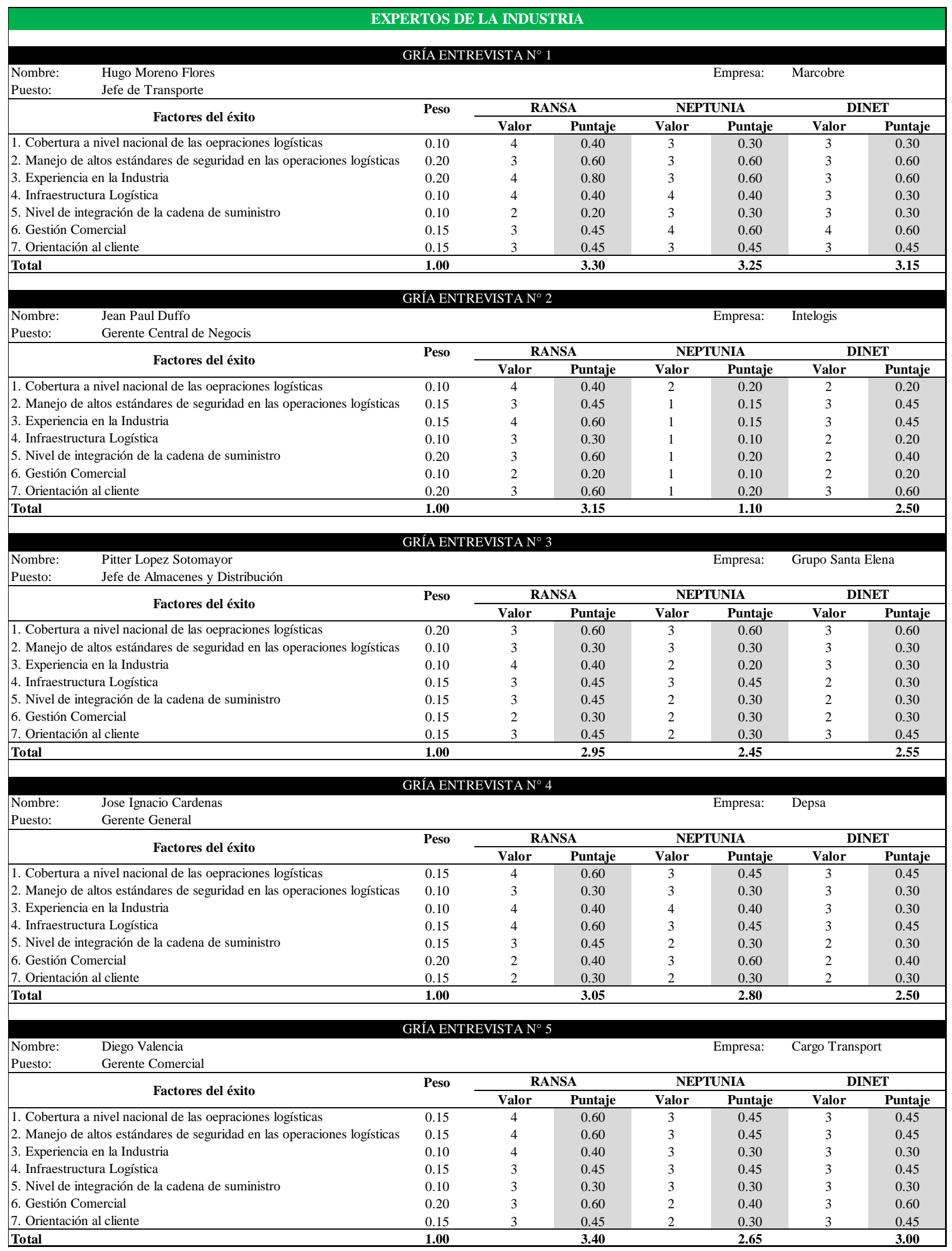


Anexo 09. Entrevistas a Expertos sobre para el diagnóstico de las áreas

\section{Entrevista 1.}

Objetivo: Recabar información acerca de las actividades que realizan las áreas primarias y de apoyo de la organización, la interacción y las principales deficiencias de las mismas.

Entrevistado: Magnolia Padilla

Cargo: Sub Gerente de Operaciones

\section{¿Cuáles son las áreas primarias que tiene la empresa?}

El core del negocio corresponde a los servicios de almacenamiento, transporte y distribución, y los mismos pertenecen al área de Operaciones. Además, para obtener clientes dentro de los servicios necesitas que el área comercial realice su gestión, así que esas dos áreas las considero como principales.

\section{¿Cuáles son las áreas de apoyo que tiene la empresa?}

Dentro de las áreas de soporte tenemos la de servicios para la gestión de compras, mantenimiento e infraestructura, luego tenemos recursos humanos, sistemas, calidad, seguridad, consultoría y finanzas.

\section{¿Con cuál de las áreas mencionadas tiene mayor interacción?}

Sin duda sistemas, ellos nos brindan soporte respecto a los WMS que manejamos, así como la señal y el funcionamiento de los equipos RF, la caída de estos significarían un gran problema para la operación, retrasos, quejas del cliente, etc

Luego tenemos a Seguridad y Calidad, para cumplir con los estándares que se requieren como centro de distribución y para las auditorías de los clientes. Asimismo, el área de servicios nos brinda soporte en la gestión de compras de materiales, mantenimientos preventivos y correctivos, y por último recursos humanos, para el reclutamiento de nuevos candidatos y celebraciones de cumpleaños e integraciones. 


\section{¿Cuáles considera que son las principales deficiencias del área a la que Usted pertenece?}

Yo tengo a cargo la sub gerencia de almacenes y considero que el hecho de tener operaciones manuales recae en tener una alta estructura de costos, ya sea variables y fijos, porque tenemos cuentas con un gran número de operarios, tenemos horas extras, tenemos un gasto importante de materiales como strech film y etiquetas, contratamos jornaleros, entre otros. Si contaríamos con un WMS esta no sería la figura. Además, al realizar la comparación de la cantidad de personal cotizado con lo real vamos a evidenciar una deficiencia en la asignación de recursos.

\section{¿Cuáles considera que son las principales deficiencias de las áreas de apoyo?}

Respecto a Comercial, es importante que realicen una correcta negociación con los clientes sin afectar a la Operación, tenemos clientes como Delosi donde se tiene un servicio de re paletizado que no se cobra y en Arcor, el cliente te paga las posiciones promedio y no el pico. Al mismo tiempo, en Maquila se cotizan servicios el mismo día que lo solicitan.

Además, en el caso de almacén, hablamos de tarifas establecidas hace años y las condiciones del cliente en cuanto a volumen y demás claramente han cambiado.

Yo puedo hacer todo lo posible por ajustar mis costos pero si mis tarifas no cubren mis costos operativos no voy poder ser lo más rentable posible.

Con el área de TI tengo dificultades con el tiempo de respuesta, tengo varios pendientes con ellos y no nos atienden hasta ahora. Por ejemplo, si tengo una caída de señal yo no puedo operar y el cliente nos va a llamar a quejarse, aquí la atención debe ser inmediata pero no es así. Además, considero que el soporte que brindan cuando se trata de implementaciones de sistemas no es el correcto, porque delegan a la operación el levantamiento de procesos y demás cuando realmente no tenemos tiempo para eso.

Por otro lado, con recursos humanos tengo complicaciones con los tiempos de reclutamiento que son casi de dos meses, es importante que la reposición sea en menos y que no afecte mi operación. 


\section{Entrevista 2.}

Objetivo: Recabar información acerca de las actividades que realizan las áreas primarias y de apoyo de la organización, la interacción y las principales deficiencias de las mismas.

Entrevistado: Sheryl Samaniego

Cargo: Jefe de Operaciones

\section{¿Cuáles son las áreas primarias que tiene la empresa?}

El área de Operaciones, somos nosotros lo que ofrecemos los servicios a los clientes y te generan la venta.

\section{¿Cuáles son las áreas de apoyo que tiene la empresa?}

Las áreas de apoyo que tenemos son: TI, Servicios, Calidad, Seguridad y Recursos Humanos.

\section{¿Con cuál de las áreas mencionadas tiene mayor interacción?}

Con el área de servicios tenemos una comunicación diaria por la contratación de jornaleros para maquila y en almacén tenemos algunas cuentas que requieren de personal para estiba y desestiba de contenedores. También, con el área de Calidad para cuentas como Sodexo donde tenemos muestreos y mensualmente tenemos reuniones para revisar los resultados de buenas prácticas de almacén y maquila, de igual manera, con el área de Seguridad para revisar el índice de accidentabilidad.

Además, tenemos reuniones mensuales con TI para revisar nuestros requerimientos y en el día a día si tenemos inconvenientes respecto a la señal o los sistemas que manejamos, realizamos la coordinación pero no siempre la respuesta es inmediata.

\section{¿Cuáles considera que son las principales deficiencias del área a la que Usted pertenece?}

Tenemos muchos procesos manuales, ya sea reportes administrativos o lo relacionado a la operación como recepción y despacho a causa de no contar con un WMS.

Yo tengo controles y filtros que se pueden eliminar pero al ser todo manual deben mantenerse, igual el número de personas. Si bien se pueden implementar mejoras y demás, la Operación no 
tiene tiempo para esto, yo considero que es necesario que se asigne a un equipo para mapear los procesos y encontrar oportunidades de mejora.

\section{¿Cuáles considera que son las principales deficiencias de las áreas de apoyo?}

Principalmente la gestión comercial, yo he comparado los acuerdos de nivel de servicio con lo real y tenemos incumplimiento respecto a los horarios de atención pactados como las capacidades de recepción y despacho. Cabe mencionar que nadie te valida cual es la última versión del contrato y nosotros no tenemos alcance a una carpeta o drive donde se tenga esa documentación. De igual manera, se tienen concesiones comerciales que afectan la rentabilidad de la operación.

Otro punto importante es que no contamos con información fehaciente porque cuando comparamos nuestros gastos con lo que se carga en los estados de resultados, tenemos diferencias y tenemos que estar validando y solicitando la modificación, sin tener la información clara uno no puede tomar decisiones.

Asimismo, con el área de TI necesitamos potenciar nuestra comunicación y los tiempos de atención, los requerimientos no tienen una fecha fin y si la tienen simplemente no se cumplen.

Por otro lado, con recursos humanos tenemos dificultades respecto a los tiempos de reclutamiento, si a mí se me va un colaborador no puedo esperar dos o tres meses para la reposición porque eso afecta el flujo de mi operación. Con Calidad, es importante que nos brinden el soporte debido cuando se tienen nuevos clientes y se necesite habilitar un almacén, ya sea para las certificaciones, como la actualización de layouts.

Finalmente, con el área de servicios tengo inconvenientes de manera recurrente, no sé cuál es el criterio para elegir a sus proveedores pero no pueden dejar de abastecernos y si esto pasa, deberían de tener un plan de contingencia. 


\section{Entrevista 3.}

Objetivo: Recabar información acerca de las actividades que realizan las áreas primarias y de apoyo de la organización, la interacción y las principales deficiencias de las mismas.

Entrevistado: Julio Robles

Cargo: Gerente de Distribución

¿Cuáles son las áreas primarias que tiene la empresa?

El área de operaciones y comercial.

\section{¿Cuáles son las áreas de apoyo que tiene la empresa?}

Dentro de las áreas de soporte tenemos a recursos humanos, servicios, sistemas y seguridad.

\section{¿Con cuál de las áreas mencionadas tiene mayor interacción?}

En el caso de distribución, diariamente coordinamos con servicios para la asignación de cuadrillas

y con sistemas para el tracking. De igual manera, con Recursos Humanos coordinamos la celebración de cumpleaños, eventos, beneficios al personal, etc.

\section{¿Cuáles considera que son las principales deficiencias del área a la que Usted pertenece?}

La asignación de unidades porque tenemos dificultades en las entregas con la flota tercera y la consolidación por tiendas, de tal manera que se aproveche todo el espacio del camión.

\section{¿Cuáles considera que son las principales deficiencias de las áreas de apoyo?}

En general, los tiempos de respuesta porque no se tiene una integración con las áreas de apoyo. La comunicación debe mejorar y la atención de nuestras solicitudes debe ser en el menor tiempo posible porque como consecuencia nuestros clientes se quejan.

Por otro lado, se tienen un área de innovación y consultoría pero realmente yo aún no veo que revisen y mejorar nuestros procesos, no tengo claro que funciones o proyectos tienen asignados porque en Operaciones hay mucho por hacer.

Finalmente, el envío de los Estados de Resultados se hace muchas veces uno o dos días antes del Comité mensual y no tenemos el tiempo debido para el análisis y para preparar nuestros sustentos. 


\section{Anexo 10. Relaciones contractuales débiles}

La siguiente tabla muestra las consideraciones de atención y capacidades determinadas en los contratos, las cuales no se cumplen

\begin{tabular}{|c|c|c|c|}
\hline Cliente & Proceso & Consideraciones de atención y capacidades & Cumplimiento \\
\hline \multirow{6}{*}{ ALICORP } & Recepción & $\begin{array}{l}\text { Horario - Capacidad: } \\
24 \text { HORAS } 3 \text { TURNO } \\
22 \text { UT POR TURNO } \\
3 \text { UT EN SIMULTANEO } \\
\text { Importación } \\
\text { Devoluciones } \\
\text { Manipuleo extra con mayor detalle }\end{array}$ & $\mathrm{NO}$ \\
\hline & Almacenamiento & $\begin{array}{l}\text { Delta II: } 24,400 \\
\text { Delta I : Droguería: } 168 \text { - Consumo: } 2,440 \\
\text { Alfa: 6,308 } \\
\text { Zona de No Conformes: } \\
\text { Droguería } 318 \text { mts2 } 143 \text { consumo } \\
476 \text { droguería y } 133 \text { consumo } \\
\text { * La ocupabilidad se afecta por mercadería a despacho. Es decir, si hay paletas } \\
\text { a despachar y sobrepasa el tiempo de recojo se almacena en los rack para } \\
\text { liberación de canales. } \\
\text { * Mercadería que pasa a otro proceso como Maquila/ por demora de aviso de } \\
\text { entrega en importación también pasa a rack. } \\
\text { ERI: } \\
\text { Mínimo de } 99 \% \text { - Tolerancia: } 0.0037 \% \text { (Valorizado In/Out) } \\
\text { Mermas: } \\
\text { Tolerancia: } 0.012 \% \text { (Valorizado In/Out) } \\
\text { BPAs: } \\
\text { Mínimo de } 85 \% \\
\text { Exactitud de canal de despacho: } \\
\text { Mínimo de } 85 \% \text { por SKU o por cantidad }\end{array}$ & $\begin{array}{l}\text { SI } \\
\text { SI } \\
\text { NO }\end{array}$ \\
\hline & $\begin{array}{l}\text { Lanzamiento de } \\
\text { pedidos }\end{array}$ & $\begin{array}{l}\text { Corte: Todos los días 11:00 pm } \\
\text { Excepciones: acuerdo con el jefe de turno }\end{array}$ & No \\
\hline & Despacho & $\begin{array}{l}\text { Horario - Capacidad: } \\
\text { Las UT que se presenten } \\
\text { Especiales: DEX - MACRO } \\
\text { Se maneja como prioridades } \\
\text { Cuadrillas }\end{array}$ & SI \\
\hline & Devoluciones & Dentro de Recepción cobro por unidades & SI \\
\hline & Otros Servicios & $\begin{array}{l}\text { CLIENTE ESPECIAL: PROMART } \\
\text { Repaleizado y retiquetado } \\
\text { Paletas especiales } \\
\text { HHEE }\end{array}$ & SI \\
\hline DELOSI & Recepción & $\begin{array}{l}\text { Horario } \quad \text { - } \quad \text { Capacidad: } \\
\text { 08:00 - 17:00 - 9,000 bultos/día } \\
\text { Recepción Proveedores Locales }\end{array}$ & $\begin{array}{l}\text { NO } \\
\text { NO }\end{array}$ \\
\hline
\end{tabular}




\begin{tabular}{|c|c|c|c|}
\hline & & MIE - LUN: 08:00 a 15:00 horas & \\
\hline & & $\begin{array}{l}\text { SAB: 08:00 a 11:00 horas } \\
\text { Recepción Importados } \\
\text { MAR - JUE (2 cont.): 08:00 a 14:00 } \\
\text { LUN - VIE (Carga Suelta <10 ton): 08:00 a 15:00 } \\
\text { Cobro de cuadrilla } \\
\text { Tiempo de espera de cuadrilla } \\
\end{array}$ & $\begin{array}{l}\text { SI } \\
\text { SI }\end{array}$ \\
\hline & Almacenamiento & $\begin{array}{l}\text { Take or pay: } \\
2,550 \text { posiciones (incluye zona de merma) } \\
\text { *En la ocupabilidad no entra las paletas en pre-despacho (para despacho) en } \\
\text { los canales. } \\
\text { Transferencia }\end{array}$ & SI \\
\hline & $\begin{array}{l}\text { Lanzamiento de } \\
\text { pedidos }\end{array}$ & $\begin{array}{l}\text { Corte: Domingo y Lunes (Migración de pedidos al AS400) } \\
\text { Excepciones: Si la fecha de corte es expedición }\end{array}$ & No \\
\hline & Despacho & $\begin{array}{l}\text { Horario - Capacidad: } \\
\text { Lunes a Viernes: } 9000 \text { bultos/día - } 2 \text { camiones por hora } \\
\text { Sábado: } 4500 \text { bultos/día } \\
\text { Despacho Provincias (según esquema) } \\
\text { LUN - VIE: 08:00 - 13:00 } \\
\text { SAB: 08:00 a 11:00 horas } \\
\text { Despacho Regular Local (10 rutas) } \\
\text { Turno Amanecida (4 rutas) 04:00 - 6:00 } \\
\text { Turno Tarde (6 rutas) 16:00 - 20:00 } \\
\text { Sábado (4 rutas) } \quad \text { 13:00 - 16:00 } \\
\text { *Atención de paletas que no alcanzaron en la capacidad del camión se atiende } \\
\text { al día siguiente }\end{array}$ & NO \\
\hline & Devoluciones & $\begin{array}{l}\text { Recepción Devoluciones (Proveedores Locales) } \\
\text { *Miércoles a Lunes: 08:00 a 15:00 horas } \\
\text { *Sábado: 08:00 a 11:00 horas }\end{array}$ & $\mathrm{NO}$ \\
\hline & Otros Servicios & $\begin{array}{l}\text { Etiquetado por Producción: bulto peso menor a } 4 \mathrm{KG} \\
\text { Etiquetado por Jornal: bulto peso mayor a } 4 \mathrm{KG} \\
\text { Re empaque o Acondicionado } \\
\text { Recupero de Mercadería }\end{array}$ & \\
\hline & Recepción & $\begin{array}{l}\text { IMPORTACION } \\
3 \text { a } 4 \text { Contenedores por embarque (SEMANAL) } \\
\text { LOCAL (cajas vacías y folletería) } \\
1 \text { UT diario } \\
\text { *Tarifa incluye: cuadrilla y análisis órgano eléctrico }\end{array}$ & NO \\
\hline ORIFLAME & Almacenamiento & $\begin{array}{l}\text { BPA: } 1,032 \text { posiciones } \\
\text { CLIMATIZADO: } 2,016 \text { posiciones } \\
\text { PICK AND PACK: } 6,080 \mathrm{M} 2 \\
\text { ZONA NO BPA: } 200 \text { en promedio (Reserva) } \\
\end{array}$ & SI \\
\hline & $\begin{array}{l}\text { Lanzamiento de } \\
\text { pedidos }\end{array}$ & $\begin{array}{l}\text { CORTE: } \\
\text { 08:00 a 13:00 pm -- Despacho hasta las 11:00 del otro día } \\
\text { PARA CIERRE: } \\
\text { 3era semana: Jue - Vie: 08:00 - 15:00 } \\
\end{array}$ & SI \\
\hline & Despacho & $\begin{array}{l}\text { Se despacha al mismo horario de Lanzamiento de Pedidos a Maquila (zona } \\
\text { contigua) }\end{array}$ & SI \\
\hline & Devoluciones & $\begin{array}{l}\text { FECHA: 2er Viernes de mes - De catálogos } \\
\text { Dentro de Recepción cobro por unidades }\end{array}$ & NO \\
\hline
\end{tabular}




\section{Anexo 11. Deficiente asignación de recursos humanos}

La siguiente tabla muestra la mala designación de recursos humanos dentro de los procesos internos.

\begin{tabular}{|c|c|c|c|c|c|c|c|c|c|}
\hline \multicolumn{2}{|c|}{ Headcount } & $\begin{array}{c}\text { Almacenero } \\
1\end{array}$ & $\begin{array}{c}\text { Almacenero } \\
2\end{array}$ & $\begin{array}{l}\text { Operador } \\
\text { de Equipos }\end{array}$ & $\begin{array}{c}\text { Supervisor } \\
\text { de } \\
\text { Operaciones }\end{array}$ & $\begin{array}{c}\text { Asistente } \\
\text { Administrativo }\end{array}$ & $\begin{array}{l}\text { Supervisor } \\
\text { de Cuenta }\end{array}$ & $\begin{array}{c}\text { Practicante } \\
\text { Slotting }\end{array}$ & $\begin{array}{c}\text { Total } \\
\text { general }\end{array}$ \\
\hline \multirow{2}{*}{ IDE } & Asignado & 0 & 0 & 0 & 0 & 0 & 0 & 0 & $\mathbf{0}$ \\
\hline & Cotizado & 3 & 4 & 2 & 1 & 0 & 0 & 0 & 10 \\
\hline \multirow{2}{*}{ Hugues } & Asignado & 0 & 0 & 0 & 0 & 0 & 0 & 0 & $\mathbf{0}$ \\
\hline & Cotizado & 1 & 1 & 0 & 0 & 0 & 0 & 0 & 2 \\
\hline \multirow{2}{*}{ Listo } & Asignado & 4 & 12 & 0 & 1 & 0 & 0 & 0 & 17 \\
\hline & Cotizado & 3 & 13 & 0 & 1 & 0 & 0 & 0 & 17 \\
\hline \multirow{2}{*}{ Oriflame } & Asignado & 2 & 4 & 1 & 1 & 0 & 0 & 0 & 8 \\
\hline & Cotizado & 2 & 3 & 1 & 1 & 0 & 0 & 0 & 7 \\
\hline \multirow{2}{*}{ Perufarma } & Asignado & 2 & 8 & 1 & 2 & 0 & 1 & 1 & 15 \\
\hline & Cotizado & 1 & 6 & 2 & 1 & 0 & 1 & 0 & 11 \\
\hline \multirow{2}{*}{ DH } & Asignado & 1 & 2 & 0 & 0 & 0 & 0 & 0 & 3 \\
\hline & Cotizado & 1 & 2 & 0 & 0 & 0 & 0 & 0 & 3 \\
\hline \multirow{2}{*}{ Sodexo } & Asignado & 8 & 14 & 2 & 1 & 0 & 0 & 0 & 25 \\
\hline & Cotizado & 9 & 12 & 2 & 1 & 1 & 0 & 0 & 25 \\
\hline \multirow{2}{*}{ Payless } & Asignado & 3 & 4 & 1 & 0 & 0 & 1 & 0 & 9 \\
\hline & Cotizado & 3 & 3 & 1 & 0 & 0 & 1 & 0 & 8 \\
\hline \multirow{2}{*}{ Tesa/Mumuso } & Asignado & 2 & 0 & 0 & 0 & 0 & 1 & 0 & 3 \\
\hline & Cotizado & 1 & 4 & 0 & 0 & 0 & 1 & 0 & 6 \\
\hline \multirow{2}{*}{ Slotting } & Asignado & 0 & 0 & 0 & 1 & 0 & 0 & 0 & 1 \\
\hline & Cotizado & 0 & 1 & 0 & 1 & 0 & 0 & 1 & 3 \\
\hline \multirow{2}{*}{ Comun } & Asignado & 0 & 0 & 0 & 0 & 0 & 0 & $\overline{0}$ & $\mathbf{0}$ \\
\hline & Cotizado & 4 & 2 & 0 & 0 & 1 & 0 & 0 & 7 \\
\hline
\end{tabular}




\section{Anexo 12. Información no fehaciente para la toma de decisiones}

La siguiente tabla muestra un caso real de información comparativa de costos mensual dentro de las operaciones de Ransa para brindar sus servicios al mercado en el año 2018, en el cual se aprecia montos diferentes entre la información cargada y la real, dificultando la toma de decisiones al momento de evaluar las estrategias existentes y proponer nuevas.

\begin{tabular}{|c|c|c|c|c|c|c|c|}
\hline Partida & Servicio & \multicolumn{2}{|c|}{ Monto carga } & \multicolumn{2}{|c|}{ Monto real } & \multicolumn{2}{|c|}{ Carga VS Real } \\
\hline Alquiler de Maquinaria y Equipos & Proceso de Valor Agregado & $\mathrm{S} /$. & $1,493.55$ & $\mathrm{~S} /$. & $1,493.55$ & $\mathrm{~S} /$. & - \\
\hline Alquiler de Maquinaria y Equipos & Almacén Delta 1 & $\mathrm{~S} /$. & $27,321.31$ & $\mathrm{~S} /$. & $23,086.42$ & $\mathrm{~S} /$. & $4,234.89$ \\
\hline Alquiler de Maquinaria y Equipos & Almacén Bravo & $\mathrm{S} /$. & $9,690.55$ & $\mathrm{~S} /$. & $7,289.51$ & $\mathrm{~S} /$. & $2,401.04$ \\
\hline Alquiler de Maquinaria y Equipos & Almacén Charlie & $\mathrm{S} /$. & $24,699.88$ & $\mathrm{~S} /$. & $22,350.47$ & $\mathrm{~S} /$. & $2,349.41$ \\
\hline Alquiler de Maquinaria y Equipos & Almacén Alfa & $\mathrm{S} /$. & $64,993.77$ & $\mathrm{~S} /$. & $59,016.77$ & $\mathrm{~S} /$. & $5,977.00$ \\
\hline \multicolumn{6}{|c|}{ Total Alquiler de Maquinaria y Equipos } & S/. & $14,962.34$ \\
\hline Gasto de Materiales & Proceso de Valor Agregado & $\mathrm{S} /$. & $4,504.77$ & $\mathrm{~S} /$. & $4,481.00$ & $\mathrm{~S} /$. & 23.77 \\
\hline Gasto de Materiales & Almacén Delta 1 & $\mathrm{~S} /$. & $21,217.00$ & $\mathrm{~S} /$. & $20,967.00$ & $\mathrm{~S} /$. & 250.00 \\
\hline Gasto de Materiales & Marquez 2 & $\mathrm{~S} /$. & 73.40 & $\mathrm{~S} /$. & 28.53 & $\mathrm{~S} /$. & 44.87 \\
\hline Gasto de Materiales & Almacén Bravo & $\mathrm{S} /$. & $1,592.63$ & $\mathrm{~S} /$. & $1,592.63$ & $\mathrm{~S} /$. & - \\
\hline Gasto de Materiales & Almacén Charlie & $\mathrm{S} /$. & 552.51 & $\mathrm{~S} /$. & 552.51 & $\mathrm{~S} /$. & - \\
\hline Gasto de Materiales & Almacén Foxtrot & $\mathrm{S} /$. & 294.55 & $\mathrm{~S} /$. & 273.55 & $\mathrm{~S} /$. & 21.00 \\
\hline Gasto de Materiales & Almacén Alfa & $\mathrm{S} /$. & $18,389.99$ & $\mathrm{~S} /$. & $17,831.00$ & $\mathrm{~S} / \mathrm{.}$ & 558.99 \\
\hline \multicolumn{6}{|c|}{ Total Gasto de Materiales } & S/. & 898.63 \\
\hline \multicolumn{6}{|c|}{ Total General } & $\mathrm{S} /$. & $15,860.97$ \\
\hline
\end{tabular}




\section{Anexo 13. Falta de integración de áreas de apoyo}

En las siguientes 3 tablas se muestran casos reales de la falta de colaboración por parte de las áreas de apoyo con la implementación de nuevos clientes.

Caso 1: Estatus de solicitudes de la implementación del cliente Herbalife

\begin{tabular}{|c|c|c|c|c|c|}
\hline $\mathbf{N}^{\circ}$ & Actividades & Área & Fecha de solicitud & Fecha de atención & Días de espera \\
\hline 1 & Evaluación de la cobertura Acces Point & Sistemas & 24-Ene & 24-Ene & 0 \\
\hline 2 & Envío de presupuesto reubicación de antenas y puntos de red & Sistemas & 24-Ene & 11-Mar & 46 \\
\hline 3 & Confirmación Softeon Flex en el Bravo & Sistemas & 24-Ene & 24-Ene & 0 \\
\hline 4 & Prueba de señal de equipos RF & Sistemas & 24-Ene & $5-\mathrm{Feb}$ & 12 \\
\hline 5 & Envío de presupuesto de instalación de Tomacorrientes & Mantenimiento & 31-Ene & 11-Mar & 39 \\
\hline 6 & Confirmación de balanza de 1 TON & Mantenimiento & 31-Ene & 11-Mar & 39 \\
\hline 7 & Confirmar si procede mantenimiento de puertas & Mantenimiento & 19-Feb & 11-Mar & 20 \\
\hline 8 & Definición de Zona Homedelivery y Administrativa & Operación & 31-Ene & 31-Ene & 0 \\
\hline 9 & Envío de presupuesto de configuración de racks de 6 a 7 niveles & Infraestructura & 28-Ene & 11-Mar & 42 \\
\hline 10 & Definir nuevo alcance de Homedelivery & Infraestructura & $25-\mathrm{Feb}$ & $25-\mathrm{Feb}$ & 0 \\
\hline 11 & Envío de presupuesto de Homedelivery & Infraestructura & $25-\mathrm{Feb}$ & 8-Mar & 11 \\
\hline 12 & Confirmación Temperatura Almacén Simple con picos $>32^{\circ}$ & Cliente & 21-Feb & $25-\mathrm{Feb}$ & 4 \\
\hline 13 & $\begin{array}{l}\text { Visita al almacén Charlie y envío de presupuesto con ajuste de } \\
\text { Climatizado }\end{array}$ & Mantenimiento & 28-Ene & 11-Mar & 42 \\
\hline
\end{tabular}


Caso 2: Estatus de solicitudes de la implementación del cliente Banco Pichincha

\begin{tabular}{|c|c|c|c|c|c|}
\hline $\mathbf{N}^{\circ}$ & Actividades & Área & Fecha de solicitud & Fecha de atención & Días de espera \\
\hline 1 & Limpieza y baldeado de espacio liberado & Operaciones & 27-Feb & 27-Feb & 0 \\
\hline 2 & Envío de presupuesto de desarmado de zona estantería & Mantenimiento & 7-Feb & $25-\mathrm{Feb}$ & 18 \\
\hline 3 & Aprobación de presupuesto & Operaciones & $25-\mathrm{Feb}$ & 1-Mar & 4 \\
\hline 4 & Envío de presupuesto de instalación de puntos de red & Sistemas & 7-Feb & 1-Mar & 22 \\
\hline 5 & Aprobación de presupuesto & Operaciones & 4-Mar & 8-Mar & 4 \\
\hline 6 & Envío de presupuesto de instalación de tomacorrientes & Mantenimiento & 11-Feb & 21-Feb & 10 \\
\hline 7 & Aprobación de presupuesto & Operaciones & $25-\mathrm{Feb}$ & 1-Mar & 4 \\
\hline 8 & Instalación de mueble y equipo de cómputo & Operaciones & 11-Mar & 11-Mar & 0 \\
\hline 9 & Configuración de Softeon Lite & Sistemas & 7-Feb & 11-Mar & 32 \\
\hline
\end{tabular}

Caso 3: Estatus de solicitudes del proyecto de incremento de capacidad de almacenes

\begin{tabular}{|c|c|c|c|c|c|}
\hline $\mathbf{N}^{\circ}$ & Actividades & Área & $\begin{array}{l}\text { Fecha de } \\
\text { solicitud }\end{array}$ & $\begin{array}{l}\text { Fecha de } \\
\text { atención }\end{array}$ & Días de espera \\
\hline 1 & Envío de presupuesto de racks selectivos & Compras & 8 -Feb & 28-Feb & 20 \\
\hline 2 & Revisión con SSOMA y Provedor de racks selectivos & SSOMA & $28-\mathrm{Feb}$ & 4-Mar & 4 \\
\hline 3 & $\begin{array}{c}\text { Aprobación de inversión de racks selectivos - Almacén } \\
\text { Delta } 1\end{array}$ & Operaciones & 4-Mar & 11-Mar & 7 \\
\hline 4 & $\begin{array}{l}\text { Envío de presupuesto de racks acumulativos - Almacén } \\
\text { Delta } 1\end{array}$ & Compras & $8-\mathrm{Feb}$ & 4-Mar & 24 \\
\hline 5 & $\begin{array}{c}\text { Revisión con SSOMA y Provedor de racks } \\
\text { acumulativos }\end{array}$ & SSOMA & 4-Mar & 5-Mar & 1 \\
\hline 6 & $\begin{array}{l}\text { Aprobación de inversión de racks acumulativos - } \\
\text { Almacén Delta } 1\end{array}$ & Operaciones & 6-Mar & 11-Mar & 5 \\
\hline 7 & $\begin{array}{c}\text { Traslado de contenedor para Zona administrativa } \\
\text { Delosi }\end{array}$ & Mantenimiento & 28-Feb & 11-Mar & 11 \\
\hline 8 & $\begin{array}{l}\text { Habilitación de contenedor para Zona administrativa } \\
\text { Delosi }\end{array}$ & Mantenimiento & 28-Feb & 11-Mar & 11 \\
\hline 9 & $\begin{array}{l}\text { Envío de presupuesto de racks selectivos - Almacén } \\
\text { Charlie }\end{array}$ & Compras & $11-\mathrm{Feb}$ & 4-Mar & 21 \\
\hline 10 & Revisión con SSOMA y Provedor de racks selectivos & SSOMA & 5-Mar & 8-Mar & 3 \\
\hline 11 & $\begin{array}{c}\text { Aprobación de inversión de racks selectivos - Almacén } \\
\text { Charlie }\end{array}$ & Operaciones & 8-Mar & 11-Mar & 3 \\
\hline
\end{tabular}




\section{Anexo 14. Alta estructura de costos operativos}

En la siguiente tabla se muestra un comparativo de costos y gastos proyectados y reales en el año 2018.

\begin{tabular}{|c|c|c|c|c|c|}
\hline Partidas & & Proyectado 2018 & & al 2018 & $\begin{array}{l}\text { Real VS } \\
\text { Proyectado }\end{array}$ \\
\hline Sueldos Y Salarios & $\mathrm{S} /$ & $-67,618,307$ & $\mathrm{~S} /$ & $-73,406,718$ & $109 \%$ \\
\hline Alquiler De Inmuebles & $\mathrm{S} /$ & $-50,647,287$ & $\mathrm{~S} /$ & $-51,528,690$ & $102 \%$ \\
\hline Gastos Y Comisiones & S/ & $-2,488,239$ & $\mathrm{~S} /$ & $-3,239,579$ & $130 \%$ \\
\hline Reparación Y Mantenimiento & $\mathrm{S} /$ & $-1,439,341$ & $\mathrm{~S} /$ & $-2,702,337$ & $188 \%$ \\
\hline Suministros - Materiales & $\mathrm{S} /$ & $-1,580,331$ & $\mathrm{~S} /$ & $-1,607,439$ & $102 \%$ \\
\hline Servicios Complementarios Al Personal & S/ & $-995,913$ & $\mathrm{~S} /$ & $-1,385,924$ & $139 \%$ \\
\hline Transporte Y Fletes & $\mathrm{S} /$ & $-711,635$ & $\mathrm{~S} /$ & $-1,138,103$ & $160 \%$ \\
\hline Suministros - Gasto De Vehículos & S/ & $-783,442$ & $\mathrm{~S} /$ & $-1,042,571$ & $133 \%$ \\
\hline Servicios De Asesoría Y Consultoría & $\mathrm{S} /$ & $-543,234$ & $\mathrm{~S} /$ & $-985,708$ & $181 \%$ \\
\hline Atenciones Al Personal & S/ & $-635,273$ & S/ & $-739,480$ & $116 \%$ \\
\hline Gasto Relacionados Con El Personal & $\mathrm{S} /$ & $-381,718$ & $\mathrm{~S} /$ & $-571,594$ & $150 \%$ \\
\hline Servicios De Almacenaje & $\mathrm{S} /$ & $-31,158$ & $\mathrm{~S} /$ & $-564,339$ & $1811 \%$ \\
\hline Servicios De Agua Y Desague & $\mathrm{S} /$ & $-265,177$ & $\mathrm{~S} /$ & $-557,135$ & $210 \%$ \\
\hline Servicios De Adm. Y Control De R. Sólidos & $\mathrm{S} /$ & $-254,474$ & $\mathrm{~S} /$ & $-358,350$ & $141 \%$ \\
\hline Servicios De Estiba Y Desestiba & $\mathrm{S} /$ & $-234,157$ & $\mathrm{~S} /$ & $-352,838$ & $151 \%$ \\
\hline Servicios De Montacarga & $\mathrm{S} /$ & $-134,746$ & $\mathrm{~S} /$ & $-233,004$ & $173 \%$ \\
\hline Servicios De Manipuleo & $\mathrm{S} /$ & $-145,766$ & S/ & $-227,150$ & $156 \%$ \\
\hline Sanciones Administrativas & $\mathrm{S} /$ & $-87,485$ & S/ & $-210,223$ & $240 \%$ \\
\hline Servicios De Fumigación & $\mathrm{S} /$ & $-40,069$ & $\mathrm{~S} /$ & $-169,380$ & $423 \%$ \\
\hline Suministros - Bienes No Activados & S/ & $-72,538$ & $\mathrm{~S} /$ & $-160,421$ & $221 \%$ \\
\hline Seguros & $\mathrm{S} /$ & $-111,661$ & $\mathrm{~S} /$ & $-151,830$ & $136 \%$ \\
\hline Gastos $\mathrm{Ti}$ & $\mathrm{S} /$ & $-5,650$ & $\mathrm{~S} /$ & $-129,072$ & $2284 \%$ \\
\hline Suministros - Bienes No Activados & $\mathrm{S} /$ & $-29,144$ & $\mathrm{~S} /$ & $-124,905$ & $429 \%$ \\
\hline Sanciones Administrativas & $\mathrm{S} /$ & $-51,519$ & $\mathrm{~S} /$ & $-119,873$ & $233 \%$ \\
\hline Alquiler De Inmuebles & S/ & $-58,604$ & $\mathrm{~S} /$ & $-84,815$ & $145 \%$ \\
\hline Seguros & $\mathrm{S} /$ & $-8,654$ & S/ & $-64,508$ & $745 \%$ \\
\hline Servicios De Seguridad Industrial & S/ & $-6,612$ & $\mathrm{~S} /$ & $-31,885$ & $482 \%$ \\
\hline Gastos De Laboratorio & $\mathrm{S} /$ & $-19,971$ & $\mathrm{~S} /$ & $-31,571$ & $158 \%$ \\
\hline Otros Servicios Prestados & S/ & $-8,039$ & $\mathrm{~S} /$ & $-23,509$ & $292 \%$ \\
\hline Licencias Y Derechos & $\mathrm{S} /$ & $-8,739$ & $\mathrm{~S} /$ & $-23,311$ & $267 \%$ \\
\hline Servicios De Seguridad Industrial & S/ & $-1,707$ & S/ & $-15,989$ & $937 \%$ \\
\hline Suministros - Otros & $\mathrm{S} /$ & $-6,493$ & S/ & $-15,126$ & $233 \%$ \\
\hline Servicios Logísticos & $\mathrm{S} /$ & $-1,862$ & $\mathrm{~S} /$ & $-12,602$ & $677 \%$ \\
\hline Servicios De Balanza & $\mathrm{S} /$ & $-2,462$ & $\mathrm{~S} /$ & $-11,848$ & $481 \%$ \\
\hline Servicios De Montacarga & S/ & $-6,172$ & $\mathrm{~S} /$ & $-11,414$ & $185 \%$ \\
\hline Suministros - Gasto De Vehículos & $\mathrm{S} /$ & $-3,309$ & $\mathrm{~S} /$ & $-9,740$ & $294 \%$ \\
\hline Servicios De Montacarga & $\mathrm{S} /$ & -284 & S/ & $-3,238$ & $1140 \%$ \\
\hline Servicios De Balanza & $\mathrm{S} /$ & -132 & S/ & $-1,950$ & $1475 \%$ \\
\hline
\end{tabular}




\section{Anexo 15. Encuesta Clima Laboral}

A continuación, en la siguiente página se presenta el resultado de la Encuesta de Clima Laboral realizada el 2018. Asimismo, consta de 56 preguntas y fueron realizadas a un total de 600 personas de Lima y provincias.

\begin{tabular}{|c|c|c|c|c|}
\hline \multicolumn{5}{|c|}{ ENCUESTA CLIMA LABORAL 2018} \\
\hline $\mathbf{N}^{\circ}$ & Enunciados & SI & NO & $\%$ \\
\hline 1 & La empresa busca innovar constantemente en productos y servicios. & 556 & 44 & $93 \%$ \\
\hline 2 & La empresa promueve las buenas ideas o conductas de mejora continua. & 489 & 111 & $81 \%$ \\
\hline 3 & Mi superior inmediato nos anima a dar sugerencias e ideas para mejorar el trabajo. & 467 & 133 & $78 \%$ \\
\hline 4 & Mi empresa es una de las mejores en el sector. & 533 & 67 & $89 \%$ \\
\hline 5 & Los productos y/o servicios de la empresa satisfacen las necesidades del cliente. & 556 & 44 & $93 \%$ \\
\hline 6 & La empresa busca ofrecer servicios y productos de calidad. & 600 & $\mathbf{0}$ & $100 \%$ \\
\hline 7 & Me han explicado con claridad los objetivos y responsabilidades de mi puesto. & 556 & 44 & $93 \%$ \\
\hline 8 & He recibido información acerca de los objetivos de mi área. & 556 & 44 & $93 \%$ \\
\hline 9 & En mi área, el trabajo está bien organizado. & 400 & 200 & $67 \%$ \\
\hline 10 & $\begin{array}{l}\text { Mi superior inmediato asigna y coordina adecuadamente el trabajo entre los miembros del } \\
\text { equipo. }\end{array}$ & 444 & 156 & $74 \%$ \\
\hline 11 & $\begin{array}{l}\text { Recibo información importante y oportuna sobre la empresa (acontecimientos, cambios, } \\
\text { situación del negocio, etc.) }\end{array}$ & 467 & 133 & $78 \%$ \\
\hline 12 & Puedo expresar libremente mis opiniones sin temor. & 422 & 178 & $70 \%$ \\
\hline 13 & Mi superior inmediato me comunica claramente qué espera de mi trabajo. & 422 & 178 & $70 \%$ \\
\hline 14 & Cuando quiero conversar con mi superior inmediato, muestra interés por escucharme. & 578 & 22 & $96 \%$ \\
\hline 15 & $\begin{array}{l}\text { En mi área, las condiciones físicas y ambientales de trabajo (baño, luz, ventilación, ruido, } \\
\text { temperatura) son adecuadas. }\end{array}$ & 533 & 67 & $89 \%$ \\
\hline 16 & En mi área, las condiciones de seguridad son apropiadas para el trabajo que realizo. & 467 & 133 & $78 \%$ \\
\hline 17 & La empresa se preocupa por la salud e integridad física de sus colaboradores. & 556 & 44 & $93 \%$ \\
\hline 18 & $\begin{array}{l}\text { Cuento con la infraestructura, herramientas, materiales, equipos y/o máquinas necesarias } \\
\text { para realizar bien mi trabajo. }\end{array}$ & 489 & 111 & $81 \%$ \\
\hline 19 & La empresa busca el equilibrio entre la vida laboral y personal de sus colaboradores. & 400 & 200 & $67 \%$ \\
\hline 20 & Mi superior inmediato asigna y distribuye adecuadamente la carga laboral. & 444 & 156 & $74 \%$ \\
\hline 21 & Mi superior inmediato se interesa por mi desarrollo. & 489 & 111 & $81 \%$ \\
\hline 22 & $\begin{array}{l}\text { Los ascensos en la empresa se dan de forma justa de acuerdo al desempeño y esfuerzo de } \\
\text { los colaboradores. }\end{array}$ & 422 & 178 & $70 \%$ \\
\hline 23 & $\begin{array}{l}\text { La experiencia que me brinda trabajar en esta empresa es valiosa para mi desarrollo } \\
\text { profesional. }\end{array}$ & 556 & 44 & $93 \%$ \\
\hline 24 & $\begin{array}{l}\text { Existen las mismas oportunidades de capacitación para todos de acuerdo a los puestos que } \\
\text { ocupamos. }\end{array}$ & 489 & 111 & $81 \%$ \\
\hline 25 & $\begin{array}{l}\text { Mi superior inmediato conversa conmigo sobre las tareas que he realizado bien y sobre } \\
\text { aquellas en las que debo mejorar. }\end{array}$ & 444 & 156 & $\mathbf{7 4 \%}$ \\
\hline 26 & $\begin{array}{l}\text { En mi área se agradece, felicita y/o da incentivo al trabajador que hace más de lo que se le } \\
\text { pide. }\end{array}$ & 578 & 22 & $96 \%$ \\
\hline 27 & La empresa da incentivos adecuados a los colaboradores que tienen buen desempeño. & 511 & 89 & $85 \%$ \\
\hline 28 & A las personas aquí se les paga de acuerdo al trabajo que hacen. & 378 & 222 & $63 \%$ \\
\hline 29 & Mi sueldo es similar al que se ofrece en otras empresas para puestos como el mío. & 289 & 311 & $48 \%$ \\
\hline 30 & Estoy conforme con los beneficios otorgados por la empresa. & 311 & 289 & $52 \%$ \\
\hline 31 & Cuando hay un problema en el área, todos nos enfocamos y apoyamos en solucionarlo. & 467 & 133 & $78 \%$ \\
\hline 32 & En mi área nos organizamos para cumplir nuestros objetivos como equipo. & 511 & 89 & $85 \%$ \\
\hline 33 & Las coordinaciones entre las áreas de la organización son adecuadas y a tiempo. & 467 & 133 & $78 \%$ \\
\hline 34 & Todas las áreas trabajan en conjunto para alcanzar los objetivos organizacionales. & 556 & 44 & $93 \%$ \\
\hline 35 & La empresa es un lugar acogedor y amigable para trabajar. & 444 & 156 & $74 \%$ \\
\hline 36 & En la empresa se celebran fechas y eventos especiales. & 467 & 133 & $78 \%$ \\
\hline 37 & En mi área, cuando ingresa un nuevo integrante se le hace sentir bienvenido. & 467 & 133 & $\mathbf{7 8 \%}$ \\
\hline 38 & En mi área celebramos los logros como equipo. & 444 & 156 & $74 \%$ \\
\hline 39 & $\begin{array}{l}\text { Cuando hay diferentes puntos de vista y/o ideas entre miembros del área, conversamos para } \\
\text { llegar a un acuerdo. }\end{array}$ & 511 & 89 & $85 \%$ \\
\hline
\end{tabular}




\begin{tabular}{|llccc|}
\hline 40 & En mi área las relaciones entre el personal son positivas, lo que crea un grato ambiente de & $\mathbf{4 0 0}$ & $\mathbf{2 0 0}$ & $\mathbf{6 7 \%}$ \\
& trabajo. & $\mathbf{4 8 9}$ & $\mathbf{1 1 1}$ & $\mathbf{8 1 \%}$ \\
41 & Mi superior inmediato mantiene buenas relaciones con los integrantes del área. & $\mathbf{8 9}$ & $\mathbf{8 5 \%}$ \\
42 & En la organización todos los trabajadores interactúan y se respetan entre sí sin importar la & $\mathbf{5 1 1}$ & $\mathbf{4 6}$ & $\mathbf{7 3 \%}$ \\
& raza, sexo, lugar de procedencia u orientación sexual. & $\mathbf{4 6 7}$ & $\mathbf{1 3 3}$ & $\mathbf{2 2}$ \\
43 & Siento que la mayoría de los colaboradores están comprometidos con la empresa. & $\mathbf{5 6 \%}$ \\
44 & Me siento comprometido con los objetivos de la empresa. & $\mathbf{5 7 8}$ & $\mathbf{2 2}$ & $\mathbf{9 6 \%}$ \\
45 & Quiero trabajar aquí por mucho tiempo. & $\mathbf{5 1 1}$ & $\mathbf{8 9}$ & $\mathbf{8 5 \%}$ \\
46 & Estoy orgulloso de decir a otros que trabajo en esta empresa. & $\mathbf{5 7 8}$ & $\mathbf{2 2}$ & $\mathbf{9 6 \%}$ \\
47 & Me gustan las tareas que tengo a cargo. & $\mathbf{4 6 7}$ & $\mathbf{1 3 3}$ & $\mathbf{7 8 \%}$ \\
48 & Mi puesto de trabajo me permite demostrar mis habilidades. & $\mathbf{4 5 6}$ & $\mathbf{7 4 \%}$ \\
49 & Mi superior inmediato me motiva para dar un esfuerzo extra en mi trabajo. & $\mathbf{5 5 6}$ & $\mathbf{4 4}$ & $\mathbf{9 3 \%}$ \\
50 & Siento que mi participación es importante en los logros que mi área consigue. & $\mathbf{4 8 9}$ & $\mathbf{1 1 1}$ & $\mathbf{8 1 \%}$ \\
51 & Me han explicado la misión, visión y valores de la empresa. & $\mathbf{5 5 6}$ & $\mathbf{4 4}$ & $\mathbf{9 3 \%}$ \\
52 & En general, los líderes (supervisores, jefes y gerentes) de la empresa se caracterizan por ser & $\mathbf{5 3 3}$ & $\mathbf{6 7}$ & $\mathbf{8 9 \%}$ \\
53 & honestos, rectos y éticos. & $\mathbf{4 8 9}$ & $\mathbf{1 1 1}$ & $\mathbf{8 1 \%}$ \\
54 & Con esta empresa aprendemos de nuestros fracasos y salimos adelante rápidamente. & $\mathbf{5 5 6}$ & $\mathbf{4 4}$ & $\mathbf{9 3 \%}$ \\
55 & Estoy orgulloso de trabajar en el Grupo Romero. & $\mathbf{5 5 6}$ & $\mathbf{4 4}$ & $\mathbf{9 3 \%}$ \\
56 & He recibido información sobre la misión y visión del Grupo Romero & &
\end{tabular}




\section{Anexo 16. Ficha técnica - Matriz de evaluación de los factores internos por expertos de Ransa}

\section{Presentación}

Buen día, antes de comenzar queremos agradecerle por recibirnos y brindarnos su tiempo para llevar a cabo esta entrevista. Dicho esto, la información que nos brinde será de uso estricto para el desarrollo de nuestra tesis.

\section{Objetivos de investigación}

Conocer al detalle el nivel de importancia e impacto que tienen los factores internos sobre la estrategia general interna y viceversa.

\section{Método de devaluación}

Primero, asignar un peso de 0.00 (menos importante) a 1.00 (más importante) a cada uno de los siguientes factores, el peso dado representa la importancia relativa para alcanzar el éxito de Ransa, sumando al final todos los pesos 1.00. Segundo, asignar una calificación de 1 (debilidad mayor), 2 (debilidad menor), 3 (fuerza menor), y 4 (fuerza mayor). Las calificaciones pertenecen a Ransa y los pesos a la industria.

\section{Guía de entrevista}

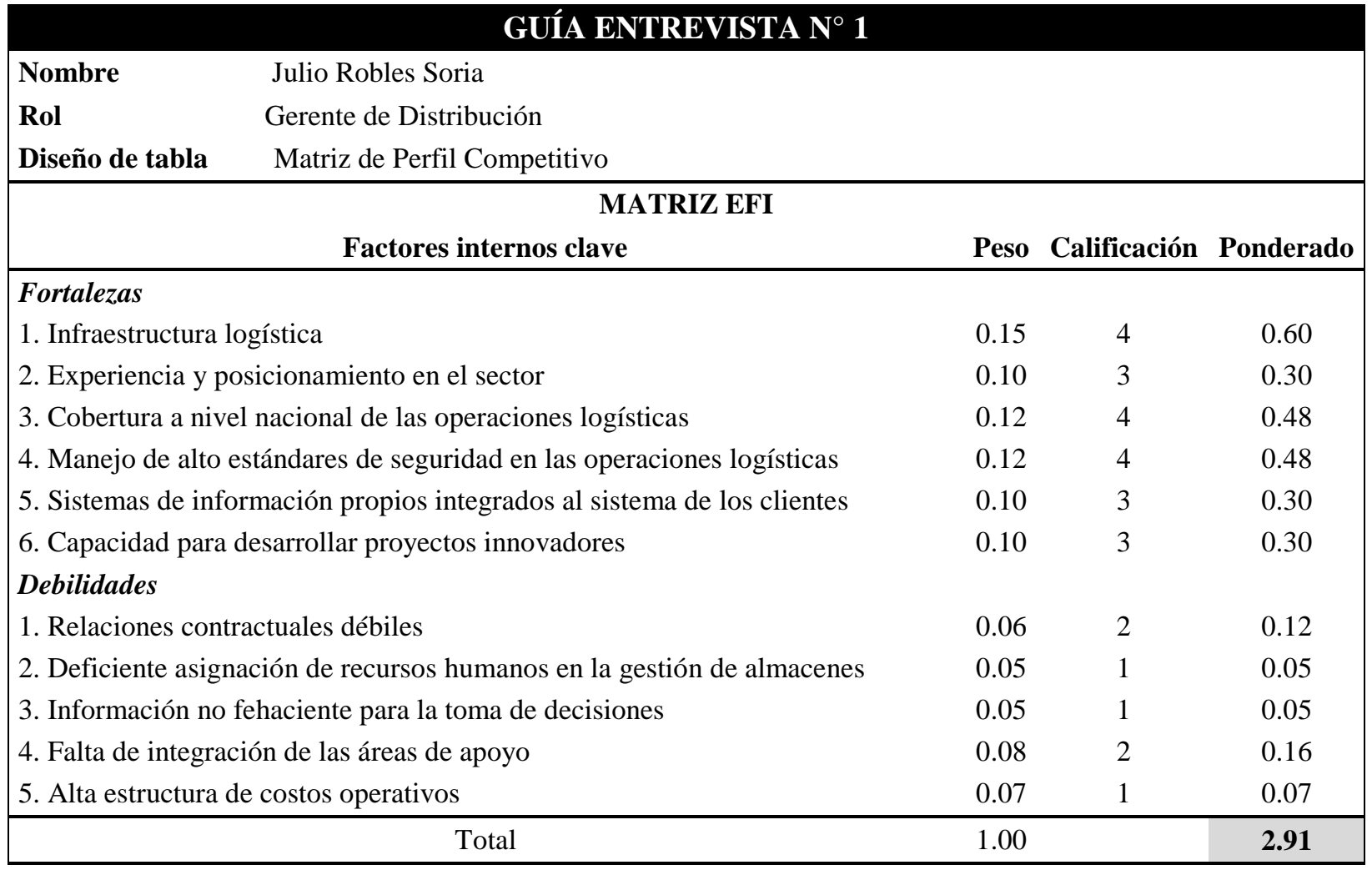




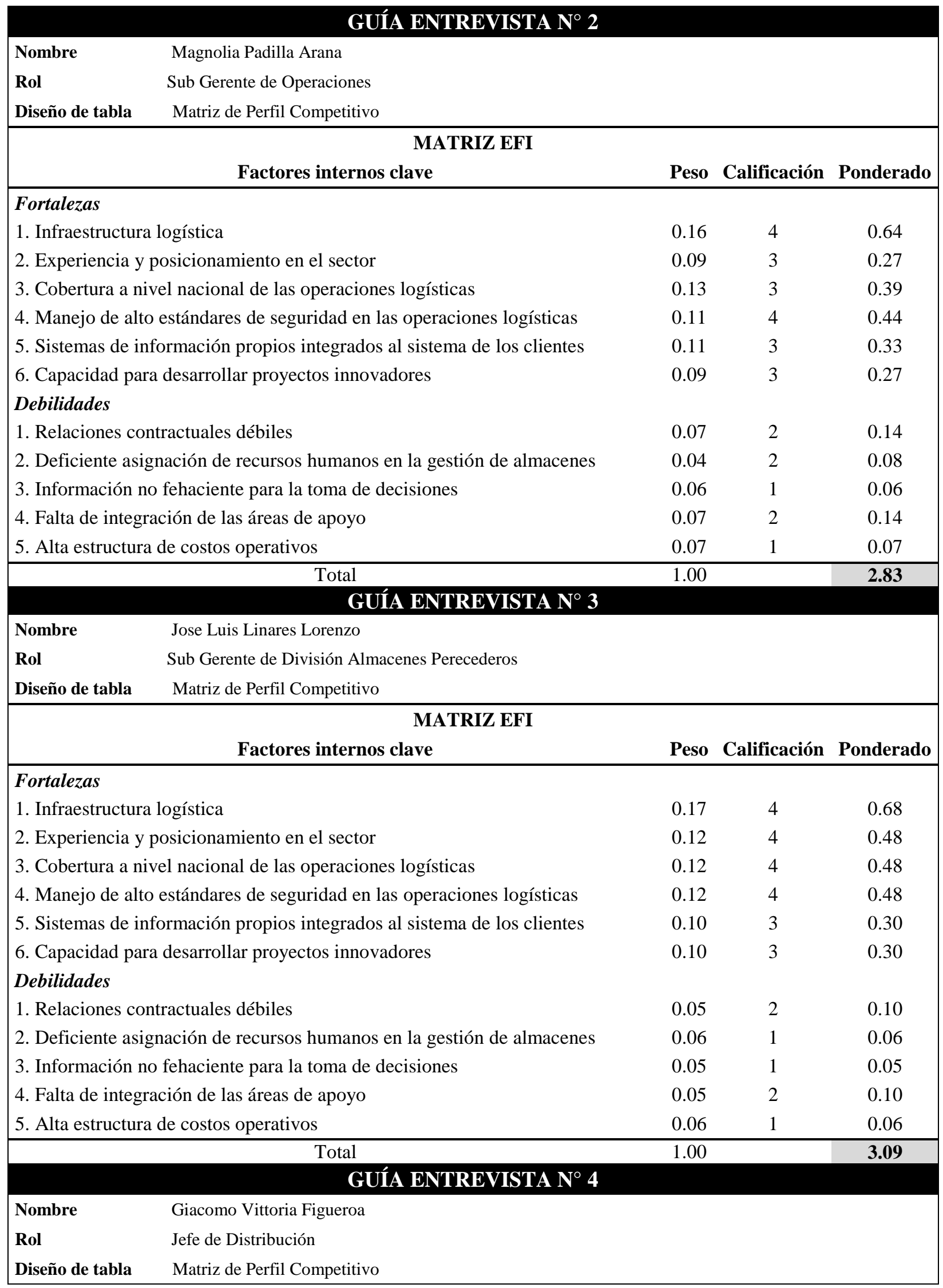




\section{MATRIZ EFI}

Factores internos clave

Peso Calificación Ponderado

Fortalezas

1. Infraestructura logística

2. Experiencia y posicionamiento en el sector

3. Cobertura a nivel nacional de las operaciones logísticas

4. Manejo de alto estándares de seguridad en las operaciones logísticas

5. Sistemas de información propios integrados al sistema de los clientes

6. Capacidad para desarrollar proyectos innovadores

Debilidades

1. Relaciones contractuales débiles

2. Deficiente asignación de recursos humanos en la gestión de almacenes

3. Información no fehaciente para la toma de decisiones

4. Falta de integración de las áreas de apoyo

5. Alta estructura de costos operativos

$\begin{array}{lll}0.14 & 4 & 0.56\end{array}$

$\begin{array}{lll}0.12 & 4 & 0.48\end{array}$

$\begin{array}{lll}0.11 & 4 & 0.44\end{array}$

$\begin{array}{lll}0.13 & 4 & 0.52\end{array}$

$\begin{array}{lll}0.09 & 3 & 0.27\end{array}$

$\begin{array}{lll}0.11 & 3 & 0.33\end{array}$

$\begin{array}{lll}0.05 & 2 & 0.10\end{array}$

$\begin{array}{lll}0.06 & 1 & 0.06\end{array}$

$\begin{array}{lll}0.04 & 1 & 0.04\end{array}$

$\begin{array}{lll}0.07 & 1 & 0.07\end{array}$

Tota

0.08

0.08

$1.00 \quad \mathbf{2 . 9 5}$




\section{Anexo 17. Ficha técnica - Lienzo estratégico de Ransa y la Industria}

\section{Presentación}

Buen día, antes de comenzar queremos agradecerle por recibirnos y brindarnos su tiempo para llevar a cabo esta entrevista. Dicho esto, la información que nos brinde será de uso estricto para el desarrollo de nuestra tesis.

\section{Objetivos de investigación}

Conocer la valoración de las variables identificadas para la elaboración del lienzo estratégico de Ransa y de la industria.

\section{Método de devaluación}

Asignar una calificación a cada variable del 0 (nulo), 1 (muy malo) al 10 (muy bueno). Se debe considerar en la Industria a las empresas que ofrecen servicio logístico integrado al momento de asignar una calificación.

\section{Guía de entrevista}




\begin{tabular}{|c|c|c|c|c|c|c|c|c|c|c|}
\hline \multirow[t]{2}{*}{$\begin{array}{l}\text { Nombre } \\
\text { Rol } \\
\text { Diseño de tabla } \\
\end{array}$} & \multicolumn{10}{|c|}{$\begin{array}{l}\text { Gerente de Distribución } \\
\text { Matriz de Perfil Competitivo }\end{array}$} \\
\hline & $\begin{array}{l}\text { Servicio } \\
\text { logístico } \\
\text { integrado }\end{array}$ & $\begin{array}{l}\text { Infraestructura } \\
\text { Propia }\end{array}$ & $\begin{array}{l}\text { Infraestructura } \\
\text { especializada }\end{array}$ & $\begin{array}{l}\text { Actividades } \\
\text { económicas } \\
\text { atendidas }\end{array}$ & $\begin{array}{c}\text { Cobertura del } \\
\text { servicio }\end{array}$ & $\begin{array}{l}\text { Relaciones } \\
\text { contractuales } \\
\text { débiles }\end{array}$ & $\begin{array}{l}\text { Tecnología } \\
\text { avanzada }\end{array}$ & $\begin{array}{l}\text { Procesos } \\
\text { manuales }\end{array}$ & $\begin{array}{l}\text { Capacitación y } \\
\text { entrenamiento } \\
\text { al personal }\end{array}$ & $\begin{array}{l}\text { Certificado de } \\
\text { huella de } \\
\text { carbono para el } \\
\text { cliente }\end{array}$ \\
\hline Ransa & 10 & 8 & 9 & 9 & 6 & 4 & 8 & 5 & 9 & 10 \\
\hline Industria & 9 & 8 & 8 & 9 & 5 & 5 & 8 & 5 & 9 & \\
\hline \multirow[t]{2}{*}{$\begin{array}{l}\text { Nombre } \\
\text { Rol } \\
\text { Diseño de tabla } \\
\end{array}$} & \multicolumn{10}{|c|}{$\begin{array}{l}\text { Magnolia Padilla Arana } \\
\text { Sub Gerente de Operaciones } \\
\text { Matriz de Perfil Competitivo }\end{array}$} \\
\hline & $\begin{array}{l}\text { Servicio } \\
\text { logístico } \\
\text { integrado }\end{array}$ & $\begin{array}{l}\text { Infraestructura } \\
\text { Propia }\end{array}$ & $\begin{array}{l}\text { Infraestructura } \\
\text { especializada }\end{array}$ & $\begin{array}{l}\text { Actividades } \\
\text { económicas } \\
\text { atendidas }\end{array}$ & $\begin{array}{c}\text { Cobertura del } \\
\text { servicio }\end{array}$ & $\begin{array}{l}\text { Relaciones } \\
\text { contractuales } \\
\text { débiles }\end{array}$ & $\begin{array}{l}\text { Tecnología } \\
\text { avanzada }\end{array}$ & $\begin{array}{l}\text { Procesos } \\
\text { manuales }\end{array}$ & $\begin{array}{l}\text { Capacitación y } \\
\text { entrenamiento } \\
\text { al personal }\end{array}$ & $\begin{array}{l}\text { Certificado de } \\
\text { huella de } \\
\text { carbono para el } \\
\text { cliente }\end{array}$ \\
\hline Ransa & 10 & 8 & 10 & 10 & 8 & 5 & 7 & 6 & 9 & 10 \\
\hline Industria & 10 & 7 & 9 & 9 & 5 & 6 & 7 & 6 & 9 & \\
\hline $\begin{array}{l}\text { Nombre } \\
\text { Rol } \\
\text { Diseño de tabla }\end{array}$ & \multicolumn{10}{|c|}{$\begin{array}{l}\text { Jose Luis Linares Lorenzo } \\
\text { Sub Gerente de División Almacenes Perecederos } \\
\text { Matriz de Perfil Competitivo }\end{array}$} \\
\hline & $\begin{array}{l}\text { Servicio } \\
\text { logístico } \\
\text { integrado }\end{array}$ & $\begin{array}{l}\text { Infraestructura } \\
\text { Propia }\end{array}$ & $\begin{array}{l}\text { Infraestructura } \\
\text { especializada }\end{array}$ & $\begin{array}{l}\text { Actividades } \\
\text { económicas } \\
\text { atendidas }\end{array}$ & $\begin{array}{c}\text { Cobertura del } \\
\text { servicio }\end{array}$ & $\begin{array}{l}\text { Relaciones } \\
\text { contractuales } \\
\text { débiles }\end{array}$ & $\begin{array}{l}\text { Tecnología } \\
\text { avanzada }\end{array}$ & $\begin{array}{l}\text { Procesos } \\
\text { manuales }\end{array}$ & $\begin{array}{l}\text { Capacitación y } \\
\text { entrenamiento } \\
\text { al personal }\end{array}$ & $\begin{array}{l}\text { Certificado de } \\
\text { huella de } \\
\text { carbono para el } \\
\text { cliente }\end{array}$ \\
\hline Ransa & 10 & 8 & 10 & 10 & 7 & 6 & 6 & 6 & 9 & 10 \\
\hline Industria & 10 & 7 & 9 & 9 & 6 & 7 & 6 & 5 & 9 & \\
\hline \multicolumn{11}{|c|}{ GUÍA ENTREVISTA $\mathrm{N}^{\circ} 4$} \\
\hline $\begin{array}{l}\text { Nombre } \\
\text { Rol } \\
\text { Diseño de tabla } \\
\end{array}$ & \multicolumn{10}{|c|}{$\begin{array}{l}\text { Giacomo Vittoria Figueroa } \\
\text { Jefe de Distribución } \\
\text { Matriz de Perfil Competitivo }\end{array}$} \\
\hline & $\begin{array}{l}\text { Servicio } \\
\text { logístico } \\
\text { integrado }\end{array}$ & $\begin{array}{l}\text { Infraestructura } \\
\text { Propia }\end{array}$ & $\begin{array}{l}\text { Infraestructura } \\
\text { especializada }\end{array}$ & $\begin{array}{l}\text { Actividades } \\
\text { económicas } \\
\text { atendidas }\end{array}$ & $\begin{array}{c}\text { Cobertura del } \\
\text { servicio }\end{array}$ & $\begin{array}{l}\text { Relaciones } \\
\text { contractuales } \\
\text { débiles }\end{array}$ & $\begin{array}{l}\text { Tecnología } \\
\text { avanzada }\end{array}$ & $\begin{array}{l}\text { Procesos } \\
\text { manuales }\end{array}$ & $\begin{array}{l}\text { Capacitación y } \\
\text { entrenamiento } \\
\text { al personal }\end{array}$ & $\begin{array}{l}\text { Certificado de } \\
\text { huella de } \\
\text { carbono para el } \\
\text { cliente }\end{array}$ \\
\hline Ransa & 10 & 8 & 10 & 10 & 7 & 3 & 7 & 5 & 9 & 10 \\
\hline Industria & 9 & 7 & 9 & 10 & 5 & 7 & 7 & 6 & 9 & \\
\hline
\end{tabular}




\section{Anexo 18. Ficha técnica-Matriz PEYEA}

\section{Presentación}

Buen día, antes de comenzar queremos agradecerle por recibirnos y brindarnos su tiempo para llevar a cabo esta entrevista. Dicho esto, la información que nos brinde será de uso estricto para el desarrollo de nuestra tesis.

\section{Objetivos de investigación}

Conocer la valoración de las variables identificadas para la elaboración de la Matriz PEYEA de Ransa.

\section{Método de devaluación}

Asignar una calificación de +1 (peor) a +6 (mejor) a las dimensiones Fortaleza Financiera (FF) y Fortaleza de la Industria (FI). Asignar una calificación de -1 (mejor) a -6 (peor) a las dimensiones Ventaja Competitiva (VC) y Estabilidad del Entrono (EE).

\section{Guía de entrevista}

\begin{tabular}{|c|c|c|c|c|c|c|}
\hline \multirow[t]{2}{*}{$\begin{array}{l}\text { Variable } \\
\text { Expertos }\end{array}$} & \multirow{2}{*}{$\begin{array}{l}\text { Alcance } \\
\text { Mínimo }\end{array}$} & $\begin{array}{c}\text { Jefe de } \\
\text { Facturación }\end{array}$ & $\begin{array}{c}\text { Jefe de } \\
\text { Gestión de } \\
\text { Costos } \\
\end{array}$ & $\begin{array}{l}\text { Gerente de } \\
\text { Finanzas }\end{array}$ & \multirow{2}{*}{$\begin{array}{l}\text { Alcance } \\
\text { máximo }\end{array}$} & \multirow{2}{*}{$\begin{array}{c}\text { Promedio } \\
\text { (redondeado } \\
\text { por exceso) }\end{array}$} \\
\hline & & $\begin{array}{c}\text { Carlos } \\
\text { Barroso }\end{array}$ & $\begin{array}{c}\text { Rosa } \\
\text { Reategui }\end{array}$ & $\begin{array}{c}\text { Victor } \\
\text { Cabanillas }\end{array}$ & & \\
\hline & 1 & 2 & 34 & 5 & 6 & \\
\hline \multicolumn{7}{|l|}{ Fortaleza Financiera } \\
\hline Flujo de caja & Bajo & 1 & 2 & 2 & Alto & 1.67 \\
\hline $\begin{array}{l}\text { Facilidad de salida del } \\
\text { mercado }\end{array}$ & Difícil & 2 & 2 & 2 & Fácil & 2.00 \\
\hline $\begin{array}{l}\text { Riesgo involucrado en el } \\
\text { negocio }\end{array}$ & Alto & 3 & 3 & 2 & Bajo & 2.67 \\
\hline $\begin{array}{l}\text { Economías de escala y de } \\
\text { experiencia }\end{array}$ & Bajo & 4 & 5 & 5 & Alto & 4.67 \\
\hline \multicolumn{7}{|l|}{ Fortaleza de la Industria } \\
\hline Potencial de crecimiento & Bajo & 4 & 5 & 5 & Alto & 4.67 \\
\hline Potencial de utilidades & Bajo & 5 & 4 & 5 & Alto & 4.67 \\
\hline Estabilidad financiera & Bajo & 4 & 4 & 4 & Alto & 4.00 \\
\hline Conocimiento tecnológico & Simple & 4 & 5 & 5 & Complejo & 4.67 \\
\hline
\end{tabular}




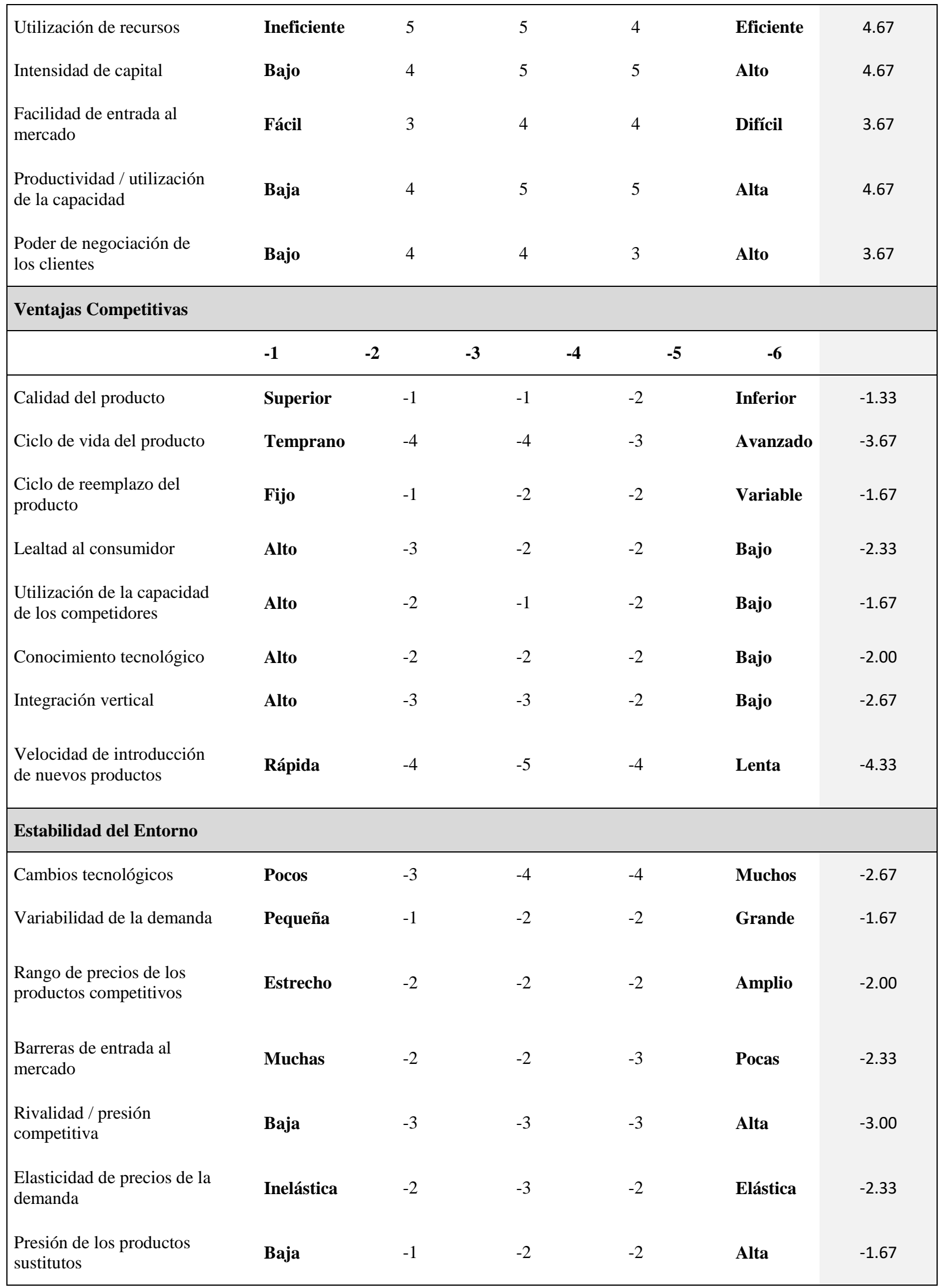




\section{Anexo 19. Fortaleza Financiera (FF) - Matriz PEYEA}

A continuación, se presenta información financiera resultante del año 2016, sustento complementario del Anexo 11.

\begin{tabular}{|c|c|c|c|c|}
\hline Indicador & Resultado & Dimensión & Parámetros predeterminados & Calificación \\
\hline ROA & -0.03 & $\begin{array}{c}\text { Fortaleza } \\
\text { financiera }\end{array}$ & Si ROA de la empresa es < que cero & 1 \\
\hline ROE & -0.07 & $\begin{array}{c}\text { Fortaleza } \\
\text { financiera }\end{array}$ & Si ROE de la empresa es < que cero & 1 \\
\hline Liquidez & $96 \%$ & $\begin{array}{c}\text { Fortaleza } \\
\text { financiera }\end{array}$ & Si liquidez de la empresa es mayor a 77\% & 6 \\
\hline $\begin{array}{c}\text { Endeudamiento } \\
\text { Participación en el } \\
\text { mercado }\end{array}$ & $52 \%$ & $\begin{array}{c}\text { Fortaleza } \\
\text { financiera }\end{array}$ & $\begin{array}{c}\text { Si endeudamiento es < 75\%, > 5\% y < 10\% del } \\
\text { endeudamiento industrial }\end{array}$ & 3 \\
\hline Inflación & $1.36 \%$ & $\begin{array}{c}\text { Estabilidad del } \\
\text { entorno }\end{array}$ & $\begin{array}{c}\text { Si la inflación es > al promedio de los últimos } \\
\text { períodos hasta en 5\% }\end{array}$ & -1 \\
\hline $\begin{array}{c}\text { Rotación de } \\
\text { Inventarios }\end{array}$ & -40865 & $\begin{array}{c}\text { Fortaleza } \\
\text { financiera }\end{array}$ & $\begin{array}{c}\text { Si la inflación es > al promedio de los últimos } \\
\text { períodos hasta en 5\% }\end{array}$ & 1 \\
\hline
\end{tabular}


Anexo 20. EERR 2016R, 2017R, 2018R, 2019P, 2020P, 2021P, 2022P por servicio ofrecido

A continuación, se presenta el Estado de Resultados de los años 2016, 2017 y 2018, además de la proyección del mismo para los años 2019, 2020, 2021 y 2022, detallado por los principales servicios ofrecidos por Ransa Comercial S.A.

\begin{tabular}{|c|c|c|c|c|c|c|c|c|c|c|c|c|c|c|}
\hline \multirow{2}{*}{ GyP Gestión } & \multicolumn{7}{|c|}{ Almacenaje } & \multicolumn{7}{|c|}{ Transporte } \\
\hline & $2016 R$ & $2017 \mathrm{R}$ & $2018 R$ & $2019 P$ & $2020 P$ & $2021 \mathrm{P}$ & $2022 P$ & 2016 R & $2017 \mathrm{R}$ & $2018 \mathrm{R}$ & $2019 \mathrm{P}$ & $2020 P$ & $2021 P$ & $2022 P$ \\
\hline VENTAS NETAS & 207,409 & 203,723 & 192,538 & 8185,542 & 2178,800 & $0 \quad 172,303$ & $3 \quad 166,042$ & 160,263 & $3 \quad 152,497$ & $7 \quad 132,910$ & $0 \quad 121,155$ & 5110,439 & 100,671 & 91,767 \\
\hline VENTAS INTERNAS & 745 & -220 & $27 \epsilon$ & $6 \quad 276$ & 276 & $6 \quad 276$ & 276 & 11,281 & 11,066 & 13,439 & 13,439 & 13,439 & 13,439 & 13,439 \\
\hline COSTOS VARIABLES & $-20,998$ & $-19,391$ & $-20,20$ & $-18,640$ & $-17,963$ & $-17,310$ & $-16,681$ & $-121,109$ & $9-116,199$ & $9-103,210$ & $-92,651$ & $-84,457$ & $-76,987$ & $7-70,177$ \\
\hline MARGEN DE CONTRIBUCIÓN & 187,156 & 184,112 & 172,605 & $5 \quad 167,178$ & 8161,114 & $4 \quad 155,269$ & $9 \quad 149,637$ & 50,434 & $4 \quad 47,365$ & $5 \quad 43,139$ & 41,942 & 39,421 & 37,123 & 35,028 \\
\hline COSTOS FUOS DIRECTOS & $-143,243$ & $-135,144$ & $-121,01 \epsilon$ & $6-122,614$ & $4-118,159$ & $9-113,865$ & $5-109,728$ & $-35,536$ & $-35,615$ & $-30,731$ & $-27,724$ & $-25,272$ & $-23,037$ & $-20,999$ \\
\hline COSTOS FUOS INDIRECTOS & $-36,236$ & $-33,899$ & $-29,993$ & $3-30,731$ & $1 \quad-29,614$ & $4 \quad-28,538$ & $8-27,501$ & $-10,698$ & $-14,221$ & $-10,611$ & $-9,686$ & $-8,830$ & $-8,049$ & 9 $-7,337$ \\
\hline UTILIDAD BRUTA & 7,676 & 15,069 & 21,595 & 13,833 & 13,340 & 12,866 & 12,408 & 4,199 & $-2,472$ & 1,797 & 4,532 & 5,320 & 6,038 & 6,692 \\
\hline GASTOS DE ADMINISTRACIÓN & & & & & & & & -11 & & & & & & \\
\hline GASTOS DE VENTAS & -484 & -770 & $-1,57$ & $-1,574$ & $-1,574$ & $-1,574$ & $-1,574$ & -317 & -351 & -54 & -54 & -54 & -54 & -54 \\
\hline OTROS I/E OPERATIVOS & $-1,285$ & $-5,328$ & $-65 €$ & -656 & -656 & -656 & -656 & 1,507 & $-1,257$ & -521 & -521 & -521 & -521 & -521 \\
\hline UTILIDAD OPERATIVA & 5,907 & 8,971 & 19,365 & 11,603 & 11,110 & 10,636 & 10,178 & 5,378 & $-4,079$ & 1,221 & 3,957 & 4,745 & 5,463 & 6,117 \\
\hline DEPRECIACIÓN Y AMORTIZACIÓN & $-7,590$ & $-7,759$ & $-6,89$ & $-6,894$ & $-6,894$ & $-6,894$ & $-6,894$ & $-4,270$ & $-4,085$ & $-4,357$ & $-4,357$ & $-4,357$ & $-4,357$ & $-4,357$ \\
\hline EBITDA & 13,497 & 16,730 & $26,25 c$ & 18,497 & 18,005 & 17,530 & 17,072 & 9,648 & 6 & 5,578 & 8,314 & 9,101 & 9,820 & 10,474 \\
\hline \multirow{2}{*}{ GyP Gestión } & \multicolumn{7}{|c|}{ Distribución } & \multicolumn{7}{|c|}{ Otros } \\
\hline & $2016 R$ & $2017 \mathrm{R}$ & $2018 R$ & $2019 \mathrm{P}$ & $2020 P$ & $2021 \mathrm{P}$ & $2022 \mathrm{P}$ & 2016 R & $2017 \mathrm{R}$ & $2018 R$ & $2019 P$ & $2020 P$ & $2021 P$ & $2022 P$ \\
\hline VENTAS NETAS & 52,578 & 52,135 & 53,736 & 54,336 & 54,942 & 55,554 & 56,174 & 125,865 & 113,895 & 131,862 & 135,993 & 140,253 & 144,647 & 149,178 \\
\hline VENTAS INTERNAS & -150 & 153 & 474 & 474 & 474 & 474 & 474 & $-12,246$ & $-11,224$ & $-14,337$ & $-14,337$ & $-14,337$ & $-14,337$ & $-14,337$ \\
\hline COSTOS VARIABLES & $-29,917$ & $-32,954$ & $-34,820$ & $-33,490$ & $-33,864$ & $-34,241$ & $-34,623$ & $-61,166$ & $-63,312$ & $-74,090$ & $-72,699$ & $-74,976$ & $-77,325$ & $-79,747$ \\
\hline MARGEN DE CONTRIBUCIÓN & 22,510 & 19,334 & 19,390 & 21,319 & 21,552 & 21,787 & 22,024 & 52,452 & 39,359 & 43,437 & 48,957 & 50,940 & 52,985 & 55,094 \\
\hline COSTOS FIOS DIRECTOS & $-12,727$ & $-11,853$ & $-10,924$ & $-12,184$ & $-12,320$ & $-12,457$ & $-12,596$ & $-32,291$ & $-25,682$ & $-27,001$ & $-31,134$ & $-32,109$ & $-33,115$ & $-34,152$ \\
\hline COSTOS FIOS INDIRECTOS & $-3,858$ & $-3,612$ & $-2,761$ & $-3,515$ & $-3,554$ & $-3,593$ & $-3,633$ & $-10,140$ & $-8,157$ & $-6,987$ & $-9,300$ & $-9,592$ & $-9,892$ & $-10,202$ \\
\hline UTILIDAD BRUTA & 5,925 & 3,870 & 5,705 & 5,621 & 5,678 & 5,736 & 5,795 & 10,021 & 5,520 & 9,449 & 8,523 & 9,239 & 9,978 & 10,739 \\
\hline GASTOS DE ADMINISTRACIÓN & & & & & & & & $-1,432$ & $-1,301$ & $-1,342$ & $-1,342$ & $-1,342$ & $-1,342$ & $-1,342$ \\
\hline GASTOS DE VENTAS & -289 & -59 & -85 & -85 & -85 & -85 & -85 & $-2,145$ & $-1,700$ & $-1,635$ & $-1,635$ & $-1,635$ & $-1,635$ & $-1,635$ \\
\hline OTROS I/E OPERATIVOS & -57 & -817 & -448 & -448 & -448 & -448 & -448 & 703 & -584 & -635 & -635 & -635 & -635 & -635 \\
\hline UTILIDAD OPERATIVA & 5,579 & 2,993 & 5,172 & 5,088 & 5,145 & 5,203 & 5,262 & 7,148 & 1,934 & 5,838 & 4,912 & 5,628 & 6,367 & 7,128 \\
\hline DEPRECIACIÓN Y AMORTIZACIÓN & -456 & -317 & -349 & -349 & -349 & -349 & -349 & $-2,752$ & $-1,396$ & $-1,261$ & $-1,261$ & $-1,261$ & $-1,261$ & $-1,261$ \\
\hline EBITDA & 6,035 & 3,310 & 5,521 & 5,437 & 5,494 & 5,552 & 5,611 & 9,899 & 3,330 & 7,099 & 6,173 & 6,889 & 7,627 & 8,389 \\
\hline
\end{tabular}

Nota: 2018R: 2018 Real; 2019P: 2019 Proyectado. 


\section{Referencias}

Barney, J. B. \& Griffin, R. (1992). The Management of Organizations: Strategy, Structure, Behavior. Boston, Estados Unidos: Houghton Mifflin Co.

Chan Kim W. \& Mauborgne, R. (2005). La estrategia del océano azul. Bogotá, Colombia: Editorial Norma S.A.

Christopher, M. (2000). Logística y aprovisionamiento. Barcelona: Editorial Folio S.A.

Coyle, J.J., Bardi, E.J. y Langley, \& C.J. Jr (2003). The Management of Business Logistics: A

Supply Chain Perspective. Séptima Edición. South-Western Publising, Mason OH.

David, F.R. (2013). Conceptos de administración estratégica. Juárez, México: Pearson.

Dellazzoppa, H. (2011). Los primeros años de ARLOG. Concepto Logístico, (0), p. 19.

De La Torre, A., López, G., Luna, C., Meza, R., \& Mixán, M. (2016). Planeamiento Estratégico de Ransa Comercial S.A. (Tesis de maestría inédita). Pontificia Universidad Católica del Perú, Lima.

D’Alessiio, F. (2008). El proceso estratégico, un enfoque de gerencia. México D.F.: Pearson Educación.

Ley N757. Diario Oficial el Peruano de La República del Perú, Lima, Perú, 13 de noviembre de 1991.

Porter, M. (1985). Competitive Advantage. New York, EEUU: The Free Press

Porter, M. (1991). Estratégia competitiva: técnicas para análise de indústrias e da concorrência. 8va ed. Rio de Janeiro, Brazil: Campus.

Project Management Institute (6ta edición). (2017). Project Management Body of Knowledge. Newtown Square, Pennsylvania, EEUU: Project Management Institute, Inc. 
Control de Gestión de Ransa (2018). Reporte de Control Presupuestal Ventas - Perú Logístico. Recuperado de la Vicepresidencia de Finanzas.

Win, A. (2008). The value a 4PL provider can contribute to an organization. International Journal of Physical Distribution \& Logistics Management. Vol. 38, n 9, pág. 674-684. 


\section{Referencias electrónicas}

Altos costos logísticos afectan exportaciones peruanas (04 de marzo de 2015). Gestión. Recuperado de https://bit.ly/2Bq176a

Ballester, M. (2018). 7 tendencias en logística para este 2018. Clave i. Recuperado de goo.gl/Pp6Tnu

Clasificación de los diferentes operadores logísticos (22 de junio del 2018). BLUM Consultoría Empresarial. Recuperado de goo.gl/ddF4Hp

Chan Kim W. \& Mauborgne, R. (2012). La estrategia del océano azul. Recuperado de https://cutt.ly/XfA2zXk

Choque, J. (2018). Una mirada de alerta a los costos logísticos del comercio exterior peruano. Recuperado de goo.gl/wkKfKp

Chuquino, J. (2017). Inventarios: El qué, el por qué y el cómo. Recuperado goo.gl/PzH9J9

Costa, F. (2018). Panorama de la Economía Peruana 1950 - 2017, Recuperado de goo.gl/GSVXZU

Cruz, J., \& Barón, A. (2018). Así frena la corrupción la inversión pública y el crecimiento. Recuperado de https://bit.ly/2xGB7Rf

Cuáles son las empresas más importantes del sector logístico (03 de agosto de 2017). El Comercio. Recuperado de goo.gl/AcMoLL

Del Moral, M \& Campero, B. (2013). El impacto ambiental de los procesos logísticos. Revista Énfasis. Recuperado de goo.gl/q5YMCM

Estamos haciendo repartos (15 de octubre del 2018). Perú Retail. Recuperado de https://bit.ly/2raCozY

Euromonitor International (2019). Las 10 principales tendencias globales de consumo para 2019. Recuperado de https://n9.cl/4ort 
Fernández, A. (2001). El Balanced Scorecard: ayudando a implantar la estrategia. Recuperado de https://bit.ly/2Wj1r2H

Goncalves, L. (s.f.). Qué es la metodología ágil. Recuperado de https://bit.ly/351xQFL

Guerra, J. (2017). Buenas Prácticas de Almacenamiento. Recuperado de goo.gl/o4QFgy

Habrá mayor competitividad para el sector logístico. (02 de diciembre de 2017). Diario Oficial del Bicentenario El Peruano. Recuperado de https://bit.ly/2BoOcAY

Inflación Estados Unidos - índice de precios al consumo (10 de mayo de2019). Recuperado de http://cort.as/-APER

Impulsa (2018). Organigrama Corporativo Ransa. Recuperado de goo.gl/qznja4

Informalidad sigue dominando la creación de empleo en el Perú (16 de agosto de 2018). El Comercio. Recuperado de https://bit.ly/2MhgG7c

Innovaciones tecnológicas para la industria (05 de junio de 2018). Siemens. Recuperado de goo.gl/eXSmkn

Instituto Nacional de Estadística e Informática (2018). Demografía empresarial en el Perú, II trimestre 2018. Recuperado de goo.gl/uNv7Sq

Instituto Nacional de Estadística e Informática (2017). Demografía empresarial en el Perú, III trimestre 2017. Recuperado de https://bit.ly/2SIZz0E

Instituto Nacional de Estadística e Informática (2017). Panorama de la Economía Peruana 1950 - 2017. Recuperado de https://goo.gl/wvBjm4

Instituto Nacional de Estadística e Informática (2017). Perú: Estructura Empresarial, 2017. Recuperado de goo.gl/u4rUR7 
Instituto Nacional de Estadística e Informática (2017). Densidad Empresarial de las empresas comerciales, según región (emp. Por cada mil habitantes). Recuperado de https://bit.ly/2GoR01O

Instituto Nacional de Estadística e Informática (s.f.). Producto Bruto Interno según Actividad Económica (Nivel 54) 2007 - 2017 (Valores a precios constantes de 2007). Recuperado de goo.gl/h5bd6Z

Instituto Nacional de Estadística e Informática (s.f.). Producto Bruto Interno total y por habitante (1994 - 2017). Recuperado de goo.gl/GhkeR8

INEI: más de 9 millones de personas habitan en Lima (18 de enero de 2018). Andina. Recuperado de https://bit.ly/2YBBZla

La corrupción no solo afecta el PBI (09 de diciembre de 2017). La República. Recuperado de https://bit.ly/2Mgjosk

Maldonado, J. (2014). La estrategia empresarial, su formulación, planeación e implementación. Recuperado de goo.gl/VTs43V

MD Group (14 de enero del 2019). El gran reto que tienen hoy las empresas es mejorar sus procesos logísticos. Logistiguía: Directorio de proveedores de servicios logísticos. Recuperado de http://logistiguia.mdgroup.com.pe/

MEF: Plan de infraestructura contempla 52 proyectos (25 de julio de 2019). Gestión. Recuperado de https://bit.ly/2MjHBOM

Meserón, S. (2007). Resumen de la historia logística. Venezuela: Evolución de la logística. Recuperado de https://bit.ly/2piXmbE

Ministerio de Economía y Finanzas (2018). Acuerdos Comerciales. Recuperado de https://bit.ly/2zC2g9p 
Ministerio de Comercio Exterior y Turismo (2016). Análisis Integral de Logística en Perú. Recuperado de https://bit.ly/2KqFnxe

Ministerio de Transporte y Comunicaciones (2014). Plan de Desarrollo de los Servicios Logísticos de Transporte, Plan de Mediano y Largo plazo. Recuperado de goo.gl/cizWwA

Damodaran, A. (2019). Betas por sector (EE.UU.). Recuperado de https://bit.ly/2RuHHW9

Damodaran, A. (2019). Rendimientos anuales sobre acciones, bonos Ty facturas T: 1928 Actual. Recuperado de https://bit.ly/2sc2GSN

Obras perjudicadas en el sur a consecuencia de la corrupción (30 de diciembre de 2018). La República. Recuperado de https://bit.ly/2JU73IS

Operadores logísticos esperan mejora de red vial (26 de julio de 2016). El Comercio. Recuperado de https://bit.ly/2BlOqc7

Perú aumentó sus exportaciones en 22.7\% (31 de enero de 2018). Gestión. Recuperado de https://bit.ly/2R7yWxn

Perú: Ministerio de la Producción; Dirección General de Estudios Económicos, Evaluación y Competitividad Territorial; Dirección de Estudios Económicos MYPE e Industria. (2015). Anuario Estadístico Industrial, MYPE y Comercio Interno (BNP Publicación No. 2016 - 11146). Recuperado de goo.gl/Quf65w

Perú reportó el riesgo país más bajo de la región (06 de octubre de 2019). La República.

Recuperado de https://bit.ly/340QsKi

Proyecciones económicas del BCR para 2017 - 2018 (19 de septiembre de 2017). Gestión.

Recuperado de goo.gl/vBnRex

Ransa (s.f.). Historia. Recuperado de goo.gl/Wvrnj8 
Ransa (s.f.). Quiénes somos. Recuperado de goo.gl/LcME3t

Ransa (s.f.). Servicios logísticos. Recuperado de goo.gl/ohGCim

Ransa (s.f.). Servicios. Recuperado de goo.gl/tDEHUA

Ramos, J. (21 de mayo de 2017). Outsourcing logístico (I). El Peruano. Recuperado de goo.gl/NknK7z

Salamanca, S. (2017). La evolución tecnológica de UPS. Recuperado de https://bit.ly/2OYsY6j

Salinas, R. (2008). Enfoque al cliente. Recuperado de https://bit.ly/2LnJGaJ

Chuquino, J. (2014). Sistemas de Información Logística. Recuperado de https://cutt.ly/afETLBW

The World Bank (2018). Global Rankings 2018. Recuperado de http://cort.as/-EAw7

United Nations Conference on Trade and Development (s.f.). Convenio de las Naciones Unidad sobre el transporte marítimo de mercancías. Recuperado de goo.gl/8Bc2f5

United Parcel Service (2019). Soluciones. Recuperado de https://bit.ly/2KBSrhm

¿Cuáles son los distintos tipos de logística? (27 de abril de 2019). Perú Retail. Recuperado de https://cutt.ly/JfQGRqS. 